九州大学学術情報リポジトリ

Kyushu University Institutional Repository

\title{
Studies on the development and relative growth in the carp, Cyprinus carpio (Linne)
}

Hoda, S. M. Shamsul

Basrah University, College of Science

Tsukahara, Hiroshi

Fisheries Laboratry, Department of Agriculture, Kyusyu University

https://doi.org/10.5109/22811

出版情報 : 九州大学大学院農学研究院紀要. 16 (4)，pp. 387-509，1971-11. Kyushu University バージョン：

権利関係 : 
Journal of the Faculty of Agriculture, Kyushu University, Vol. 16, No. 4

November 30, 1971

Studies on the development and relative growth in the carp, Cyprinus carpio (Linné)

\section{S. M. Shamsul HODA ${ }^{11}$ and Hiroshi TSUKAHARA""}

Contents

I Introduction

II Materials and methods

III Spawning activities

1) Embryology

V Li: $\because a 1$ and post-larval development

VI tructure of integument and its oerivatives
1. Head skin
2. Barbel
3. Nasal flap
4. Operculum
5. Conjunctiva of eye
6. Caudal fin

III Structure of alimentary canal

A. Bucco-pharynx
1. Mouth

2. Maxillary valve

3. Bucco-pharyngeal folds

4. Pharyngeal teeth

5. Horny pad

6. Bucco-pharyngeal lining

7. Gill

B. Oesophagus

C. Intestine

1. Intestinal folds

2. Intestinal coiling

3. Intestinal lining

VIII Relative growth

IX Discussions and conclusions

$X$ Summary

XI References

I. Introduction

The carp, Cyprinus carpio ( $\mathrm{L}$.), cosmopolitan in its distribution is able to thrive in different water conditions varying from clear to dirty. In Japan the artificial propagation of this fish in different hatcheries has been conducted for nearly two centuries and forms one of the most important fresh-water fishes both from food and ornamental point of view. The reason for its wide propagation seems to lie in its omnivorous habits, in the production of immeasurable eggs and healthy development of eggs and larvae to the marketable size. However, the product development of the carp as protein for domestic or industrial application depends largely upon ample availability, which is conditioned by the agreeable knowledge of its life history.

1) A Japanese Government Scholarship Holder from Pakistan, at present teaching in Basrah University, College of Science, Basrah, Iraq.

2) Fisheries Laboratory, Faculty of A griculture, Kyushu University, Fukuoka, Japan. 
Kuntz and Radcliff (1918) reasonably stated 'Adequate measures for conversion of our fisheries resources and the production of maximum quantity of food with minimum expenditure through propagation methods require as their basis a reasonably complete knowledge of their life histories and habits of fishes.'

A search in the literatures dealing with the various aspects of carp life explores the names of Pictet(1909), Smallwood and Smallwood (1929, 1931), Smallwood and Derrickson (1933), Curry (1939), Uchida (1939), Klust (1940), Hamai (1941), Suyehiro (1942), Englis h (1952), Eberl-Rothe (1952), Hikita (1956), Rheder (1959) and McCrimmon (1968). These works are related with the outlines or descriptions of development, rate of growth, the age and maturity and anatomy of the alimentary canal, which appear in some aspects inadequate and demand a detailed knowledge of its embryology and general growth.

Gill shows marked anatomical correlation to the feeding mechanism in fishes and the papers dealing with the gross and minute structures are of Duvernoy (1839), Biétrix (1895), Goodrich (1930), Bijtel (1943, 1949), Iwai (1964), Dutta Munshi (1960, 1966), etc. However, these literatures are sufficiently exhaustive in treatment so as to give us a full picture of the anatomy and histology and therefore a scarcity is felt in the availability of the account at various stages of growth, which forms an important part in the study of the life of a fish.

The epidermal layer of the integument is the foremost part of the body exposed to particular ecological conditions; its main function being protection from changing environments and the preservation of the constant milieu interieur. Under the circumstances, the chemical and tactile senses distributed over the skin and its derivatives serve to acquaint the fish with the nature of the environment, the edibility of food, the approach of enemies, etc. Therefore a histological examination of the head skin, the barbels, the nasal flaps, the operculus, the conjunctiva of the eye, and the caudal fin of the carp was made with a particular emphasis on the distribution of sense organs which are so important in fulfilling the requirements of life.

In the life history of an animal the study of its growth in relation to its various organs becomes essential because it indicates in some way the equilibrium between the growing organs and the body length. Unfortunately, the same in the carp remained almost untouched till now except for a few references on the weight-length relationship.

Under the conditions mentioned above, a detailed study was undertaken from March, 1967 to October, 1969 to get a clear picture of the following subjects : 
1. Observations on the spawning activities.

2. Development of eggs and larvae.

3. Development of the alimentary canal.

4. Minute anatomy of the head skin, the barbels, the nasal flaps, the conjunctiva of eye and the caudal fin.

5. Relative growth.

An attempt has been made to clarify the above-mentioned aspects of life of the carp with an aim to correlate the morphological and histological differentiations of organs and their relative growth with the culture and propagation methods. Although many related questions still remain to be answered satisfactorily, it is hoped that this report will throw light on the path of the commercial as well as biological problems of Cyprinus carpio (L.).

The authors extend their heartfelt thanks to Mr. Teruo Honda of the Fisheries Laboratory, Kyushu University, for his kind cooperation in the study of the spawning behaviour of the carp. Thanks are also due to Professor Tasuku Hanaoka of the Fisheries Laboratory and Professor Sadayoshi Miyake of the Zoological Laboratory for their kind reading of the manuscript and assistance in the publication of the same.

\section{Materials and methods}

The ripe carp were brought from a pond of 'Nakayanagi', a Japanese restaurant, Fukuoka, in April-July, 1967 to the experimental pond of the Fisheries Laboratory, Kyushu University. The prepared spawning pond measured $2 \times 2 \times 0.7 \mathrm{~m}$. The 'slang net' was spread over the bottom of the pond for the attachment of the eggs. Long ribbons cut from 'Hyzex' sheets (chemically synthesized from polyethylene) measuring $65 \mathrm{x} 5 \mathrm{~cm}$ represented vegetation and were bound together to a small bag containing pieces of stones heavy enough to dip to the bottom of the pond. Such bags in groups of five were placed close to the corners and the middle of the pond containing water to a depth of nearly $50 \mathrm{~cm}$. Thus the simulated natural spawning ground was prepared. Five series of spawning carp in the various ratios $(2 \delta: 1 \%$,

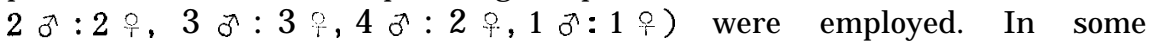
cases after the start of the spawning, the individuals were stripped (dry method) for marking out different stages. Occasionally, the fertilized eggs spread over the hyzex ribbons were put into small aquaria measuring $60 \times 30 \times 30 \mathrm{~cm}$ or into the 5 litre round-bottomed flask. 
The observations made on the various stages of embryos and larvae were either photomicrographed or sketched with the help of camera lucida. The eggs at intervals of 15-30 minutes were fixed either in $10 \%$ neutral formalin or Bouin's solution. As to the various organs, the materials were usually fixed in Bouin's fixative but occasionally Zenker's or Helly's fluid or Heidenhain's 'Susa' were also used. The sections were cut at $5-8 \mu$. Both the double and the triple stains were employed. For the gross anatomical examinations the fry and the young were fixed and preserved in $10 \%$ neutral formalin.

The fish were fed till about one month after hatching on daphnia and after this they were fed on a mixed diet containing vitamins and minerals in various proportions.

The ossification or skeletal structures of the teeth and the gill apparatus were revealed by Alizarine Red. Victoria blue or Wijh's toluidine blue were used for the cartilage. All the sketches were drawn with the camera lucida. The length of the carp used in this paper is total length unless otherwise specified. However, a relationship of the standard length and the fork length to the total length is calculated by simple least square method so that it may be helpful for ref erence.

$$
\begin{aligned}
& \text { Standard length }(\mathrm{mm})=0.825 \times \text { Total length }(\mathrm{mm})-0.277 \\
& \text { Fork length }(\mathrm{mm})=0.903 \times \text { Total length }(\mathrm{mm})-0.088
\end{aligned}
$$

\section{Spawning activities}

The carp is so extensively domesticated everywhere that it can be induced to spawn under entirely artificial conditions. Recently Swee and McCrimmon (1966) published an account on its reproductive biology in Lake St. Lawrence, Ontario. In order to understand its spawning activities more clearly an observation was made in the experimental pond from April 4 to July 26, 1967.

\section{Observation}

Ovulating females were easily distinguished by their distended appearance of the soft abdomen (Fig. 1 A). The males developed pearl organs on the head. Before introduction into the experimental pond the abdomen of both the sexes were pressed to see the discharge of the gonadal products and hence to confirm their readiness for spawning.

The temperature appeared to play a dramatic role in the spawning behaviour of the carp. In series A (Table 1), the fish did not spawn at $15-18^{\circ} \mathrm{C}$ but they did at $19-20^{\circ} \mathrm{C}$ after keeping them in the water 
stabilized by the thermostat at that temperature for about 10-12 hours. In series $\mathrm{B}$ the carp did not spawn at $18-20^{\circ} \mathrm{C}$ but they did one hour,after being transferred into the water controlled at $28-29^{\circ} \mathrm{C}$ and in series $\mathrm{C}$ they did not spawn for two days even at a temperature variation from $22^{\circ} \mathrm{C}$ to $27^{\circ} \mathrm{C}$, but spawning was noticed on the third day at a lower temperature of $22-23^{\circ} \mathrm{C}$.

Table 1. Length and weight of the carp, spawning time, and the temperature in the experimental pond.

\begin{tabular}{|c|c|c|c|c|c|c|c|c|}
\hline \multirow[b]{2}{*}{ Serie:s } & \multirow[b]{2}{*}{$\begin{array}{l}\text { Length } \\
(\mathrm{mm})\end{array}$} & \multicolumn{2}{|c|}{ Weight (kg) } & \multicolumn{3}{|c|}{ Time of experiment (1967) } & \multirow{2}{*}{$\begin{array}{c}\text { Number- } \\
\text { of } \\
\text { mating }\end{array}$} & \multirow{2}{*}{$\begin{array}{l}\text { Temper- } \\
\text { ature } \\
\left({ }^{\circ} \mathrm{C}\right)\end{array}$} \\
\hline & & $\begin{array}{l}\overline{\mathbf{B}} \text { efore } \\
\text { spawn- } \\
\text { ing }\end{array}$ & $\begin{array}{l}\text { After } \\
\text { pawn- } \\
\text { ing }\end{array}$ & Date & $\begin{array}{c}\text { Date } 0 \mathrm{f} \\
\text { spawn- } \\
\text { ing }\end{array}$ & \begin{tabular}{|c|} 
Spawning \\
period \\
observed
\end{tabular} & & \\
\hline A & $\begin{array}{c}590 \text { 우 } \\
530 \text { 우 } \\
540 \text { 하 } \\
1 \text { ㅈ: } 2 \text { 우 }\end{array}$ & $\begin{array}{l}4.9 \\
2.2 \\
3.0\end{array}$ & & Apr. 5-7 & 7 & $\begin{array}{l}6: 00-7: 17 \text { a.m. } \\
8: 30-9: 34 \text { a.m. }\end{array}$ & $\begin{array}{c}7 \\
31 \\
38\end{array}$ & $15-20$ \\
\hline B & $\begin{array}{c}600 \text { 우 } \\
490 \text { ㅎ } \\
510 \text { 万 } \\
2 \text { ㅊ:1우 }\end{array}$ & $\begin{array}{l}6 \\
1.9 \\
2.3\end{array}$ & $\begin{array}{l}3.8 \\
1.6 \\
2\end{array}$ & May 2-4 & 4 & $5: 40-6: 46$ a.m. & 61 & $18-29$ \\
\hline $\mathrm{C}$ & $\begin{array}{c}590 \text { 우 } \\
490 \text { 하 } \\
1 \text { ㅈ: } 1 \text { 우 }\end{array}$ & $\begin{array}{l}4.0 \\
2.15\end{array}$ & $\begin{array}{l}3 \\
2\end{array}$ & $24-26$ & 26 & $\begin{array}{l}7: 36-9: 50 \text { a.m. } \\
10: 48-11: 26 \text { a.m. }\end{array}$ & \begin{tabular}{c|c}
145 & \\
4 & 2 \\
187 &
\end{tabular} & $22-27$ \\
\hline
\end{tabular}

Pre-spawning phase It is noticed, 30-60 minutes after introduction of the fish into the pond, that the male swims with the female for about 8-15 seconds and then either the female runs forward or the male lags behind the males (Fig. $1 \mathrm{C}$ ). The female is followed by another male or by the same male after a few seconds. Occasionally the male touches the female's genital part, lateral flank and cheek in succession with his snout and then passes forward (Fig. 1 E). The approach is also marked in the reverse order (Fig. 1 D), but it is more frequent from the posterior end than the anterior one. A particular male was never found to be trying to run the sexual race over another or to be approaching a female or showing more propensity than others for a particular one. Such activities without the actual spawning may be correlated with the pre-spawning phase of the teleost.

Spawning phase A few minutes before the actual spawning, the activities of the pre-spawnig phase are frequently repeated. The male nudges the female genital part, the lateral flank of the body and the cheek in succession for about 3-4 seconds, or swims very slowly 

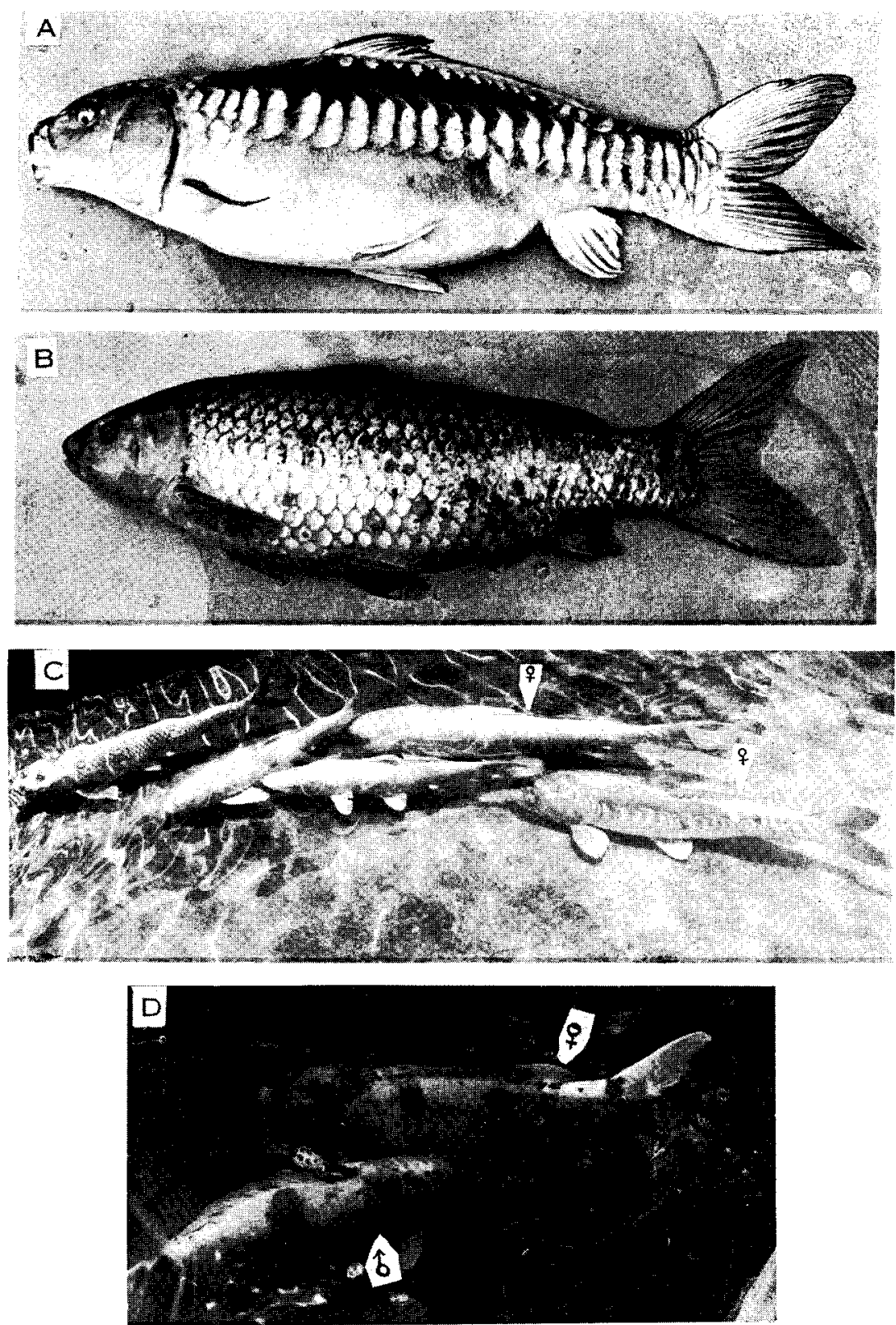

Fig. 1. Photographs of the ripe carp, spawning behaviour, and the spawned eggs.

A. Ripe female, $490 \mathrm{~mm}$ in total length and $2.5 \mathrm{~kg}$ in body weight.

B. Ripe male, $470 \mathrm{~mm}$ in total length and $2 \mathrm{~kg}$ in body weight.

C. Association of two females and three males in the experimental pond.

D. A male gliding the female from the anterior side. 

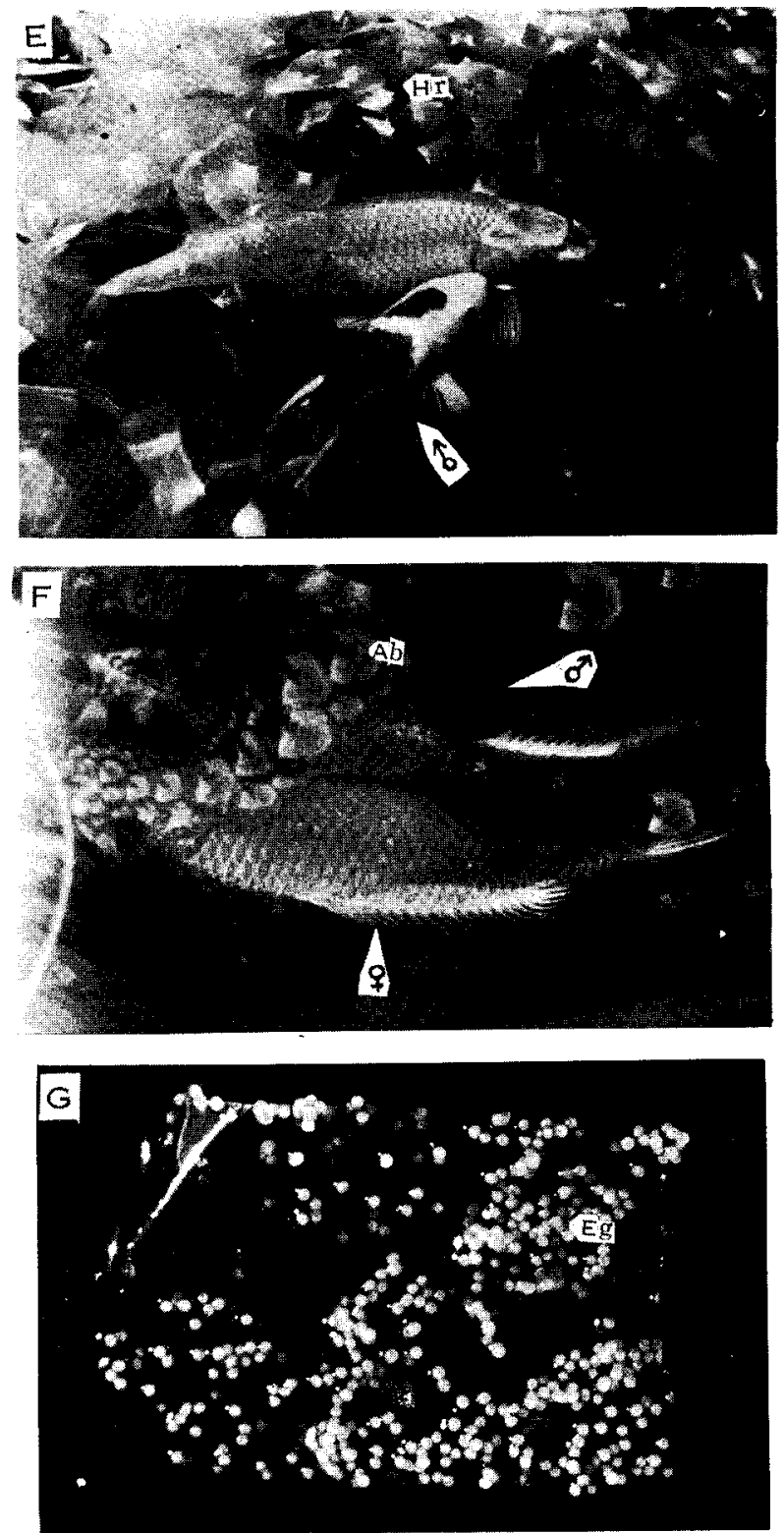

(Fig. I, continued)

E. A male gliding the female from the posterior side.

F. Actual spawning.

G. Spawned eggs attached to the hyzex ribbon.

Hr. Hyzex ribbon: Eg. Egg: Ab. Air bubble. 
along the side of the female lying almost parallel to her for about 2-3 seconds, about $5-8 \mathrm{~cm}$ below the water level ; they balance each other with pectoral fins stretched, dorsal fins erect and the genital regions approximated to each other, beat up simultaneously and quikly their caudal regions producing a splashing sound in the water with the instant discharge of the milt and the ova (Fig. $1 \mathrm{~F}$ ), run together for about 30-50 $\mathrm{cm}$ and then separate. The fluttering sound can be heard from a distance of about 4-6 $\mathrm{m}$. These spawning acts are frequently exercised near, above or below the hyzex ribbons, thus enabling the emitted eggs to stick to them. The shedding of ova is distinctly observed sinking from the sight of splashing down to the hyzex ribbons or slang net on the bottom, but the issuing milt was never visible from the same distance of about $\mathbf{2 - 3} \mathrm{m}$. The spawning is accomplished with continuing change of the males with the female, as there is no pairing and no particular orientation of individuals between them.

Neither electric light $(60$ Watt) from a distance of about $8-10 \mathrm{~m}$ nor torch light $(4.5 \mathrm{~V})$ used for recording the water temperature in the pond at night caused any marked disturbance in their sexual activities. The peak of the spawning generally occurred at dawn. The movement and the loud sound of the persons around the spawning pond was also observed not to affect the sexual play.

In the series of May 26,1967, the spawning continued from $6: 45$ a. m. to $11: 41$ a. m., and at $12: 15$ p. m., i. e., 34 minutes later, finger pressure over the abdomen of the spent individuals caused emission of ova (about 400-600 in number) and the milt. Fertilization took place and the divisions of the cells were clearly observed under a binocular microscope.

It may be stated that during the course of spawning, occasionally the carp emitted their generative products $40-46 \mathrm{~cm}$ below the water surface and a little farther away from the hyzex ribbons. Of course, the lashing of the peduncle and the tail was there and observed distinctly.

Reference to Fig. 2 shows that there is an irregular short or long period of rest after a certain number of spawning acts. The interval is longer in the beginning than in the middle or late period.

Post-spawning phase In this phase, their behaviour is to some extent lethargic. They seem to rest at the bottom of the pond, and after 30-90 minutes of rest they hover aimlessly with slow movement. They (particularly the male ones) appear to eat the eggs, thus exhibiting 'appetitive behaviour' at the post-spawning phase.

The number of the spawned eggs from a female, $590 \mathrm{~mm}$ in total length and $4.9 \mathrm{~kg}$ in body weight, was estimated to be nearly 765,000 . Their number in a single act of spawning is roughly 1,500-1,600. In 
passing it may be mentioned that the water in the said pond becomes turbid and bubbled during the spawning which may be due to mucilaginous matters coming along with the milt and the eggs.

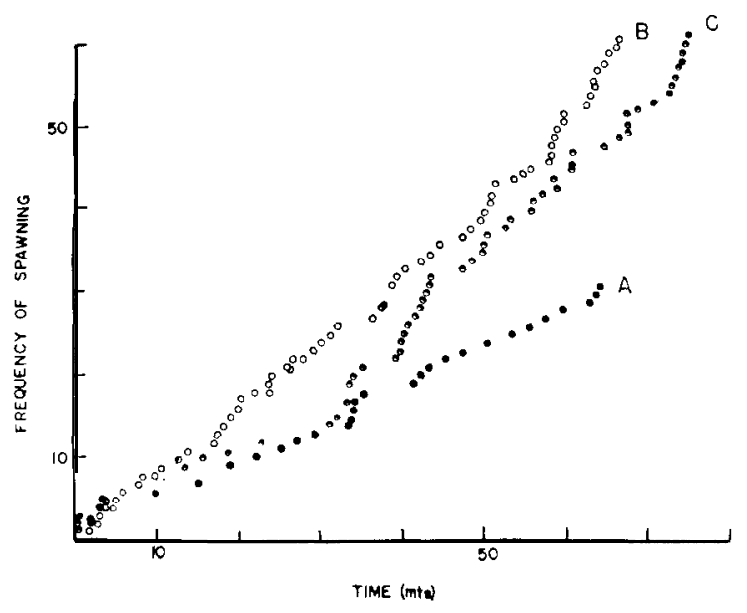

Fig. 2. Frequency of spawning act against time in minutes,

A, B and C indicate series of experiments.

\section{Embryology}

Four series as tabulated below were prepared for the study of the embryos within the eggs of the carp.

Table 2. Experimental series, time of fertilization, water temperature, and incubation period of the embryos of the carp.

\begin{tabular}{|c|c|c|c|c|c|}
\hline Series & Date & $\begin{array}{c}\text { Time of } \\
\text { fertilization }\end{array}$ & $\begin{array}{l}\text { Method of } \\
\text { fertilization }\end{array}$ & $\begin{array}{c}\text { Temperature } \\
\left({ }^{\circ} \mathrm{C}\right)\end{array}$ & $\begin{array}{l}\text { Incubation } \\
\text { period (hrs) }\end{array}$ \\
\hline A & Apr. 7 & 6 a.m. & Natural & $13-17$ & 90 \\
\hline B & May 4 & 8 a.m. & Artificial & $18-19$ & 88 \\
\hline $\mathrm{C}$ & May 26 & 9: 43 a.m. & do. & $22-23$ & GO \\
\hline D & Jun. 21 & 8 a.m. & do. & $24-25$ & 70 \\
\hline
\end{tabular}

The fertilized eggs were subjected to natural temperature throughout the incubation period and therefore a wide range of temperature caused marked fluctuations in the relative development of the consecutive stages. However, in the present paper maximum attempt has been made to distinguish various stages of embryos by criteria 
easily visible with morphological changes supported by histological studies based upon both preserved and living materials. The following descriptions are based upon the eggs developing at $13-17^{\circ} \mathrm{C}$.

Morphology of egg Microscopic study of the fully matured ovarian eggs ready for spawning reveals a double-layered perivitelline membrane on the outside (Fig. $3 \mathrm{~B}$ ) with a nucleus near the periphery of the yolky cytoplasm in which the globules are irregularly dispersed. The micropyle is seen as a depression on one side of the egg (Fig. $3 \mathrm{C}$ ). The centrally situated nucleus, irregular in shape, in a ripe ovum moves towards the periphery before ovulation. The newly spawned eggs are soft and are firmly fixed to the object (i. e., hyzex ribbons) by their mucilaginous vitelline membrane. They become waterhardened within 10-20 minutes. They are demersal, rounded in shape, pale yellow in colour and a little transparent. The transparency increases with the development of embryos which is probably due to absorption of the yolk granules and the enlarged space between the egg membrane and the yolk (Fig. 4 B). They are telolecithal and devoid of oil globules like so many eggs of cyprinid fishes.

Fertilization At fertilization dramatic changes follow ; the chorion is separated from the plasma membrane of the egg by the perivitelline space, filled up with a fluid. Within a few minutes after fertilization the separation of the perivitelline space is completed. The diameter of the yolk is 1.04-1.48 mm in eggs of 1.4-2.04 $\mathrm{mm}$ in diameter. The side of the chorion by which it is attached to the object becomes a little flattened.

One-celled stage At nearly 10 minutes after fertilization the protoplasm flows to heap at the animal pole and forms a raised blastodisc continuous with its margin with a plasma membrane confining the yolk (Fig. 5 A). Within 30-45 minutes the bulging of the cap-like structure into the space is completed and thus a well-defined cell is distinguished (Fig. 4 C).

Abbreviation for Figs. 3-5. An. anus ; AV. auditory vesicle ; Bc. blastocoel ; BC. blastula cell ; BF. branchial fold; BR. brain: Cp. central periblast; DGT. cylinderical thickening for gut ; Ed. endoderm ; Es. epidermal stratum ; Ecp. ectodermal cap; Et. ectoderm; ET. endodermal thickening for future gut; Ey. eye; GA. gill arch ; Gt. gut ; Hd. head; HT. heart ; IN. intestinal cavity; Kd. pronephric tubule; kv. kupffer's vesicle ; LHD. left hepatic duct ; LL. left liver ; LV. liver; Lp. lens placode ; LO. lateral line organ ; mv. maxillary valve; Mf. median fin fold ; MD, mesodermal plate; Mp. micropyle; Mr. myomeres; MS. mesodermal somites; NC. nucleus ; nt. notochord ; PB. periblast ; pN. periblast nuclei ; pdn. dividing periblast nuclei ; PH. hypoblast ; Prf. pre-anal fold ; RL. right liver ; SB. swim bladder ; SC. secretory cell; SG. segmentation cavity; Yk. yolk. 

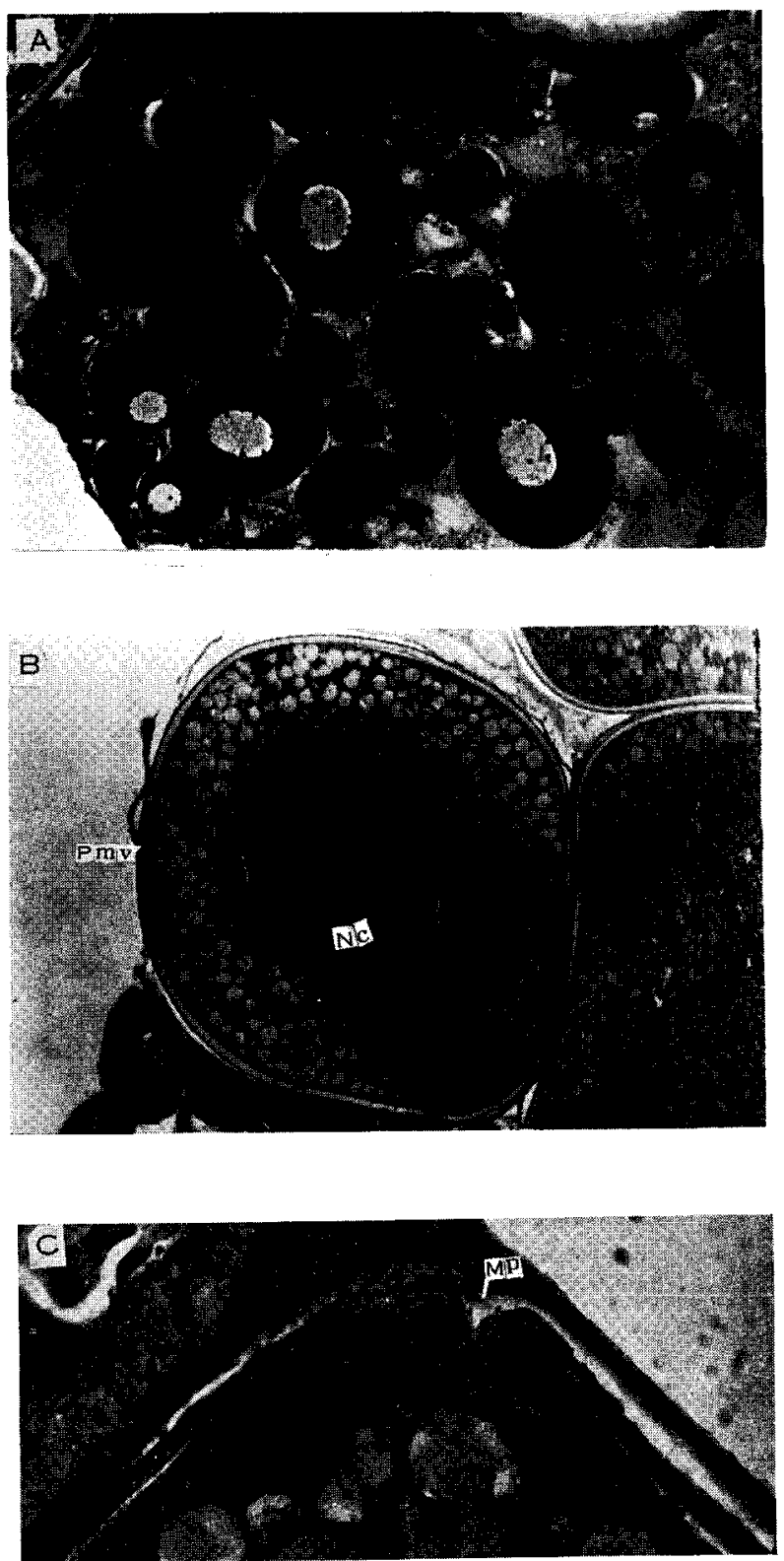

Fig. 3. Photomicrographs of ovarian eggs.
A. Section through the ovarian eggs. X 50 .
B. Section through ripe ovarian egg. X 100 .
C. Section of egg showing micropyle. X 100. 

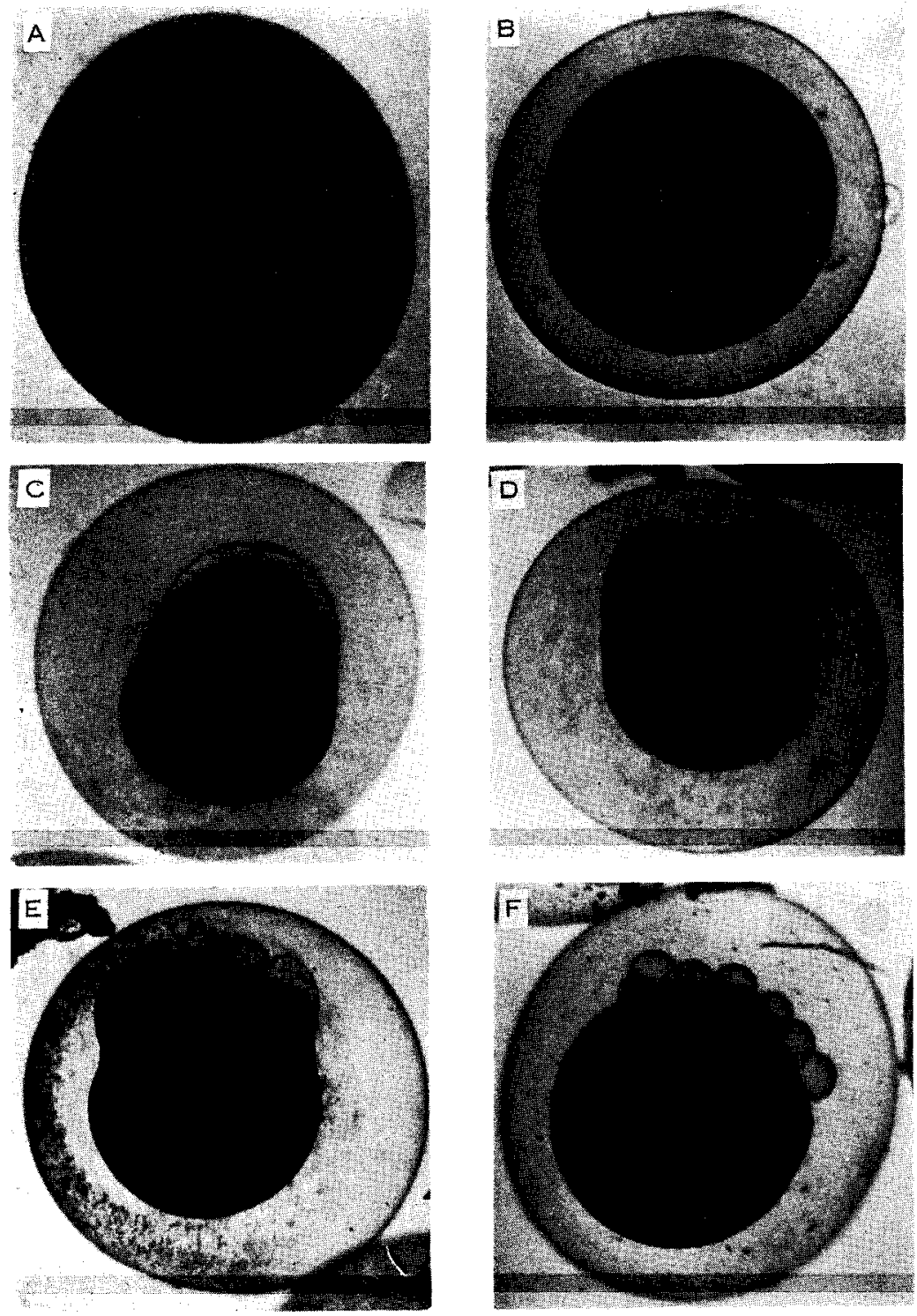

Fig. 4. Photomicrographs of living eggs and embryos.
A. Unfertilized egg.
B. Fertilized egg.
C. 1-celled stage.
D. 2-celled stage.
E. 8-celled stage.
F. 16-celled stage. 

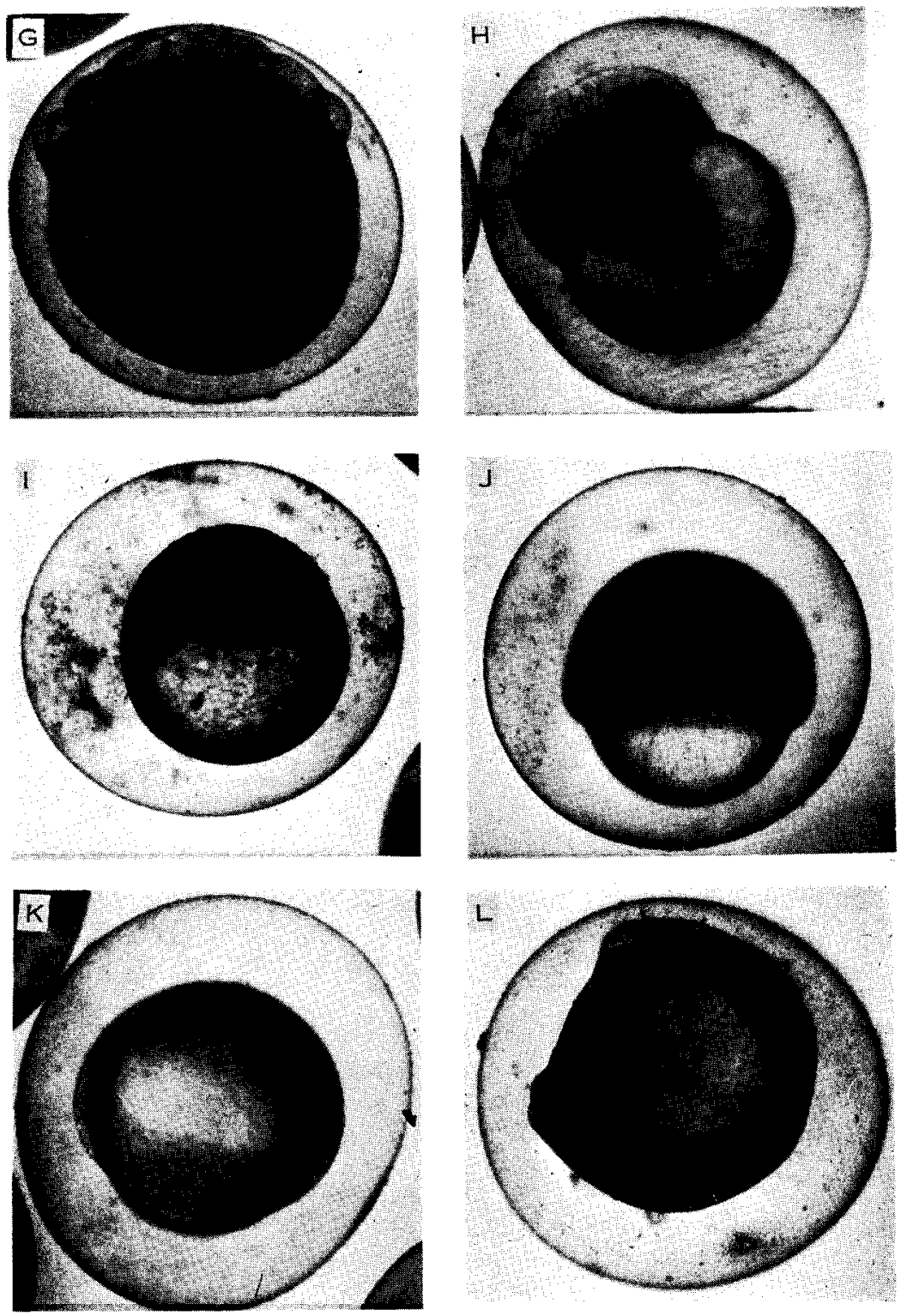

(Fig. 4, continued)

G. 64-celled stage.

H. Morula stage.

I. Blastula stage.

J. Gastrula stage.

K. Late gastrula stage

L. Head fold formation. 

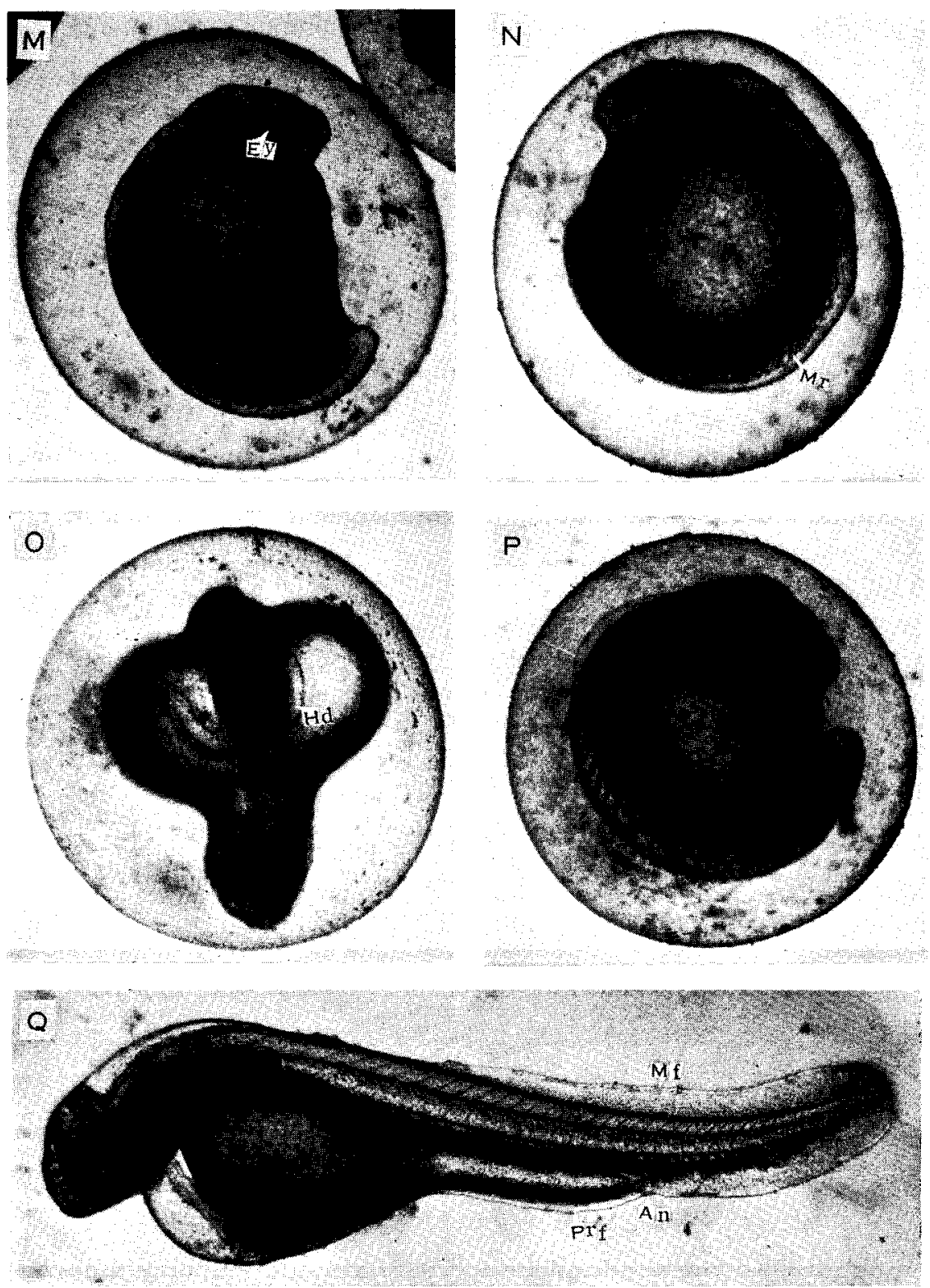

(Fig. 4, continued)

M. 6-myomere embryo.

N. 13-myomere embryo.

0. 24-myomere embryo.

P. Lateral aspect of 0 .

Q. Hatched larva. 

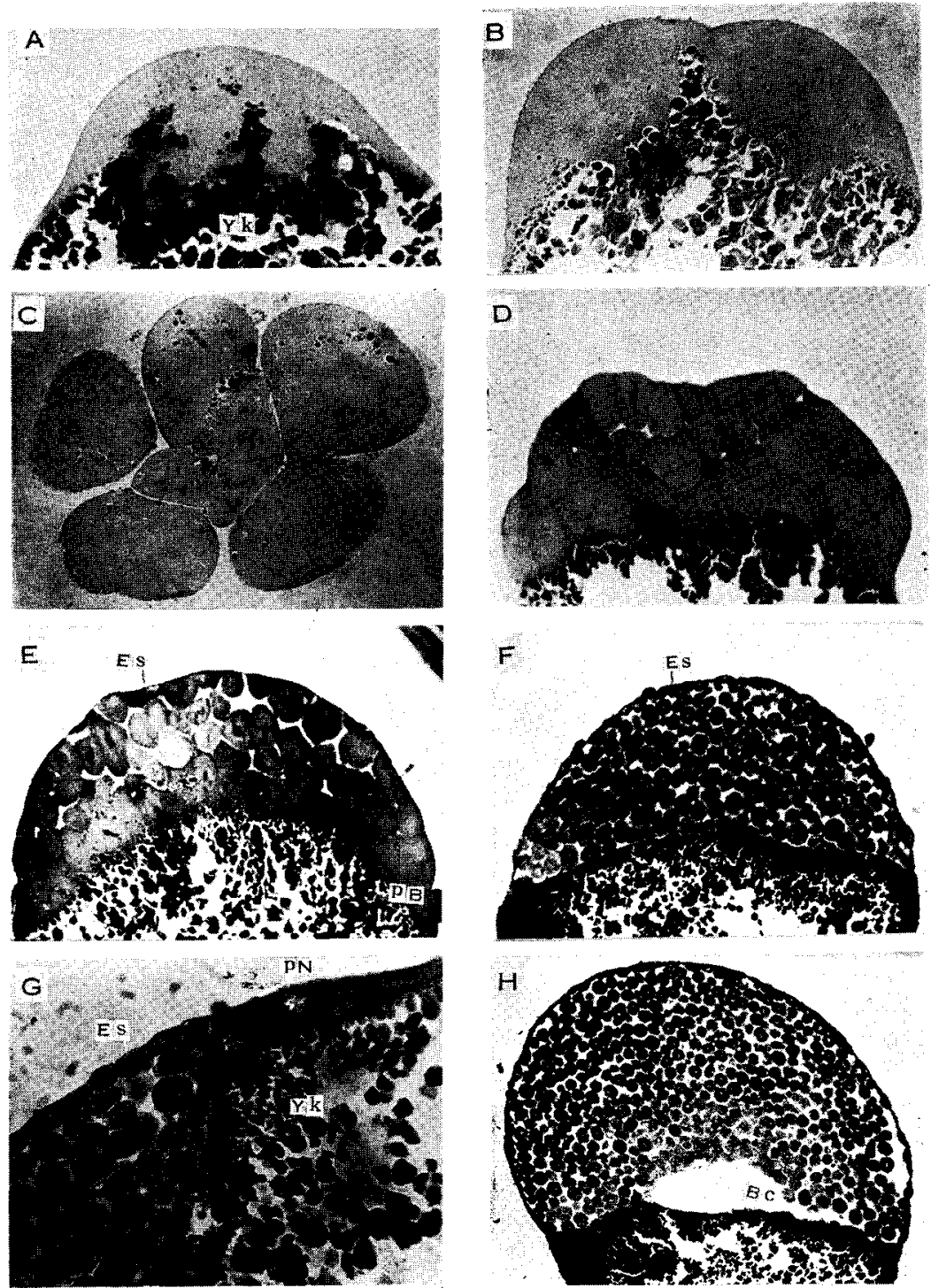

Fig. 5. Photomicrographs of the histological structures of eggs and embryos.
A. Section through l-celled egg. X 80.
B. Section through 2-celled egg. $X 50$.
C. Cross section through 8-celled egg. $X 80$
D. Vertical section through 32 - or 64-celled egg. $X 80$.
E. Vertical section through before-morula. X 50 .
F. Vertical section through morula. X 50.
G. A part of $F$ enlarged. X 200.
H. Vertical section through blastula. $\times 80$. 

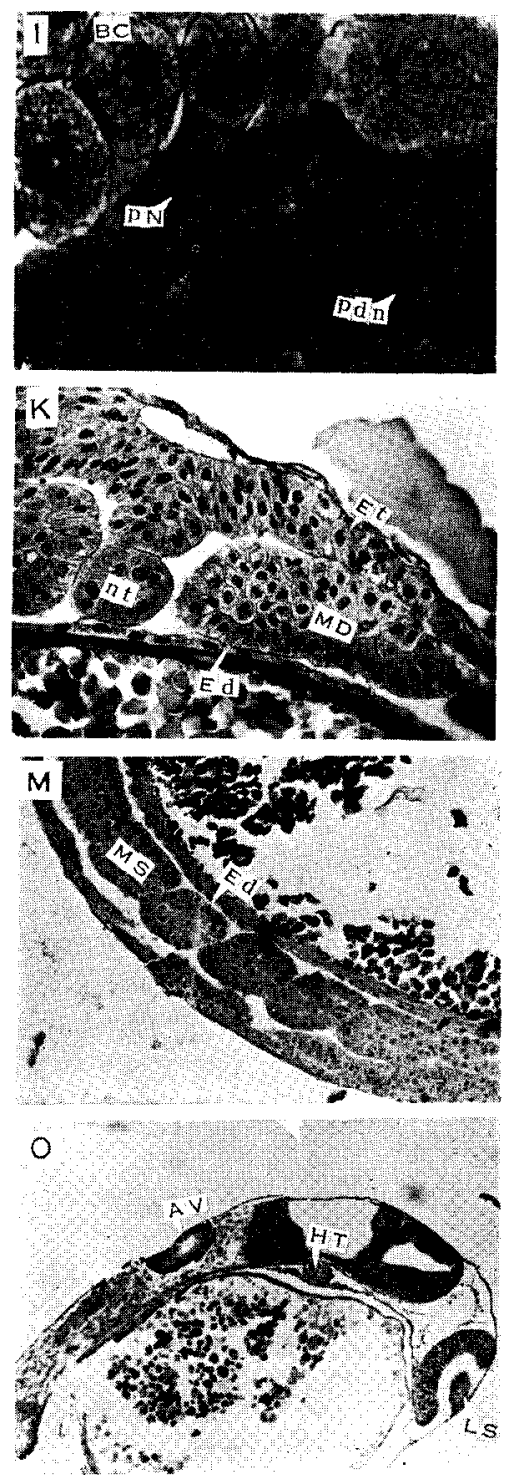
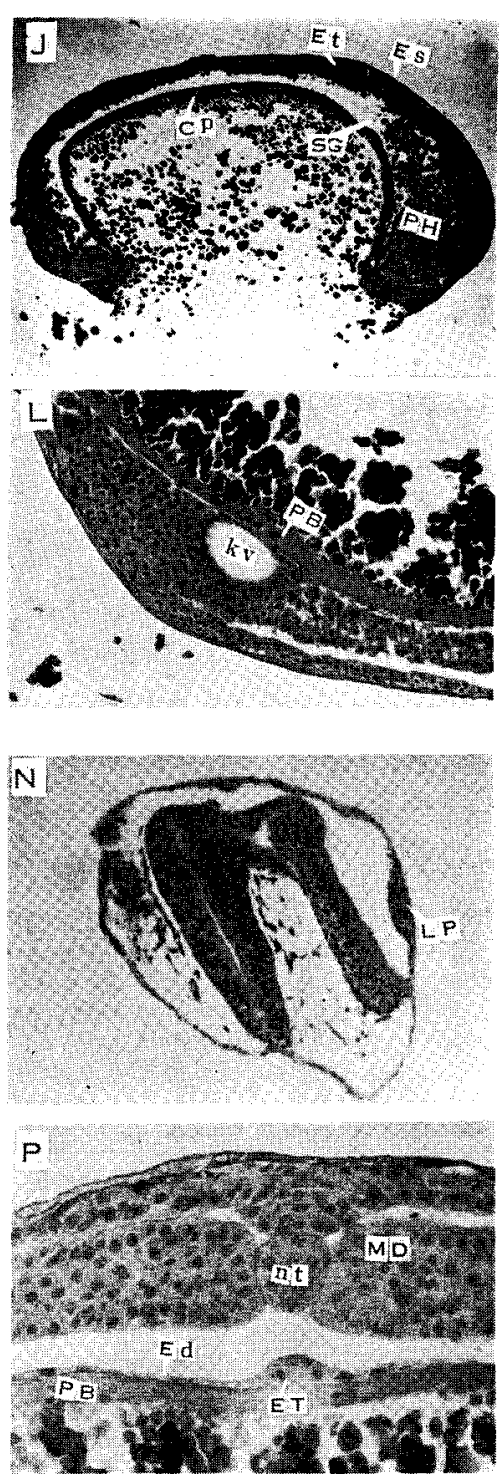

(Fig. 5, continued)

I. Vertical section through the periblast at blastula. X 200 .

J. Vertical section through gastrula. $X 20$.

K. Transverse section through embryo. X 50 .

L. Sagittal section through the posterior region of embryo. X 200.

$M$. Sagittal section through the embryo. $X 100$.

N. Transverse section through eye of embryo. X 50 .

0 . Sagittal section through embryo. X 50 .

P. Transverse section through the trunk of embryo. $X$ ZOO. 

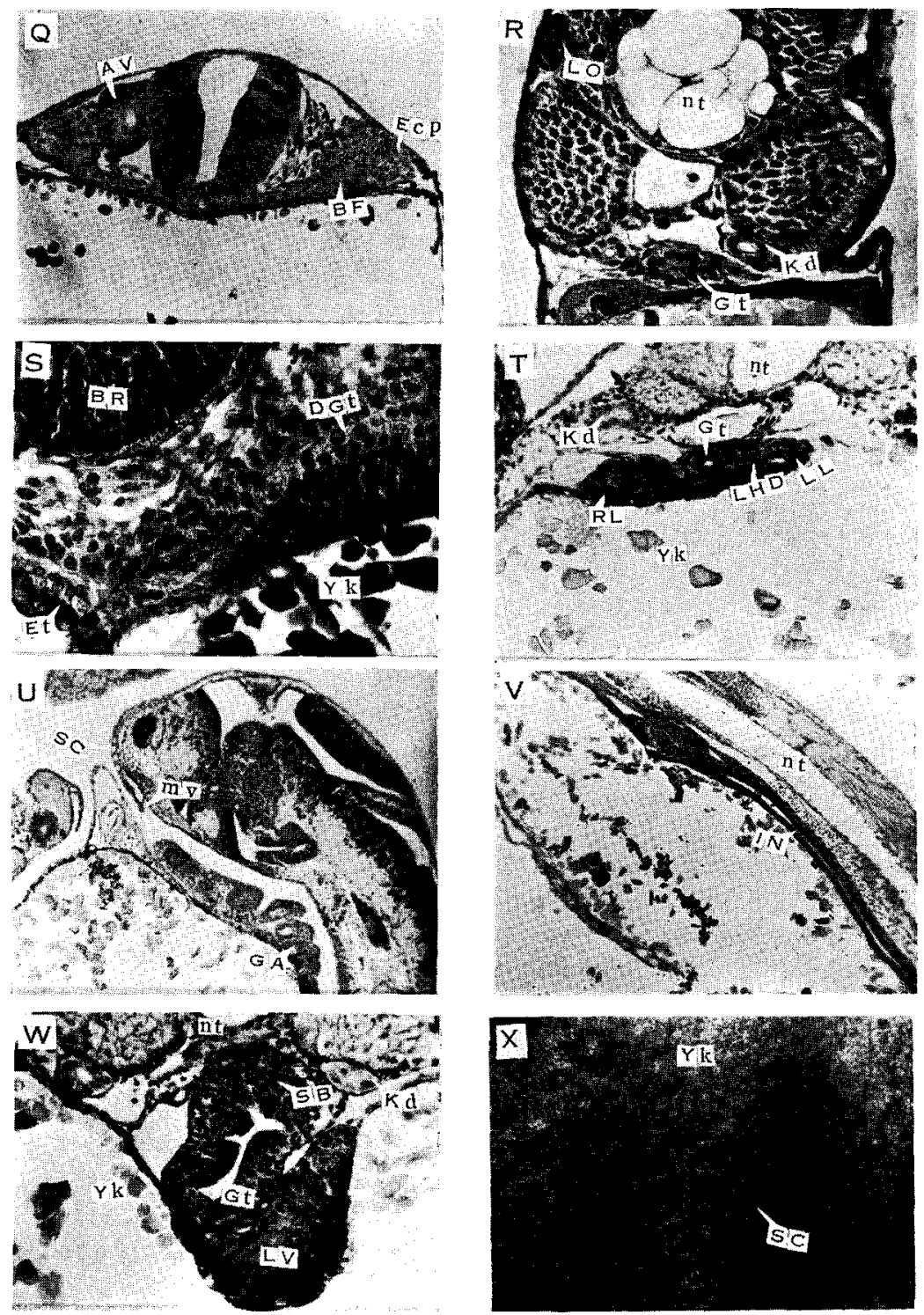

(Fig. 5, continued)

Q. Transverse section through auditory region of embryo. X 200 .

R. Transverse section through trunk of embryo. X 100.

S. Sagittal section through anterior end of embryo. X 200.

$\mathrm{T}$. Transverse section through anterior gut of embryo. X 200.

U. Longitudinal section through bucco-pharyngeal cavity of embryo. X 100 .

V. Posterior part of U. X 100 .

W. Transverse section through anterior gut of embryo. X 200

$X$. A part of yolk sac before hatching. $\times 120$. 
Two-celled stage The first cleavage, which is about 4 hours after fertilization, is meroblastic or discoidal due to heavy yolk distribution, and results in two cells of equal size (Fig. 4 D). In the serial sections examined the cleavage furrow is a barely perceptible depression at the centre of the one-celled disc and the two dividing cells are joined by a layer of the protoplasm (Fig. 5 B).

Four-celled stage After about 5 hours 30 minutes the second segmentation, which is also meridional but at right angles to the first, results in a rosette of 4 cells or blastomeres of equal size, nearly $330 \mu$ each in diameter and shows bilateral type of cleavage, characteristic of the teleost. The next succeeding divisions of cells begin before the completion of the cell membrane.

Eight-celled stage Third cleavage plane is oriented parallel to plane one and at right angle to plane two, separating the germinal disc of the 4-celled stage into eight blastomeres of equal size, arranged four by four in two lines, and this condition is attained by 6 hours after fertilization (Fig. $4 \mathrm{E}$ ). The disc is now considerably raised above the yolk. Serial sections in various planes indicate complete divisions of cells enclosed by the cell membrane (Fig. 5 C).

Sixteen-celled stage The fourth cleavage plane, which is attained at about 8 hours after fertilization, double and parallel to the second, divides the blastoderm into sixteen cells, arranged into four rows, measuring about $180 \mu$ in diameter (Fig. 4 F). In histological preparations metaphase and telophase stage of mitotic divisions are frequently met with under the microscope.

Thirty two-celled stage The fifth segmentation results in the production of 32 cells measuring $170 \mu$ in diameter, at about 10 hours after fertilization. As cell divisions proceed the blastoderm becomes distinct due to increase in size.

Sixty four-celled stage With the advance of the successive and complex cleavages, there is progressive increase in the number of the cells followed by decrease in their size, measuring nearly $150 \mu$ in diameter (Figs. 4G, 5D) 15 hours after fertilization. The blastodisc has increased so much so as to envelop the yolk on the upper side. After this stage the fate of complex planes of segmentations are no longer traced out and the symmetry is also lost. The periblasts, both the marginal and the central ones, are clearly established with distinct nuclei (Fig. 5 E). In serial sections the cells are seen 3-4 layers deep and at the superficial layer the cells are being flattened out which is the first indication of the future epidermal stratum.

Morula stage The morula is the outcome of the continued rapid multiplication of the blastomeres formed at about 17 hours after fertilization. It looks like a solid mass of cells, spherical in shape, bearing 
over the yolk like a cap (Fig $4 \mathrm{H}$ ). The size of the cells is reduced to about $60 \mu$ in diameter (Fig. $5 \mathrm{~F}$ ). The marginal periblast is thicker than the central one and the nuclei of the various sizes, about 8-20 $\mu$ in diamater, are scattered irregulary in the granular mass (Fig. 5G). The epidermal stratum with flattened cells is clearly definable at this stage.

Blastula stage The blastula is disinguished at about 20 hours after fertilization (Figs. $4 \mathrm{I}, 5 \mathrm{H}$ ). With the development the cells become smaller and smaller in size until the blastodisc is flattened down to form a lenticular cap over a greater portion of the yolk surface (Fig. 4 I). The periblast layer containing nuclei about 20-25 $\mu$ in diameter forms the floor on which the embryo rests. The dividing nuclei are marked in the periblastic mass (Fig. 5 I). The blastocoel is present (Fig. $5 \mathrm{H}$ ).

Gastrula stage This stage is achieved by $\mathbf{2 4}$ hours after fertilization. With the continuation of the expansion of the blastoderm its peripheral rim is thickened by piling up of the cells while the central area is thinned out (Figs. $4 \mathrm{~J}, 5 \mathrm{~J}$ ). The thickened rim is designated as the 'germ ring' (Fig. $4 \mathrm{~J}$ ) and is an ingrowing under-layer. The thickening at one end is more pronounced than the other one and this marks the posterior end of the germ ring referred to as the 'embryonic shield' in teleosts and it is here that the gastrulation commences (Fig. $5 \mathrm{~J}$ ). By this time the blastodisc has covered about 60 $65 \%$ of the yolk, and the undersurface has definitely assumed a concave shape and the ectoderm is differentiated. It consists of epidermal stratum and the stratified layer below this, consisting of 3-5 layers of polygonal cells (Fig. $5 \mathrm{~J}$ ). The primitive hypoblast is distinguished from the ectoderm (polygonal cells) at the posterior pole, where the region of the dorsal lip of the growing blastoderm is marked. The epidermal stratum does not seem to take part in the invagination process and at no point has it been marked to be continuous with the ingrowing layer of the germ ring. At about 28 hours after fertilization (late gastrula) the anterior pole of the blastoderm has grown forward approaching the dorsal lip and forms the ventral lip of the developing embryo.

\section{Embryo stage}

Head fold As the gastrula proceeds the blastopore is closed and the compact cells of the ectoderm is thickened at the anterior end differentiating the primordium of the brain which becomes slightly raised above the yolk (Fig. $4 \mathrm{~L}$ ). By this time the embryo has reached a point about 30 hours after fertilization. The neural plate is differetiated from the ectodermal layer and the notochordal area is marked out. The process of endodermal differentiation from the hy- 
poblast has already started but is scattered. By 32 hours after fertilization the endodermal cells become arranged into a single layer of flattened cells with their nuclei situated afar (Fig. $5 \mathrm{~K}$ ). The mesodermal-endodermal differentiation is first marked at the posterior region of the developing embryo which passes on gradually towards the anterior end. The mesoderm throughout the trunk region consists of 3-6 layers of lateral masses of polygonal cells, which form mesodermal plates thinning out at lateral sides, but in the head region they are replaced by only mesodermal cells. No differentiation of the somatopleur or splanchnopleur was marked. A rudiment of the eye has already appeared as ectodermal thickening at the lateral sides of the mid-brain.

Optic vesicles At 37 hours after fertilization the optic vesicles become conspicuous and 4-6 myomeres have developed in the middle region of the body (Fig. $4 \mathrm{M}$ ). The embryo lies without torsion or twisting and its outline is distinct over the curvature of the yolk. Ventricles are marked in the brain. Kupffer's vesicle appears at a little anterior to the caudal tip of the embryo on the ventral side at the 8-16 myomere stage at 38 hours after fertilization. It is an oval structure enclosing a cavity measuring nearly $38 \times 72 \mu$ in diameter in mid-longitudinal section (Fig. $5 \mathrm{~L}$ ). The wall consists of columnar cells, 18-25 in number which seem to be derived from endoderm.

At 40 hours after fertilization the lens placode is formed from the ectodermal thickening (Fig. $5 \mathrm{~N}$ ) and the cavity in the optic vesicle has appeared. The embryo when looked at from the dorsal side exhibits three distinct primary divisions, i. e.. prosencephalon, mesencephalon and rhombencephalon, and mesodermal somites have increased to fourteen. The auditory vesicle arises as a solid mass of cells and later on becomes an enclosed sac, the wall of which consists of simple columnar cells. Superficially it appears as an oval-shaped structure anterior to the tip of the notochord, and otoliths have not appeared as yet.

The notochord is a cylindrical structure tapering to a point on both ends, and consisting of vacuolated cells, 12-18 in number in the transverse section, with the diameter of $20-25 \mu$ at the anterior end. The embryo is intimately attached to the yolk and encircles about $3 / 4$ of the yolk (Fig. $4 \mathrm{~N}$ ). Endodermal cells are enlarged below the notochord, which appears to represent the primordium of the band of cells destined to form the gut (Fig. $5 \mathrm{P}$ ).

Pigmentation in the eye At 45 hours after fertilization the lens is detached from the ectodermal layer and becomes surrounded by cuboidal cells (Fig. 5 0). At about 48 hours after fertilization the pigmentation appears in the eye which can be seen under $120 \times$. The 
heart is visible at $200 \times$ as a short tubular structure pulsating above the yolk and a little posterior to the lower end of the head (Fig. 50 ). Blood vessels with circulating corpuscles are also marked on either side of the yolk. The endodermal cells in the auditory region is being thickened and elevated on either side of the notochord marking the primordium of the pharyngeal fold, which extends laterally and dorsally to meet the ectodermal cells.

The tail of the embryo has been elongated considerably to reach near the head. The head region remains closely adhered to the yolk while the posterior extremity is being lifted away from it. With the elongation of the tail the yolk is also elongated. Kupff er's vesicle has disappeared. Two otoliths are marked in the otic vesicles.

At about 52 hours after fertilization pharyngeal folds become considerably broadened at the tip, though still remaining a solid mass of cells. The ectodermal cells (polygonal cells) are thickened to form a cap-like structure on the tip of the growing endodermal gill or pharyngeal fold (Fig. 5 Q). At 53-55 hours after fertilization the endodermal thickening for gut marked earlier has increased so much as to form a cylinderical band of cells (Fig. $5 \mathrm{R}$ ) which lie very close to the periblast wall. Nephric tubules are completely established at the dorso-lateral position to it (Fig. $5 \mathrm{R}$ ).

At about 55 hours after fertilization, on one side, a shallow invagination of the ectodermal cells is being formed behind the auditory vesicles, and on the other side, the endodermal cells of pharyngeal fold move outward to fuse to the ectodermal cap for the formation of the pharyngeal cleft. The lateral line organ is observed as a concentration of nerve cells at the mid-lateral sides of the body (Fig. $5 \mathrm{R})$. By 56 hours after fertilization melanophores are increased in the eye. The heart is easily distinguishable into atrium and ventricle and situated at the dorso-anterior side of the yolk. The onset of blood circulation is marked with a regular systole and diastole. If the embryos are punctured out of the chorion at a stage of 25-30 mesodermal somite (Fig. $40, \mathrm{P}$ ), blood vessels are observed on either side of and above the yolk, below the notochord and among the myomeres (segmental circulation) with the corpuscles moving slowly in scattered clumps through them. They course above the gut caudally to form a glomerulus of it below the tail. The cerebellum is increased considerably. The pectoral fin appears as a small acuminate projection on the horizon of the eggs as viewed along the body axis. The eye measures $194 \times 278 \mu$ in diameter in an embryo of $2.91 \mathrm{~mm}$. At the 32-myomere stage the yolk extends until 25 .

Gill cleft By 57 hours after fertilization the apex of the pharyngeal fold becomes merged with the ectodermal layer to such an extent that no line of demarcation stands between the two and a slight 
invagination of the epidermal stratum causes formation of branchial cleft. Thus the flattened epidermal cells pass inwards through pharyngeal clefts or slits. Five pharyngeal pouches are counted. The first pouch is at the level of the tip of the notochord. The mode of extending laterally to fuse with the ectodermal cells seems to be the same in all the cases. Twisting and lashing movement of the body and the tail are marked.

By 70 hours after fertilization irridescent colourations are marked with plenty of black pigments in the eye. The movement of the eye is also observed. Pigmentations on the head and yolk are more numerous than other parts of the body and ray-like streaks are faintly seen on the caudal fin. The pectoral fins show weak fluttering movements between irregular periods of quiescence when examined after removal of chorion. No sign of a swim bladder is noted. The fin fold or embryonic fold passes over the tail and ends anteriorly on the ventral side near the anal opening. The pre-anal fold is also marked. Saprolegnia frequently attacks the eggs.

Intestinal cavity By 72 hours after fertilization, undoubtedly active organo-differentiation is going on. In the anterior region the double-layered endodermal cells of the gut run forward via pharynx and is bifurcated at the sight between the head and the yolk to pass dorsally and ventrally (Fig. 5 S). No sign of stomodaeum is marked. Later on, a break occurs at the angle of the head and the yolk forming the mouth which becomes continuous with a cleft in the fore-gut already formed by the retreat of the upper and lower layer of cells.

By 78 hours after fertilization, the liver appears as two ventrolateral evaginations from the anterior part of the intestinal canal (Fig. $5 \mathrm{~T}$ ). The evagination of the right liver is anterior to the left one. No sign of gall bladder is noticed. The pneumatic duct originates from the dorsal wall of the gut in a $4.6 \mathrm{~mm}$ embryo and appears to consist of the same type of cells as the intestine (Fig. $5 \mathrm{~W}$ ). Patches of rounded cells, marked on the yolk and the head of the embryo (Fig. $5 \mathrm{X}$ ), are the secretory cells, the secretion of which help the hatched larvae in attaching to the substratum.

$\mathbf{H}$ atching larva stage In the embryo at 90 hours after fertilization, all the organs necessary for survival outside the egg membrane have developed moderately. Vigorous body movement towards the approach of hatching time is increased. During the process of the actual emergence of the inactive larva from the membrane, it regularly gives a twitching, twisting and lashing movement of the tail in consequence of which the whole body is thrown out into motion. By such repeated action it always tries to force its way out of membrane by rupturing it with its tail. Finally it succeeds and the tail comes 
out first. An infrequent lashing movement forces its body completely out of the membrane within one to five minutes. The hatched larva (Fig. 4 Q) remains attached to either hyzex ribbons or a substratum or falls to the bottom and then, flickering its pectoral fins, moves a few millimeters. The attachment is helped by the secretory cells. The fry measures $3.9-5.6 \mathrm{~mm}$ in total length. Hatching continues for 2.5 or 3.5 days.

\section{Larval and post-larval development}

The knowledge of developmental structure of an animal is essential to understand the mode of life. With this aim the anatomical changes right from hatching to the adult stage of carp are described. The temperature ranged from 16 to $27^{\circ} \mathrm{C}$ during the culture period.

39-5.6 mm newly hatched larva (Fig. $6 \mathrm{~A}, \mathrm{~B}$ ). It is transparent and internal structures are easily visible under a binocular microscope. It is curved over the antero-dorsal end of the yolk and the number of the myomeres oscillates from 34 to 36 . The pectoral fin behind the auditory vesicle measures $0.3 \mathrm{~mm}$ in a $4.8 \mathrm{~mm}$ larva and is a small elongated structure rounded at the margin. A median membranous fin fold is continued anteriorly as a pre-anal of it and the notch marks the position of the anus and also tho posterior limit of the extension of the yolk sac. The fold at the posterior region forms a protocercal type of fin as the notochord passes straight into it. A small mouth opening is present and measures 269-273x 180-134 $\mu$ in diameter. In the lateral view it is not so clear due to deflection of the head over the yolk. Black pigments are not present in general and if present they are distributed irregularly on the head, dorsal surface of the body, and along the yolk. Occasionally yellow tints are marked along the mid-dorsal surface of the body.

The yolk sac is large and heavy and the anterior end is swollen and the posterior one is elongated. The time of absorption is generrally 4-7 days. In histological preparations the yolk granules are cut in various shapes and sizes and the peripheral ones remain attached to the sac (Fig. 7 B, E). They become deeply yellow-coloured with Mallory's triple stain. Eyes are large, globular in shape, and are highly pigmented. Heart beat is counted to be 118-120 times per minute at $20^{\circ} \mathrm{C}$ and the dorsal aorta, sub-intestinal vein, the tuft of capillaries below the caudal tip of the notochord, the branchial vessels, the segmental blood vessels and the vitelline vessels on the yolk are clearly distinguished. The blood is yellow in colour.

Large and oval-shaped ear vesicles poster-o-dorsal to each eye measure $0.2 \times 0.3 \mathrm{~mm}$ approximately in diameter (Fig. $6 \mathrm{~B}$ ) and are lined by elongated cells (Fig. 7 B). A shallow, nearly semi-circular pit of 
olfactory organ situated on the snout dorso-anterior to each eye is clearly marked as in the embryo and is lined by ciliated cells.

The larva is covered with a thin layer of squamous cells 2-3 strata thick measuring about $100 \mu$ at the head region and this forms the epidermis. The epidermal cells are modified into secretory cells which cover head and yolk sac (Fig. 16 A). Well developed neuromasts are irregularly scattered around the head (Fig. $7 \mathrm{~A}$ ) indicating the development of extroceptive organs for chemical and physical senses. Pronephric tubules marked earlier extend from the posterior end of the oesophagus to the end of the intestine on its dorso-lateral position. They are lined by cuboidal cells and 8-10 such cells with large spheroidal nuclei seem to encircle the tubule in a section cut at $7 \mu$ from a $4.5 \mathrm{~mm}$ newly hatched larva. The diameter of the tubule is about 13-22 x 15-25 $\mu$, enclosing a cavity 4-6 x 5-7 $\mu$ in diameter.

Brain is well developed. The vagal lobes on either side of medulla oblongata are enlarged and prominently bulged out. The notochord extends from the posterior end of the ear vesicle to near the tail fin and is unsegmented. It consists of chondroid tissues.

The mouth opens into a large spacious buccal cavity and at the entrance of the mouth there is a thin membranous structure of oral valve consisting of 2-3 layers of large flattened cells with elongated nuclei. No mucous cells or taste buds are found on the oral valve. The cavity itself is covered by squamous cells, 2-3 layers thick, and is supported by a network of loose connective tissues (Fig. 7 A) ; a few mucous cells are present. The same layer of cells pass imperceptibly the pharyngeal region (Fig. 7 B). Muscularis mandibularis is present and seems to be responsible for the movement of the jaws in the following stages. A very thin integumental process (Fig. 7 B) projecting out from the lateral sides of the head (i. e., operculum) extends till the 2-3 gill arches. It is covered with flattened cells arranged in 3-4 layers. Beneath these cells there are endodermal cells enclosing mesodermal cells with large oval nuclei inside.

The cells at the dorsal region of the posterior pharynx multiply rapidly to form polyhedral cells which are of the sight of the horny pad. The enamel and the dentine of the teeth is formed in larva 5.5 $\mathrm{mm}$ in total length. They lie embedded in the foliceous tissues and appear to be functionless (Fig. $7 \mathrm{M}$ ).

The oesophagus is short and measures about $100 \mu$ in length in a $4.5 \mathrm{~mm}$ larva. The cavity appears to be lined by low cuboidal-type cells outside of which is a single layer of connective tissue sheath. The intestine is a long and straight tube extending till 22-23 myomere, and the first part of it is a little enlarged in diameter. The cavity is lined by a- single layer of columnar cells (Fig. 7 D) and 
A

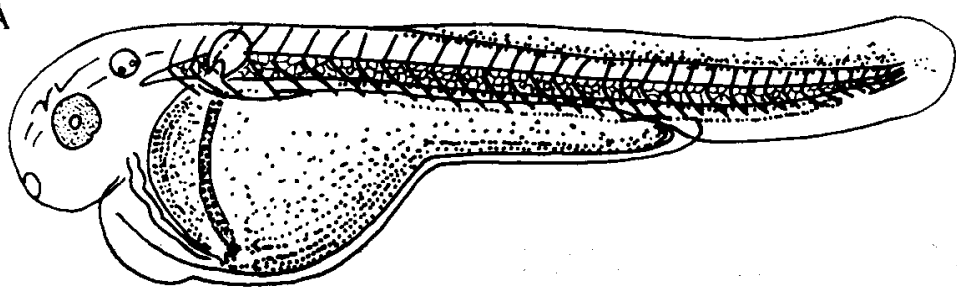

$\mathrm{B}$

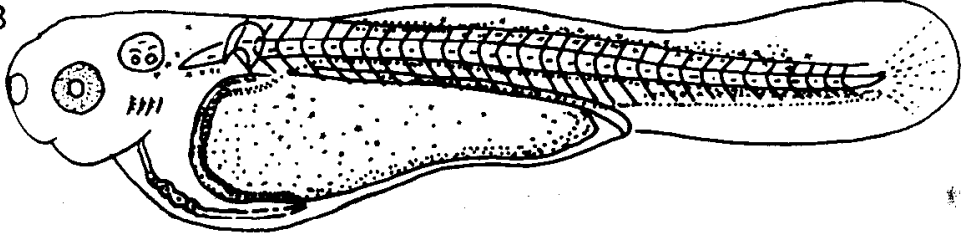

C
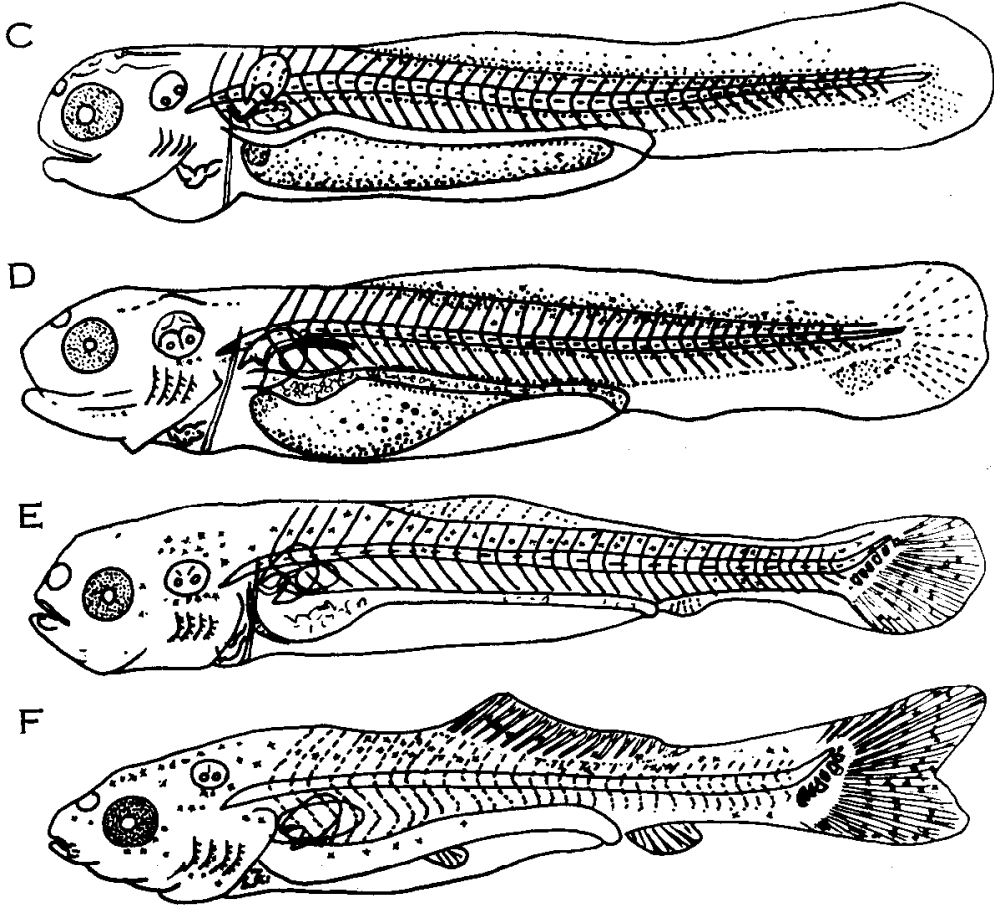

Fig. 6. Development of larvae of carp.
A. $4.8 \mathrm{~mm}$ newly hatched larva.
B. $5.1 \mathrm{~mm}$ larva (2 days after hatching).
C. $6.6 \mathrm{~mm}$ larva (3 days after hatching).
D. $7 \mathrm{~mm}$ larva (7 days after hatching).
E. $9.5 \mathrm{~mm}$ larva (9 days after hatching).
F. $16 \mathrm{~mm}$ post-larva ( 2 weeks after hatching). 
the lumen is usually circular except the anterior part which becomes to some extent dorso-ventrally compressed in cross sections, most probably because of the yolk beneath. The anterior part does not seem to run straight backward. Outside the columnar cells there is a single layer of connective tissue continuous with that of the oesophagus. The anterior part has a greater number of cells and is taller than the posterior one. Twenty to 30 cells encompass a transverse section of a $4.2 \mathrm{~mm}$ larva (Table 14) and the number increases rapidly with size of the larva (Fig. 8). Intestinal and liver cells are usually found at various stages of leavage, particularly metaphase and telophase. The cell membrane of the adjacent cells is faintly distinguishable. Occasionally granular cells of unidentified character are marked (Fig. 7 D). The periblast wall below the intestine is markedly depressed. The liver cells start arranging themselves into lobular forms in a $4.2 \mathrm{~mm}$ larva, which are distinctly observed in a $5.3 \mathrm{~mm}$ larva and the blood vessels penetrate into them (Fig. $7 \mathrm{E}, \mathrm{F}$ ). The gall bladder appears to be formed in a $5.3 \mathrm{~mm}$ larva (Fig. $7 \mathrm{E}$ ). The pancreas is differentiated along the left dorsal side of the intestine as a mass of cells deeply stained with Delafield's haematoxylin or Mallory's stain (Fig. $7 \mathrm{H}$ ), and stands out among the liver cells by $6.3 \mathrm{~mm}$ in total length.

Examination of the intestinal contents reveals that the larvae feed upon green algae from the pond after 24-36 hours from the time of hatching.

5.1-6.8 mm larva (Fig. $6 \mathrm{C}$ ). The yolk is considerably decreased which is indicated by thinning out of the anterior broadened end of the yolk and the reduced one presents a rod-like structure broader at the anterior part. The head is being straightened out and mouth opening is being shifted towards the anterior end. The gape measures nearly $800 \mu$ in a $5.6 \mathrm{~mm}$ larva. The shoulder girdle has already appeared behind the operculum and now it is prominently marked.

Fig. 7. Photomicrographs of the histological structures of digestive system of the carp.

A. Horizontal section through the buccal region and the heart of $4.1 \mathrm{~mm}$ newly hatched larva. X 50 .

B. Transverse section through the pharyngeal cavity at the level of auditory region of $4.1 \mathrm{~mm}$ newly hatched larva. X 100 .

C. Gill arch of B, enlarged. X 400 .

D. Longitudinal section through the intestine of $4.4 \mathrm{~mm}$ newly hatched larva. $\times 500$.

E. Transverse section through intestine of $5.3 \mathrm{~mm}$ larva. $\mathrm{X} 100$.

F. Transverse section through intestine of $5.3 \mathrm{~mm}$ larva. $X 100$.

G. Longitudinal section through the intestine of $6 \mathrm{~mm}$ larva. $\times$ ZOO.

H. Transverse section through the anterior part of the intestine of $6.3 \mathrm{~mm}$ larva. 

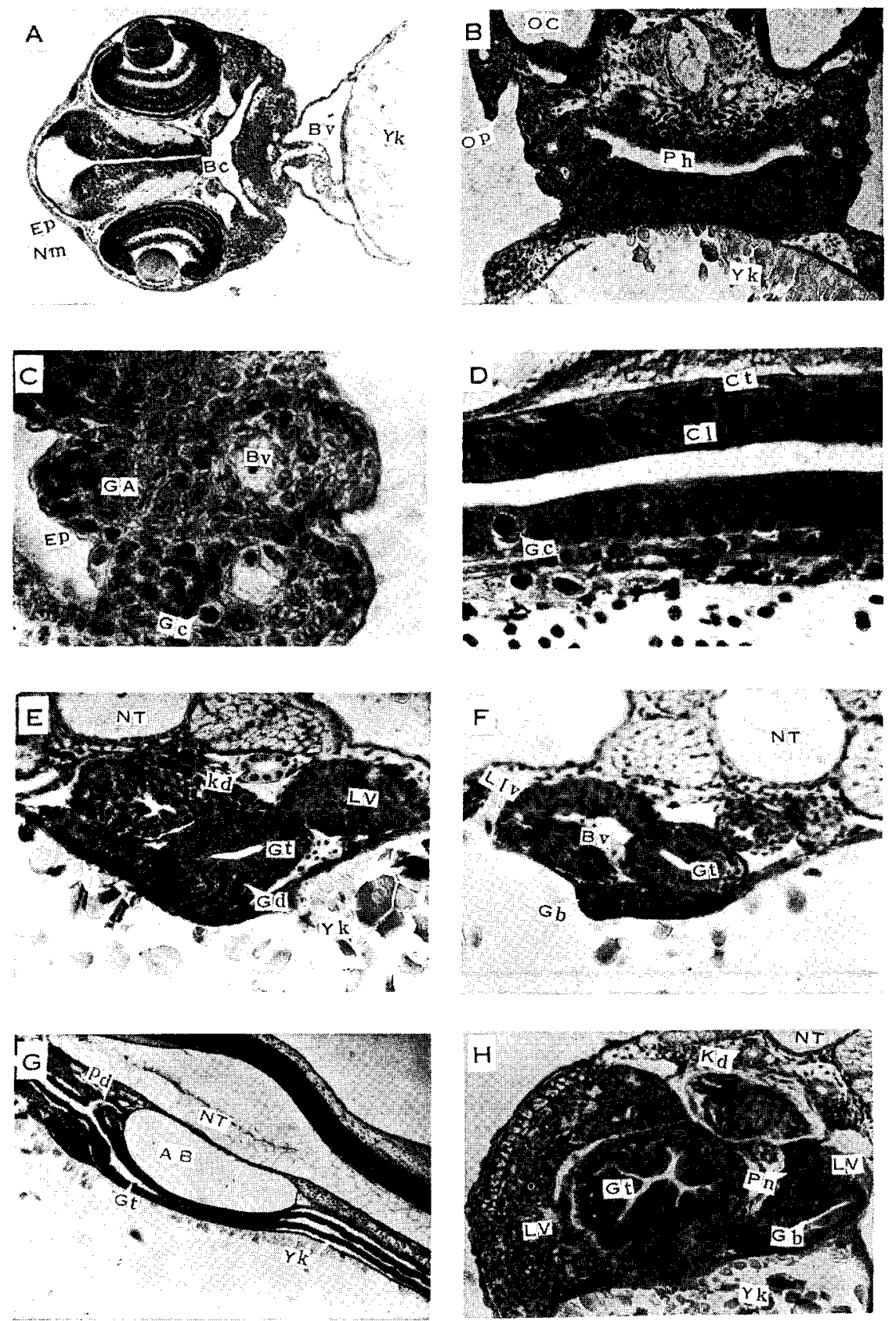

Fig. 7. 
Posterior air bladder shines as a silvery speck at the anterodorsal position of the intestine below the notochord at $6 \mathrm{~mm}$. It is an almost oval-shaped structure slightly broader at the anterior end than the posterior one and is inflated with air. The larva can swim freely and occasionally it takes rest, attaching itself with the mouth region to the wall or the bottom of the pond.

Melanophores have increased and do not show any particular arrangement along the lateral line. Radial streaks are marked in the caudal fin. Operculum moves rhythmically. The pectoral fins have increased about $0.8 \mathrm{~mm}$ in length in a $6.8 \mathrm{~mm}$ larva.

The lining of the mouth cavity is 4-5 strata thick and consists of stratified squamous cells. The mucous cells are now prominent. Taste buds, which appeared at an earlier stage, about 10-12 hours after hatching (Fig. $29 \mathrm{~A}$ ), are now quite prominently marked on the mucosal papillae (Fig. $7 \mathrm{~J}$ ) in a $6.8 \mathrm{~mm}$ larva.

The pharyngeal wall is also thickened, measuring about $10-17 \mu$ and consists of stratified squamous cells impregnated with mucous cells and taste buds (Fig. $7 \mathrm{~K}$ ). The mucous cells measure about $10-15 \times 12-18$ $\mu$ in diameter. Dense papillae cover the mucosal lining. The pharygeal teeth fixed in the foliaceous mass of tissues project into the cavity, and consist of an outer layer, the enamel (which takes up slight haematoxylin colour), below which is the cement covering the pulp cavity. The cement and the enamel are formed of odontoblasts. Resides these there are doveloping replacement teeth lying deep among the tissues.

Hornified cells of the horny pad are clearly distinguishable on the pharyngeal roof opposite to the teeth (Fig. $7 \mathrm{~K}$ ). The oesophagus measures about $118-300 \mu$ in length in a $6.8 \mathrm{~mm}$ larva. The pneumatic duct is short and of narrow calibre (Fig. 70 ).

(Fig. 7, contimed)

I. Transverse section through the anterior part of intestine of $6.6 \mathrm{~mm}$ larva.

J, K, L. Longitudinal sections through bucco-pharyngeal, oesophageal and intestinal regions of $6.8 \mathrm{~mm}$ larva. X100.

M. Longitudinal section through the pharyngeal teeth of $6 \mathrm{~mm}$ larva. $\times 200$.

N. Transverse section through pancreas of $8.2 \mathrm{~mm}$ larva. X 100 .

0 . Transverse section through the posterior oesophagus of $6.8 \mathrm{~mm}$ larva. $\mathrm{X} 100$.

P. Transverse section through the liver of $16.5 \mathrm{~mm}$ larva. X 500 .

Q. Transverse section through spleen, liver and pancreas of $17.5 \mathrm{~mm}$ juvenile.

AB. air bladder; Bc. buccal cavity; BV. blood vessel; Cl. columnar cell; Dt. dentine; FO. fold ; GA. gill arch ; Gb. gallbladder; Gc. granular cell; Gd. gall bladder duct; Gt. intestine; hp. horny pad; Kd. pronephric tubule; Lc. liver cells ; Llv. hepatic lobue ; LV. liver; mv. maxillary valve ; NT. notochord ; OB. odontoblast ; OC. optic or auditory cavity: Op. operculum ; pd. pneumatic duct ; Pnc. pancreatic cells ; Pn. pancreas ; SP. spleen; Tb. taste bud: YK. yolk. 

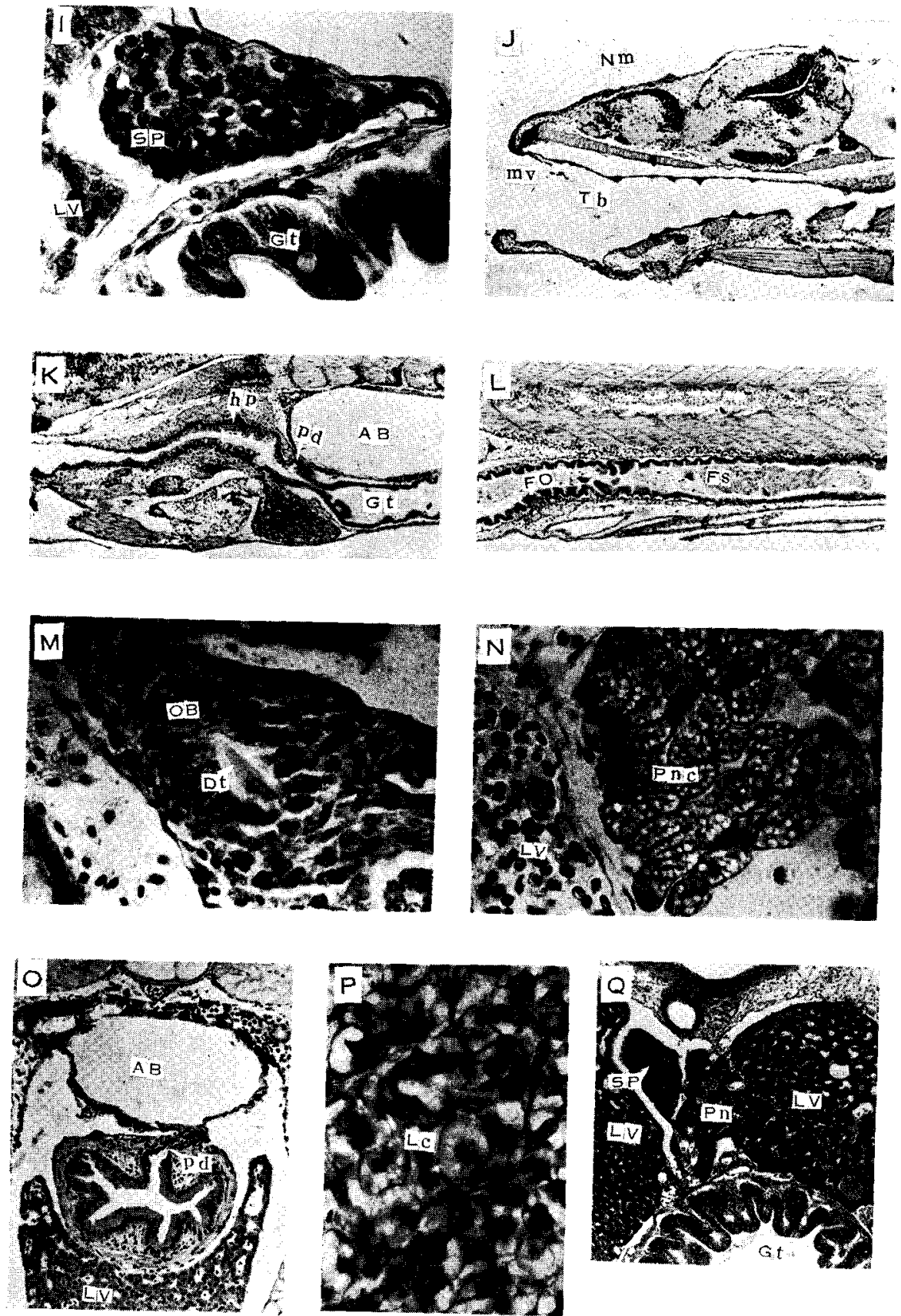

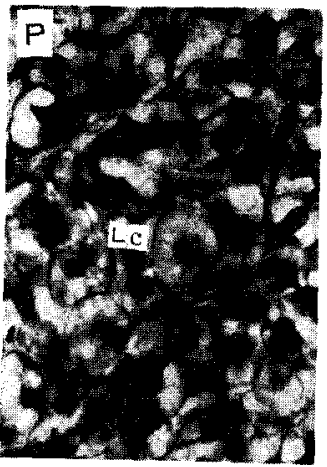

(Fig. 7, continued)

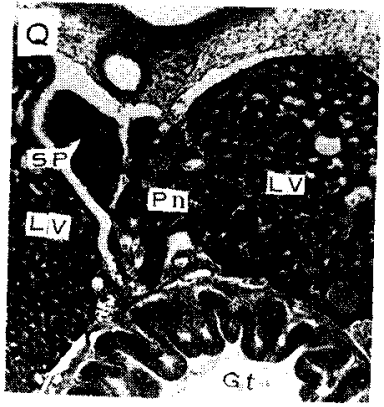


The anterior part of the intestine appears to be downwardly pushed by the growing air bladder by larva $6 \mathrm{~mm}$ in total length (Fig. $7 \mathrm{G}$ ). The mucosal folds, high and low, are many in the anterior region but decrease gradually towards the posterior end (Fig. $7 \mathrm{~K}, \mathrm{~L}$ ). The long intestine behind the swollen part or the enlarged part appears to be almost uniform in diameter. Micro-anatomically four tunics (mucosa, submucosa, muscularis and serosa) are recognized in the intestine from inside to outward and their detailed descriptions follow in the the next chapter. The lumen of the gall bladder has considerably increased by larva $6 \mathrm{~mm}$ in total length. The spleen is distinguished as a small mass of cells on the left dorso-lateral side of the intestine by larva $6.6 \mathrm{~mm}$ in total length (Fig. $7 \mathrm{I}$ ).

The larva by $6.8 \mathrm{~mm}$ in total length feeds freely on diatoms and small daphnia. Green algae fill up the first part of the intestine and seem to be broken into cell-sized pieces and they appear to be slowly decreasing in quantity while passing along and being absorbed into the posterior region. Green algae cause green coloration to the digestive tube.

7-7.7 mm larva (Fig. 6 D). Remnants of fin fold are still present but the caudal fin has become more prominent than before. Streaks of caudal rays are becoming distinct and number $12-15$ at this stage. The melanophores together with yellow tints at various regions are more enhanced than before on the head and along the middorsal surface of the body. They even prevail on the pharyngo-oesophagus and air bladder, which has increased in size. The yolk is almost completely absorbed by $8 \mathrm{~mm}$ in total length (Fig. 9). Swimming activity has increased but their habit of attaching themselves to the substratum is still noticed. When disturbed they swim for a few seonds and then rest.

Heart beat varies from 85 to 130 per minute at $24 " \mathrm{C}$ in $7.2-7.7 \mathrm{~mm}$ larvae. The blood has developed a red tint. The posterior end of the notochord is begining to turn upward in 7.5-7.7 mm larvae. Heterocercal type of caudal fin is being formed after recapitulating its former protocercal type.

The epidermis is so much thickened (about $6 \mu$ ) that it can be easily peeled off by fine forceps or needle and it consists of multilayered (2-3) epidermal cells underneath which is the connective tissue of the dermis. 'Transparent hairs' (Hikita, 1956), when viewed from dorsal side, are clearly marked on the head and either side of the body. They measure about $0.12-0.14 \mathrm{~mm}$ in length and their function seems to be sensitive.

Hepato-pancreas, reddish yellow in colour is distinctly visible in the transparent larva as a triangular mass below the enlarged part 
of the intestine and behind the heart. The pancreas extends beyond the liver caudally. Further, it is interesting to note that the pancreatic cells lie along the left dorso-lateral side of the intestine (Fig. $7 \mathrm{H}, \mathrm{Q})$.

Three or four segments of the already segmented notochord appear to be ossified as indicated by their affinity for Alizarine Ked.

7.8-9.5 mm larva (Fig. $6 \mathrm{E}$ ). This stage begins after the absorption of the yolk. Though it is already absorbed, in some cases yolk substances are present which are represented by a small mass of yolk granules below the anterior part of the intestine to be observed only in histological preparations (Fig. 9).

The dorsal fin is being distinguished. Caudal fin is differentiated due to the constriction or notch at the caudal peduncle region. Anal tins make their appearnce as a small bud of mesenchymatous tissue at nearly 7.8-8 $\mathrm{mm}$ in total length. Pelvic fins become evidenced as a small protuberance on either side of the pre-anal fin nearly at the level of the origin of the dorsal fin by $9.5 \mathrm{~mm}$ larva. Ear vesicles seem to be as large as eyes. Pancreatic tissues assume alveolus forms (Fig. $7 \mathrm{~N}$ ). Ossification of Weberian ossicles observed by $9-9.5 \mathrm{~mm}$ (Fig. $11 \mathrm{~A}$ ) to be described in the following lines. Congregation and schooling behaviour of the fry are marked but it does not seem to be very significant.

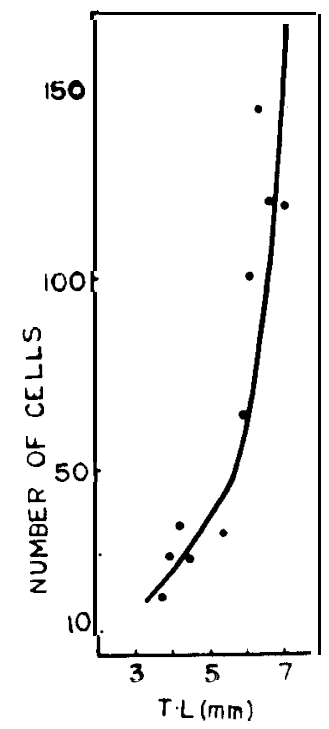

Fig. 8. Relation of number of cells from first part of intestine in transverse section to total length.

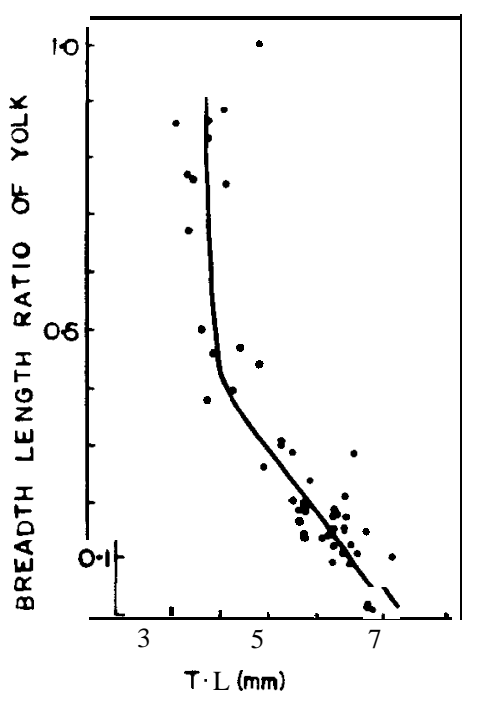

Fig, 9. Breadth-length ratio of yolk to total length. 
9.6-10.5 mm larva A hump is distictly formed behind the head. Bifurcation of the caudal fin is becoming evident and 15-18 caudal rays are counted. Seven hypural bones arranged in a fan-like manner below the upturned part of the notochord (posterior end) are enumerated (Fig. 10) in a $9.6 \mathrm{~mm}$ larva.

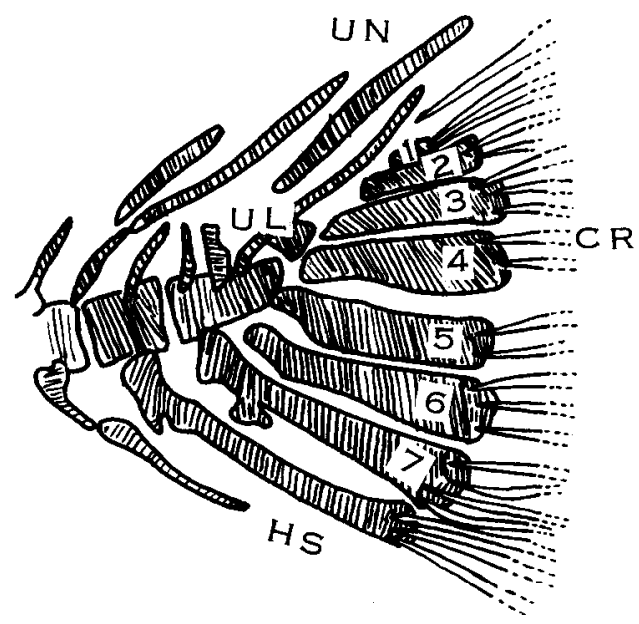

Fig. 10. Ossification of caudal skeletons of carp.

CR. caudal rays ; HS. haemal spine ; UL. urostyle ;

UN. uroneural; 1-7. number of hypurals.

Air bladder develops another chamber at the anterior end. A chain of Weberian ossicles marked earlier is seen connecting the spinal medulla anteriorly and the air bladder posteriorly. They are named from anterior to posterior claustrum, scaphium, incus and tripus (Fig. 11). The claustrum (hinlage) is an almost saucer-shaped structure attached to the ear cartilage. The scaphium (stapes, steigbül, deckl) consists of two processes with a concavity for claustrum. The interclarium (incus, ambos, lenker) is a tri-radiate bone. The tripus (malleus, hammer, hebel) is the largest bone, the posterior ramus (transformator process) of which is attached to the air bladder. Hcpatic cells assume the young condition (Fig. $7 \mathrm{P}$ ).

The larvae feed on green algae, daphnia (Fig. 12 A, B) and the paste of the mixed diet in the experimental pond.

11-16 mm larva (Fig. $6 \mathrm{~F}$ ). Dorsal fin rays are counted to be 8-14 and five soft rays are observed in the anal fin. Pelvic fins are evidently clear. 
Mouth opening measures nearly $1 \mathrm{~mm}$ and lips are fleshy and papillated. Anterior part of the air bladder becomes more evident by 11 $\mathrm{mm}$ larva than before. Adipose tissues are marked to invade the liver the pancreas by $13 \mathrm{~mm}$ larva. Spleen is surrounded by the increasing hepatopancreas (Fig. 7 0).

The intestine is being filled up more and more with daphnia (Fig. 12 B-F) and diatoms, and 13-20 daphnia are recorded only from the first part of the intestine, while 4-10 are found in the posterior region. The shells are not digested, rather defecated.

A
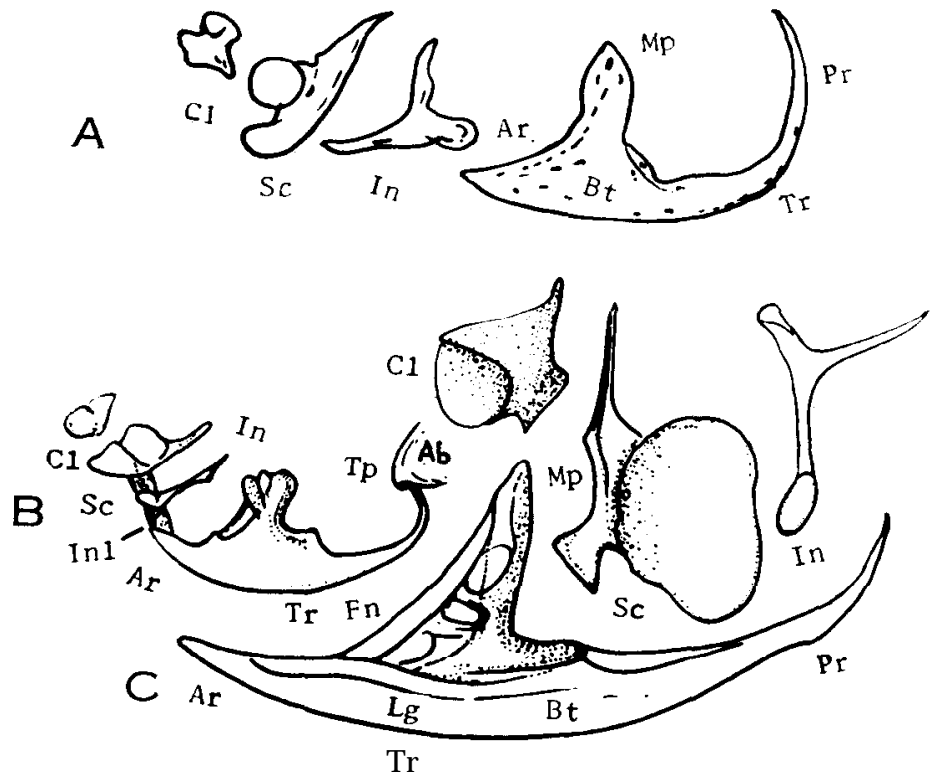

Fig. 11. Weberian ossicles of carp.

A. Weberian ossicles from $9.5 \mathrm{~mm}$ larva. $X 50$.

B. Weberian ossicles from $18 \mathrm{~mm}$ juvenile. $\mathrm{X} 20$.

C. Same as B enlarged. X 50.

Ab. air bladder ; Ar. anterior ramus; Cl. claustrum; Bt. body of tri-

pus ; In. incus ; Inl. connecting ligament; Lg. longitudinal groove ;

Mp. median process ; Pr. posterior ramus; Sc. scaphium; Tp. trans-

formator process ; Tr. tripus.

18-25 mm larva (Fig. 13 A). Pelvic fins show 2-3 soft rays. Pectoral fins have developed 6-7 rays in $16-18 \mathrm{~mm}$ juvenile. The fin rays reach the adult condition by about $25 \mathrm{~mm}$.

Scales appear at $17-18 \mathrm{~mm}$. Six to scales arranged in 2-3 rows are marked along and below the lateral line behind the operculum in $17 \mathrm{~mm}$ juvenile and about 3-5 are also observed along the lateral line at the 

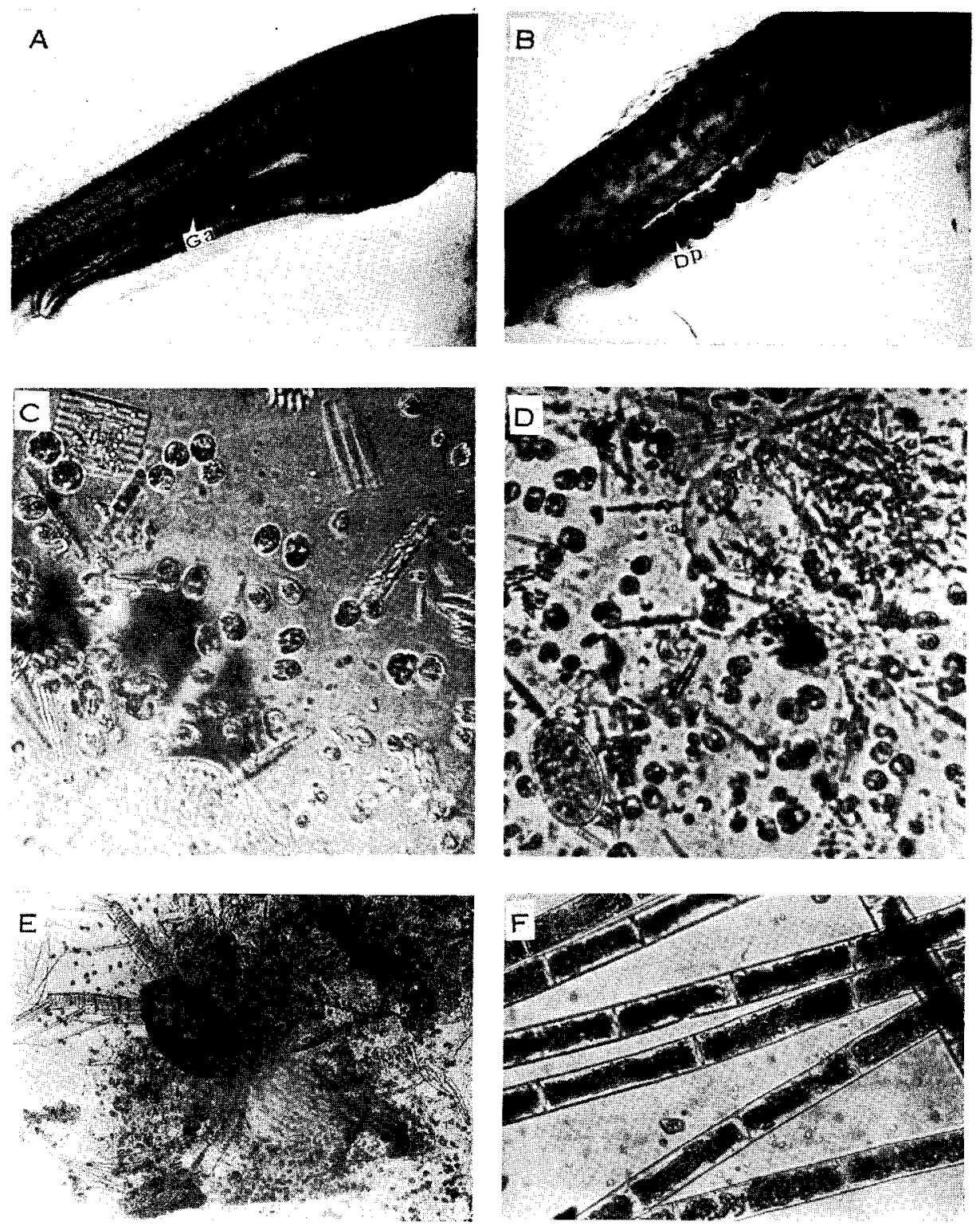

Fig. 12. Photomicrgraph of food substances in the intestine of carp.

A. Intestine of $9 \mathrm{~mm}$ larva filled with green algae.

B. Intestine of $12 \mathrm{~mm}$ larva filled with daphnia.

C, D. Intestinal contents (diatoms, algae and daphnia) from $11 \mathrm{~mm}$ larva.

E. A daphnia from just behind first limb of intestine of $11 \mathrm{~mm}$ larva.

F. Spirogyra from the first limb of intestine of $11 \mathrm{~mm}$ larva. 
caudal peduncle of 17.5-18.8 $\mathrm{mm}$ juvenile. They appear to be increasing posteriorly with the growth of the fish and by $24-30 \mathrm{~mm}$ cover the whole surface of the body. The number of scales along the lateral line is nearly 31-39.

Nasal cavities have developed 3-5 mucosal folds by 17-18 mm juvenile. Mandibular barbels make their appearance in 18.5-19 $\mathrm{mm}$ juvenile and maxillary ones at about $22 \mathrm{~mm}$. Their histological feature are described in the next chapter.

Spleen appears to be covered completely laterally by the hepatopancreas, ventrally by the intestine, and dorsally by the air bladder. The tripus of the Weberian ossicles is provided with the longitudinal grooves and fenestrations by 17-18 mm (Fig. $11 \mathrm{C}$ ).

Young over $30 \mathrm{~mm}$ (Fig. $13 \mathrm{~B}$ ). The body is compressed behind the occipital and coloration greatly varies. Belly is more lightly coloured than the back. Operculum exhibits many radial streaks. Scales become
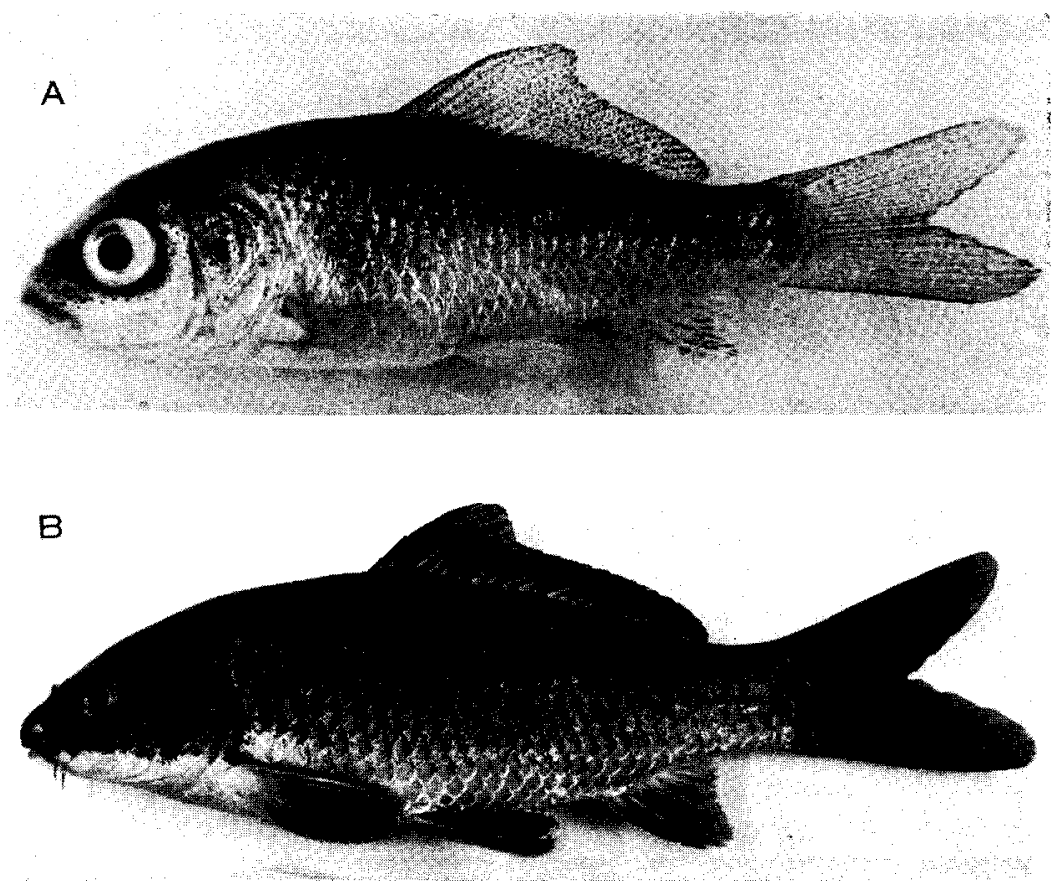

Fig. 13. Young carp.

A. Young (one month old) measuring $25 \mathrm{~mm}$ in total length.

B. Young (one year and eight months old) measuring $210 \mathrm{~mm}$ in total length. 
large and fringed posteriorly with black dots. Dorsal fin, III-IV, mostly 18-21. Anal fin, II-III, 5-6, mostly III, 5 rarely III, 6 or II, 5 but in one case III, 3 was recorded from a specimen $134 \mathrm{~mm}$ in standard length. Caudal rays, 10-10. Further growth includes the gonadal development leading to the adult condition. However, the growth of the carp is briefly stated as follows : $24-35 \mathrm{~mm}$ by 1 month, $25-50 \mathrm{~mm}$ by 2 months, $68-85 \mathrm{~mm}$ by 3 months, $80-100 \mathrm{~mm}$ by 4 months, $190-200 \mathrm{~mm}$ by 1 year, $250-280 \mathrm{~mm}$ by 2 years.

If the mixed diet is put into the pond they move quickly to eat it up and then move away. They were not found to take up the food substances full to the stomach at a stretch. The minute food substances such as algae are caught on the gill rakers. They eat in the day time or at dusk. Small pieces of potatoes or carrots are easily taken up by the fry or the young. Substances like onions or radish proved to be a little repulsive. They take up every suitable food according to the size of the mouth. During the course of pouring the food into the pond the carp become so much accustomed to the food quality that only at the foot steps of persons nearby at feeding time did they approach the appointed feeding post and awaited enthusiastically the expected daily food. They jump and flutter on the food, eat and move away.

\section{Structure of integument and its derivatives}

Multifarious approaches have been made to the study of skin and its associated structures in fishes. W right (1884), Herrick (1903), Miyadi (1929), Sato (1937), Islam (1951), Jakubowski (1961, 1963), Sing and Kapoor (1967), etc. have made worthy contributions in this field. In this short note the materials marked in figures were examined histologically with a hope to enhance our knowledge on fish integuments.

Head skin The skin of the head consists of epidermis and dermis intermixed by a thin basement membrane and stratum compacturn.

Epidermis Its thickness varies according to the position whether situated on the dorsal, lateral or ventral sides of the head. The integument from the mid-dorsal region of a newly hatched larva consists of a single layer of squamous cells each containing a large nucleus and deeply stained chromatin granules and a nucleolus. These cells are flattened and elongated along the surface (Fig. 15A). The intra-cellular bridges are clearly marked. Along the dorso-lateral side the integument becomes thickened and double layered, the outer one being squamous and the inner one being cuboidal to columnar. It appears to be thickest on the ventral side. The outer flattened cells 


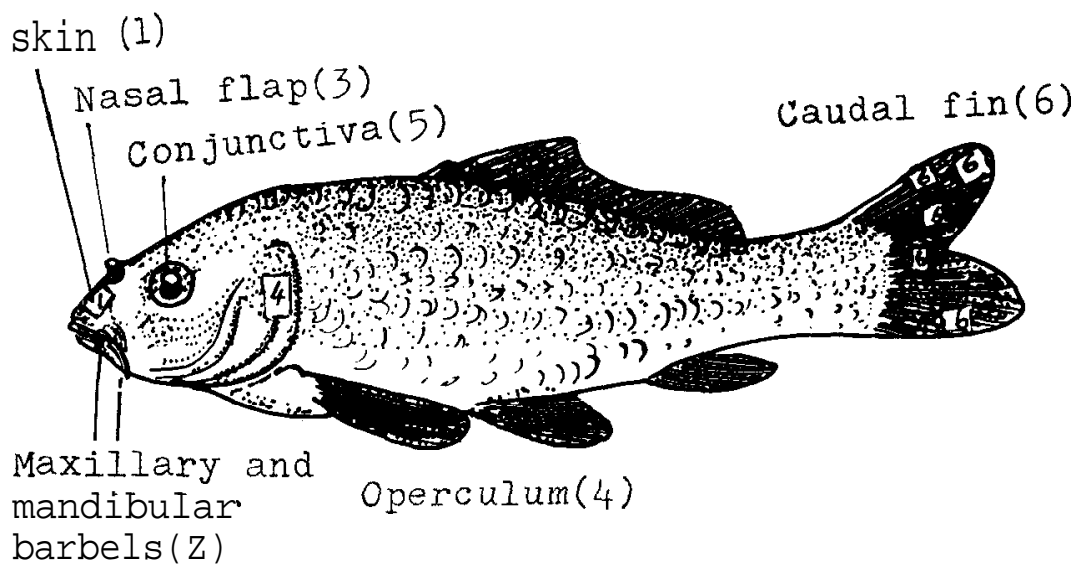

Fig. 14. The examined parts are marked in 1-6.

are disturbed due to large secretory cells which are more abundantly distributed along the ventral regions of the head and yolk than elsewhere, measuring about $6-15 \times 7-20 \mu$ in diameter (Fig. $16 \mathrm{~A}$; Table 3).

They are either oval or rounded in form with almost rounded or flattened nuclei and occasionally tend to become stratified. Their contents are granular positive to Alcian blue which is a histo-chemical test for polysaccharide. They are absent from yolk-free larvae and their secretions appear to be adhesive helping the yolk-laden larvae to stick to the substratum.

By $6 \mathrm{~mm}$ larva the head skin appears to be slightly corrugated when observed under high power. In histological preparations they

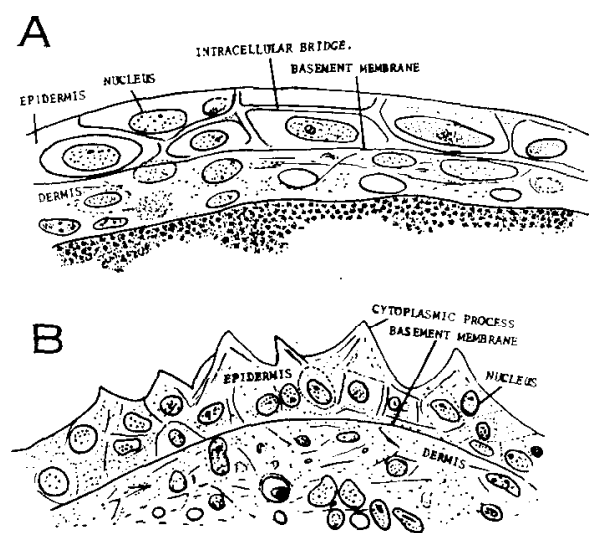

Fig. 15. A. Sketch of transverse section of dorso-lateral head skin of $5 \mathrm{~mm}$ larva.

B. Sketch of section of dorsal head skin of $6 \mathrm{~mm}$ larva. 
Table 3. Measurements ( $p$ ) of large secretory cells of head skin of carp.

\begin{tabular}{|c|c|c|c|}
\hline $\begin{array}{l}\text { T. L. } \\
\text { mm }\end{array}$ & Length (L) & Breadth (B) & Average $(\mathrm{L} \backslash \mathrm{B})$ \\
\hline 3.3 & $10-15$ & 7-13 & 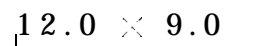 \\
\hline 4.3 & $10-17$ & $9-13$ & $15.6 " 9.0$ \\
\hline 5.4 & $13-17$ & $10-13$ & $15.8 \times 10.0$ \\
\hline 6.0 & $20-25$ & $15-$ & $21.6 \times 15.0$ \\
\hline 7. 0 & $13-17$ & 10 & 15. (1) $\quad 10.0$ \\
\hline 7.4 & $5-10$ & $5-7$ & 15.0 × 6.0 \\
\hline
\end{tabular}

appear to be cytoplasmic extensions or processes (Fig. 15B) and seem to disappear by 12-14 mm larva. The cells become gradually stratified and are progressively differentiated into a basal elongated cell layer and a superficial flattened layer between which lie several layers of rounded or polygonal cells containing rounded or oval nuclei. Sharply stained basophilic nuclei are marked along the basal layer.

Mucous cells of various sizes and forms (rounded or oval or slightly elongated) occur either opening outside the surface or lying near to it in epidermis (Fig. $16 \mathrm{D}, \mathrm{F}$; Table 4).

Table 4. Measurements ( $\mu$ ) of mucous cells and club cells of head skin of the carp.

\begin{tabular}{|c|c|c|c|}
\hline $\begin{array}{l}\text { T. L. } \\
\text { (mm) }\end{array}$ & $\begin{array}{l}\text { Mucous cells } \\
\text { dorsal side }\end{array}$ & $\begin{array}{l}\text { Mucous cells } \\
\text { ventrai side }\end{array}$ & Club cells \\
\hline $7-8$ & $d-10 \times 2-7$ & $5-9 \times 5-8$ & \\
\hline $9-11$ & $6-15 \times 5-10$ & T- $\quad$ X 10- & \\
\hline $12-15$ & $6-15 \times 5-13$ & lo- $\quad<5-10$ & $5-10 ; \quad 5-5$ \\
\hline $16-18$ & $7-15 \times 5-13$ & & $13-20 \times 7-13$ \\
\hline $19-22$ & $7-15 \times 5-13$ & $10-15 \times 5-10$ & $7-25 \times 6-20$ \\
\hline $23-26$ & $7-25 \times 4-13$ & $7-13 \times$ G-13 & $10-25 \times 10-13$ \\
\hline $27-30$ & $7-27 \times 4-13$ & & lo- ?: $10-20$ \\
\hline $31-34$ & $7-27 \times 4-13$ & & $10-25 \times 10-20$ \\
\hline $39-43$ & $7-27 \times 7-15$ & & $13-40 \times 10-27$ \\
\hline
\end{tabular}

The club cells (Kolbenzellen), also of various sizes and shapes, rounded, oval or elongated or cone-shaped tapering at one end, and about 3-4 times longer than their breadth are usually seen dispersed among the middle region of the epidermis (Fig. $16 \mathrm{D}$ ). They are first marked at larva about $11-12 \mathrm{~mm}$ in total length behind the nasal cavity. By this stage they are rounded or oval with rounded nuclei embedded in the secretory mass. By larva $18 \mathrm{~mm}$ in total length vacuoles are observed and their size and number are greater than those of mucous cells, sometimes so much so that they disturb the arrangement of the mid-epidermal cell (Fig. 16 D, F). 

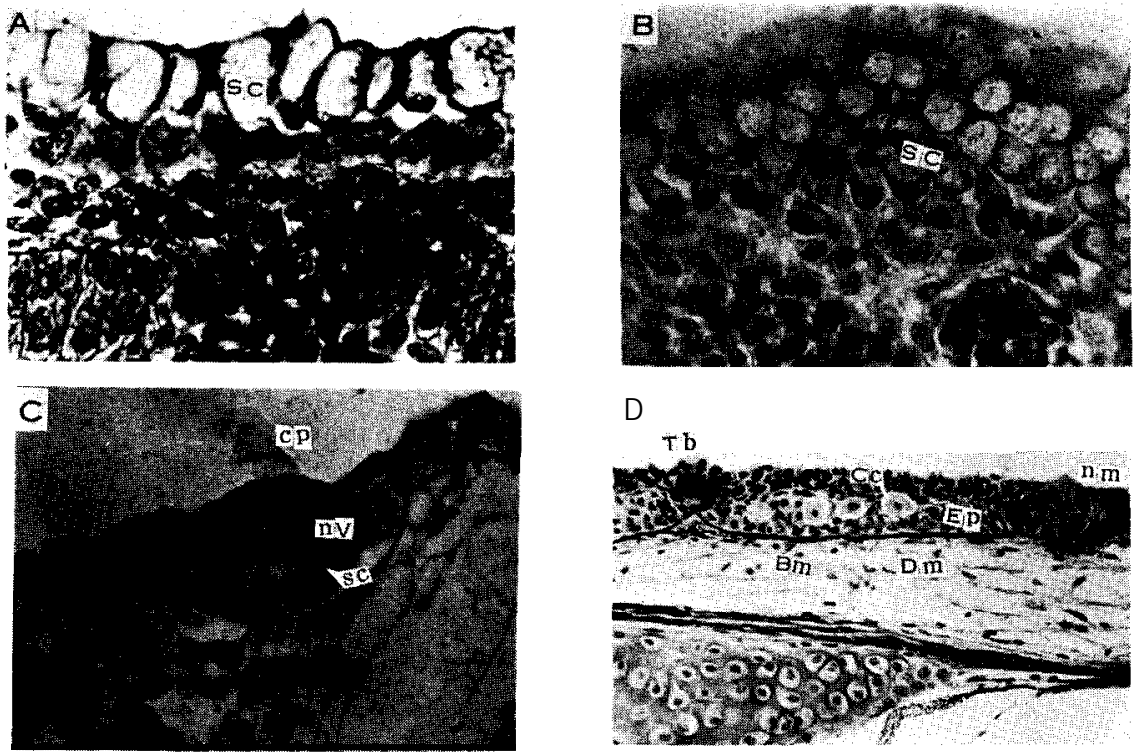

D

Tb
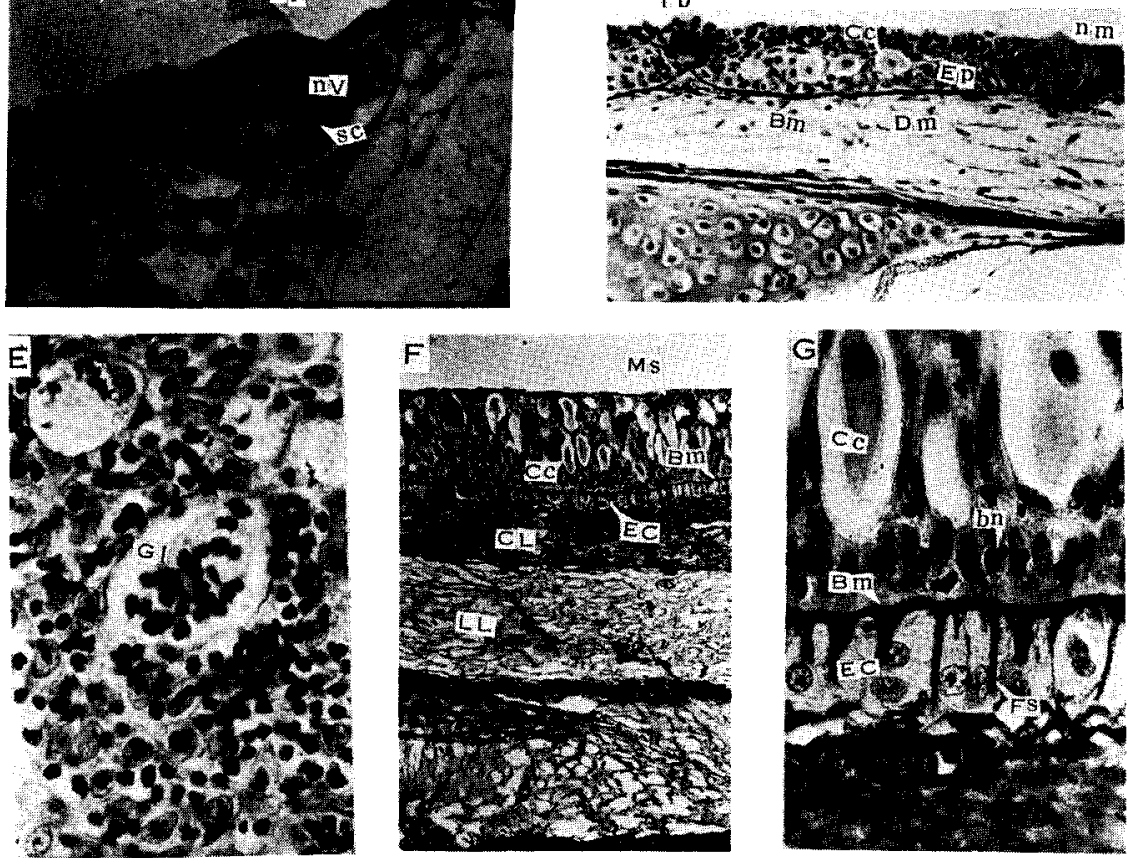

Fig. 16. Photomicrographs of the structures of the head skin of carp.

A. Transverse section through the ventral skin of $4.4 \mathrm{~mm}$ newly hatched larva. X 500 .

B. Tangential section through the ventral skin of $5.6 \mathrm{~mm}$ larva. $\mathrm{X} 500$.

C. Transverse section through the lateral skin of $6.1 \mathrm{~mm}$ larva. $X 500$.

D. Longitudinal section through the skin of $18.5 \mathrm{~mm}$ juvenile. X 200 .

E. Transverse section through the skin of $130 \mathrm{~mm}$ carp. X 1000 .

F. Transverse section through the skin of $200 \mathrm{~mm}$ carp. X 100 .

G. Section of F, enlarged. X 1000 .

Bm. basement membrane; Cc. club cells; CL. compact layer of dermis ; cp. copula ; Dm. dermis: EC. elongated cells; Ep. epidermis; Gl. giant club cells; LL. loose layer of dermis; Ms. mucous cells; nm. neuromast; nV. nerve cells; SC. secretory cells; SC. Supporting cells ; Tb. taste buds. 
Besides these, there are giant multinucleate cells (Fig. 16E) resembling club cells in form and with staining reactions distributed more along the dorsal sides of the head than the ventral ones. They may be designated as 'giant club cells'. Their exact function is unkonwn. The nuclei are more deeply stained than the ordinary club cells. Large rounded promucous cells with fine granlues are also occasionally noticed in the middle region of the epidermis of skin from near the nasal cavity.

Well developed taste buds are first marked at larva about $18 \mathrm{~mm}$ in total length when the epidermal thickness measures about $53 \mu$. They appear to be smaller in size than those of the barbels or buccal cavity or even the nasal flaps. The pit organs (neuromasts) form a broad dome resting in the epidermis and consist of lower supporting cells and upper nerve cells the processes of which extend out the surface to which a transparent and somewhat triangular 'copula' is attached (Fig. $16 \mathrm{C}$ ). The copulae are very delicate and can not withstand the mechanical action and their number on the head exceeds those on the trunk or tail regions. Their measurements are given in Table 5 .

Basement membrane This is a thin membrane which sends fibrillar sinusities on its inner sides, and is first marked by $12 \mathrm{~mm}$ larva. It is brilliantly stained blue by the ammoniacal silver technique. Among these processes a row of columnar cells or elongated cells with rounded nuclei are lodged (Fig. 16 F, G). Pigments are present.

Table 5. Measurements $(\mu)$ and counts per $\mathrm{mm}^{2}$ of taste buds and measurements of pit organs from sections of head skin of carp.

\begin{tabular}{|c|c|c|c|c|c|c|c|}
\hline \multirow{2}{*}{$\begin{array}{l}\text { T. L. } \\
(\mathrm{mm}>\end{array}$} & \multicolumn{4}{|c|}{ Taste buds } & \multicolumn{3}{|c|}{ Pit organs } \\
\hline & Numbe:r & $\begin{array}{c}\text { Height } \\
\mathrm{H}\end{array}$ & $\begin{array}{c}\text { Diame- } \\
\text { ter D }\end{array}$ & $\begin{array}{c}\text { Average } \\
\text { H-D } \\
\end{array}$ & $\begin{array}{c}\text { Height } \\
\mathrm{H}\end{array}$ & $\begin{array}{l}\text { Diame } \\
\text { ter D }\end{array}$ & $\begin{array}{c}\text { Average } \\
\text { H-D }\end{array}$ \\
\hline $7-8$ & & & & & $20-25$ & $17-25$ & $18.5-22.5$ \\
\hline $9-11$ & & & & & $20-25$ & $19-28$ & $19.0-27.5$ \\
\hline $11-15$ & & & & & $25-40$ & $26-37$ & $25.5-36.0$ \\
\hline $16-18$ & $25-40$ & $32-37$ & $22-27$ & $34.5-26.0$ & $20-37$ & $32-50$ & $31.3-43.0$ \\
\hline $19-22$ & & $32-37$ & $22-27$ & $35.5-25.5$ & $37-42$ & $37-42$ & $39.7-40.0$ \\
\hline $23-26$ & $28-50$ & $35-$ & $20-$ & $36.0-20.0$ & & & \\
\hline $27-30$ & & $37-50$ & $20-37$ & $45.0-28.5$ & $40-50$ & $37-45$ & $44.5-40.0$ \\
\hline $31-34$ & $\mid 100-20 B$ & $37-50$ & $20-37$ & $45.0-28.0$ & $50-$ & $37-45$ & $50.0-40.0$ \\
\hline $39-43$ & $80-100$ & $36-45$ & $25-$ & $45.0-25.0$ & & & \\
\hline 49 & $114-20 B$ & $37-$ & $25-$ & $45.0-25.0$ & & & \\
\hline 61 & $250-30 B$ & $37-50$ & $25-37$ & $44.5-25.3$ & & & \\
\hline 79 & $200-320$ & $37-52$ & $25-37$ & $44.5-27.7$ & & & \\
\hline $107-130$ & $200-350$ & $45-65$ & $37-42$ & $58.6-37.0$ & & & \\
\hline
\end{tabular}


Dermis This consists of loose connective tissue fibres intermingled with blood vessels and nerves. It is irregularly thicker than the epidermis, and seems to bc either absent or very thin in the yolk-sac region. When the thickness is increased (in about $30-40 \mathrm{~mm}$ specimens) two divisions are recognizable, a compact layer below the membrane consisting of dense collagenous Gbres deeply stained by a triple stain, and a loose connective tissue layer (Fig. 16 E). The collagenous fibres occasionally penetrate into it.

Barbel Barbels are the most conspicuous cutaneous extensions around the mouth of fish and are designated as feelers for searching and testing the quality of food. In carp two pairs of barbels, are present, the mandibular and maxillary ones. The former situated at each angle of the mouth and the later on the snout, and both can be seen in lateral view. The maxillary barbel is smaller than the mandibular one, i. e., nearly less than half the size of the mandibular one.

The barbel is an elongated siructure, broadest at the base and tapering gradually towards the tip (Fig. $17 \mathrm{~A}$ ). The maxillary barbel is rarely found to become bifurcated at distal end. Mandibular barbels are the first to become evident as small bud-like protuberances of the dermal layer of the skin enveloped by the epidermis at $18.5 \mathrm{~mm}$ juvenile and measuring about $217 \mu$ (Fig. 18 A). The maxillary ones are visible at larva $22 \mathrm{~mm}$ and the taste buds appear. The histological preparations expose the following structures : the epiderims, basement membrane and dermis.

Epidermis This consists of stratified layer of different types of cells of unequal thickness and is slightly thicker at the proximal end than the distal one (Figs. $17 \mathrm{~A}, 18 \mathrm{E}$ ). The cell layers are distinguishable into three regions according- to the kind and position of cells. The outermost layer is mainly composed of 2-3 layers of flattened cells. A very thin layer of squamous epithclium is marked above it which occasionally shows desquamation. Below this layer is the middle layer comprising 3-6 strata of rounded or oval cells and elongated cells. The innermost or basal layer lies above the basement membrane and consists of a single layer of elongated cells with elongated nuclei lying perpendicular to the membrane. They contain sharply stained 1-2 nucleoli and fine granules. Large number of deeply stained basophilic nuclei are distributed more in number at the proximal end than the distal part of the barbel.

Occuring either in the outer layer or the middle one, there are many mucous cells which are more frequently detected in the basal region than the middle one, but rarely marked from distal one, and they are PAS-positive (Figs. $17 \mathrm{~B} ; 18 \mathrm{E}, \mathrm{F}$ ). They are rounded, flaskshaped, or elongated with flattened nuclei thrust to the basal end of 


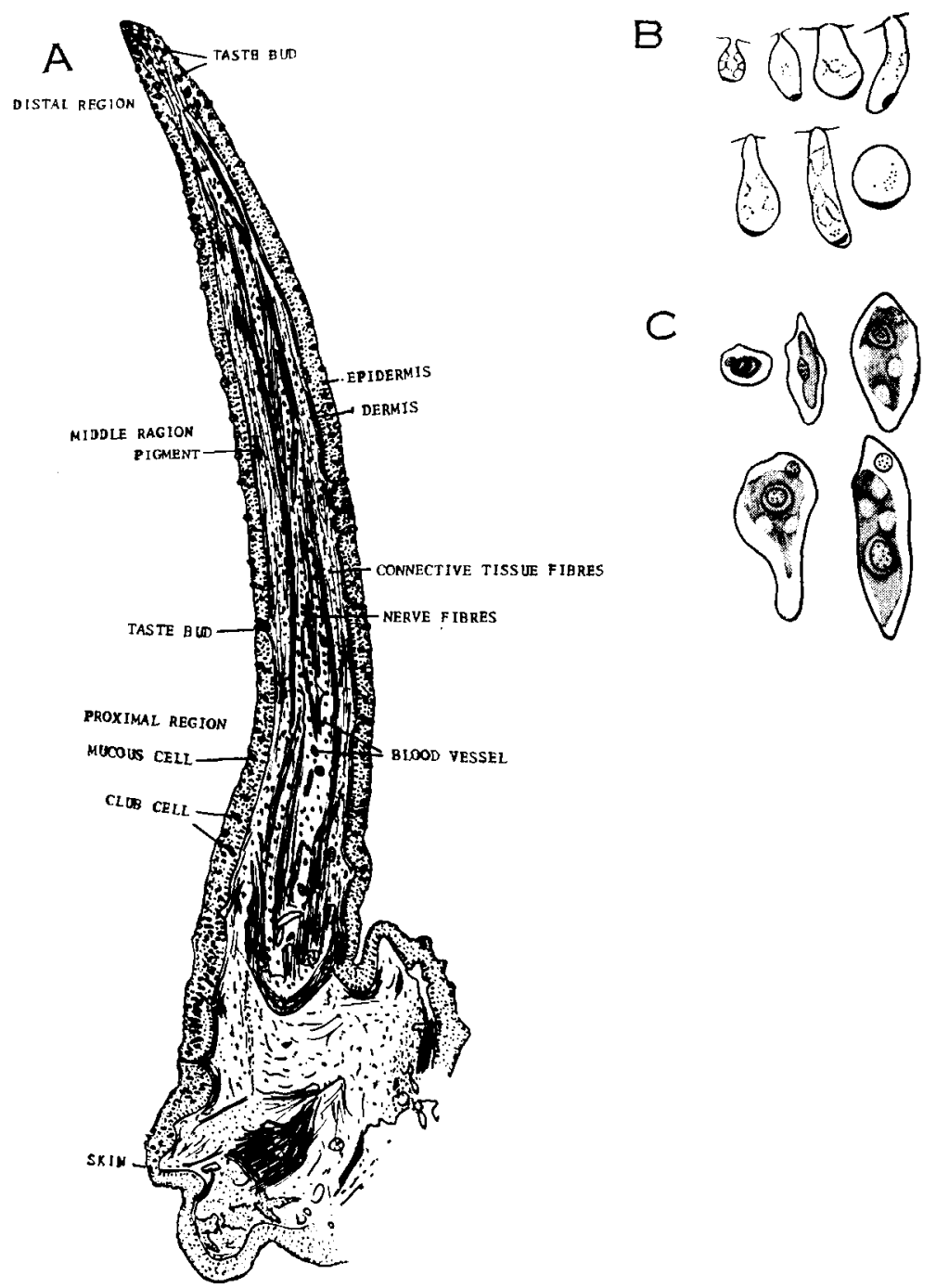

Fig. 17. A. Sketch from longitudinal section of left mandibular barbel (8 mm long) of $201 \mathrm{~mm}$ carp.

B. Various sizes of mucous cells from sections of barbel. $\times 600$.

C. Various sizes of club cells from sections of barbel. $\times 600$.

the cell, and measure about $3-5 \times 13-17 \mu$ in diameter.

The club cells like the mucous cells are mure in number at the proximal region than the middle one (Figs. $17 \mathrm{C} ; 18 \mathrm{E}, \mathrm{F}$ ). They are of various sizes and contain one or two almost centrally situated nu- 

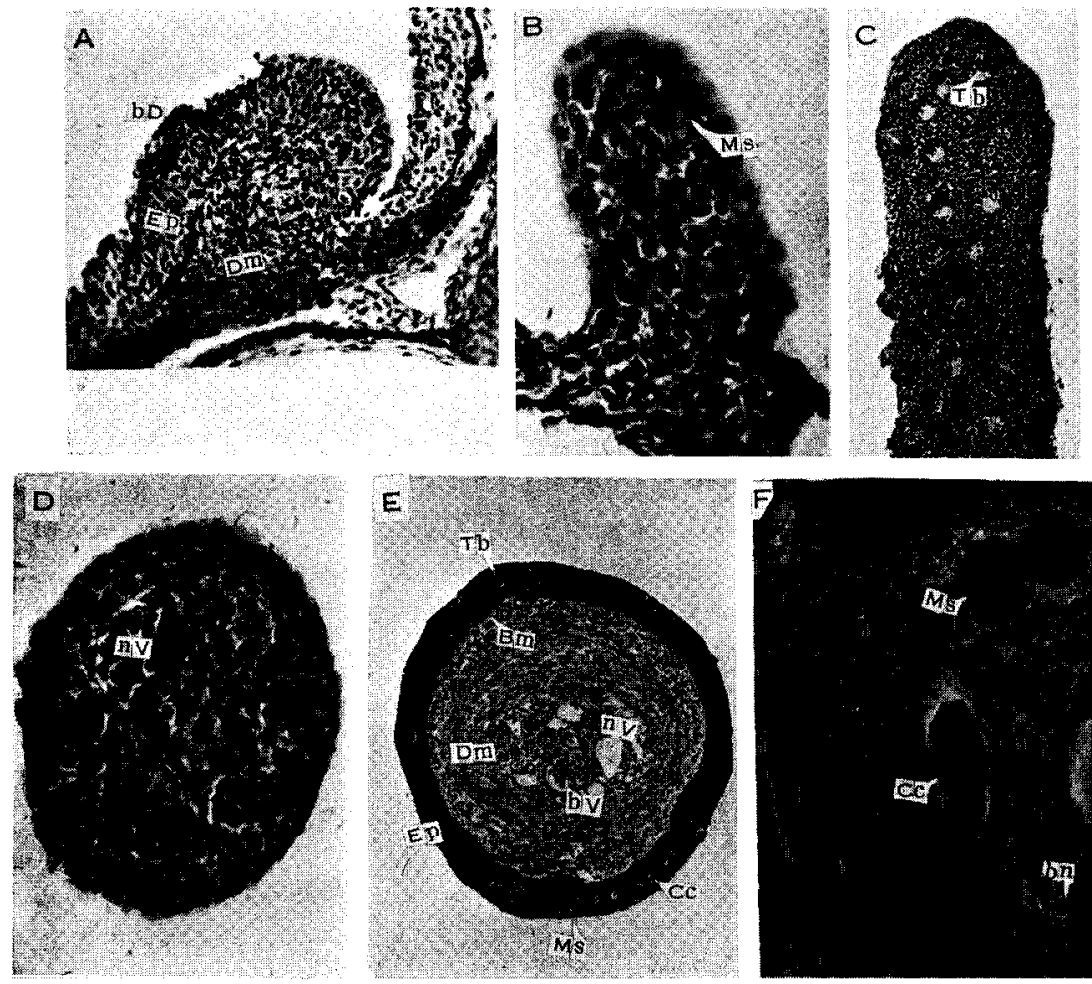

Fig. 18. Photomicrographs of the structures of barbel.

A. Section through the head skin of $18.5 \mathrm{~mm}$ juvenile. X 200 .

B. Tangential section through the maxillary marbel of $24 \mathrm{~mm}$ carp. X 500 .

C. Tangential section through the distal region of the mandibular barbel of $200 \mathrm{~mm}$ carp. x 200.

D. Transverse section through the distal region of the mandibular barbel of $183 \mathrm{~mm}$ carp. x 200.

E. Transverse section through the proximal region of D. X 200 .

F. Section through the proximal region of the mandibular barbel of $183 \mathrm{~mm}$ carp. x 500 .

bD. bud of mandibular barbel; bV. blood vessel ; bn. nerve cells ; Cc. club cells; Dm. dermis: Ep. epidermis: Ms. mucous cells; Tb. taste buds.

clei and two to four vacuolations measuring $20-30 \times 42-75 \mu$ in diameter. They are PAS-negative but occasionally their secretions are stained greenish like mucous cells by Masson's trichrome.

Lying among or peeping out or retracting from the epidermal cells are the taste organs standing on the evaginations of the dermal connective tissues. Lymphocytes are rarely present at the proximal region adove the basal cells. Their apices are rounded and protruding 
out, or truncated (Fig. $29 \mathrm{~F}$ ), or flush with the surface (Fig. 29 I) or depressed. The depressed apices are very few while the protruding ones are predominating. They measure nearly 27-50 × 60-82 $\mu$ in diameter and their density is greatest towards the distal region (Fig. 18 C, D). 'Included cells' of Olmsted (1920) are rarely present (Fig. 29 F, J).

Basement membrane Very thin and supported by a thin band of stratum compactum.

Dermis This forms the central core of the barbels and consists of loose connective tissue fibres in which blood vessels and bundles of nerves are present and black pigments lie below the membrane.

$\mathbf{N}$ asal flap Nasal apparatus shows wide varieties of adaptations among fishes. Multfarious experiments have pointed out the sensitivity and the significance of the sense of smell of fishes in procuring food and in orientation. The names of researchers in this area include Aronsolni (1884), Steiner (1888), Bateson (1890), Herrick (1906), Parker (1910), Sato (1937).

The carp possesses at the anterior end of the snout a pair of nasal cavities, a small anterior one and a large posterior one. Standing above the cavities and moving freely in various directions are leaf. like cutaneous extensions, the nasal flaps (Fig. 19 B). They protect the cavities from injuries and control the passage of water. In early stages the cavities are a single chamber and probably the flap appears by larva $18.5 \mathrm{~mm}$ in total length (Fig. $19 \mathrm{~A}$ ). It divides the cavity into two chambers by about 22-25 mm. Being an extension of the skin the flap consists of essentially the same histological elements, i. e., epidermis, basement membrane, and dermis. Epidermal thickness is greater on the anterior side than the posterior one (Fig. 19 C). Desquama. tions are occasionally marked.

Mucous cells are more numerous towards the basal region than the farther middle or post-middle ones, but their number appears to be greater on the anterior side than the posterior one, and measure about $5-10 \times 10-15 \mu$ in diameter. Promucous cells, almost rounded in form and filled up with fine granules, measuring nearly 7-15x10-20 $\mu$ in diameter are occasionally marked among the mid-epidermal cells along the proximal end of the flap. Their dense population hampers the regular arrangement of the epidermal cells (Fig. 19 D). Club cells are absent.

One or two typical taste buds are found on each dermal papilla and are more densely studded on the distal and anterior end of the flap than the proximal or post-proximal and posterior ones. A lymphocyte is rarely marked in the basal region of the bud (Fig. 29 G). The apices of the buds are either protrudiag or truncated or conically de- 

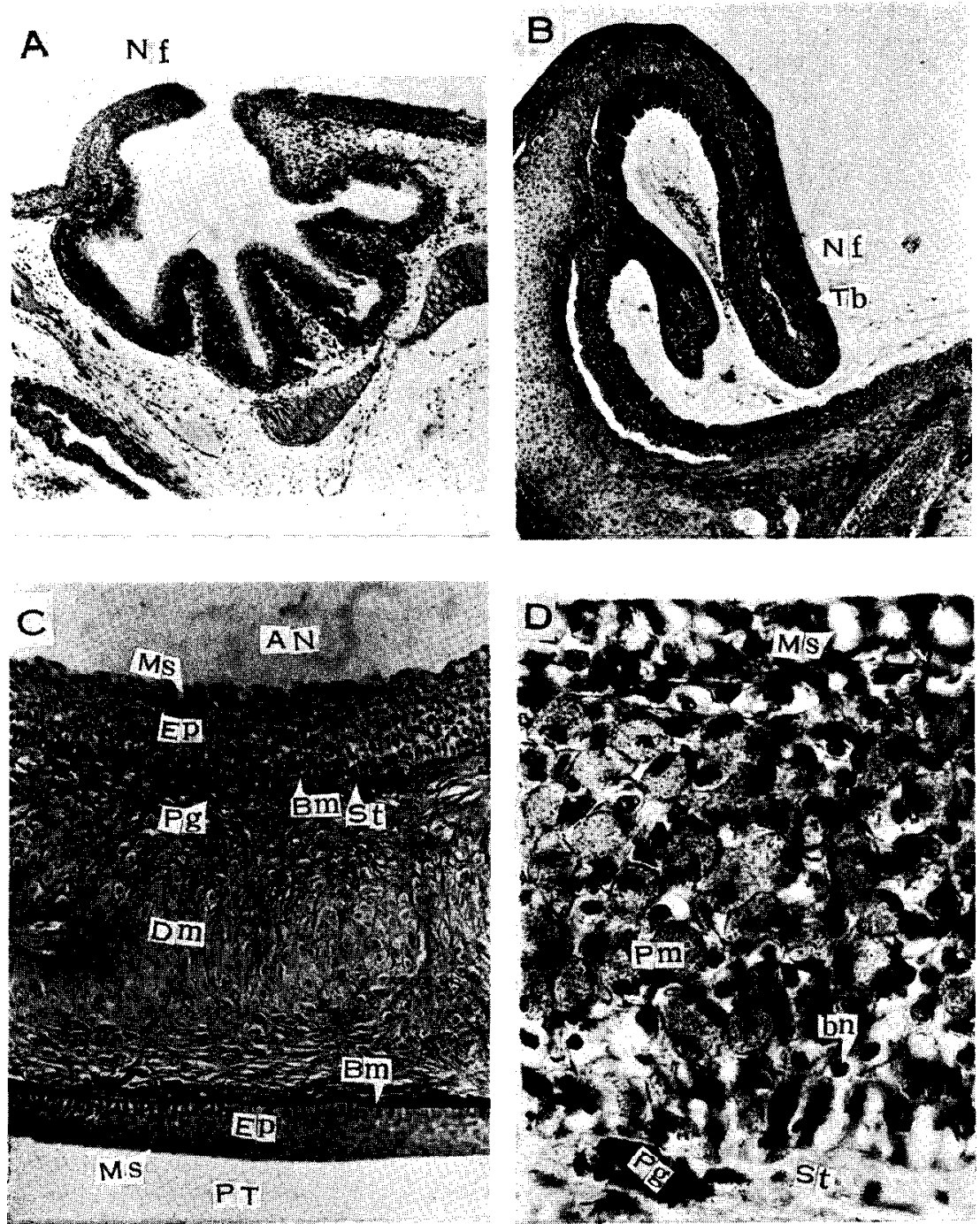

Fig. 19. Photomicrographs of the structures of the nasal flap.

A. Transverse section through the nasal cavity of $18.5 \mathrm{~mm}$ juvenile. $\times 200$.

B. Longitudinal section through the flap of $167 \mathrm{~mm}$ carp. $\mathrm{X} 100$.

C. Longitudinal section through the middle part of the flap. X ZOO.

D. Section from the middle region of the flap, enlarged. X 500 .

AN. anterior end ; Ms. mucous cell ; Nf. nasal flap ; Pg. pigment cell ;

Pm. promucous cells; PT. posterior end; St. stratum compactum;

Tb. taste bud. 
pressed (Fig. $29 \mathrm{~F}$ H).

Dermis forms the core of the flap and is thicker at the proximal ends than the middle or distal ones and tapers distally. On either side below the basement membrane are thick hyalin bands of the stratum compactum deeply stained green by Masson's trichrome, and its thickness measures about $20-25 \mu$ at the proximal region. Thin collagenous fibres extend transversely towards the centre of the dermis. Entangled within their meshes are sharply stained nuclei, nearly $2 \mathrm{x}$ $5 \mu$ in diameter. Melanophores lie below the compact layer.

Operculum This is covered on either side by similar integument. al structures as the head. The epidermis on the outer side appears to be thicker than the inner one (Fig. $20 \mathrm{~A}$ ). Club cells are more densely populated than the head. Small taste buds standing on the dermal papillae are very few and measure about $30 \times 25 \mu$ in diameter in $82 \mathrm{~mm}$ carp (Fig. $20 \mathrm{~B}$ ). Patches of neuromasts are frequently seen in sections. The inner side differs from the outer one in certain respects, i. e., mucous cells are slightly smaller than those on the outer side, club cells are few, taste buds and pit organs seem to be absent and smooth muscles are present in the matrix.

Conjunctiva of the eye This is a membranous structure covering or protecting the eye and is thinner on the outer and distal end than the inner and proximal one. Small black pigments are frequently met below the basement membrane. Tactile organs with rounded apex or slightly elongated ones often lie embedded in the epidermis and are born by the dermal elevations (Fig. $20 \mathrm{D}$ ). Taste buds are present (Fig. 20 C). Occasionally a few mucous cells are marked, but club cells are absent.

Caudal fin The general plan of the arrangement of epidermal cells is the same as of the skin. A few millimater of length at the tip is devoid of any sensory or club cells, and mucous cells are rarely marked. Near the middle or the proximal ends both are present, but the club cells prevail in number and contain as many as 2-8 nuclei (Fig. $20 \mathrm{~F}$ ). However, they are absent from the dorsal or ventral margins. Taste organs are observed on either margins (Fig. 20 E).

\section{Structure of alimentary canal}

\section{A. Bucco-pharynx}

\section{Mouth}

Lips By $7.9 \mathrm{~mm}$ larva, the lips become considerably thickened due to increased stratification of epidermal cells which are infused with taste buds (Fig. $27 \mathrm{~A}$ ) ; their density is great as well as their height 


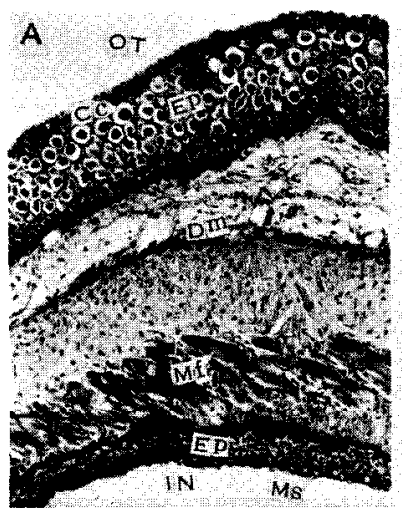

B
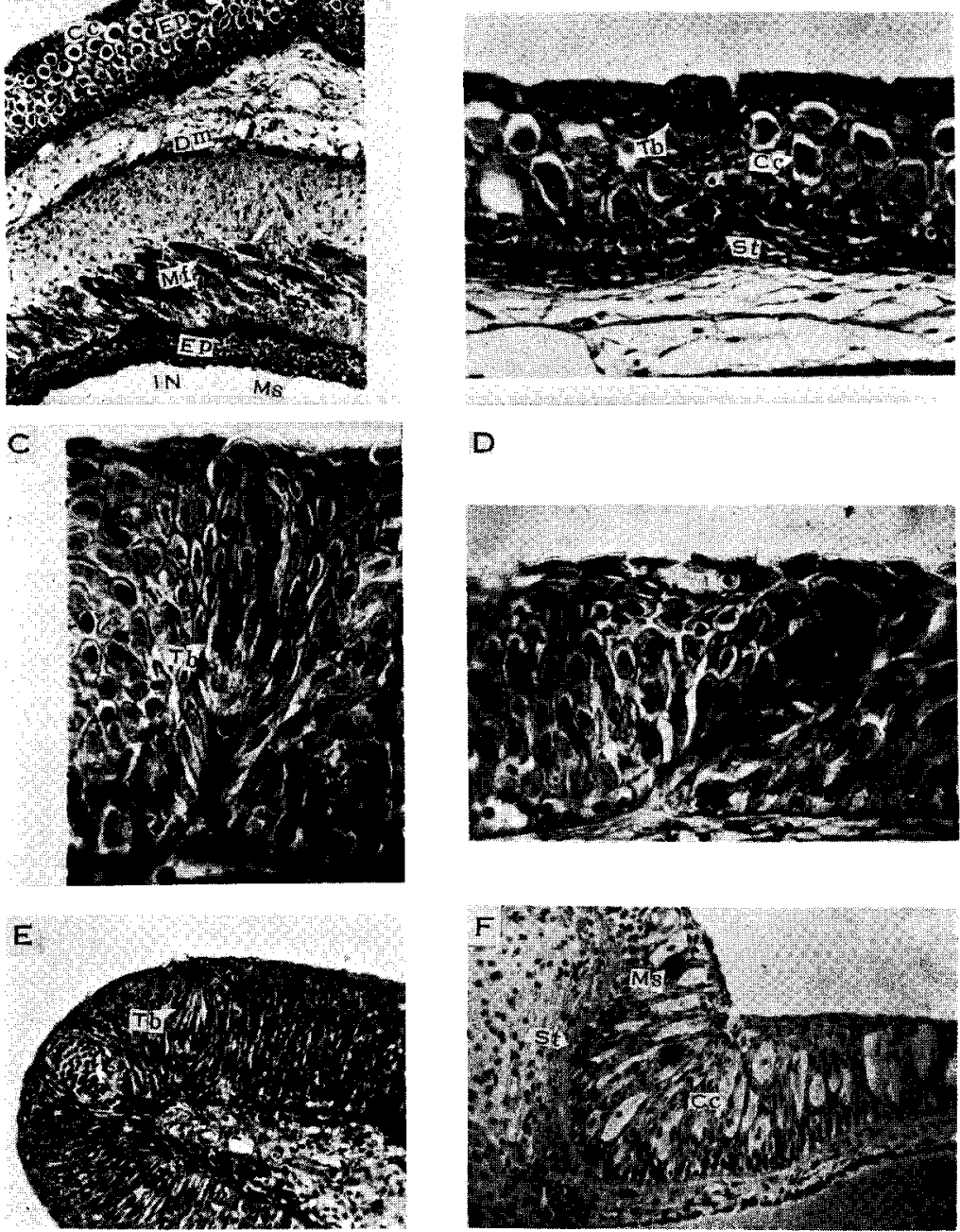

Fig. 20. Photomicrographs of the structures of the operculum, conjunctiva of the eye, and caudal fin.

A. Transverse section through the distal end of the operculum of $82 \mathrm{~mm}$ carp. X 100 .

B. Same as A from another section. X 500 .

C. Transverse section through the inner side of the conjunctiva of the eye of $82 \mathrm{~mm}$ carp. $\mathrm{x} 490$

D. Another section through the conjunctiva. X 200.

E. Vertical section through the posterior end of the caudal fin of $150 \mathrm{~mm}$ carp. $\times 100$.

F. Section through the middle region of caudal fin. $x 200$.

Cc. club cells ; Ms. mucous cells ; St. stratum compactum; Tb. taste bud 
(Table 6). Mature buds were first marked on the upper lips at about 48 hours after hatching. In sections passing tangentially through the marginal portions of the lips, they exhibit a flower-like arrangement (Fig. $27 \mathrm{H}$ ) ; the outer side of the lip has similar histological structues to the inner one. From outside inward, the epithelial layer consists of squamous cells, several layers of polygonal cells or oval cells, and a single layer of elongated cells lying above the stratum compactum (Fig. 27 L). The elongated cells measure neary 5-7x7-10 $\mu$ in diameter containing large and oval nuclei, about $4 \times 6 \mu$ in 7.9 $\mathrm{mm}$ larva. Lying below this layer is areolar connective tissue of dermis or submucosa containing blood vessels and nerves. The superficial cells are flattened. Hornified denticles resting on thick membrane are marked below and inner side of either lips (Fig. 27 C, D,

Table 6. Measurements $(\mu)$ and counts per $\mathrm{mm}^{2}$ of taste buds in the upper lip and roof of buccal cavity of the carp. Mesurements were made from sections.

\begin{tabular}{|c|c|c|c|c|c|c|}
\hline \multirow{2}{*}{ T. L. (mm) } & \multicolumn{5}{|c|}{ Upper Lip } & \multirow[b]{2}{*}{$\begin{array}{c}\text { Average } \\
(\mu)\end{array}$} \\
\hline & \multirow{2}{*}{$\begin{array}{c}\text { Number } \\
----\end{array}$} & Average & $\begin{array}{l}\mathbf{H} \mathbf{e} \mathbf{i} \mathbf{g} \mathbf{h} \mathbf{t} \\
(\mu)\end{array}$ & $\begin{array}{c}\text { Average } \\
(\mu)\end{array}$ & $\begin{array}{c}\text { Diameter } \\
(\mu)\end{array}$ & \\
\hline $5 \quad-6$ & & 40 & & 20 & & 20 \\
\hline $6.1-6.9$ & & 264 & $23-28.5$ & 24.7 & $18.5-23.5$ & 22.3 \\
\hline $7-7.8$ & $184-368$ & 276 & $23-29.7$ & 26.7 & $18.6-24$ & 23 \\
\hline $8-10$ & $272-378$ & 317.8 & $32-40.3$ & 36.9 & $20.5-28.5$ & 24.9 \\
\hline $10.1-14$ & $415-531$ & 474 & $50-63$ & 55 & $22-27$ & 24.8 \\
\hline $\begin{array}{ll}16 & -17\end{array}$ & $473.5-553$ & 511.3 & $51-63$ & 55.1 & $23.5-26$ & 24.9 \\
\hline $23-24$ & & & & & & \\
\hline $31-39$ & & & & & & \\
\hline $\begin{array}{ll}73 & -79\end{array}$ & & & & & & \\
\hline 152 & & & & & & \\
\hline 210 & & & & & & \\
\hline \multirow[b]{2}{*}{ T. L. (mm:) } & \multicolumn{6}{|c|}{ Roof of Buccal Cavity } \\
\hline & Number & Average & Height $(\mu)$ & $\begin{array}{l}\text { Average } \\
(\mu)\end{array}$ & $\begin{array}{c}\text { Diameter } \\
(\mu)\end{array}$ & $\begin{array}{c}\text { Average } \\
(\mu)\end{array}$ \\
\hline $5 \quad-6$ & $\mathrm{j} 23 \quad-205$ & 179 & $14-22$ & 14.9 & $\begin{array}{ll}9 & -17\end{array}$ & 10.8 \\
\hline $6.1-6.9$ & $142-201$ & 182 & $23.5-28.5$ & 25.8 & $20-25$ & 22.3 \\
\hline $7-7.8$ & & 353 & $25-30$ & 25.8 & $17-30$ & 23 \\
\hline $8-10$ & $\jmath 184-368$ & 330 & $22-36.7$ & 27.8 & $\begin{array}{ll}20 & -25.7\end{array}$ & 22.2 \\
\hline $10.1-14$ & $272 \quad-378$ & 372.3 & $31.6-42.2$ & 37.2 & 23.4-29.6 & 26 \\
\hline $\begin{array}{ll}16 & -17\end{array}$ & & 437 & $33.5-49.5$ & 39.9 & $18.5-25$ & 24.6 \\
\hline $23-24$ & $258-465$ & 395 & $32-45$ & 40 & $22 \quad-27$ & 25.6 \\
\hline $\begin{array}{ll}31 & -39\end{array}$ & & 585.5 & $32.5-45$ & 39.8 & $21-28.5$ & 24.4 \\
\hline $\begin{array}{ll}73 & -79\end{array}$ & $224.6-345.3$ & 279.2 & $47.3-56.7$ & 52.2 & $\begin{array}{ll}27 & -41.3\end{array}$ & 32.1 \\
\hline 152 & $149-230$ & 188 & $45 \quad-67$ & 56.4 & $25-40$ & 33.8 \\
\hline 210 & $126-276$ & 196.3 & $\begin{array}{ll}50 & -70\end{array}$ & 60.4 & $27-40$ & 35 \\
\hline
\end{tabular}


L). At the level of maxillae the epidermal cells become continuous with the same layer covering the maxillary valve. It is interesting to note that the mucosal linings of the lips are thrown into minute irregular ridges with shallow grooves among them (Fig. 22), and this seems to be helpful in straining the minute food substances from the muddy bottom.

Mouth opening It is a well known fact that the factors that bring about structural variations in the mouth and its adjacent parts in fishes are the feeding habits, and here the same is being described in carp (formalin-fixed materials) at its different stages of growth.

Stage I (Fig. 21 A). A crescentic shaped mouth opening below the eyes lies between the deflection of the head on the ventral side and antero-dorsal part of the large yolk mass in newly hatched larva irrespective of their sizes. Nasal aperture is prominent.

Stage II (Fig. $21 \mathrm{~B}$ ). Specimens measure $5-7.4 \mathrm{~mm}$ in total length when the yolk is decreasing in size and the head is being straightened out. Mouth which is still directed below, is being shaped out, and the gape is increased.

Stage III (Fig. $21 \mathrm{C}$ ). Specimens measure $7-9.5 \mathrm{~mm}$ in total length when the yolk is completely absorbed. Mouth opening is widened and is directed upward. Lower jaw appears smaller than upper one, and lips are thickening.

Stage IV (Fig. $21 \mathrm{D}$ ). Specimens measure nearly $11-12 \mathrm{~mm}$ in to tal length. Lips are thickened and taste papillae are prominent. Nostrils are being divided into two chambers. Mouth is still directed upward and considerably widened. The upper jaw seems to project a little beyond the lower one.

Stage V (Fig. 21 E). Specimens measure about $20-25 \mathrm{~mm}$ in total length. The lower lip appears to be thicker than the upper one and the lips have become slightly protrusible. The mouth is a little inferior. Barbels have devoloped and nasal flaps are prominent.

Figures $21 \mathrm{~F}$ and $\mathrm{G}$ indicate the transitional stages of development to the omnivorous type of feeding. Mouth, though terminal, is slightly inferior. A few ridges are al\& marked on the lips as stated before (Fig. 22).

M axillary valve Maxillary valves (oral valves, velar folds, and flaps of tissue), as observed in full-grown embryo, are the mucosal extensions towards the ventro-posterior direction originating from just behind the upper lip and swinging freely into the buccal cavity (Fig. $27 \mathrm{C}, \mathrm{E}, \mathrm{G})$. It is crescent shaped in outline, almost following the contour of the inner side of the upper lip (Fig. 22). Papillae of various sizes and numbers are found on its surface decreasing from 
Stage Length(mm) Figure Lateral

I I $\quad 5-7.4$
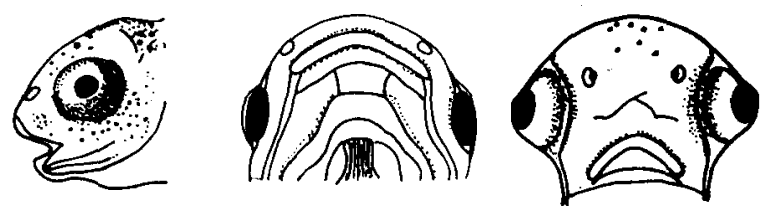

II $\quad 7-9.5$

C
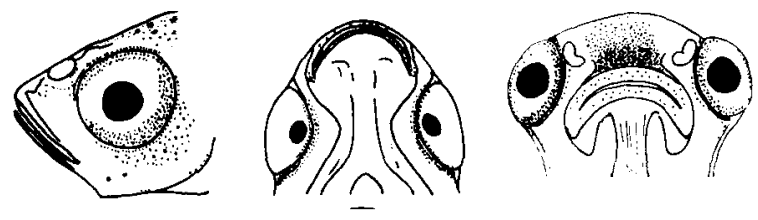

IV

$11-12$
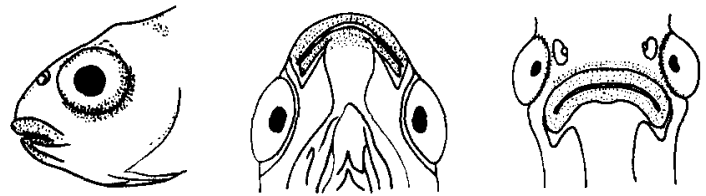

$\mathrm{V}$

$20-25$

E
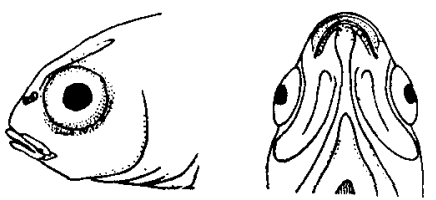

40

$40-45$
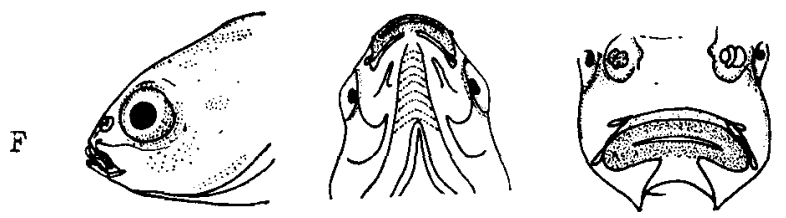

100
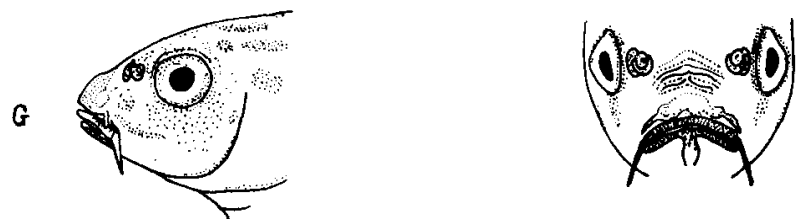

Fig. 21. Sketches of mouth changes of carp. 


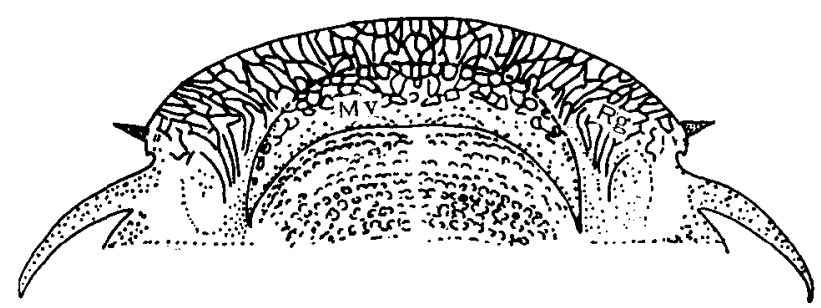

Fig. 22. Sketch of maxillary valve.

Mv. maxillary valve; Rg. ridges on the upper lip.

proximal end to distal one, and in arrangement, they follow the contour of the valve.

Histologically, it is covered on its dorsal and ventral sides by the stratified epithelial cells in the middle of which runs the dermal or submucosal connective tissue continuous with the same from the upper lip and roof of the buccal cavity (Fig. $27 \mathrm{C}, \mathrm{G}$ ). The stratified epithelium from outside inward consists of several layers of squamous cells, many layers of polygonal cells, and a single layer of columnar or elongated cells (Fig. $27 \mathrm{~F}$ ). The outermost layer of cells become flattened. Papillae bear organs of taste and mucous cells are also found but they seem to be limited to the border. They are larger and more numerous on the ventral side than the dorsal one and the latter one seems to be slightly thinner than the former one. Larger papillae at the proximal region bear 2-4 taste buds while the remaining smaller ones carry only l-2 ones. The epidermal thickness appears to be increasing with the size of the fish. Lying below the epidermis is a thin layer of stratum compactum which is clearly distinguishable by larva $16-17 \mathrm{~mm}$ in total length (Fig. $27 \mathrm{~F}, \mathrm{G}$ ).

The submucosa consists of blood vessels and nerves scattered in the connective tissues. A few black pigments are also found. In the larval stage it is not clearly marked (rather, valves consist of only squamous cells or flattened cells), but by larva 6-6.8 $\mathrm{mm}$ in total length it is found as a thin layer passing into its proximal regions dividing the squamous cells into an upper and lower strata.

Bucco-pharyngeal folds The roof of the buccal cavity seems to be concave and the floor a little convex (Figs. $7 \mathrm{~A} ; 27 \mathrm{~J}$ ). The former is strengthened by the base of the cranium while the floor is supported by the basihyal, which in the earlier stages remains freely movable due to little musculature.

A few prominent papillary folds, knob-like in outline, are seen as early as $9-10 \mathrm{~mm}$ larva. They seem to be more numerous on the roof than the floor and the sides, and in the latter case sometimes they appear to be scanty. 
By $15 \mathrm{~mm}$ larva (Fig. $23 \mathrm{~A}$ ) well developed papillary folds are arranged more or less in a regular manner. In the centre of the roof there are 3-4 distinct and broad longitudinal ridges bearing knob like papillae, 16-19 in number in each row (Fig. $23 \mathrm{~B}$ ). Just behind the maxillary valve there are a few large papillae, arranged in 2-3 rows. These are again followed posteriorly by another 2-3 transverse rows of smaller sizes which pass diagonally following the shape of the mouth cavity down the lateral sides. There are only 6-8 diagonal rows and almost all pass without any demarcation line into the anterior part of the roof of the pharynx (palatal organ of Valatour). Here the apices of the papillae become slightly flattened and the crypts shallow and become gradually smaller in size laterally and posteriorly.

On the floor the same type of papillae with the same arrangement are present in front of the basihyal and the latter one is also covered with the same papillae with the same arrangement. They continue towards the lateral side following the contour of the cavity and increase in number and height with the size of the fish (Fig. $23 \mathrm{C}, \mathrm{D}$ ).

The diagonal rows pass imperceptibly into the mucous membrane at the inner base of the operculum. The palatal organ has more numerous papillae on its anterior end than the posterior or lateral ones (Fig. 23 B, D, F). They are irregular in arrangement but are disposed longitudinally in front of the horny pad. Just behind the lower lip there are a few transversely arranged folds bearing small papillae, 3-5 in number (Fig. $23 \mathrm{E}$ ). Behind these and in front of the rudimentary tongue there is a narrow longitudinal streak which marks the beginning of the diagonal rows of folds running outwardly and backwardly (Fig. $23 \mathrm{C}, \mathrm{E}$ ). Papillae continue till the fourth gill arch, while Curry (1939) marked their convergence at the third gill arch. Secondary papillae are very few and occasionally large flattened papillae are found behind the tongue. Close and behind the horny pad and pharyngeal teeth a few longitudinal folds are found which continue into the oesophageal ones.

Pharyngeal teeth The teleosts have usually five pairs of gill arches, each holding dorso-ventrally four pieces : pharyngo-branchial, epi-branchial, ceratobranchial, hypo-branchial, and a single additional basal piece the basibranchial. Gill (branchial) arches, or their parts, are sometimes modified for the attachment of teeth which is usually recognized as a compensation for the reduction or loss of teeth in the mouth or jaws. In the carp the cerato-branchials of the fifth branchial arch are modified into a sickle-shaped structure joined ventrally by ligament and is named pharyngeal arch and bear teeth called pharyngeal teeth. Many investigators like Jurine (1821), Heckel (1842), Edward (1929), Gribb (1930), Chu (1935), Belogurov 

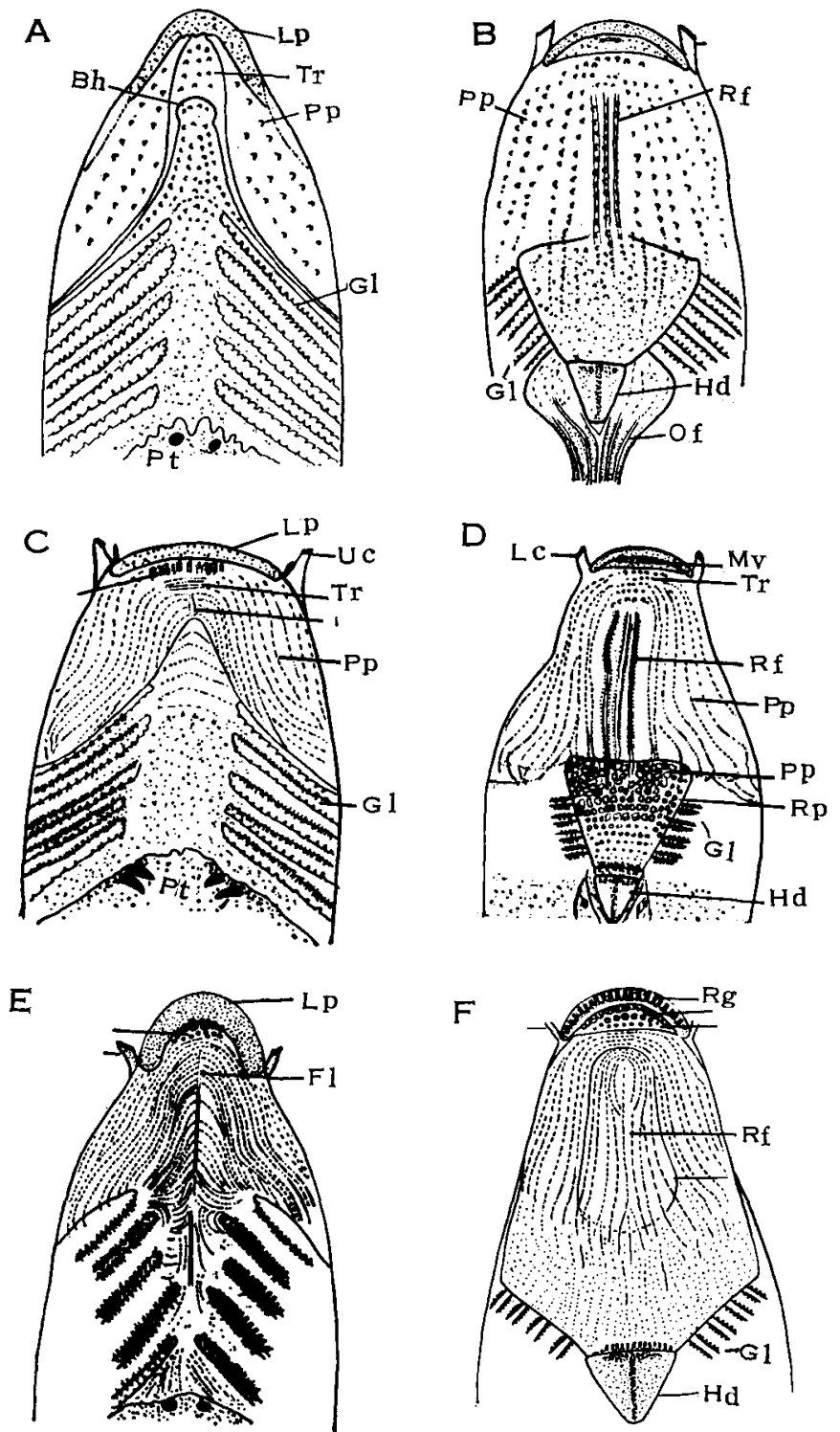

Fig. 23. Sketches of bucco-pharyngeal folds of carp. $\mathrm{A}$ and B. Floor and roof of $15 \mathrm{~mm}$ larva. C and D. Floor and roof of 100 $\mathrm{mm}$ young. E and F. Floor and roof of $200 \mathrm{~mm}$ young.

Bh. basihyal ; F1. longitudinal furrows ; G1. gill ; Hd. horny pad ; Lc. cut end of lower lip; Lp. lower lip: Of. oesophageal folds ; Pp. papillae ; Pt. pharyngeal teth; Rf. longitudinal rows of folds; Rg. ridges of lips; RP. roof of pharynx; Tr. transverse ridges; Uc. cut end of upper lip; Up. upper lip. 

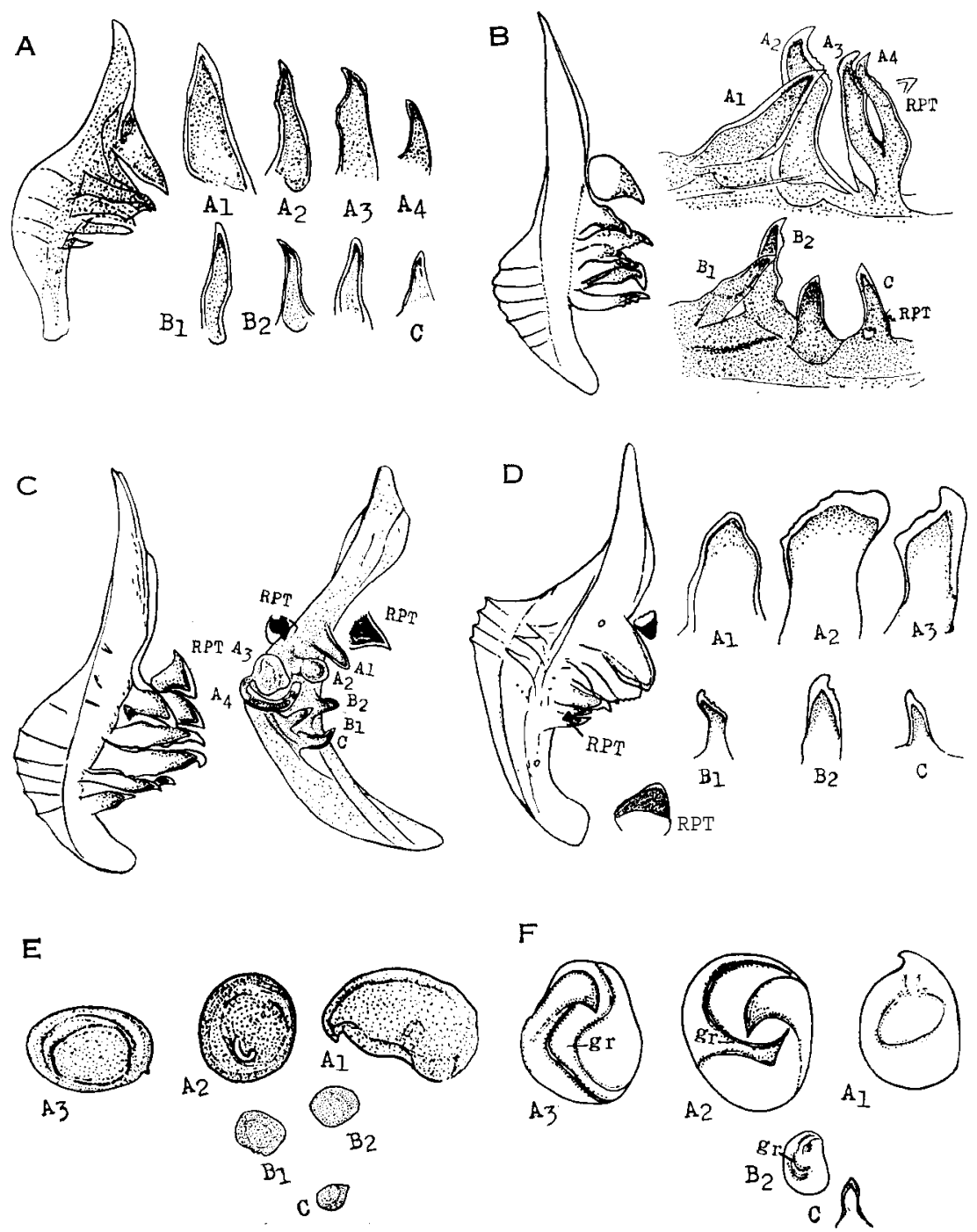

Fig. 24. Sketches of pharyngeal teeth of carp.
A. Pharyngeal teeth of $10.7 \mathrm{~mm}$ larva.
B. Pharyngeal teeth of $14.3 \mathrm{~mm}$ larva.
C. Pharyngeal teeth of $19 \mathrm{~mm}$ larva.
D. Pharyngeal teeth of $35 \mathrm{~mm}$ carp.
E. Apices of teeth of $17.3 \mathrm{~mm}$ larva.
F. Crown of teeth of $28 \mathrm{~mm}$ carp.

$A_{1}-A_{4}, B_{1}, B_{2}$, C. first, second and third row of teeth; RPT. replacing tooth ; gr. groove. 

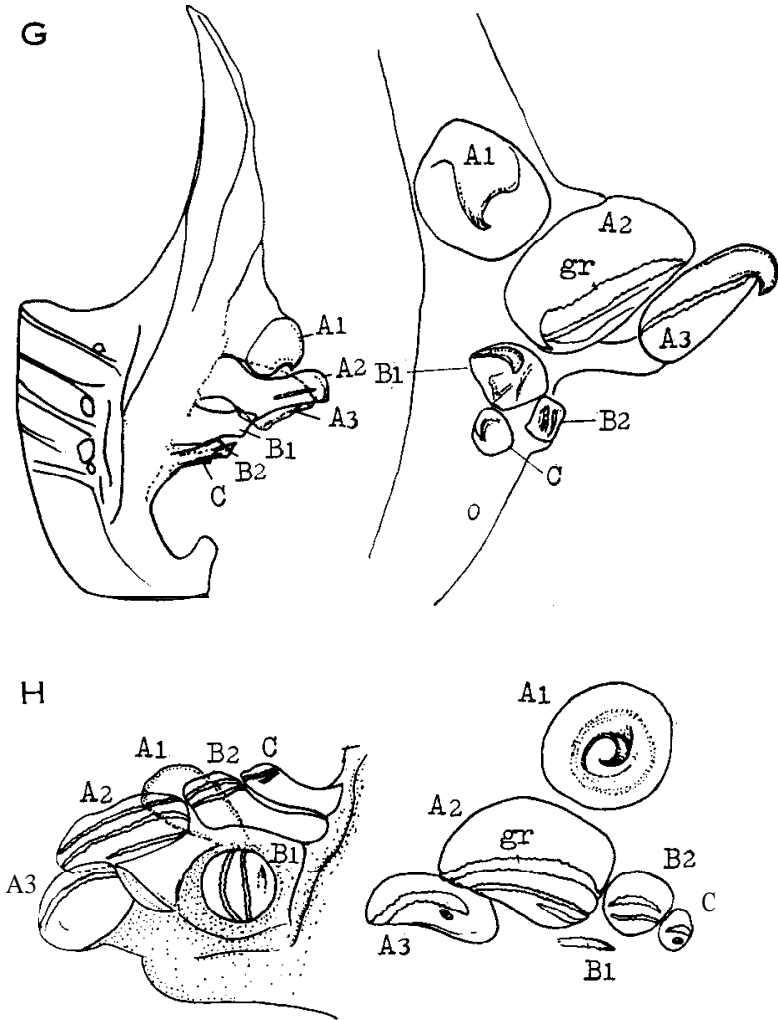

I

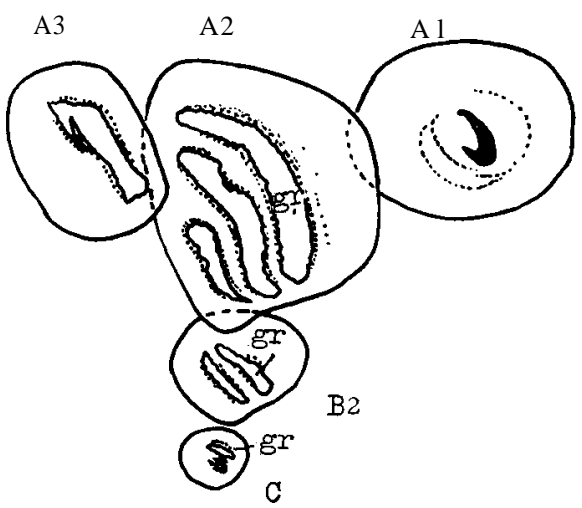

(Fig. 24, continued)

G. Pharyngeal teeth of $43 \mathrm{~mm}$ carp.

H. Pharyngeal teeth of 90-100 mm carp.

I. Crown of pharyngeal teeth of $350 \mathrm{~mm}$ carp. 
(1940), Hubbs and Hubbs (1945), Trautman and Hubbs (1948), Evans (1955), Edmund (1960), Horosywicz (1960), Vladykov and Mukerjee (1961) and Schwartz and Dutcher (1968) have worked on the structure and function of pharyngeal teeth. However, the present study is aimed to observe the changes in form and shape at different stages of the carp.

To understand clearly its structure at different stages, it is better to describe the arrangement of teeth on the pharyngeal arch of the adult. Three rows of teeth are recognized, namely $\mathrm{A}, \mathrm{B}$, and $\mathrm{C}$ rows of Figures $24 \mathrm{I}$ and $28 \mathrm{M}-\mathrm{O}$; row A consisting of three teeth, row $\mathrm{B}$ containing either one or two, and row $\mathrm{C}$ holding only one tooth. The teeth of each row differ from one another in structure and those of row $A$ may be designated antero-posteriorly as $A, A_{2}, A$, and $A$, (present till young) and row $B$ as $B_{1}$ and $B$. The tooth $A$, (anteriormost) is stout and has a cylindrical neck bearing an almost helmetshaped crown with a pointed elevation towards the cavity of pharynx (Figs. $24 \mathrm{I} ; 28 \mathrm{M}$ ). No groove or furrow is ever marked and the surface is smooth and shining after the preparation. The tooth $\mathrm{A}$, is the stoutest and has a thick cylindrical neck bearing the largest flat crown with 2-3 prominent transverse grooves or furrows. The grooves are arranged along the dorso-ventral direction on the surface of the crown. A, is the longest tooth and has a cylindrical neck bearing a flat crown with 1-2 grooves. A small groove extending for first-fourth of the crown is generally seen in all cases. The vestige of $A$, is marked on the posteriormost region attached to A,. Row $\mathrm{B}$ has a single tooth, with the occurance of two considered not unusual (Fig-. 24 G-I). The tooth $B_{2}$ has a cylindrical neck like those of row $A$ and a rough flat crown with about 2 grooves. The crown surface is much smaller than those of $\mathrm{A}$, or $\mathrm{A}$,. The neck of $\mathrm{B}_{1}$ is a thin cylindrical structure bearing a crown of the same size or smaller than $B_{2}$ and is provided with 1-2 grooves (Fig. $24 \mathrm{H}$ ). The crown of $B_{1}$ seems to be weakly attached to the neck and is usually torn out during preparation. The crown of $\mathrm{C}$ has a slender and cylindrical neck bearing a small crown with 1-2 grooves, this tooth is the smallest. The general surface of the crowns, beside the grooves (except A,), are rough and are marked with minute elevations perhaps facilitating the process of mastication.

The teeth are arranged in $3-4$ rows in the $10-28 \mathrm{~mm}$ fish in a ratio of $3: 2: 1: 1$ or $4: 2: 1: 1$ totalling 7-8 (Fig. $24 \mathrm{~A}-\mathrm{C}$ ). In the second row $B_{1}$ and $B_{2}$ are seen and an extra one lies between $A$, and $B_{1}$ (Fig. $24 \mathrm{~A})$. The tooth $\mathrm{C}$ is a single one lying at the posterior end of second row and A, remains attaching to A, (Fig. $24 \mathrm{~B}$ ). They are symmetrical in arrangement, i. e., the number of teeth on one arch is not 
the same as on the other. Alizarine Red does not penetrate into the outermost enamel substance, while all other parts and teeth are beautifully coloured indicating there degree of ossification. The teeth are broad at the base and taper at the distal end and their curved pointed ends project into the pharyngeal cavity (Fig. 24 B, C). The apices are sharp and are directed backward. They are strongly serrated on the inner margins. Their structures suggest their functioning characteristics and seem to help in holding the prey and pass them into the oesophageal cavity.

The replacing teeth, 3-4 in number, embedded in the pharyngeal tissues are present, one near the apex of $\mathrm{A}$, the other at $\mathrm{B}_{2}$ and a small one near the last tooth: the largest one being at $A$, and the smallest one at A, in $10.7 \mathrm{~mm}$ larva. Their crowns appear to be pointed (deeply stained with Alizarine) while the necks are broad and cylindrical (unstained with Alizarine). The crown grows a certain extent during a certain time and the neck appears to be formed. It is the neck which seems to be fused to the pharyngeal arch and becomes ossified. The neck of the older tooth is resorbed and in this way the older tooth is being replaced throughout the life of the fish.

The number and the structure of teeth are not fixed in the larval or post-larval stages. By $14-16 \mathrm{~mm}$ in total length $A, A_{3}$, and $B_{2}$ appear to be more strongly serrated and curved than before indicating thereby a strong carnivorous habit, as such conditions are best suited for preying (Fig. $24 \mathrm{~B}$ ). The crown of $\mathrm{A}_{2}$ is being broadened rather than pointed. When the young carp reaches 17.3-19 $\mathrm{mm}$ in total length the apices of some teeth (i. e., $A_{2}, B$,) exhibit their flattened surfaces though the pointed and curved apices are not uncommonly marked (Fig. $24 \mathrm{E}$ ). Further, the surfaces of $A_{2}, B_{1}$, and $B_{2}$ are rough or covered with minute grain-like elevations. The serrations are evident till 19-22 $\mathrm{mm}$ after which they seem to decrease with the corresponding increase of the flatness of apices or crown. In 26-28 mm young the flattening of the crown is prominent with the subsequent formation of grooves or furrows (Fig. $24 \mathrm{~F}$ ). Only one groove each is marked on $\mathrm{A}, \mathrm{A}_{3}$, and $\mathrm{B}$. The rims or outer margins of the crown remain to some extent serrated at $45-50 \mathrm{~mm}$ in total length. A, appears to be lost at nearly $28 \mathrm{~mm}$ in total length and a remnant is found to be attached to the basal end of $\mathrm{A}$, . By the time the carp reaches $90 \mathrm{~mm}$, deep grooves are formed, 1-3 in number except A, as in the adult.

The ratio of the length of pharyngeal arch to its breadth is greater in the early stages till $30 \mathrm{~mm}$ is reached, being $3-4.26$, than the later stages of about $45-50 \mathrm{~mm}$ and onward, when it is 2.2-3.46 and becomes constant at an average of about 2.87 (Fig. 25). 


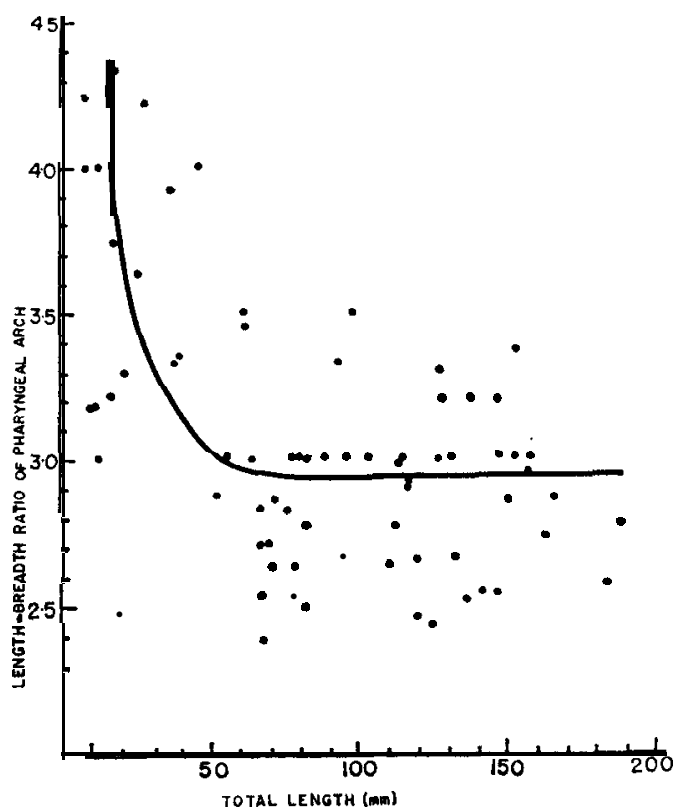

Fig. 25. Relation of length-breadth ratio of pharyngeal arch to total length.

Horny pad The horny pad (cornified or callous pad) is biconvex and almost four cornered (Fig. $26 \mathrm{C}, \mathrm{D})$. It lies behind the palatal organ bounded on the sides by the foliaceous tissues and is firmly fixed on its dorsal side to the concavity of the basi-occipital bone of the cranium. On its ventral side it is medially ridged or elevated in length wise direction and faces the dental regions of the pharyngeal arch so as to meet each other during crushing or macerating the food.

Morphologically the horny pad can be first distinguished by larva $10-13 \mathrm{~mm}$ in total length. Histologically the cells are definable by 6-6.8 $\mathrm{mm}$ larva as described in chapter VI. They become quite evident by 7-8 $\mathrm{mm}$ larva and the adult histological elements are established by 10-13 $\mathrm{mm}$ larva. Due to its soft texture till $27-28 \mathrm{~mm}$ or even $40-45 \mathrm{~mm}$, pads can be sectioned after the usual Bouin's fixation, then hardness is felt and this seems to increase with the size of the carp. However, it consists of superficial zone (stratum corneum), central zone (stratum mucosum), basal zone, basament membrane and submucosa.

The superficial zone consists of several layers of degenerating horny cells and is of irregular thickness as it always undergoes the process of sloughing. Normally it is thicker in the middle than the sides (Fig. 26 A) and has affinity for the yellow colour of Mallory's 

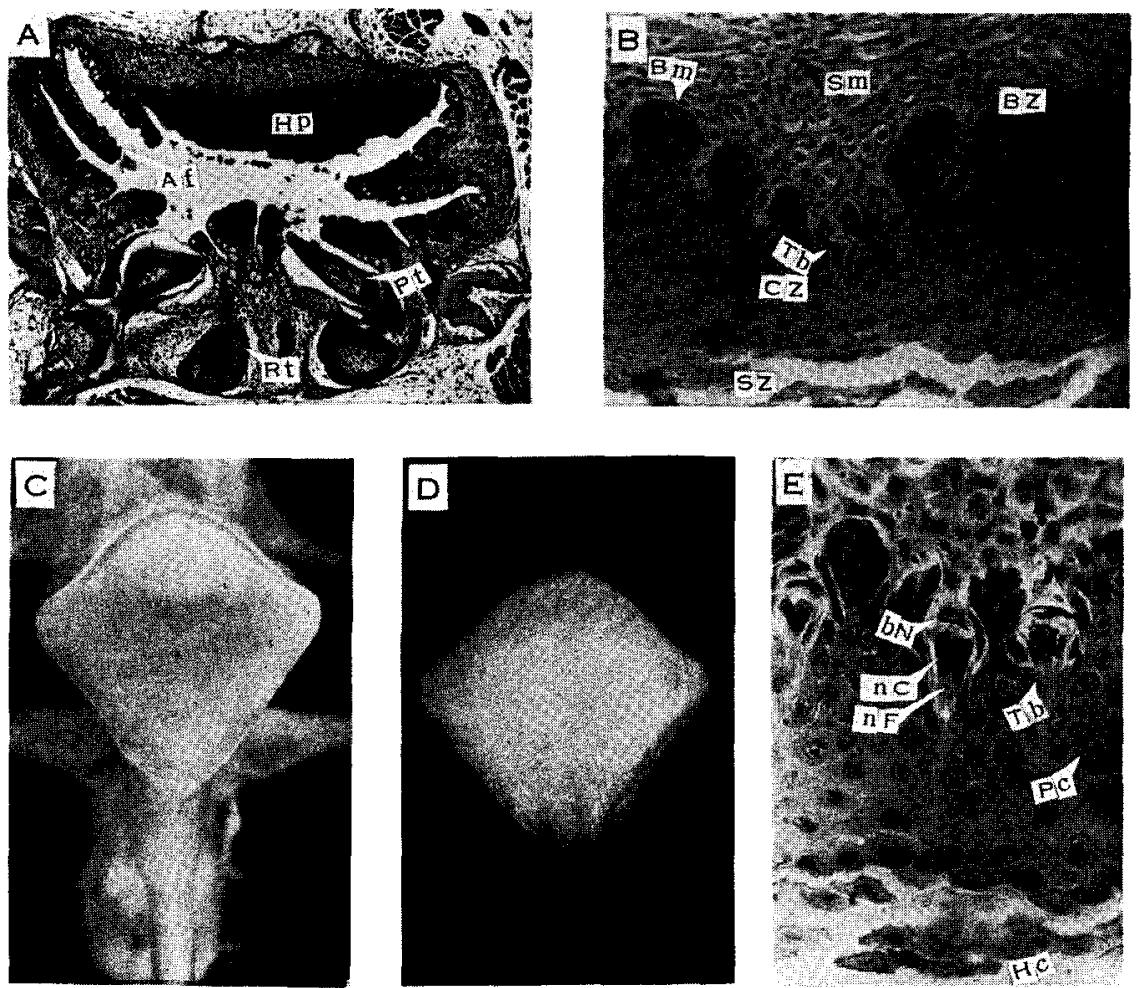

Fig. 26. Photomicrographs of the structures of horny pad.

A. Transverse section through posterior part of pharyngeal cavity of $13.1 \mathrm{~mm}$ larva. X 50 .

B. An enlarged part of transverse section through horny pad of A. x 200 .

C. D. Ventral and dorsal view of horny pad of $250 \mathrm{~mm}$ carp.

E. Taste bud from section of pad of $13.1 \mathrm{~mm}$ larva. X 500 .

Af. angular fold: Bm. basement membrane; bN. basal nucleus: BZ. basal zone; CZ. central zone; Hc. horny cells; Hp. horny pad; $\mathrm{nF}$. nerve fibres ; nC. nerve cells ; PC. polygonal cells ; Pt. pharyngeal tooth ; Rt. replacing tooth; Sm. submucosa; SZ. superficial zone; Tb. taste bud.

triple stain.

The central zone comprises multi-layers of polygonal cells and can be differentiated into an inner and an outer area (Fig. $26 \mathrm{~B}$, E). The cells of the inner area are in the state of modification into horny cells towards the superficial zone. They become flattened and are gradually hornified and disintegrated. Cells of the outer area are in the normal polygonal conditions and their intracellular bridges are com- 
pactly filled with calcified materials. The cytoplasm takes up eosin colour strongly and accepts the crimson colour of Mallory's triple stain. Nuclei are deeply stained and contain a prominant rounded or oval nucleolus ; a few chromatin granules are also observed. This layer is thrown into folds, which are first marked in about 7-8 $\mathrm{mm}$ larva, and they are longer in the middle than on the sides. In $16.8 \mathrm{~mm}$ larva a transverse section through the middle region shows nearly 22-24 folds and each one is separated from another one by finger-like projections of submucosa. The polygonal cells along the basal region appear to be smaller and denser than those towards the superficial zone.

The basal zone comprises a single layer of low columnar cells supported by an indistinct basement membrane. Usually a submucosal evagination bears a taste bud and their nerve processes pass into intra-cellular spaces of the polygonal cells of the central zone (Fig. $26 \mathrm{~B}, \mathrm{E})$. A basal cell is present at the base of the bud. The taste buds are marked till $30 \mathrm{~mm}$ in total length.

All the three histological zones of the pad seem to be the modified cells of the epithelia of the pharyngeal cavity. The mucous. secreting cells stop suddenly at the dorsal surface of the posterior pharynx where the pad is being developed and the cells are gradually transformed into polygonal forms hardened by heavy calcification. The submucosa of the anterior pharynx passes into the same layers of the pad and consists of connective tissue fibres intermingled with striated muscles.

Bucco-pharyngeal lining The histological descriptoins of the buccopharyngeal lining have been divided into an anterior or buccal cavity and a posterior or pharyngeal one.

Buccal cavity In regard to histological structures, it can be stated briefly that the buccal cavity epithelium comprises three regions of mucosa, stratum compacturn, and submucosa with muscle fibres. The mucosa is stratified and consists from outside to inside, of several

Fig. 27. Photomicrographs of the structures of buccal cavity.

A. Transverse section through lips of $7.9 \mathrm{~mm}$ larva. X 200.

B. Transverse section through anterior part of buccal cavity of $7.9 \mathrm{~mm}$ larva. $\mathrm{X} 200$.

C. Longitudinal section through buccal cavity of $7.9 \mathrm{~mm}$ larva. X 200 .

D. Lower lip of C, enlarged. X 400.

E. Transverse section of maxillary valve of $6 \mathrm{~mm}$ larva. X 400 .

F. Distal part of section of maxillary valve of $16 \mathrm{~mm}$ larva. $\mathrm{X} \mathbf{4 0 0}$.

G. Longitudinal section through maxillary valve of $16 \mathrm{~mm}$ larva. X 200 .

H. Tangential section through upper lip of $250 \mathrm{~mm}$ carp. X 100. 

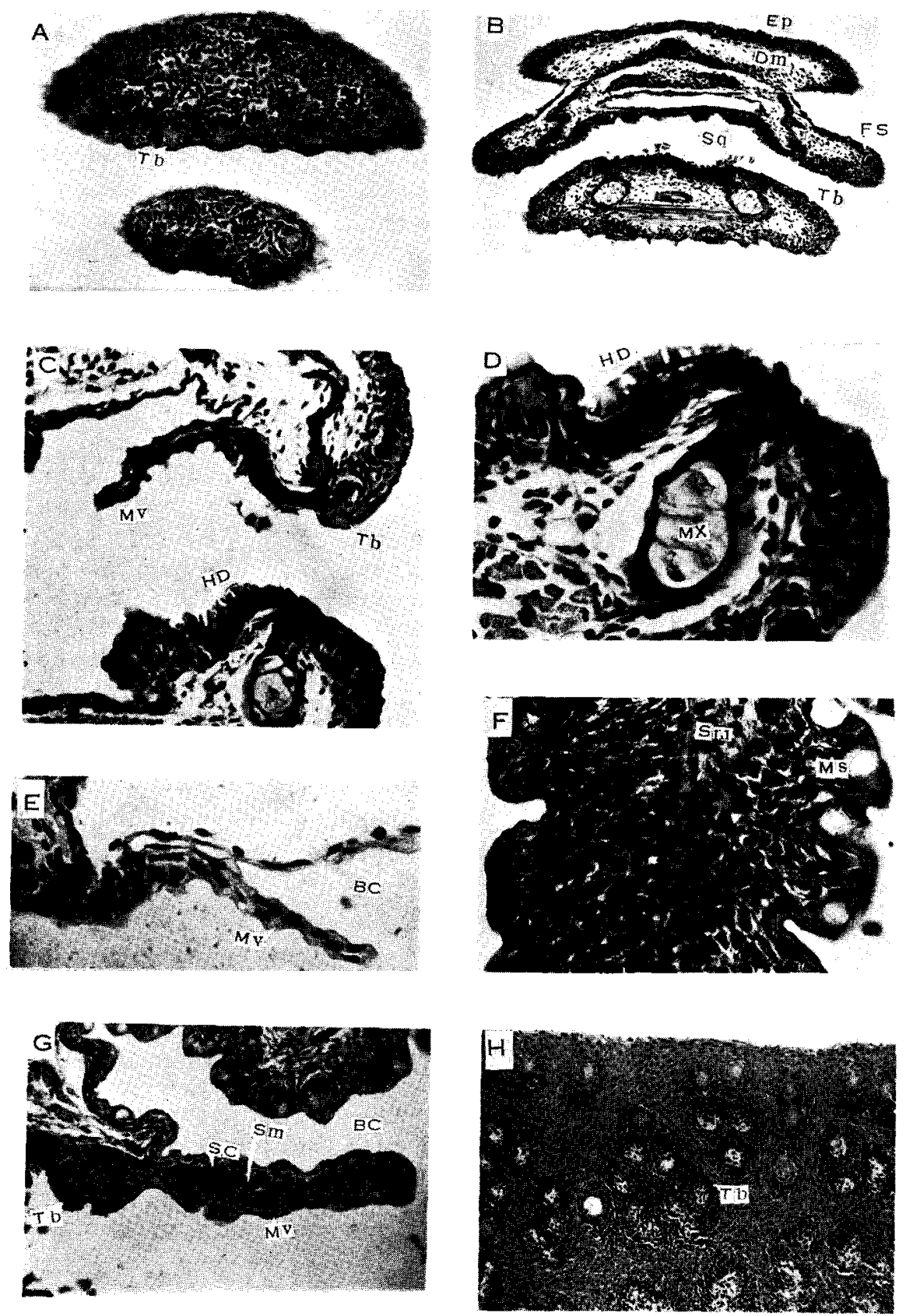

Fig. 27. 
layers of squamous cells, polygonal cells, fusiform or oval cells, and a single layer of inner basal columnar cells (Fig. $27 \mathrm{~J}-\mathrm{N}$ ). The arrangement of the cells of the middle layer, between outer squamous and innermost basal cells, is disturbed if there is heavy accumulation or gathering of secretory cells. Patches of desquamating cells are usually all stages of the fish both on the roof and floor.

By $7.9 \mathrm{~mm}$ larva the mucosa becomes 24 layers thick, consisting of low conical papillae, which are 8-10 in number in the cross section. Behind each corner of the mouth, a flap of snout-skin is marked (Fig. $27 \mathrm{~B})$ and this structure was evident since the yolk was being absorbed. It has the same histological structures as the skin but the taste buds were always marked around the distal end. The following types of cells are recognized among the epithelial cells : mucous cells, promucous cells, club cells, taste buds, and basophilic ceils.

The mucous cells interrupt or disorientate the squamous linings of the cavity (Fig. $27 \mathrm{~J}, \mathrm{~K}, \mathrm{M}, \mathrm{N}$ ) and they are of various sizes depending upon the thickness of mucosa. They measure about 5-7 $\times 4-6 \mu$ in diameter in 7-8 mm larva and attain about $40 \mathrm{x} 15 \mu$ in diametor in 300 $\mathrm{mm}$ in total length. In shape they may be goblet or elongated with their flattened nuclei pushed to the basal end of cells and they pour out their secretions from minute pores into the cavity. They have great affinity for mucicarmine, PAS, and Alcian blue. Their distribution is irregular and abundant, but they seem to be more numerous along the sides of the crypts than the tops of folds. Promucous cells are plentiful near the inner or middle layer of epithelium (Fig. $27 \mathrm{M}$ ). They are sharply distinguished by Masson's trichrome, and PAS also stains them, though this is slight, whereas the mucous cells are strongly coloured. They are rounded or slightly oval with fine granules. The cells in the basal layer are formative or germinative out

(Fig. 27, continued)

I. Longitudinal section through tongue region of $13.6 \mathrm{~mm}$ larva. $\mathrm{X} 200$.

J. Transverse section through roof of buccal cavity of $16.8 \mathrm{~mm}$ larva. X 200 .

K. Transverse section through roof of buccal cavity of $24 \mathrm{~mm}$ carp. X 400 .

L. Longitudinal section through lower lip of $250 \mathrm{~mm}$ carp. X 100 .

M. Transverse section through buccal cavity of $210 \mathrm{~mm}$ carp. $\times 400$.

$\mathrm{N}$. Transverse section through buccal cavity of $300 \mathrm{~mm}$ carp. X 100 .

0 . Transverse section through anterior part of buccal cavity of $23 \mathrm{~mm}$ carp. $\times 200$. Bc. basal cell ; BC. buccal cavity; BH. basihyal ; BL. basal layer ; Bm. bascment membrane ; Cc. club cells; Dm. dermis; Ep. epidermis; FS. fold of skin ; FP. finger-like projection; HD. horny denticles; Ms. mucous cells; Mv. maxillary valve ; Mx. matrix of mandible ; Pc. polygonal cells ; Pm. promu cous cells ; SC. stratum compactum; Sm. submucosa ; Sq. squamating cells ; Tb. taste buds. 

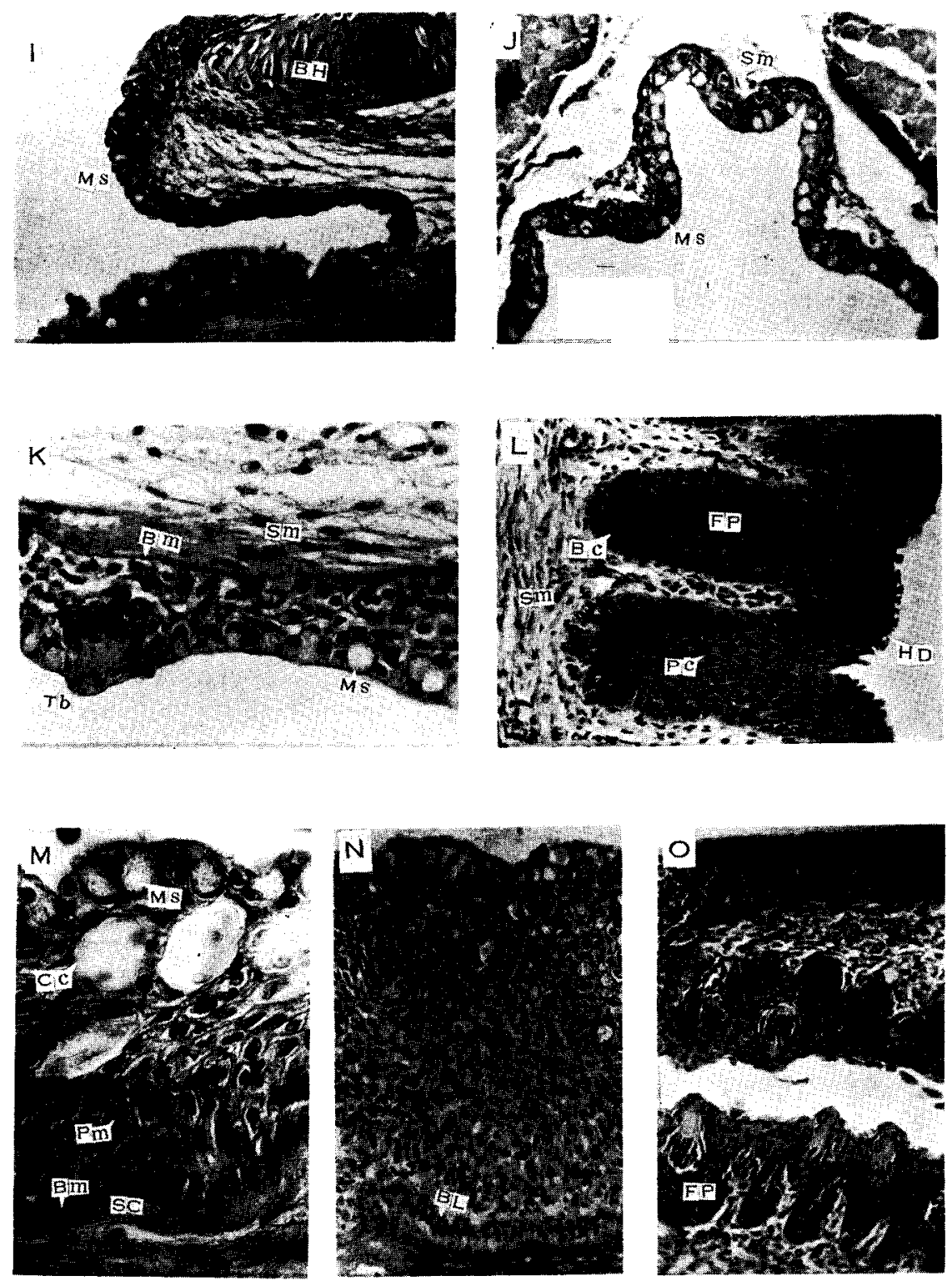

(Fig, 27, continued) 
of which these promucous cells are formed and appear to migrate towards the surface gradually. Mucous cells are also marked from the tongue region (Fig. $27 \mathrm{I}$ ).

Club cells elongated, oval, or rounded in form, lie scattered among the epithelial cells of the roof or floor but seem to be absent from the tongue region (Fig. $27 \mathrm{M}$ ). They occasionaally contain 4-5 nuclei in their secretory mass, which takes up pinkish (after Delafield's haematoxylin) or greenish (after Masson's trichrome) or light brown (after Humason and Lsusbaugh) colourations. However, they do not respond to the standard stains of mucuos. Diameter of the cells measures about $20-40 \times 15-28 \mu$ in $78-200 \mathrm{~mm}$ specimens.

Taste buds are strikingly abundant and large (Fig. $29 \mathrm{E} \mathrm{H}, \mathrm{J}$; Table 6) and show a great increase in size from about $25-27.8 \times 20-25$ $\mu$ in diameter in $68 \mathrm{~mm}$ larva to about $92 \times 32 \mu$ in diameter 300 $\mathrm{mm}$ specimen. The nerve cells appear to be spindle-shaped with the middle part slightly swollen or enlarged to accommodate the oval nuclei. Supporting or sustentacular cells are slightly elongated and either cover the nerve cells or lie mixed with them. Each papilla bears 2-4 or even 5 buds. Rarely, lymphocytes are marked either towards the proximal or distal end of the buds (Fig. 29 G) and small vacuoles are observed towards the distal ends of the buds (Fig. 29 F). A basal cell with flattened nucleus lies at the base close to the boundary line between the bud and submucosal evagination. Regarding their shape, they are bulb- or flask-shaped (Fig. 29 E) and their apices are either protruding or rarely depressed (Fig. $29 \mathrm{H}$ ). Along the sides of the cavity both the taste buds and mucous ceils are absent. The inner layer of the mucosal epithelium contains the elongated cells with oval nuclei directed perpendicularly upward and they lie among the sinusities of the thick stratum compactum. Deeply stained basophilic nlucei are abundant near the inner layer.

Stratum compacturn is a hyalin band of collagenous fibres and measures about 6,51 , and $20 \mu$ in thickness in 31,210 , and $300 \mathrm{~mm}$ specimens, respectively. It is easily discernible in the $20-24 \mathrm{~mm}$ juvenile (Fig. $27 \mathrm{~K}-\mathrm{N}$ ) and has great affinity for the blue and green colourations of Mallory's or Masson's trichrome stains. Very thin basement membrane is occasionally marked. Small black pigments are observed below the substratum compacturn in the anterior part of the cavity.

Submucosa consists of areolar connective tissues with flattened nuclei mixed with collagenous fibres, which are densely situated near the stratum compactum. Lying among these tissues are longitudinally striated muscle fibres distributed irregularly. The thickness of the muscular coat is not uniform. Adipose tissues are seen towards the inner side of submucosa, usually at the tongue region. 

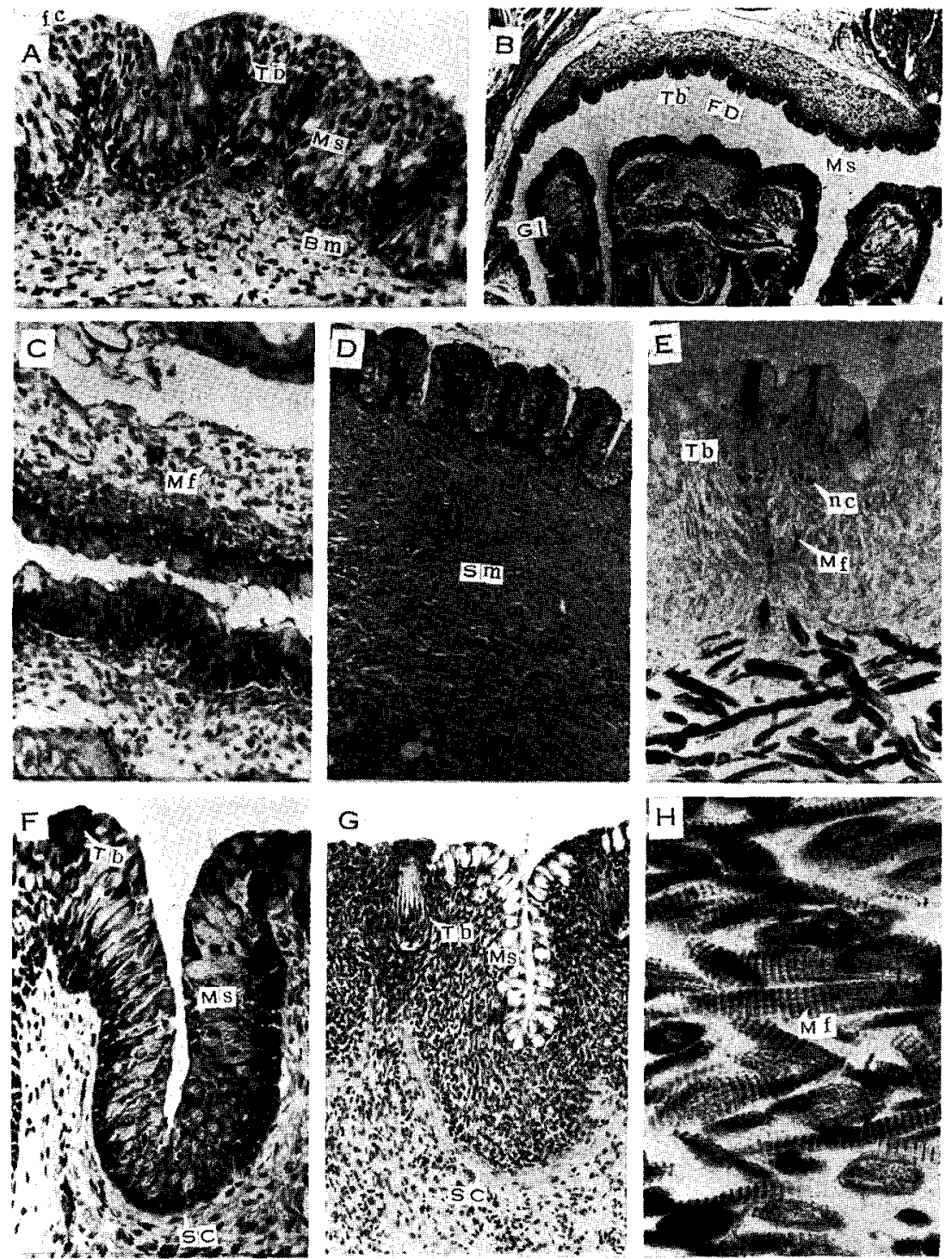

Fig. 28. Photomicrographs of structures of pharyngeal cavity.

A. Transverse section through roof of pharyngeal cavity of $31 \mathrm{~mm}$ carp. X 200 .

B. Transverse section through roof of pharyngeal cavity of $16.8 \mathrm{~mm}$ larva. $\mathrm{X} 200$.

C. Longitudinal section through pharyngeal cavity of $7.7 \mathrm{~mm}$ larva. $\times 200$.

D. Section through roof of pharyngeal cavity of $325 \mathrm{~mm}$ carp. X 50 .

E. Transverse section through roof of pharyngeal cavity of $152 \mathrm{~mm}$ carp. $\times 200$.

F. Section through mucosa of pharyngeal arch. X 200.

G. Section through junctional part of bucco-pharyngeal cavity of $325 \mathrm{~mm}$ carp. $\mathrm{x} 100$.

H. Submucosa of E, enlarged. $\times 500$. 
Pharyngeal cavity The anterior pharynx consists of the palatal organ on the dorsal side, the gill on the lateral sides, and the basihyal on the ventral side. Histologically. lining of the cavity consists of the same layers of cells as the buccal cavity. In a newly hatched larva the mucosal lining is 1-2 layers thick, and consists of squamous cells which in crease to about 8-10 layers by $7.7 \mathrm{~mm}$ larva (Fig. $28 \mathrm{C}$ ). Outermost cells facing the cavity are flattened with flattened nuclei parallel to the surface and their shedding is occasionally marked.

Intermingled with epithelial cells are mucous cells and taste buds (Fig. 28 A-E). The former ones interrupt the normal arrangement of the stratification of the epithelial cells, as a result of which the basal columnar cells become smaller in size, and where these cells are scanty, the epithelial cells tend to beome larger. They are oval, rounded, and sacciform and their nuclei lie at the base usually compressed as in the buccal cavity. A discharged mass of mucus is ususally marked along the free surface (Fig. $28 \mathrm{C}, \mathrm{D}$ ). Alcian blue and PAS give more than the outer half of the epithelium a continuous sequence of blue and red colorations, respectively. These cells at the junction of the buccal and pharyngeal cavity do not form stratified layers, rather they are distributed haevily along the border (Fig. 28 G).

Lying among the epithelial cells and standing on the submucosal projections are the taste buds of the same structure and form as in the buccal cavity. Their number and measurements at various stages are given in Table 7 . They increase in size with the thickness of the epithelia and their density is observed to be 2-4 on a single papilla, being more on the roof than floor. In one transverse section through the roof of $16.8 \mathrm{~mm}$ larva, the taste buds were counted to be 42 in number ; thus the roof appears to be highly gustatory.

Basement membrane is occasionally marked and is very thin. The stratum compactum is thicker at the anterior region of the cavity

\section{(Fig. 28, continued)}

I. Transverse section through posterior pharynx of $16.8 \mathrm{~mm}$ larva. $~ 200$.

J. Section through replacement tooth of $10.6 \mathrm{~mm}$ larva. X 200 .

K. Longitudinal section through second tooth of $16.8 \mathrm{~mm}$ larva. $\times 400$.

L. Pharyngeal arch and teeth of $15 \mathrm{~mm}$ larva. X 32 .

M. Pharyngeal arch and teeth of adult carp.

N. Ventral view of $\mathrm{M}$.

0 . Frontal view of $\mathrm{N}$.

$A_{1}-A_{3}$. first, second and third teeth of first row ; B. tooth of second row; Bm. basement membrane; C. tooth of third row; $\mathrm{Cn}$. canaculi; DN. dentine; FD. fold; fc. flattened cell ;G1. gill; Mf. muscle fibres; Ms. mucous cells; nc. nerve cells ; OB. odontoblasts ; PC. pulp cavity ; PT. pharyngeal tooth ; RT. replacing tooth; SC. stratum compactum; Sm. submucosa; Tb. taste bud. 

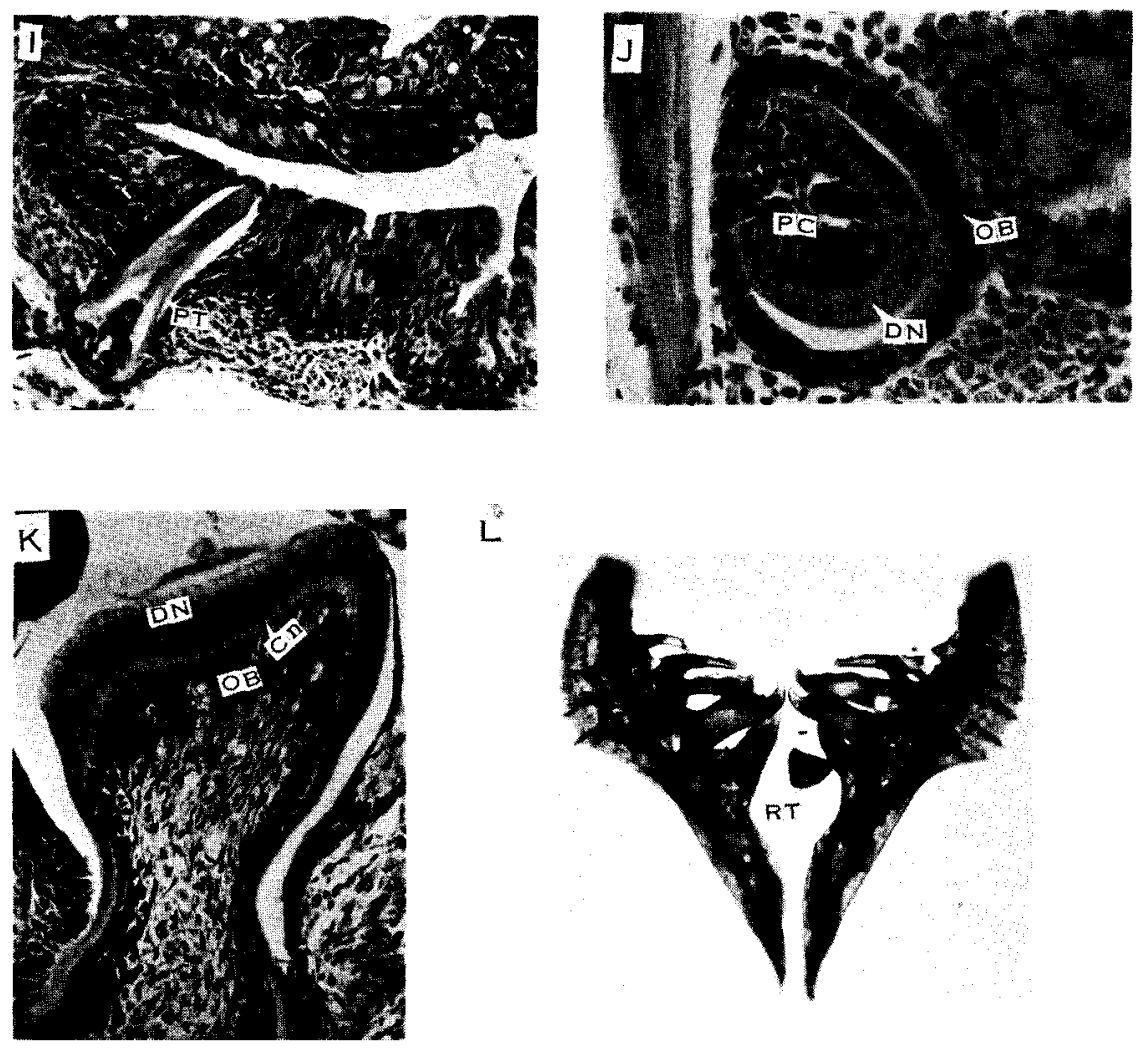

L
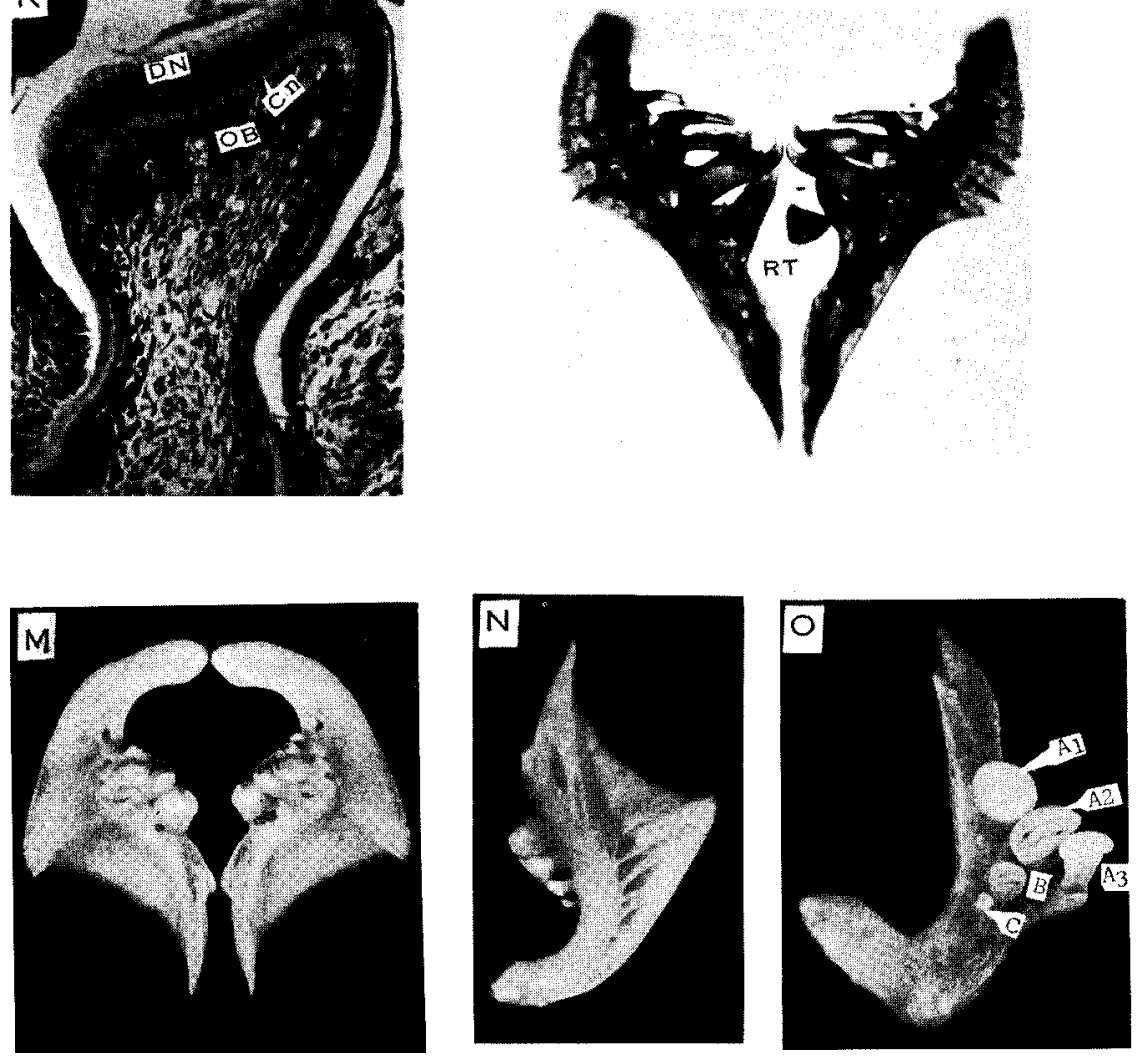

(Fig. 28, continued) 
Table 7. Counts and measurements of taste buds per $\mathrm{mm}^{2}$ in the roof of pharynx of the carp. Measurements were made from sections.

\begin{tabular}{|c|c|c|c|c|c|c|c|}
\hline $\begin{array}{l}\text { T. L. } \\
(\mathrm{mm})\end{array}$ & Number & & $\begin{array}{l}\text { Average } \\
\text { number }\end{array}$ & $\underset{(\mu)}{\text { Height }}$ & $\begin{array}{c}\text { Average } \\
\text { height } \\
(\mu)\end{array}$ & $\begin{array}{c}\text { Diameter } \\
(\mu)\end{array}$ & $\begin{array}{c}\text { Average } \\
\text { diameter } \\
(\mu)\end{array}$ \\
\hline $\begin{array}{ll}5 & -6\end{array}$ & $132-298$ & & 215 & $16-22$ & 19.6 & $15-22$ & 17.8 \\
\hline 6. $1-7$ & $212-405$ & & 313 & $18-32$ & 22.5 & $14-25$ & 21.2 \\
\hline $7.1-8$ & $119-545$ & & 482 & $22-32$ & 25.8 & $18-23$ & 20.8 \\
\hline $9-10$ & & & 614 & $30-35$ & 32.0 & $18-24$ & 24.6 \\
\hline $11-14$ & & & 621 & $35-43$ & 39. 2 & $22-29$ & 26.8 \\
\hline $15-17$ & $645-1063$ & & 831 & $34-45$ & 40.0 & $17-22$ & 19.4 \\
\hline $23-24$ & 603- 953 & & 750 & $40-50$ & 45.4 & $22-28$ & 24.8 \\
\hline $\begin{array}{ll}31 & -39\end{array}$ & 645- 983 & & 852 & $37-43$ & 41.0 & $22-29$ & 25.3 \\
\hline 152 & $553-845$ & & 695 & $65-70$ & 67.0 & $25-37$ & 28.8 \\
\hline 210 & $553-968$ & 1 & 675 & $65-72$ & 68.1 & $30-37$ & 33.2 \\
\hline
\end{tabular}

and thinner and irregular in other regions.

The submucosa consists of areolar connective tissues intermixed with striated muscles running transversely along the surface. Longitudinal and obliquely vertical arrangements are also encountered (Fig. 28 E,H). The muscle fibres even penetrate into the papillae bearing taste buds and remain closely associated with the stratum compactum as revealed by the silver technique. They are cut in section in various lengths and are longer in the middle or central regions then the sides and floor. Nerve supply is rich and blood vessels are present. Large fat tissues are found below this layer.

The mucous membrane on the pharyngeal arch is raised into irregular folds varying in height according to the size of the specimen, and its features become quite prominent with the naked eye by $30-40$ $\mathrm{mm}$ in total length. Histologically, it consists of the same constituents as the pharnx (Fig. 28 F). The density of mucous cells is broken at the tops of folds. Taste buds, 1-2 in number, are usually born on the submucosal evaginations and their presence suggests their mechanical help in relation to the feeding mechanism.

In the posterior region of the pharynx the mucosal folds are either broad or bluntly pointed. In the lateral regions angular folds are more elongated than others (Fig. $26 \mathrm{~A}$ ). The replacing tooth, consisting of central pulp cavity, is filled with connective tissue cells, or mesoblasts, and is surrounded by dentine which in turn is enveloped by odontoblasts (Fig. $28 \mathrm{~J}$ ). Figure $28 \mathrm{~K}$ is a section passing longitudinally through the second tooth of the first row (i. e., A,). The odontoblasts are arranged orderly around the dentine forming a continuous 

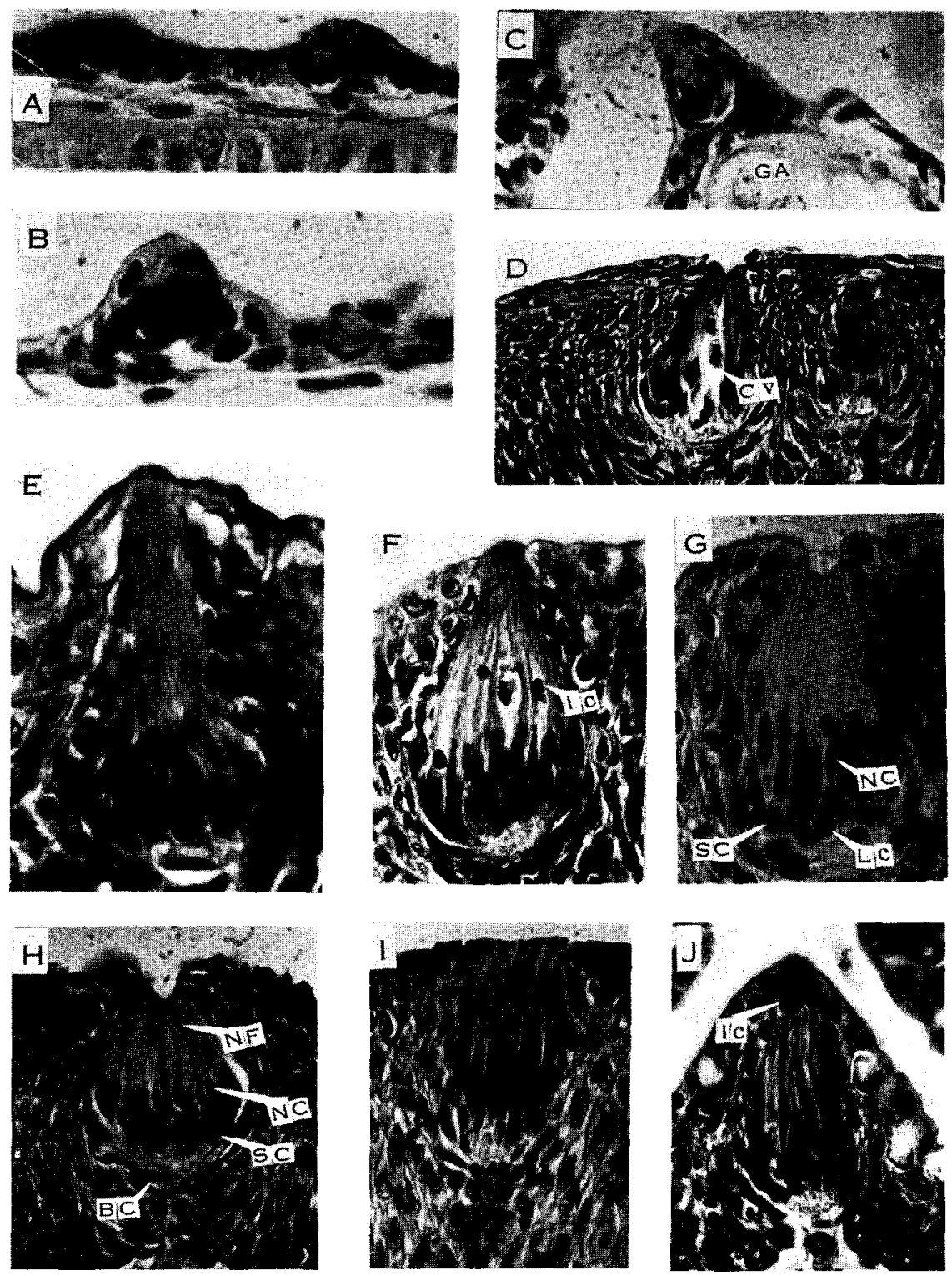

Fig. 29. Taste buds from sections of different organs of carp. A and B. taste buds (immature) from buccal cavity of $5.6 \mathrm{~mm}$ larva, 10-12 hours after hatching; C. from gill arch of $5.3 \mathrm{~mm}$ larva; D. from barbel; E. from buccal cavity; F. from gill arch; G. from nasal cavity; H. from nasal flap ; I. from barbel; J. from buccal cavity. BC. basal cell ; $\mathrm{Cv}$. cavitation; Ic. included cell ; Lc. lymphocyte ; NC. nerve cell; NF. nerve fibre; SC. supporting cell. 
layer of elongated cells with oval nuclei. The dentine is formed by the underlying odontoblasts. Freshly formed dentine lies close to the odontoblasts while the older dentine gives rise to the formation of enamel ; their cytoplasmic processes lie in the canals or tubules of dentine.

Gill There are four pairs of gill arches bearing gill rakers and gill lamellae (gill filaments). Each arch is composed of five bony pieces arranged dorso-ventrally, known as pharyngo-, epi-, cerato-. hypo-, and a single basi-branchial lying on the floor of the pharynx ; dorsally, they are connected to the roof of the skull. Cerato-branchial is the longest one, and it bears the majority of gill filaments. The size of lamellae is in decreasing order on the epi- and hypo-branchials. Dorsally, the pharyngo-branchials are free from lamellae.

For the sake of easy and clear understanding a gill may be divided into three regions (Fig. $30 \mathrm{~J}$ ) : (1) brancial head comprising the bony gill arch and gill rakers ;(2) two primary gill lamellae, the outer (oral) and the inner (aboral), supported by cartilaginous gill rays and bearing hemibranchs, which are outer and inner with respect to the lamellae to which they are attached ; and (3) the interbranchial septum (diaphragme branchiale of Duvernoy, or gill septum of Goodrich) consisting of muscles, blood vessels and nerves. The septum joins the two hemibranchs with the gill arch and reaches about half the length of the lamellae. The tendons of the abductor muscles lie outside the efferent branchial vessels and the two sets of adductor muscles cross obliquely the interbranchial septum to become inserted on the gill rays of the opposite lamellae (Fig. $30 \mathrm{~J}$ ).

The joining ends of the epi- and cerato-branchials are cartilaginous which help free movement of the arches during respiration (Fig. $30 \mathrm{I})$. The gill rays are flattened, being broader at the proximal end than at the free distal end. They consist of cartilaginous cells en-

Fig. 30. Sketches of gill of carp.

A. Gill of $4.6 \mathrm{~mm}$ larva. X160; B. Gill of $5.3 \mathrm{~mm}$ larva. X160; C. Gill of 6.6 $\mathrm{mm}$ larva. X80; D. Gill of $10 \mathrm{~mm}$ larva. X80; E. A part of gill of $7.6 \mathrm{~mm}$ larva. X120; F. Gill of $10 \mathrm{~mm}$ larva. X32; G. Gill of $35 \mathrm{~mm}$ larva. X32; H. A part of gill of $17.3 \mathrm{~mm}$ larva. X120, black spots mark the extent of ossification; I. The joining ends of epi- and cerato-branchials ; J. Complete gill cut transversely ; K. Afferent branchial vessels.

ae. aboral primary gill lamella ; av. afferent branchial vessel ; bd. bud of lamella ; bm. abductor muscles ; cb. cerato-branchials ; dm. adductor muscles ; eb. epibranchials; ev. efferent branchial vessels; ga. gill arch; gl. gill ray; gr. gill raker; ht. heart ; ms. mucous cells ; oe. oral lamella; pl. primary gill lamella; pp. papilla ; sl. secondary lamella; tb. taste bud. 


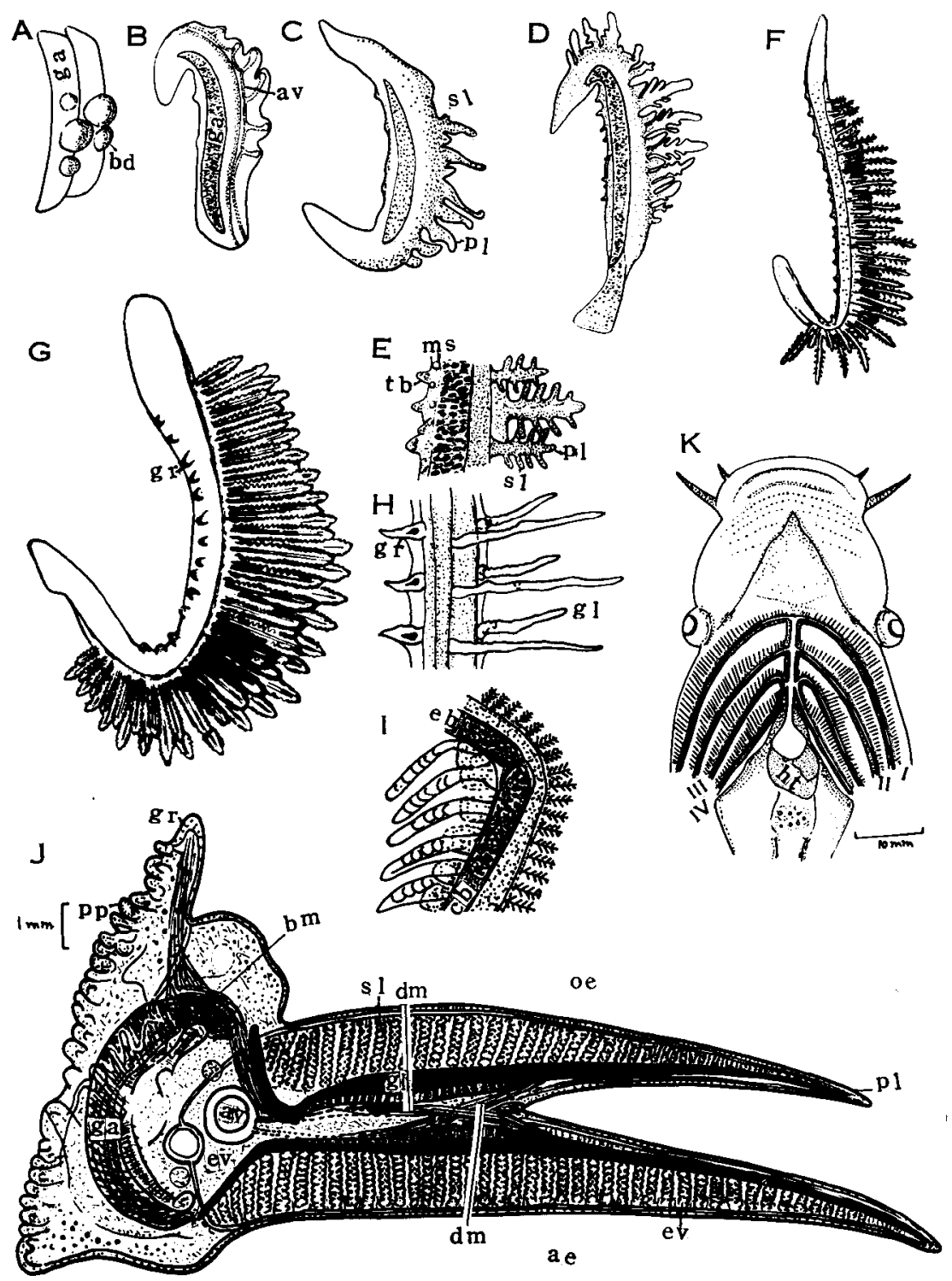

Fig. 30 . 

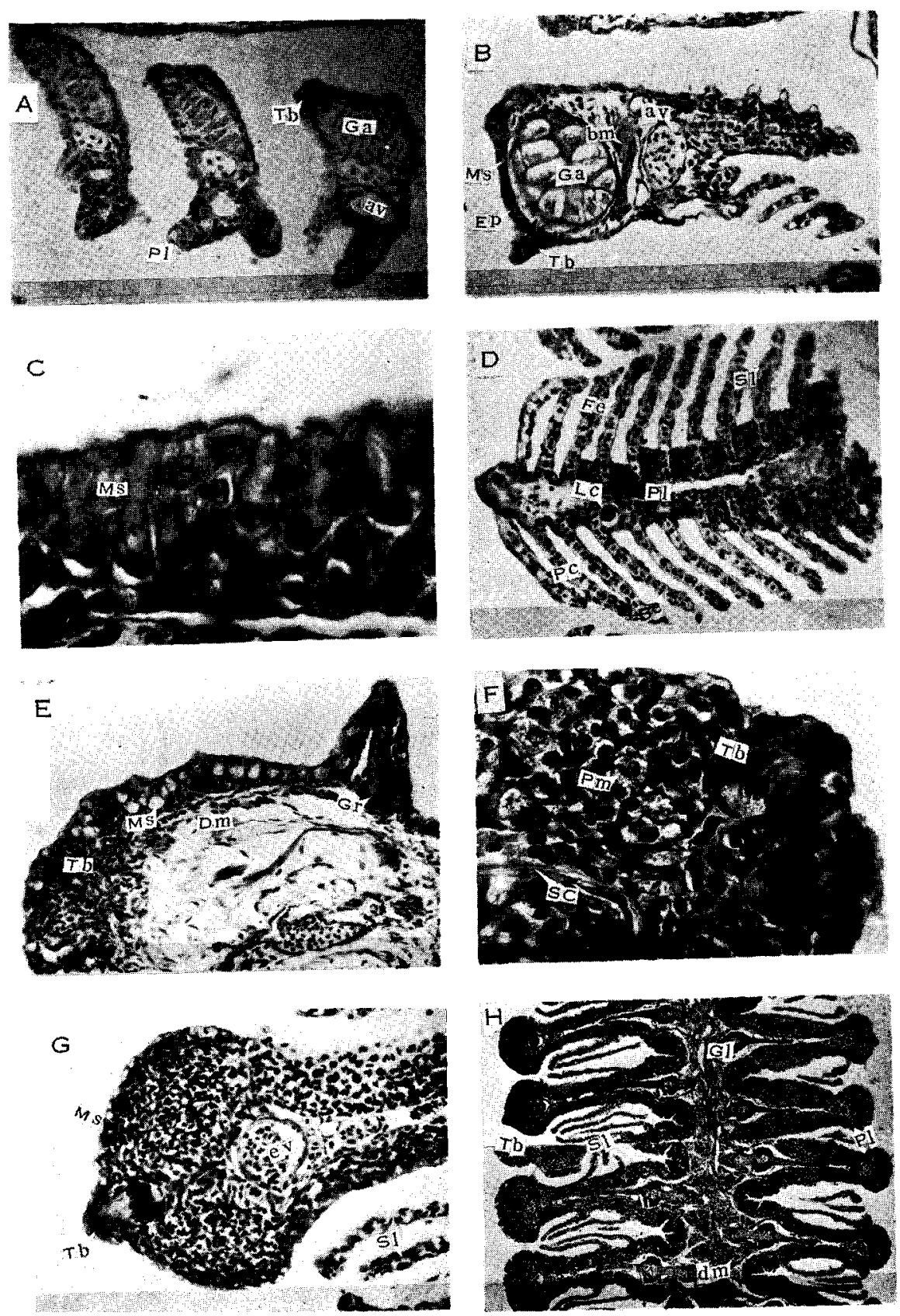

Fig. 31. 

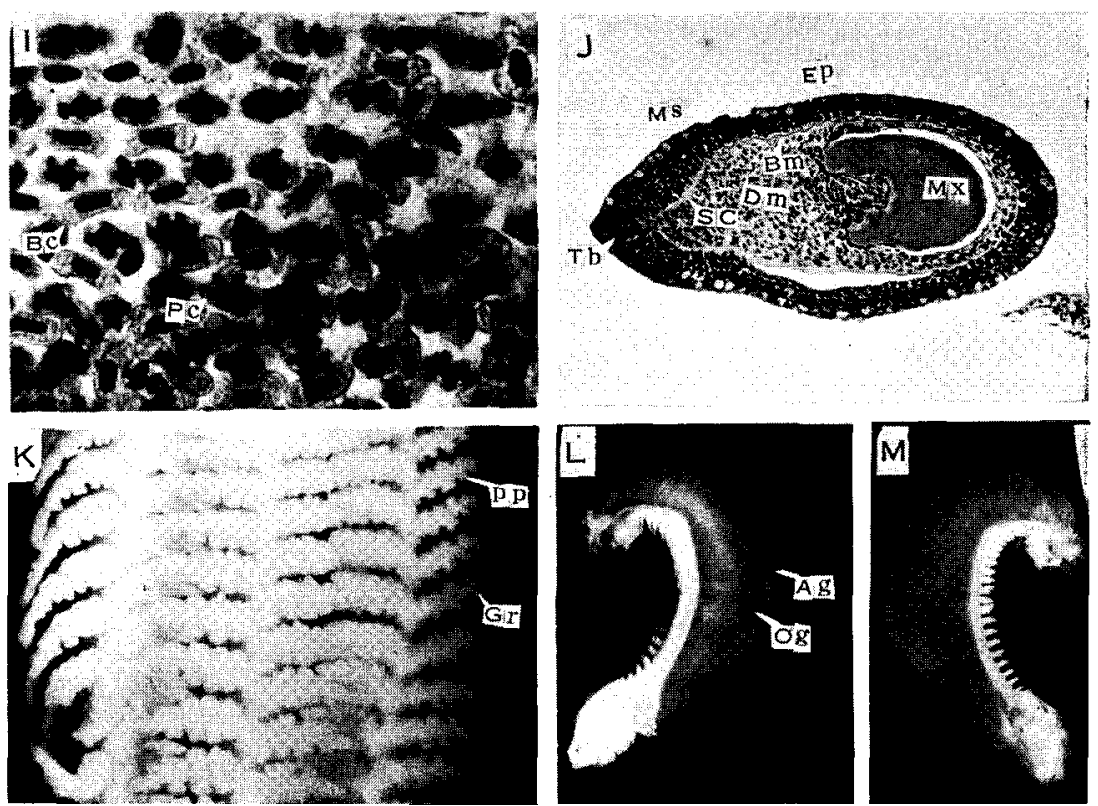

Fig. 31. Photomicrographs of structure of gills.

A. Transverse section through gill of $6 \mathrm{~mm}$ larva. $\times 200$.

B. Transverse section through gill of $7.9 \mathrm{~mm}$ larva. $\times 200$.

C. Transverse section through gill arch of $13.6 \mathrm{~mm}$ larva. $\times 500$.

D. Longitudinal section through gill of $31 \mathrm{~mm}$ young. $\times 200$.

E. Transverse section through gill of $16 \mathrm{~mm}$ larva. X200.

F. Transverse section through distal region of gill arch of $200 \mathrm{~mm}$ carp. x500.

G. Longitudinal section through primary gill lamella of $200 \mathrm{~mm}$ carp. $\mathrm{x} 500$.

H. Longitudinal section through gill of $200 \mathrm{~mm}$ carp. X50.

I. Tangential section through secondary gill lamella of $200 \mathrm{~mm}$ carp. $\mathrm{x} 500$.

J. Transverse section through distal region of gill raker of $200 \mathrm{~mm}$ carp. x200.

K. Gill rakers on three gill arches of $250 \mathrm{~mm}$ carp.

$\mathrm{L}$ and $\mathrm{M}$. First right gill arch of $250 \mathrm{~mm}$ carp.

Ag. aboral gill lamella; av. afferent branchial vessel ; Bc. blood capillary ; bm. abductor muscle ; Bm. basement membrane ; Dm. dermis ; dm. adductor muscle ; Ep. epidermis ; ev. efferent branchial vessel ; Fe. flattened epithelium ; Ga. gill arch ; Gl. gill ray ; Gr. gill raker ; Lc. large secretory cell ; Ms. mucous cell ; Mx. matrix of gill raker ; Og. oral primary gill lamella; PC. pilaster cells or supporting cells ; Pl. primary gill lamella; Pm. promucous cells ; pp. papilla ; SC. stratum compactum ; Sl. secondary gill lamella; Tb. taste bud. 
veloped by bony matrix which helps in rigidity and flexibility. The connection to the arch is strengthened by connective tissues, there being no special articulating surface between them. The secondary lamellae are ridges or processes of the primary gill lamellae standing nearly at right angles to them and contain blood vessels and supporting cells strengthened by respiratory epithelium.

Four gill arches separated by very narrow gill slits are counted in a newly hatched larva. They decrease in size antero-posteriorly, bending slightly in the middle of the cerato-branchial and are set ob-

Table 8. Measurements and counts of size of gill arch (SA). size of smaller gill lamellae (SG), size of larger gill lamellae (SL), number of gill lamellae (NL), number of gill rakers (NR), and number of taste buds (NB) of carp. Measurements were made in millimeter.

\begin{tabular}{|c|c|c|c|c|c|c|c|c|c|c|}
\hline \multirow{2}{*}{$\begin{array}{l}\text { T. L. } \\
(\mathrm{mm})\end{array}$} & \multicolumn{6}{|c|}{ ARCH I } & \multicolumn{4}{|c|}{ ARCH II } \\
\hline & SA & SG & SL & NL & NR & NB & SA & NL & NR & NB \\
\hline $\begin{array}{l}4.6 \\
5.6 \\
5.3 \\
5.6 \\
5.8\end{array}$ & $\begin{array}{l}0.25 \\
0.34 \\
0.41 \\
0.59 \\
0.68\end{array}$ & $\begin{array}{l}0.01 \\
0.03 \\
0.03\end{array}$ & $\begin{array}{l}3.02 \\
3.05 \\
3.05 \\
0.10 \\
0.10\end{array}$ & $\begin{array}{l}2 \\
3 \\
6 \\
8 \\
6\end{array}$ & & $\begin{array}{l}2 \\
2 \\
3\end{array}$ & $\begin{array}{l}0.25 \\
0.25 \\
0.31 \\
0.59 \\
0.68\end{array}$ & $\begin{array}{l}2 \\
2 \\
4 \\
6 \\
6\end{array}$ & & \\
\hline $\begin{array}{l}6.6 \\
7.0 \\
7.4 \\
8.8 \\
9.6\end{array}$ & $\begin{array}{l}0.75 \\
0.88 \\
0.90 \\
1.02 \\
1.02\end{array}$ & $\begin{array}{l}0.05 \\
0.05 \\
0.03 \\
0.05 \\
0.09\end{array}$ & $\begin{array}{l}0.15 \\
0.27 \\
0.15 \\
0.17 \\
0.32\end{array}$ & \begin{tabular}{r|r}
8 \\
20 \\
25 \\
28 \\
40
\end{tabular} & & $\begin{array}{r}3 \\
7 \\
15 \\
28 \\
40\end{array}$ & $\begin{array}{l}0.68 \\
0.85 \\
0.83 \\
1.03 \\
1.03\end{array}$ & $\begin{array}{r}7 \\
18 \\
17 \\
26 \\
38\end{array}$ & & $\begin{array}{r}3 \\
7 \\
15 \\
18 \\
30\end{array}$ \\
\hline $\begin{array}{l}12.1 \\
13.2 \\
14.5 \\
15.2 \\
18.5\end{array}$ & $\begin{array}{l}1.88 \\
1.56 \\
1.81 \\
2.34 \\
2.50\end{array}$ & $\begin{array}{l}0.13 \\
0.19 \\
\\
0.19 \\
0.19\end{array}$ & $\begin{array}{l}0.44 \\
0.50 \\
0.56 \\
0.69 \\
0.56\end{array}$ & $\begin{array}{l}40 \\
56 \\
58 \\
60 \\
56\end{array}$ & $\begin{array}{l}14+14 \\
13+14\end{array}$ & $\begin{array}{l}32 \\
26 \\
30\end{array}$ & $\begin{array}{l}1.88 \\
1.56 \\
1.81 \\
2.19 \\
2.1 \mathrm{C}\end{array}$ & $\begin{array}{l}36 \\
56 \\
42 \\
50 \\
56\end{array}$ & $14+13$ & $\begin{array}{l}28 \\
26 \\
30\end{array}$ \\
\hline $\begin{array}{l}23.1 \\
23.4 \\
24.7 \\
25.3 \\
31.0\end{array}$ & $\begin{array}{l}2.90 \\
2.81 \\
2.97 \\
2.97 \\
3.50\end{array}$ & (3. 19 & $\begin{array}{l}1.00 \\
0.78 \\
0.81 \\
1.00 \\
1.20\end{array}$ & \begin{tabular}{l|}
66 \\
72 \\
66 \\
66 \\
76
\end{tabular} & $\begin{array}{l}13+14 \\
16+16 \\
13+12 \\
14+17 \\
14+17\end{array}$ & & $\begin{array}{l}2.6 C \\
2.81 \\
2.81 \\
2.81 \\
3.2 C\end{array}$ & $\begin{array}{l}60 \\
72 \\
78 \\
66 \\
66\end{array}$ & $\begin{array}{l}13+14 \\
18+18 \\
16+17 \\
16+18 \\
15+18\end{array}$ & \\
\hline $\begin{array}{l}38.5 \\
42.0 \\
54.0 \\
62.0 \\
68.0\end{array}$ & $\begin{array}{l}5.00 \\
5.00 \\
6.20 \\
7.00 \\
8.50\end{array}$ & & $\begin{array}{l}2.00 \\
2.70 \\
2.80 \\
2.80\end{array}$ & $\begin{array}{r}92 \\
88 \\
108 \\
128 \\
146\end{array}$ & $\begin{array}{l}15+17 \\
16+20 \\
15+16 \\
20+25 \\
18+19\end{array}$ & & $\begin{array}{l}4.4 \mathrm{C} \\
5.0 \mathrm{C} \\
6.1 \mathrm{C} \\
6.7 \mathrm{C} \\
7.7 \mathrm{C}\end{array}$ & $\begin{array}{l}102 \\
102 \\
104 \\
128 \\
14 \mathrm{~d}\end{array}$ & $\begin{array}{l}20+20 \\
20+21 \\
18+20 \\
22+23 \\
20+20\end{array}$ & \\
\hline $\begin{array}{r}85.0 \\
90.0 \\
104.0 \\
159.0 \\
163.0\end{array}$ & $\begin{array}{r}8.50 \\
9.90 \\
12.70 \\
15.50 \\
16.50\end{array}$ & & $\begin{array}{l}3.20 \\
\\
3.70 \\
6.50 \\
6.50\end{array}$ & $\begin{array}{l}148 \\
154 \\
168 \\
170 \\
196\end{array}$ & $\begin{array}{l}19+26 \\
18+16 \\
20+25 \\
16+26 \\
18+19\end{array}$ & & $\begin{array}{r}8.5 \mathrm{C} \\
9.8 \mathrm{C} \\
10.0 \mathrm{c} \\
15.5 \mathrm{C} \\
16.5 \mathrm{C}\end{array}$ & $\begin{array}{l}144 \\
170 \\
156 \\
170 \\
196\end{array}$ & $\begin{array}{l}26+26 \\
11+15 \\
26+25 \\
26+27 \\
19+21\end{array}$ & \\
\hline $\begin{array}{l}166.0 \\
172.0 \\
182.0 \\
200.0\end{array}$ & $\begin{array}{l}16.50 \\
16.00 \\
20.00 \\
20.00\end{array}$ & & $\begin{array}{l}7.00 \\
8.00 \\
8.00\end{array}$ & $\begin{array}{l}164 \\
200 \\
212 \\
226\end{array}$ & $\begin{array}{l}15+19 \\
20+26 \\
16+22 \\
16+24\end{array}$ & & $\begin{array}{l}16.50 \\
15.50 \\
19.50 \\
19.50\end{array}$ & $\begin{array}{l}168 \\
204 \\
210 \\
212\end{array}$ & $\begin{array}{l}21+22 \\
26+27 \\
25+23 \\
23+23\end{array}$ & \\
\hline
\end{tabular}


(Table 8, continued)

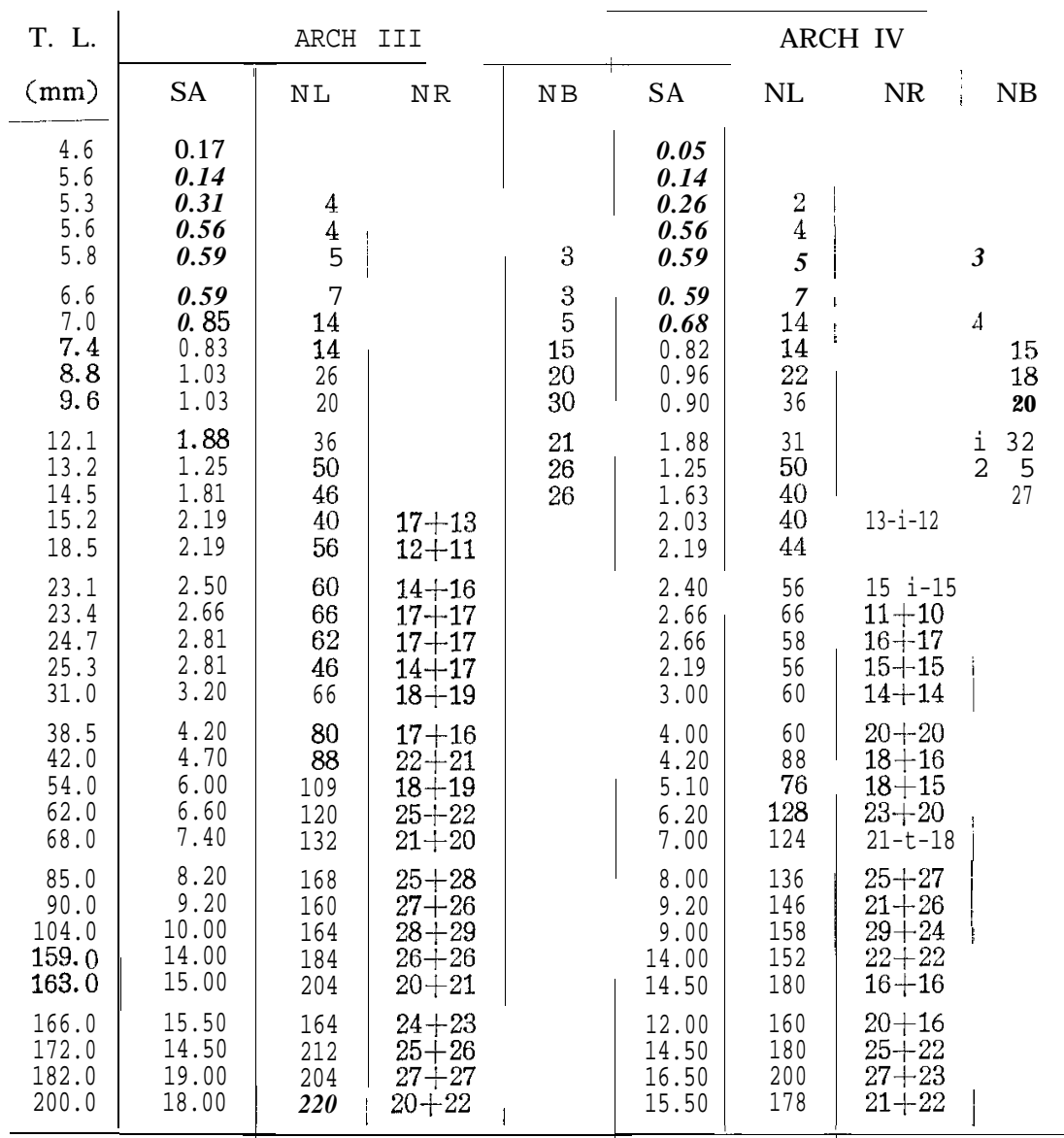

liquely in the dorso-ventral position on either side of the pharyngeal cavity. The first arch is the longest and the fourth arch is the smallest; gill lamellae are absent (Table 8). Small buds of lamellae, 2-3 in number, appear first near the middle region of the outer side of the first and second gill arches 15-16 hours after hatching (about $4.6 \mathrm{~mm}$ larva) (Fig. $30 \mathrm{~A}$ ). They were not marked on the third and fourth gill arches. By about 20 hours after hatching (about $5.3 \mathrm{~mm}$ in total length) 5-6 lamellae are counted, in the centre of which run blood vessels (Fig. $30 \mathrm{~B}$ ). Irregular small elevations are detected on the lamellae by $6-6.5 \mathrm{~mm}$ in total length ; these mark the stage of the formation of secondary gill lamellae. Soon they become prominent and number about 2-4 on either side of the large gill lamellae on the first arch (Fig. 30 C, D). Large lamellae are born on the cerato-branchials. The outer ones are smaller in size than the inner ones. By 
$10 \mathrm{~mm}$ larva the number of lamellae is increased to about 28-38 (Fig. $30 \mathrm{~F}$; Table 8). The brannchial septum is marked runnig nearly half the length of lamellae. In $35 \mathrm{~mm}$ young the number of lamellae is increased to about 70-85 (Fig. $30 \mathrm{G}$ ).

Histologically, in a newly hatched larva the gill is covered with a single layer of flattened epithelium below which are mesenchymal tissues, in the centre of which is a mass of cartilaginous tissues of the arch, and blood vessels are present. Mucous cells are not identified, but dividing cells are usually encountered (Fig. $13 \mathrm{C}$ ). Endodermal cells with large nuclei envelop the arches and the blood vessels.

Small bud-like structures are seen at about 20 hours after hatching on the inner sides of the arches and by $7.6 \mathrm{~mm}$ larva the taste buds and mucous cells are clearly recognized in either borax carmine or other histological preparations (Fig. $30 \mathrm{E} ; 31 \mathrm{~B}$ ). Primary lamellae totalling 16-25 arc formed; these in turn carry about 5-10 secondary ones. By larva $6 \mathrm{~mm}$ in total length the epidermis of the arch consists of 2-3 layers of large squamous cells, 10-12 $\mu$ in thickness (Fig. 31 A). Nuclei are rounded or slightly oval. One to nucleoli and some granules are also present in the nucleus. The taste buds are marked on the outer and inner border of the arch and appear to increase in height and number with the growth of fish (Table 9). Mucous cells are markedly present and are rounded, oval or elongated. They contain the flattened nuclei near the bottom of the cell (Fig. $31 \mathrm{C}$ ). Their measurements are given in Table 10 .

Table 9. Measurements and counts per $\mathrm{mm}^{2}$ of epidermal thickness and buds of gill arches of carp. Measurements were made from sections in $\mu$.

\begin{tabular}{|c|c|c|c|c|c|c|c|}
\hline $\begin{array}{l}\text { T. L. } \\
(\mathrm{mm})\end{array}$ & $\begin{array}{c}\text { Epithelial } \\
\text { th i c k n e s s } \\
\text { Average }\end{array}$ & \multicolumn{2}{|c|}{$\begin{array}{c}\text { Number of taste } \\
\text { buds } \\
\text { Average }\end{array}$} & \multicolumn{2}{|c|}{$\begin{array}{l}\text { Heights of taste } \\
\text { buds } \\
\text { Average }\end{array}$} & \multicolumn{2}{|c|}{$\begin{array}{l}\text { Diameter of } \\
\text { taste buds } \\
\text { Average } \\
\end{array}$} \\
\hline $5-6$ & $3.0-\quad 5.0 \quad 4.0$ & O.O- 0.8 & 0.4 & $15.0-?$ & 15.0 & $10.0-15.0$ & 12.5 \\
\hline $7-10$ & $3.0-17.0 \quad 8.9$ & $0.8-6.3$ & 2.1 & $12.0-32.0$ & 22.8 & $10.0-22.5$ & 18.8 \\
\hline $11-15$ & $25.0-32.0 \quad 29.3$ & $3.9-10.4$ & 8.0 & $27.0-42.0$ & 32.9 & $15.0-22.0$ & 21.5 \\
\hline $16-20$ & $25.0-52.0 \quad 39.5$ & $11.1-20.0$ & 13.4 & $35.0-42.0$ & 40.8 & $17.0-25.0$ & 22.1 \\
\hline $21-25$ & $37.0-58.0 \quad 45.2$ & $12.7-21.0$ & 16.8 & $37.0-47.0$ & 42.3 & $17.0-25.0$ & 22.1 \\
\hline $26-30$ & & & & $37.5-47.0$ & 42.3 & $22.5-25.0$ & 23.2 \\
\hline $31-35$ & $45.0-70.0 \quad 58.3$ & & 17.0 & $37.5-55.0$ & 43.3 & $22.5-25.0$ & 23.4 \\
\hline $36-40$ & $45.0-75.0 \quad 69.0$ & $14.7-21.5$ & 17.0 & $40.0-55.0$ & 46.9 & $22.5-27.5$ & 24.8 \\
\hline 200 & $63.0-163.0$ & & & $58.5-74.0$ & 67.1 & $23.0-39.0$ & 34.4 \\
\hline
\end{tabular}

Underlying this layer is a thin basement membrane. Below this, there is the dermis consisting of connective fibres and scattered smooth muscle fibres. With the increase of fish length no particular change is notic- 
Table 10. Diameters of different mucous cells from gill arch of carp. Measurements were made from sections in $\mu$.

\begin{tabular}{c|c|c|c}
\hline $\begin{array}{c}\text { T. L. } \\
\text { (mm) }\end{array}$ & $\begin{array}{c}\text { Rounded mucous } \\
\text { cells }\end{array}$ & $\begin{array}{c}\text { Oval mucous } \\
\text { cells }\end{array}$ & $\begin{array}{c}\text { Elongated mucous } \\
\text { cells }\end{array}$ \\
\hline $6-7$ & $2-12 \times 3-13$ & $7-10 \times 10-15$ & \\
$7-11$ & $7-12 \times 8-13$ & $7-10 \times 10-15$ & $5-6 \times 14-20$ \\
$12-18$ & $7-16 \times 8-17$ & $7-13 \times 13-20$ & $5-7 \times 18-32$ \\
$19-24$ & same & $7-13 \times 13-22$ & $5-7 \times 30-35$ \\
$25-33$ & same & same & same \\
$34-39$ & same & $7-13 \times 15-30$ & same \\
\hline
\end{tabular}

ed in the epidermis or dermis of the arch other than the thickness (Table 9). Large cells with large basophilic rounded nuclei in the empty cytoplasm are occasionally seen at the base of the secondary gill lamellae (Fig. 31 D). Melanophores are present near the basement membrane. Leucocytes deeply stained with haematoxylin are irregularly scattered in the middle and basal area of the epidermis, and occasionally promucous cells are also observed (Fig. 31 F). Abductor muscles are first clearly marked in the 6-7 $\mathrm{mm}$ larva, between the arch and the efferent branchial vessel (Fig. $31 \mathrm{~B}$ ).

The primary gill lamellae have the same structures as the arch ones. The epidermal cells of the arch become continuous with those of the primary gill lamellae but reduced in number and size and, hence, their thickness. The subepidermal connective tissues are also reduced and the smooth muscle fibres are absent. The mucous cells on the inner side of the primary gill lamellae are better developed than those on the outer side. The taste buds of the normal type born on the subepidermal evaginations of the lamellae are prominently marked (Fig. $31 \mathrm{G}, \mathrm{H}$ ). They measure nearly $40-60 \times 20-40 \mu$ in diameter in about $200 \mathrm{~mm}$ fish. In regard to their distributional pattern the following points are to be noted. (a) They are more evidently marked on the outer hemibranchs than the inner ones. (b) They are greater in number on the lamellae of the first arch than those on the succeeding posterior ones. (c) They are more abundantly distributed on the primary gill lamellae born by the hypo-branchial and the ventral ends of the cerato-branchials than other parts. (d) Their number is greater at the regions attached to the interbranchial septum than the unattached or free ends of the lamellae.

The secondary gill lamellae in transverse section appear to consist of blood capillaries and pilaster or supporting cells of Biétrix (1895) which are narrow and elongated structures with large oval nuclei lying between them. The cells are surrounded by collagenous substances as is evidenced by Masson's trichrome. In horizontal sections 
scraping through the surfaces of the lamellae the pilaster cells appear as amoeboid in outline (Fig. 31 I). The lamellae are enveloped by a thin layer of flattened epithelium (Fig. $31 \mathrm{D}$ ).

The gills are permeated by the efferent and afferent branchial vessels ; the former ones lie just outside of the gill arch and send their branches to the gill lamellae on their outer sides, and the latter ones lie outside of the efferent ones and send their branches into lamellae on their inner sides (Fig. $30 \mathrm{~J}$ ). In passing it may be pointed out that there are four afferent branchial vessels emerging from either side of the ventral aorta. The third and fourth branchial vessels are joined together at the place of origin and soon bifurcate in order to supply their respective arches (Fig. $30 \mathrm{~K}$ ).

The gill rakers line the concave pharyngeal margins of the arches and are arranged in a double series. On the first arch the anterior ones are long and slender, and the posterior ones are short and nodule, while on the second, third and fourth ones, they are short and nodule only (Fig. $31 \mathrm{~K}-\mathrm{M}$ ). They are broad at the base and bluntly pointed at the distal ends and the free ends of longer rakers on the first arch are directed downwards. They are arranged alternate to each other in such a manner that those of one arch fit closely against the same of the adjacent arch to enhance the filtering mechanism and the retaining of small substances (Fig. $31 \mathrm{~K}$ ). Their appearance on the arch is doubtful in the early stages but in larva $15-16 \mathrm{~mm}$ long they give a positive test to Alizarine Red and appear in sections (Figs. $30 \mathrm{H}, 31 \mathrm{E}$ ). In this stage they seem to be of the same form, i. e., swollen at the place of attachment to the arch and bluntly tapered distally. Histologically, the rakers consist of the same constituents as the arch (Fig. $31 \mathrm{~J}$ ). Taste buds are born on their papillae. Stratum compactum of irregular thickness is present and becomes thinner towards the arch and the lamellae.

\section{B. Oesophagus}

The oesophagus is a short muscular tube, extending from behind the pharynx to the intestine, and is limited posteriorly by the transverse septum. It runs dorso-ventrally in an oblique direction above the pericardial chamber and pierces the septum passing into the enlarged part of the intestine. Its length and breadth appear to be of approximately equal size.

Histologically, it consists of the usual layers of tunics found in teleots, i. e., mucosa, submucosa, muscularis mucosa, and serosa (Fig. $32 \mathrm{~A}, \mathrm{~B})$. The mucosa are thrown into longitudinal ridges or folds, first noted by larva $6.8 \mathrm{~mm}$ in total length (Fig. $7 \mathrm{~K}, 0$ ). Their number and height are tabulated below. 
Table 11. Number and height of oesophageal folds of carp. Measurements were made from sections.

\begin{tabular}{c|ccc}
\hline T. L. mm & Number of folds & Height of folds \\
\hline 6.8 & I & $6-8$ & । \\
$8-10$ & $5-10-63 \mu$ \\
13.1 & $10-12$ & & $150-200 \mu$ \\
24.5 & 1 & $2-1$ & \\
39.0 & $14-19$ & & $160 \sim 200 \mu$ \\
$152-157$ & $17-24$ & & \\
$200-300$ & $24-27$ & 1 & $1.0-1.7 \mathrm{~mm}$ \\
\hline
\end{tabular}

The mucosal epithelium is stratified and appears to consist of flattened, oval, fusiform, and a basal layer of low columnar or cuboidal cells. A thin layer of flattened cells with compressed or flattened nuclei lies parallel to the surface and shows evidence of having sloughed off occasionally. Oval or fusiform cells are prominent only at those places where mucous cells are scarce.

The stratified epithelium in the posterior part of the oesophagus passes into a single layer of columnar epithelium of intestinal type, first seen in 11-12 mm larva; thus, a mixture of two types of epithelium is present. The tops and either sides of the folds are covered by stratified epithelium and crypts are lined with the columnar cells. The latter are long and narrow containing oval nuclei with a single or rarely double nucleoli and prominently stained leucocytes are marked (Fig. 32C).

Mucous secreting cells are abundant in distribution in the anterior part like those of the pharynx (Fig. $32 \mathrm{~A}, \mathrm{~B}$ ). They measure about $7-13 \times 8-20 \mu$ in diameter in $6.8 \mathrm{~mm}$ larva and $17-20 \times 32-55 \mu$ in diameter in $300 \mathrm{~mm}$ specimen. They decrease in size and number in the posterior region, particularly where mixed epithelia are found. Taste buds are observed but not so numerous as in the pharynx and they decrease posteriorly. They are present on the tops of folds only and were first marked in $6.8 \mathrm{~mm}$ larva. Their measurements are about $25 \times 20 \mu, 30 \times 20 \mu$, and $63 \times 25 \mu$ in diameter in 6.8, 13.1, and $210 \mathrm{~mm}$ specimens, respectively.

Basement membrane is also present and thin stratum compacturn is marked occasionally. Submucosa consists of areolar connective tissue impregnated with blood vessels and nerves and extends till the tips of the folds below the basement membrane, and a few striated longitudinal muscles pass into it. Circular muscles are also not rare. Collagenous and reticular fibres are also noticed (Fig. 32 D). At the junction of oesophagus and intestine an oval thickening of unidentified 

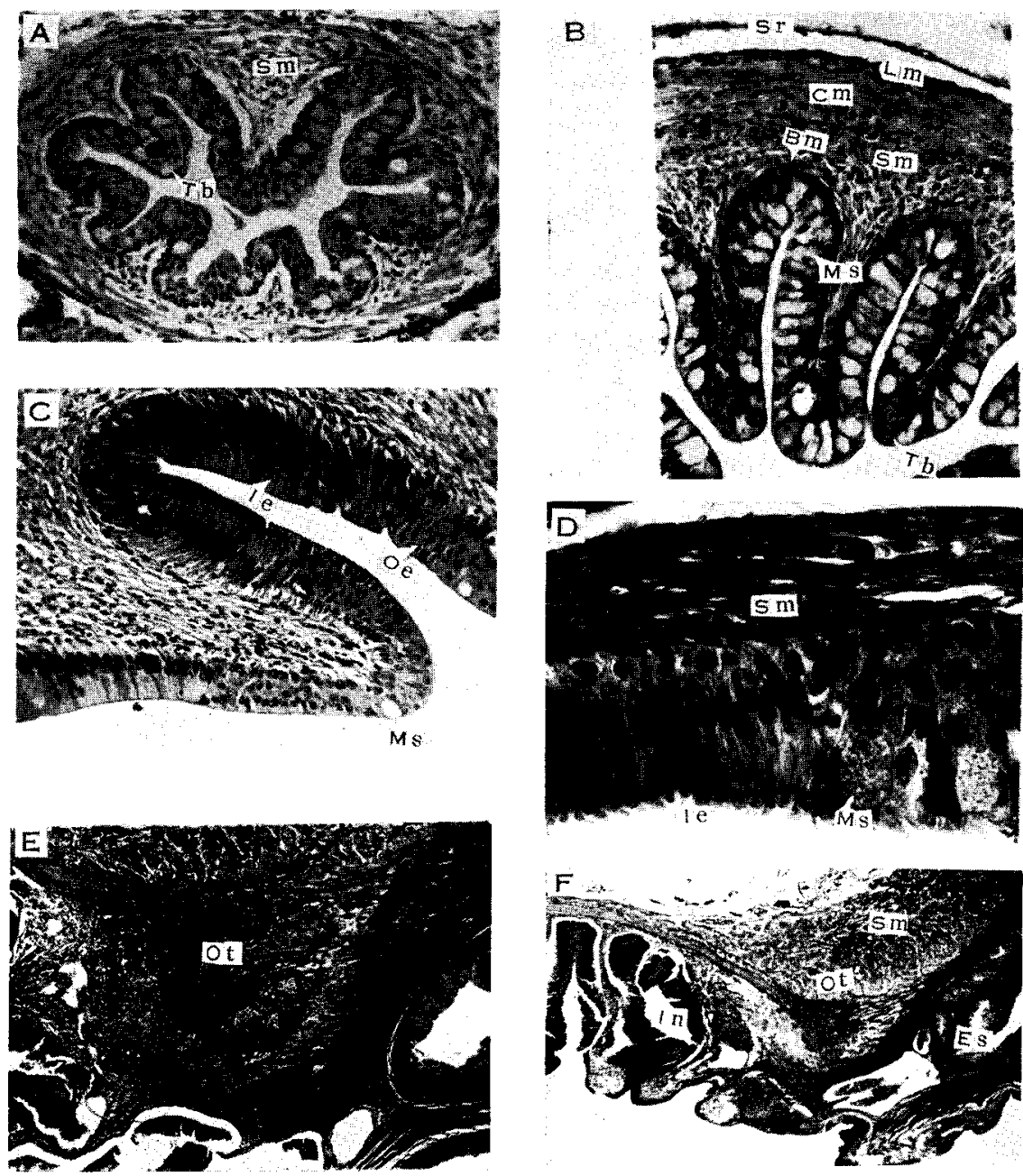

Fig. 32. Photomicrographs of structures of oesophagus of carp.

A. Transverse section through oesophagus of $10.6 \mathrm{~mm}$ larva. $\times 200$.

B. Transverse section through anterior oesophagus of $16 \mathrm{~mm}$ larva. X200.

C. Transverse section through posterior oesophagus of $152 \mathrm{~mm}$ carp. X200.

D. Longitudinal section through posterior oesophagus of $152 \mathrm{~mm}$ carp. X200.

E. Longitudinal section through oesophageo-intestinal junction of $152 \mathrm{~mm}$ carp. X200.

F. Longitudinal section through oesophageo-intestinal junction of $152 \mathrm{~mm}$ carp. X20.

Bm. basement membrane; Cm. circular muscles; Es. oesophagus; Ie. intestinal epithelium ; In. intestine ; Lm. longitudinal muscles ; Ms. mu cous cells ; Ot. oesophageal thickening ; Sm. submucosa ; Sr. serosa ; Tb. taste bud. 
character is observed in the submucosa and measures about $1 \times 2 \mathrm{~mm}$ in diameter in $210 \mathrm{~mm}$ specimen (Fig. $32 \mathrm{E}, \mathrm{F}$ ). Circular and longitudinal muscles constitute the muscularis mucosa, and though irregular in thickness, the former forms a major thickness mainly in the posterior region. The serosa is a thin layer of connective tissue containing flattened nuclei. The pneumatic duct is narrow and increases in calibre gradually with the size of fish. It is strengthened by thick coats of circular and radial muscles from outside and, internally-, it is lined by the same type of mucosal epithelium as the oesophagus, but taste buds and mucous cells are absent.

\section{Intestine}

Intestinal folds Intestinal folds are ridges of mucous membrane and help to increase the absorptive area of the digestive tract for food. They are the continuations of the oesophageal ones and their appearance was noticed almost simultaneously in about $6.0 \mathrm{~mm}$ larva. They run almost longitudinally throughout the whole tract of the intestine and their number is variable acording to the size of the fish (Table 12). Their height is greater in the first part of the intestine than the anal one.

Table 12. Number of the intestinal folds of carp. Counts were made from transverse sections.

\begin{tabular}{|c|c|c|}
\hline T. L. $(\mathrm{mm})$ & $\begin{array}{l}\text { First part of } \\
\text { intestine }\end{array}$ & $\begin{array}{c}\text { Posterior part } \\
\text { intestine }\end{array}$ \\
\hline 6.0 & $8-10$ & $6-7$ \\
\hline 6.3 & $10-13$ & $6-8$ \\
\hline 7.7 & $10-13$ & $6-8$ \\
\hline 9.0 & $12-15$ & $6-8$ \\
\hline 13.1 & $15-18$ & $10-14$ \\
\hline "O-24 & $25-30$ & 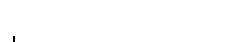 \\
\hline 39 & ca. 30 & $10-14$ \\
\hline 300 & network & $24-26$ \\
\hline
\end{tabular}

By $9 \mathrm{~mm}$ larva the longitudinal folds, high or low, become curved to an angle on their way to the posterior region (Fig. $33 \mathrm{~A}$ ). They converge at the anus where their arrangement is always longitudinal (Fig. $33 \mathrm{E}, \mathrm{F}$ ). By larva $20-24 \mathrm{~mm}$ in total length the number of the folds is increased to about 25-30 in the enlarged part of the intestine and are joined to each other by lateral or side branches (Fig. 33 B). By 24-26 $\mathrm{mm}$ specimens the number of the lateral branches joining the 

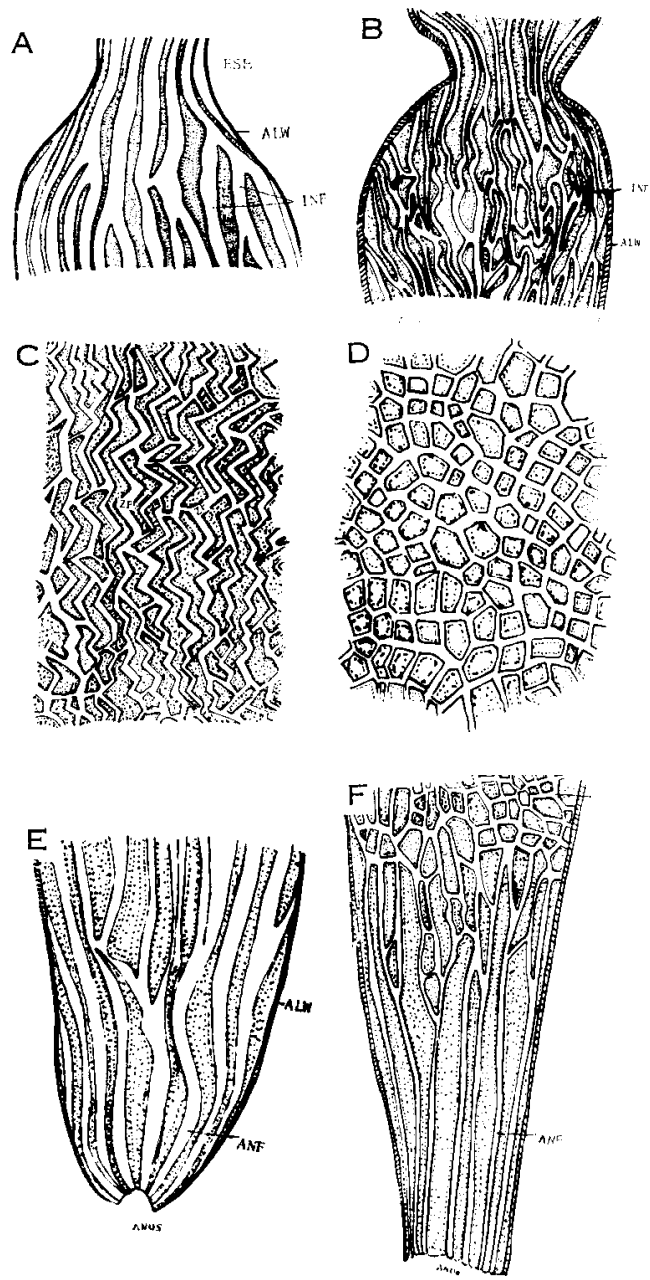

Fig. 33. Oesophageo-intestinal folds of carp.

A. Oesophageo-intestinal folds of $9 \mathrm{~mm}$ larva.

B. Oesophageo-intestinal folds of $20 \mathrm{~mm}$ juvenile.

C. Intestinal folds of $31-34 \mathrm{~mm}$ carp.

D. Intestinal folds of $26 \mathrm{~mm}$ young.

E. Anal folds of $15 \mathrm{~mm}$ larva.

F. Anal folds of $25 \mathrm{~mm}$ young.

ALW. intestinal wall; ANF. anal fold; ESF. oesophageal fold; INF. intestinal fold. 
adjacent longitudinal folds has considerably increased so as to produce a network appearance ; such networks are closer in the first part of intestine than the middle or posterior one (Fig. $33 \mathrm{D}$ ). Some specimens of $31-35 \mathrm{~mm}$ in total length possess zigzag mucosal folds or plicae running in antero-posterior direction and are joined together by lateral branches which also cause network structure (Fig. $33 \mathrm{C}$ ). By $60-80 \mathrm{~mm}$ specimens a network of folds of considerable height (l-1.5 mm) are observed. Two sets of nets, one on the inner side and another on the outer side are clearly visibleunde $r$ a binocular at young about $200 \mathrm{~mm}$ in total length ; these are denser in the enlarged part of the intestine (Fig. $37 \mathrm{~N}$ ).

Intestinal coiling The anterior part of the intestine following the oesophagus is an elongated sac-like structure and has a gradual diminution in diameter posteriorly. The intestine runs straight caudally near the posterior end of the body cavity, from where it sharply turns forward dorso-sinistrally till about the middle part of it, and then runs ventrally reaching near behind the ocsophagus. Again it takes an upward and sinistral course, backs again forming a downward loop with the right limb dorsoventrally convexed and ends with the anus (Fig. 34,4). The chole dochal duct unites with the pancreatic duct and then immediately opens into the intestinal swelling directly at the ventro-lateral side.

While tracing the development of the intestine at the embryonic stage it was found to be nearly straight and appears to be of the same shape and structure also after hatching. This stage has been regarded as the basis of further development of the coiling. The air bladder seems to a certain extent to be related to the coiling process by virtue of its position on the dorsal side of the digestive system. However, for easy and convenient understanding the developing process is divided into the following seven stages (Table 13).

Stage I. (Fig. 34 I). The earliest stage of the developing intestine is a more or less straight tube running over the yolk sac. The part behind the oesophagus and the part before the anal opening may be regarded as the anterior and posterior regions, respectively, and the part between these two should be considered as the middle one for further reference, as there is no demarcation line to differentiate them morphologically.

Stage II (Fig. $34 \mathrm{II}$ ). By $6 \mathrm{~mm}$ larva the development of the air bladder and the enlargement of the liver on both sides of the intestine push or thrust down the anterior end of the intestine, and thus a slight bend is formed and subsequent enlargement of this part is easily observed. The downward bend is continued along with growth in the size of the air bladder and the larva. 
Table 13. Stage, type of intestinal coiling, and total length of carp.

\begin{tabular}{|c|c|c|c|}
\hline STAGE & TYPE OF COILING & FIGURE NUMBER & $\begin{array}{c}\text { TOTAL LENGTH } \\
\text { OF CARP }\end{array}$ \\
\hline 1 & & $34-I$ & Newly hatched. \\
\hline 11 & 20 & $34-11$ & $5-9$ \\
\hline 111 & & $34-I I I$ & $10-12$ \\
\hline IV & & $34-I V$ & $12-16$ \\
\hline $\mathrm{V}$ & & $34-v$ & $17-26$ \\
\hline $\mathrm{y}$ & & $34-V I$ & $25-28$ \\
\hline V11 & & $34-V I I$ & $28-30$ \\
\hline
\end{tabular}

Stage III (Fig. 34 III). This stage is reached at the post-larval period, the total length being $11-12 \mathrm{~mm}$, and the development of the anterior chamber of the bladder is observed clearly. The downward U-shaped pushing is accompanied with raising or lifting up of the right arm as in the figure, and subsequently conspicuous enlargement of the anterior end of of the canal ' $a-b$ ' is marked (Fig. 34 III).

Stage IV (Fig. 34 IV). The bend at ' $c$ ' proceeds anteriorly above the enlarged part of intestine and below the air bladder in horizontal plane. The part ' $b-c$ ' either lies dorso-sinistral to the first part ' $a-b$ ' or simply above it, and the second arm of the bend overlies these two. Sometimes an upward bend at ' $b$ ' is marked. Three arms are distinguished in which the first and the last ones are longer than the middle one, 'b-c'.

Stage V (Fig. $34 \mathrm{~V}$ ). The growth carries the bend ' $c$ ' more forward than before and it passes ventro-dextrally to the enlarged part of the intestine. An extra bend is clearly formed at ' $b$ ' which passes on the right side, and after making a turn comes to the left side, runs again forward dorso-ventrally till near the anterior portion of ' $a-b$ ' or near the hind end of the gall bladder, and at length passes to the anal end dorso-ventrally.

Stage VI (Fig. 34 VI). Growth of the intestine continues and the first part of it passes caudo-dextrally and bends at ' $b$ ' and ' $c$ ' as in 

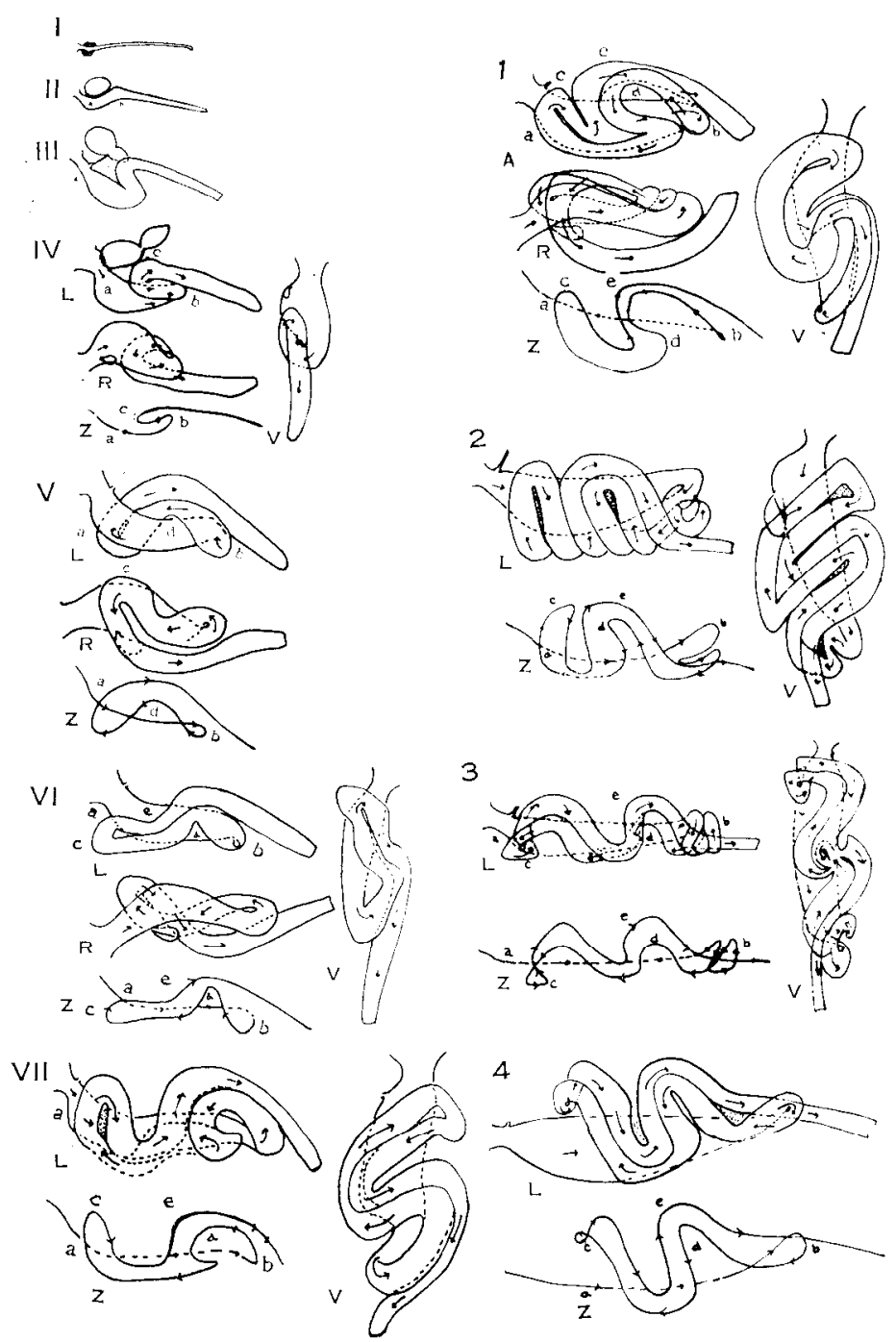

Fig. 34. Sketches of development of intestinal coiling of carp.

I. Intestine of $4.5 \mathrm{~mm}$ in total length ; II. $7.3 \mathrm{~mm}$; III. $11.5 \mathrm{~mm}$; IV. $12.9 \mathrm{~mm}$; V. $24 \mathrm{~mm}$; VI. $27 \mathrm{~mm}$; VII. $29 \mathrm{~mm} ; 1.49 \mathrm{~mm}$; 2. $127 \mathrm{~mm}$; 3. $231 \mathrm{~mm}$; $4.183 \mathrm{~mm}$.

$\mathrm{L}, \mathrm{R}, \mathrm{V}$ and $\mathrm{Z}$ represent left, right, ventral aspects and type of coiling, respectively.
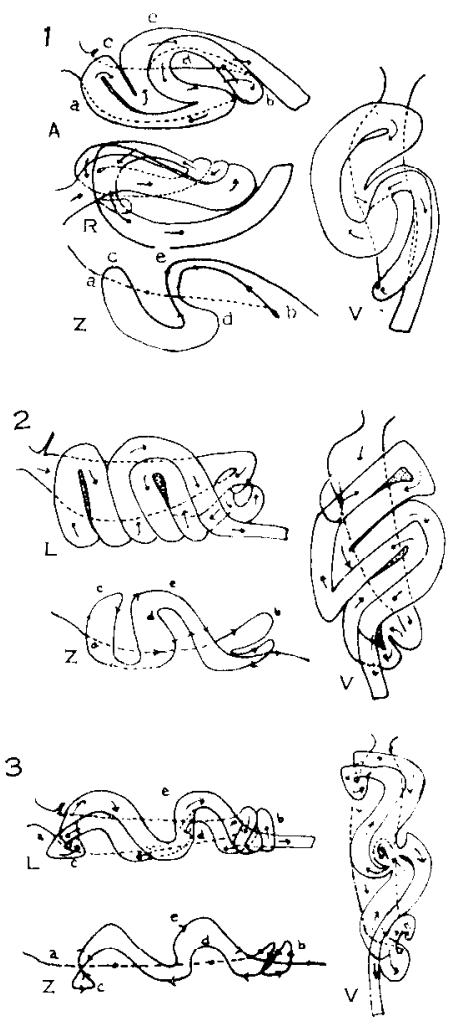
the previous case, but differing from that by the development of a bend at ' $d$ ' anterior to ' $b$ ' and an almost similar but shallower one at ' $e$ ' postero-dopsal to 'c'. The loop of ' $d$ ' is normally dorsal and dextral to the first part of intestine while the same of ' $e$ ' lies only dorsal to the anterior end. The deeper loop of ' $\mathrm{d}$ ' may be due to the freedom from pressure by the air bladder and from the increasing volume of liver at the posterior end.

Stage VII (Fig. 34 VII). The loop of ' $c$ ' is surprisingly raised dorsal to the intestine, deepening the loop of ' $e$ '. The same of ' $d$ ' is considerably deepened. In other words the loops of ' $d$ ' and ' $e$ ' become more prominent than the former stage and are directed dorso-ventrally and ventro-dorsally, respectively. The part of the intestine of ' $d$ ' passes antero-sinistrally along the ventral side of ' $a-b$ ' and the same of ' $e$ ' runs sinistro-posteriorly along the dorsal side of ' $a-b$ '. Thus three siphonal loops are establised at this stage which is the normal loop structure of the carp, which by this time has reached nearly 28-30 $\mathrm{mm}$ in total length (Table 13).

Further development results in the deepening of the loop at ' $\mathrm{d}$ ' and ' $e$ ' and an increase in length of the intestine. The intestinal arms are all cemented together by the hepato-pancreatic mass which forms a shallow concavity above into which the air bladder is fitted. The position of the enlarged part of the intestine appears to be variable, sometimes dorso-dextral and sometimes ventro-sinistral depending perhaps on the growth of the liver and swim bladder with respect to the space in the body cavity.

Extra bends or loops are also formed at ' $b$ ' and 'c' to keep pace with the increasing length of intestine. In the larger specimens the coils become complicated, but maintain the typical pattern of coiling, differing only in the process of formation of the bends (Fig. 34,1 4). Such complexity seems to be the outcome of rapid intestinal gawth. Occasionally the bend of ' $c$ ' passes ventral to 'a-b' near the gall bladder, twists on itself and then runs dorso-posteriorly towards 'e' (Fig. $34,3)$.

Besides the regular forms described above, irregular forms are also met with and eleven figures of abnormal winding arc illustrated (Fig. 35 A-K). They seem to occur only after the normal stage of VI or VII is reached by $26-30 \mathrm{~mm}$ in total length. In almost all the forms the intestine, instead of reaching straight to the posterior end of the coelom, either winds or turns in the middle and forms complicated coiling. In case it reaches the hind part of coelom, further development of winding is in a haphazard manner.

The diameter of the canal varies slightly in different regions, and appears to be dependent upon the degree of distension by food sub- 

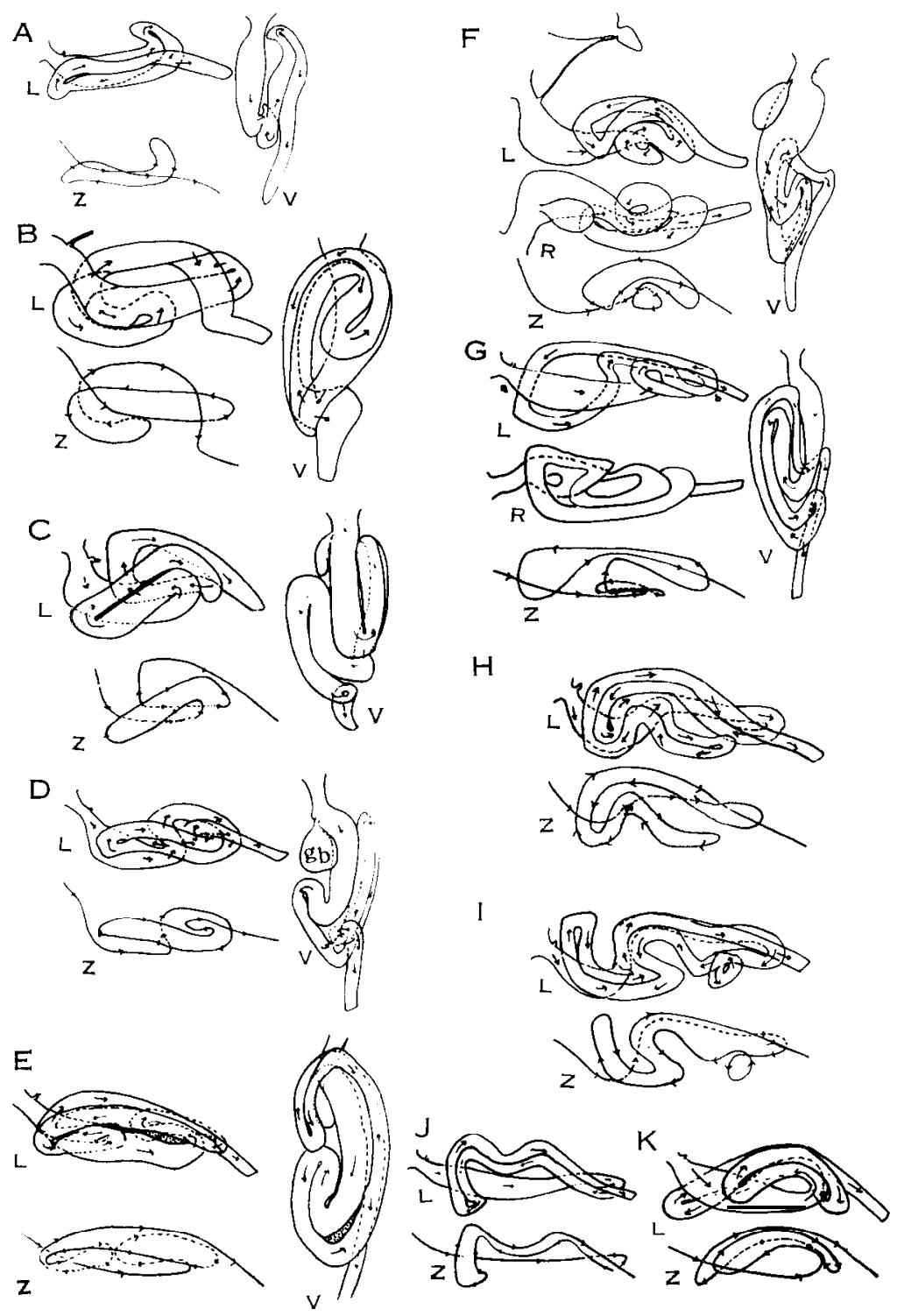

Fig. 35. Sketches of irregular intestinal coiling of carp.

A. Intestine of $29 \mathrm{~mm}$ carp; B. $30 \mathrm{~mm}$; C. $41 \mathrm{~mm}$; D. $39 \mathrm{~mm}$; E. $45 \mathrm{~mm}$; F. $127 \mathrm{~mm}$; G. $123 \mathrm{~mm}$; H. $72 \mathrm{~mm}$; I. $100 \mathrm{~mm}$; J. $200 \mathrm{~mm}$; K. $163 \mathrm{~mm}$. L. R, V and $Z$ represent left lateral, right lateral, ventral aspects and type of coiling, respectively: gb. gall bladder. 


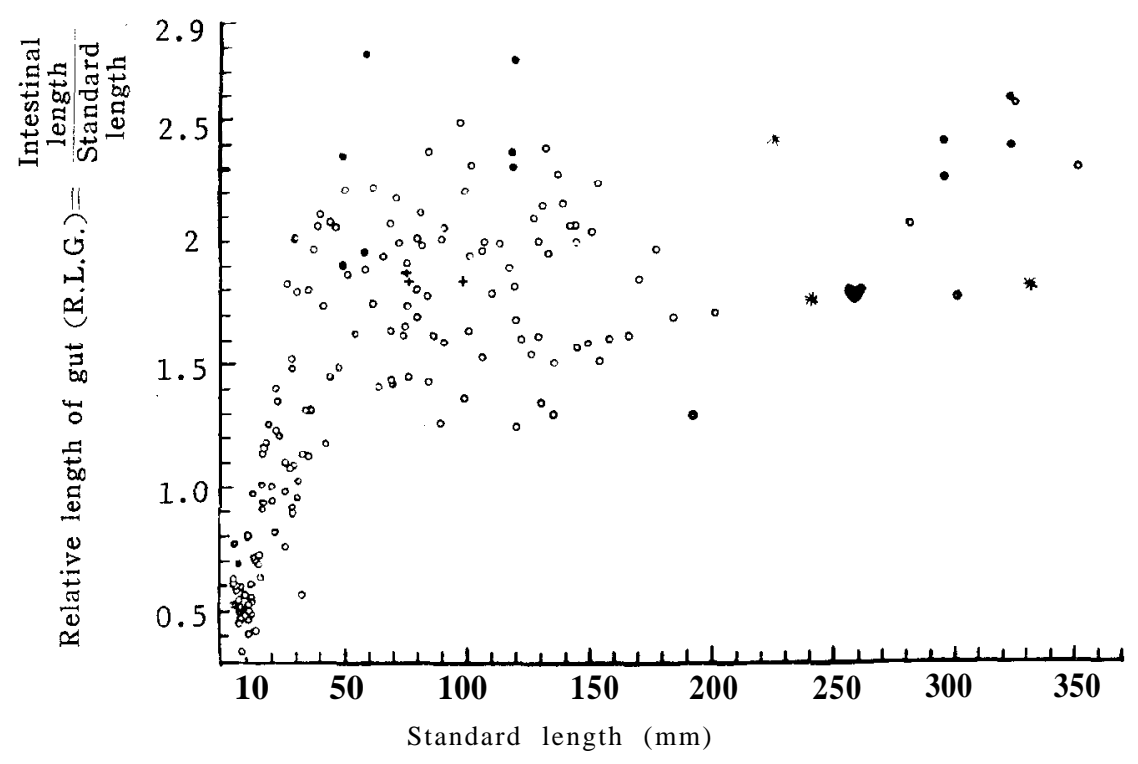

Fig. 36. Relation between relative length of gut (R. L. G.) and standard length.

* Curry, 1939 ; @ Klust, 1940 ; † Al-Hussaini, 1949 ; $\vee$ Kafuku, 1958 ;

O Present observation.

stances. The relative length of the gut (i. e., the ratio of intestinal length to standard length) appears to be nearly $1.5-2.5$ in $30-40 \mathrm{~mm}$ in total length, after which the value becomes constant in 50-60 larv $\mathrm{mm}$ in total length (Fig. 36).

Intestinal lining Histologically, the intestine consists of mucosa, submucosa, muscularis, and serosa. The mucosa is thrown into folds as described before, and a few of them form connecting links which in cross section appear either circular, oval, elliptical, or elongated

Fig. 37. Photomicrographs of the structures of intestine.
A. Transverse section through the middle intestine of $6 \mathrm{~mm}$ larva. X200.
B. Transverse section through first part of intestine of $7.7 \mathrm{~mm}$ larva. X200.
C. Transverse section through first part of intestine of $13.6 \mathrm{~mm}$ Iarva. X50.
D. Transverse section through middle part of intestine of $23 \mathrm{~mm}$ juvenile. X200.
E. Section of the distal part of mucosal fold of $78 \mathrm{~mm}$ carp. X1000.
F. Transverse section of the crypt through first part of intestine of $300 \mathrm{~mm}$ carp. $\mathrm{x} 200$.
G. Pear-shaped cell, enlarged. X1000.
H. Transverse section through posterior region of intestine of $82 \mathrm{~mm}$ carp. X200. 

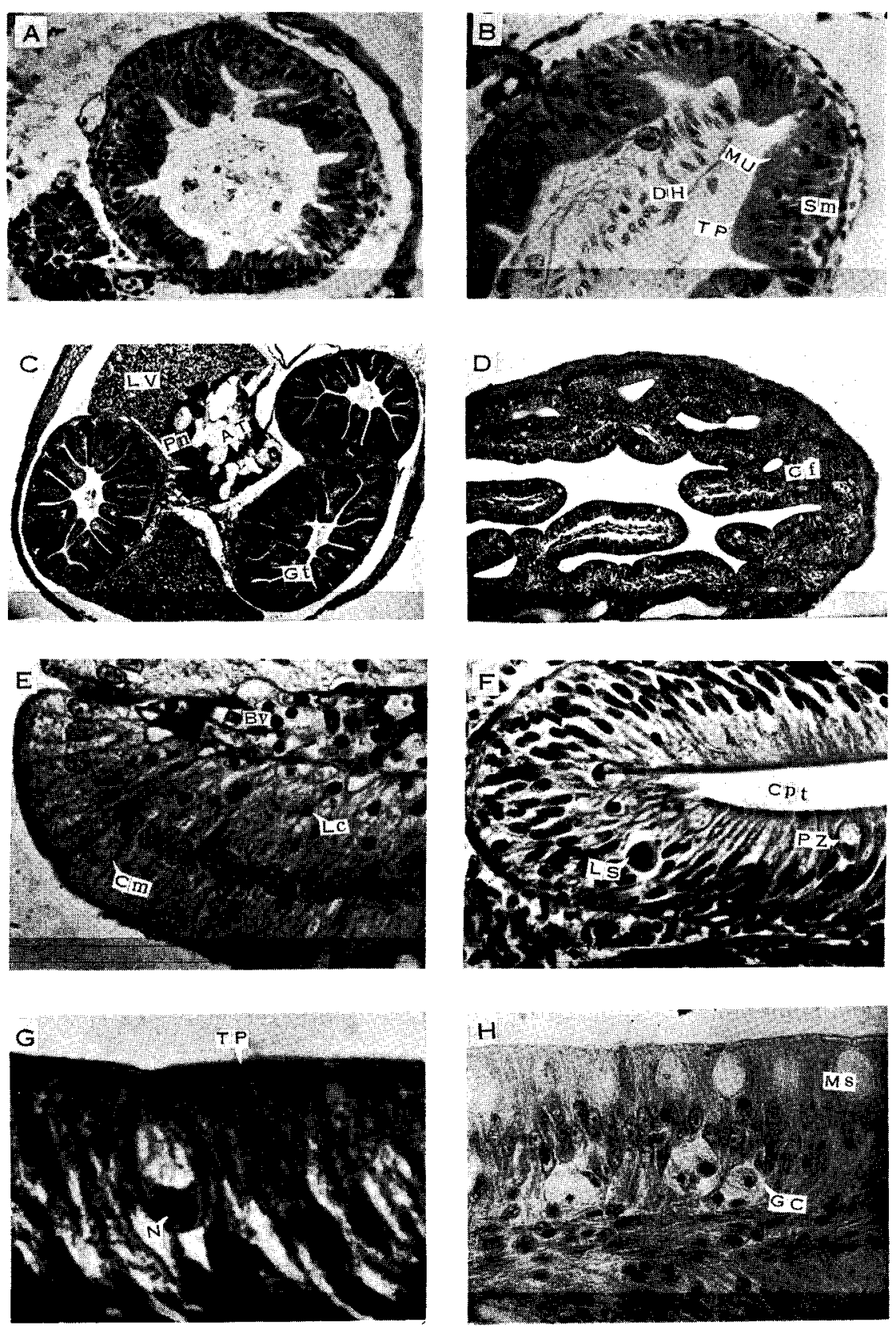

Fig. 37. 

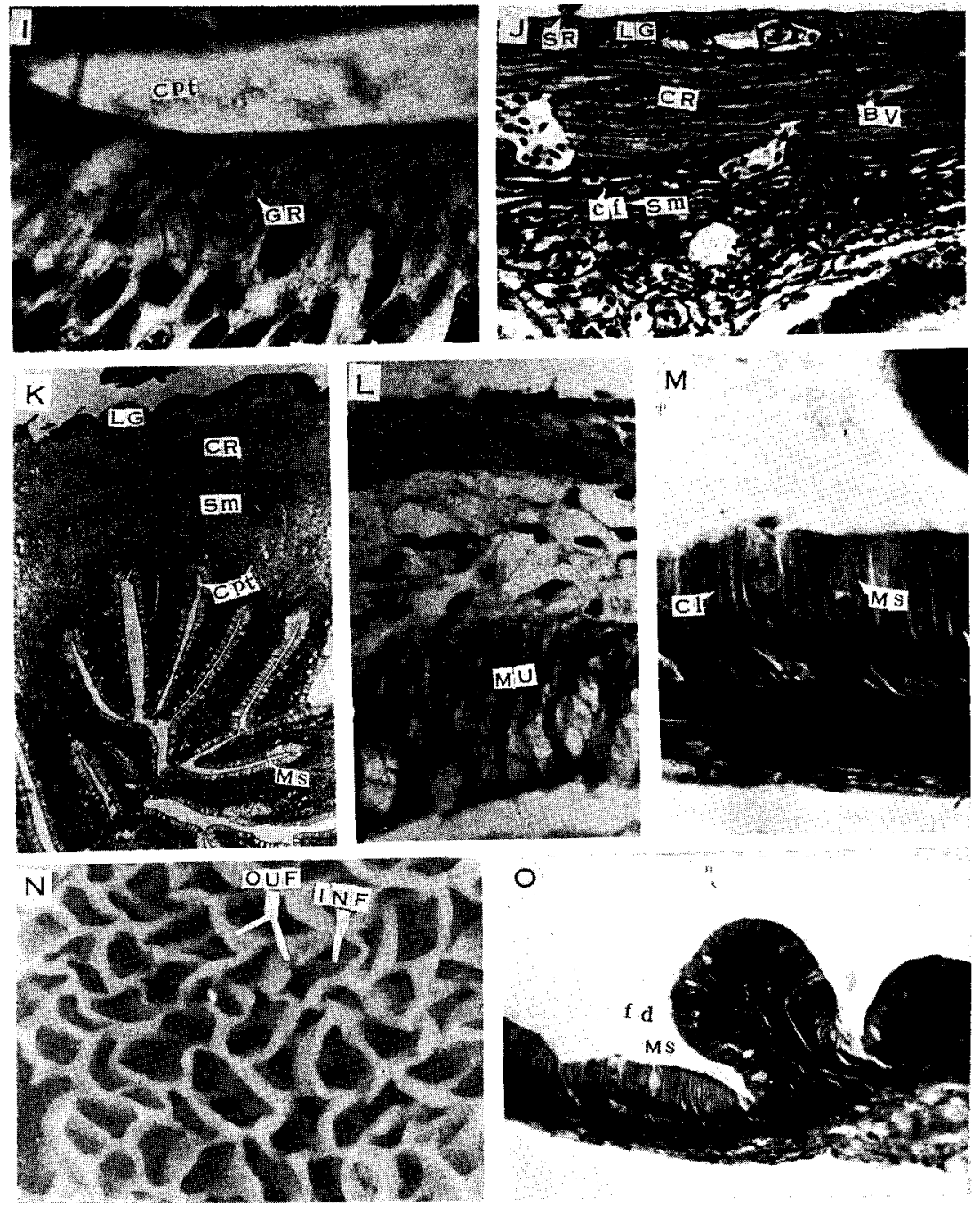

(Fig. 37, continued)

I. Section through crypt of first part of intestine of $82 \mathrm{~mm}$ carp. X1000.

J. Transverse section through first part of intestine of $210 \mathrm{~mm}$ carp. X100.

K. Transverse section through third limb of intestine of $82 \mathrm{~mm}$ carp. X200.

L. Transverse section through the anal region of intestine of $320 \mathrm{~mm}$ carp. X200.

$M$ and 0. Section through wall of gall bladder. X490, X200.

$\mathrm{N}$. Folds of first part of intestine of $250 \mathrm{~mm}$ carp.

AT. adipose tissue; BV. blood vessel; cf. connective tissue fibre; Cf. connecting folds ; Cl. columnar cells ; cm. cell membrane; CR. circular muscle; Cpt. Crypt; DH. daphnia; GC. large secretory cell; Gt. intestine: Lc. Leucocyte; LS. large unidentified cell ; LV. liver ; Ms. mucous cells ; MU. mucosa ; N. nucleus ; OUF. outer fold of intestine; INF. inner fold on intestine: Pn. pancreas: PZ. pear-shaped cell; Sm. submucosa ; SR. serosa ; Tp. top plate ; GR. granular cell. 
and of different sizes with a cavity lined by a layer of columnar cells (Fig. $37 \mathrm{D}$ ).

The epithelium forming the mucosa consists of columnar cells wider at the top than the base. The nuclei are oval, measuring nearly $6 \times 2$ $\mu$ in diameter and lying below the centre of the cell with deeply stained 1-2 nucleoli. The height of the cells varies being greatest in the anterior part and least in the posterior one (Table 14). The cells at the bottom of the crypt become narrower and more crowded and their nuclei smaller than ones at the sides and tops of the folds (Fig. 37 F). The cell membrane at the bottom of the crypts are not prominent but they are easily marked at the sides and tops of the folds (Fig. 37E). The cells are covered by a thin border called 'top plate' (canal layer, striated border) which is revealed more prominently by a triple stain than by a simple double stain. The outer and inner layers are exposed by taking up the light greenish colouration of Masson's trichrome thus suggesting its collagenous nature (Fig. $37 \mathrm{G}$ ). It is of irregular thickness and elastic thus helping in the stress and strain due to food substances.

Lying among the cells are goblet cells and they reach almost the same size as the epithelial cells. The distal part is swollen and the nucleus is pushed towards the basal end. They are more commonly available at the sides and the crypts than the tops, and appear to increase in size and number posteriorly. In the anal part they form stratification, the heavy discharge of which seems to help in facilitating the defecation. In low and shallow crypts they assume elongated form rather than goblet one (Fig. $37 \mathrm{H}, \mathrm{K}, \mathrm{L}$ ) and measure about 20 $\mathrm{x} 6 \mu$ in diameter in $210 \mathrm{~mm}$ specimen. They appear to have permanent stoma, narrowed or widened, according to presence or absence of mucus. Fine secretory granules are stained brown by Humason and Lausbaugh stain.

Other cellular structures which are observed without an order in the neighbourhood of epithelial cells include leucocytes or lymphocytes, granular cells, pear-shaped cells (Plehnscezellen), and certain unidentified cells. Leucocytes are darkly stained rounded structures with scanty cytoplasm, common either at the base or middle region of the epithelium and occasionally migrating within a short distance of free border (Fig. $37 \mathrm{E}, \mathrm{F}, \mathrm{H}$ ). They were counted to be $8-12$ in a section of the fold from the anterior end of the intestine. Large granular cells with many coarse granules (basophilic) are found among the epithelial cells (Fig. 37 I). Large cells of unidentified character, rounded or nearly oval occur among the proximal ends of the cells close to the basement membrane (Fig. 37 F). Such cells with two nuclei are occasionally marked from the posterior end of the intestine 
Table 14. Measurements and counts of height (H. Cl) and number (N.Cl) and their average (Av) of columnar cells from first, middle, and posterior part of intestine. Measurements were made from sections in $\mu$.

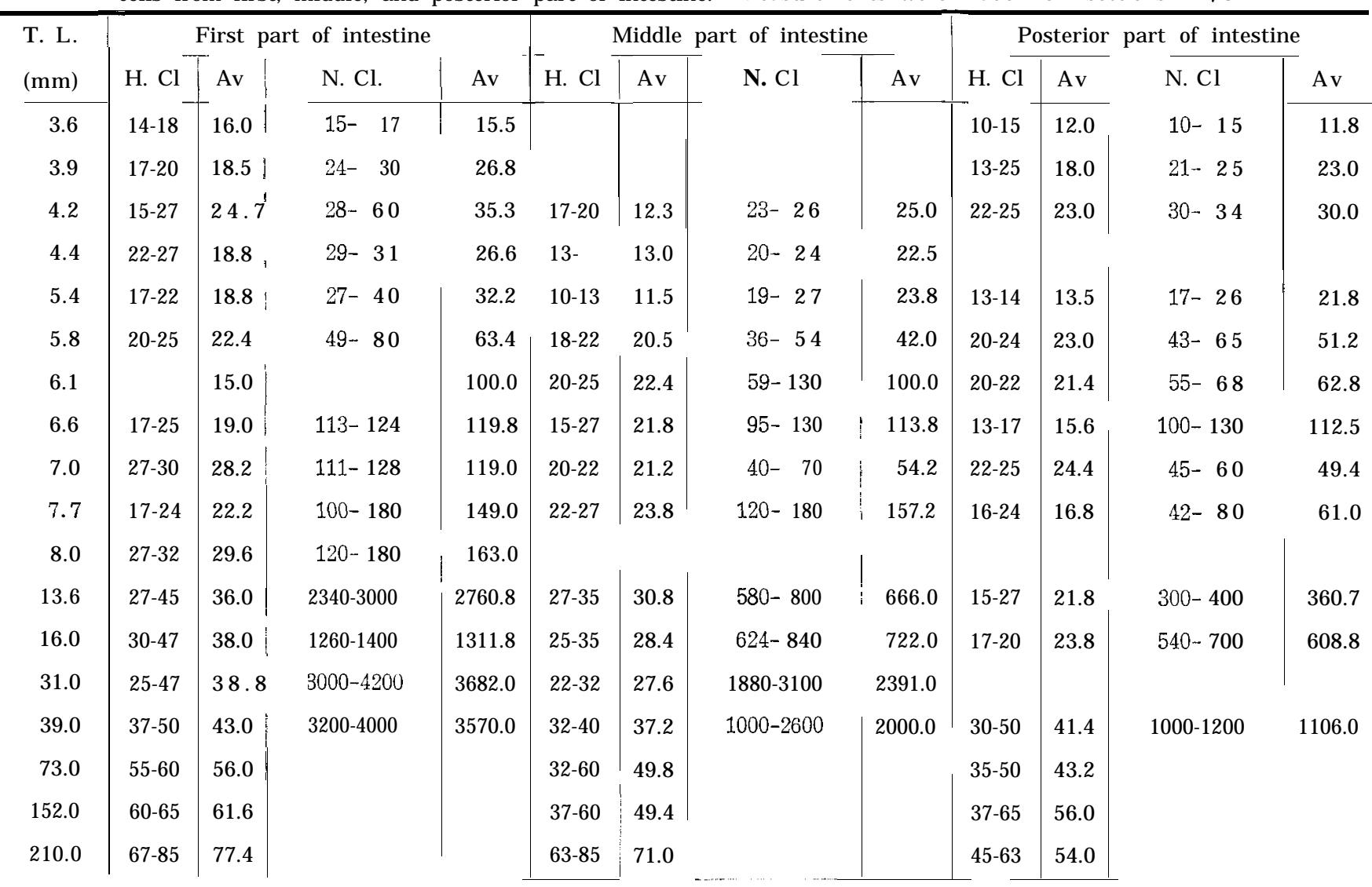


and are negative to both PAS and Alcian blue (Fig. $37 \mathrm{H}$ ). Pear-shaped cells are opening into the cavity and their number is $2-8$ in a transverse section of a fold. They measure about 15-20x6-7 $\mu$ in diameter and are more prominently marked from the middle part of the intestine than other regions (Fig. $37 \mathrm{G}$ ). Their nuclei are slightly flattened containing chromatin granules and are basal in position. They do not respond to a mucous test and their function is unknown. Basement membrane is prominently present and the flattened nuclei are marked along the basal surface of the columnar cells (Fig. $37 \mathrm{~F}$ ). The stratum compacturn seems to be absent or very thin and not easily differentiated from the membrane.

The submucosa is a layer of connective tissue in which the fibres of collagenous nature are distributed (Fig. $37 \mathrm{~J}$ ). It is more extensive with coarser fibres at the anal regions than other parts of the intestine. It is surrounded by a thick layer of circular muscles outside of which is a thin layer of longitudinal muscles, the former one appearing about 2-4 times thicker than the latter one and is considerably decreased in the anal region. However, the muscularis is thicker in the anterior region than other parts of the intestine. The serosa consists of a thin layer of flattened cells of nearly equal thickness. Vascular tissues richly permeate it, cross the muscular area, enter the submucosa and reach the tipe of the folds (Fig. $37 \mathrm{E}$ ). The subserosa is not marked.

The gall bladder is a sac-like structure with a narrow neck connected to the right ventro-lateral side of the enlarged part of intestine behind the oesophagus. Histologically, it has the same type of layers of cells as the intestine. The mucosa is thrown into a few folds with broad and rounded tops and consists of tall and narrow columnar cells interposed between which are goblet cells of intestinal nature.

\section{Relative growth}

It is an accepted fact that an organ showing differential growth with respect to the length of the body maintains a constant differential growth rate over a considerable period of time. In other words, if ' $\mathrm{X}$ ' represents the size of the body of an animal and ' $\mathrm{Y}$ ' of an organ or tissue, then ' $\mathrm{Y}$ ' increases as a constant power of ' $\mathrm{X}$ ', i. e., $\mathrm{X}^{b}$, so that they may be connected by an equation $\mathrm{Y}=A \mathrm{X}^{\mathrm{b}}$, where ' $\mathrm{A}$ ' is another constant (the value of ' $\mathrm{Y}$ ' when ' $\mathrm{X}$ ' is unity). If plotted logarithmically it becomes $\log \mathrm{Y}=\mathrm{b} \log \mathrm{X}+\log \mathrm{A}$, which is the equation to a straight line in the study of relative growth. The growth of an organ or a part of it is either faster or slower than or is nearly 


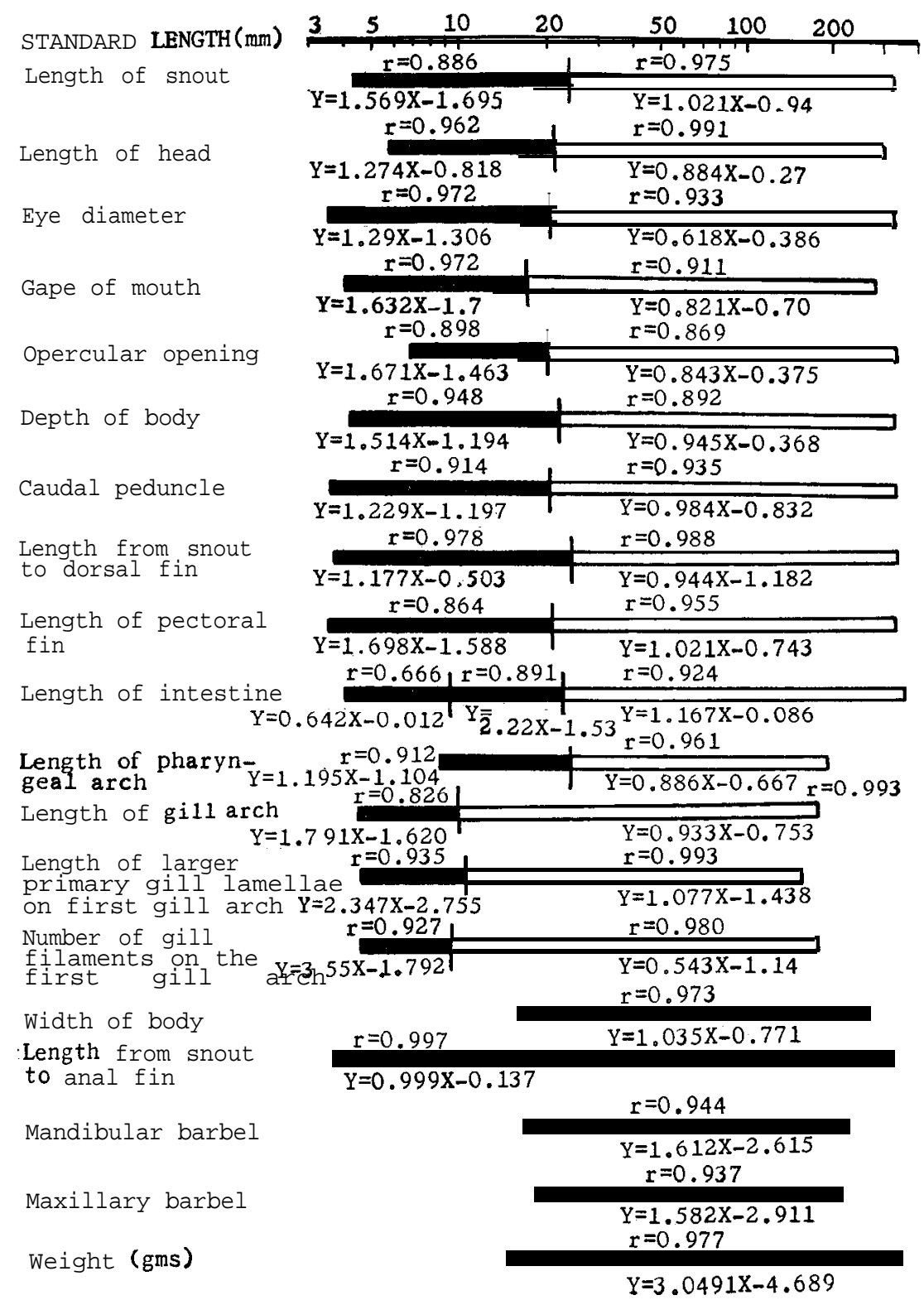

Fig. 38. Relative growth equations, coefficient of correlations ( $r$ ), and inflection points (marked by vertical lines) of organs of carp. 
identical with that of the body size. To denote the same with different rates from that of the body, different terms have been used by vairous authors. In this report the terms used by Huxley and Teissier (1936) are followed. When growth coefficient or growth ratio is greater or less or at exactly 1 , the organ in question is growing faster or slower or exactly at the same rate as body size, indicating thereby 'positive allometry' or " negative allometry 'or ' isometry ', respectively.

However, the length, diameter, and thickness of parts or organs (head, snout, eye, mouth, barbel, opercular opening, pectoral fin, snoutinsertion to the dorsal and anal fin, gill arch, gill lamellae, pharyngeal arch, intestine, columnar cells of intestine, taste buds, head skin, body width, and body height) are plotted along Y-axis against body size along $\mathrm{X}$-axis on the logarithmic paper with an aim of establishing diagonistic morphometric characters at different stages in the life of the carp. Significant changes are noticed to occur in the body parts as marked at intersection or inflection points on the growth curve. Figures 38 and 40 show relative growth equations, coefficient of correlations ( $r$ ), and inflection points of each organ.

Length of snout (Figs. 38, 39 A). Two apparent growth ratios in the growth of snout length of the carp from the time of hatching to $325 \mathrm{~mm}$ in standard length are observed with an inflection point at 24 $\mathrm{mm}$. Till this length the growth is positive allometry (relative growth coefficient is 1.569), after which it becomes nearly constant showing isometry (1.021).

Length of head (Figs. 38, 39 B). In the case of the growth of head length an inflection point is marked at $21 \mathrm{~mm}$. The first growth period shows positive allometry (1.274) and the second one nearly isometry (0.884).

Eye diameter (Figs. 38, 39 C). The eye diameter shows one inflection point on the growth curve at $20 \mathrm{~mm}$. Before this length the relative growth co-efficient is 1.290 , a case of positive allometry, and after this it sinks down to 0.618 , a case of conspicuous negative allometry. This is a remarkable reduction by half of that formerly observed.

Gape of mouth (Figs. 38, $39 \mathrm{D}$ ). An inflection point at $17 \mathrm{~mm}$ divides the growth rate of the gape of mouth into two periods, the first one showing positive allometry (1.632) and the second one showing negative allometry (0.821).

O perculer opening (Figs. 38, $39 \mathrm{E}$ ). The opercular opening shows two growth phases demarcated by an inflection point at $20 \mathrm{~mm}$; the first growth phase ending at this length shows positive allometry 

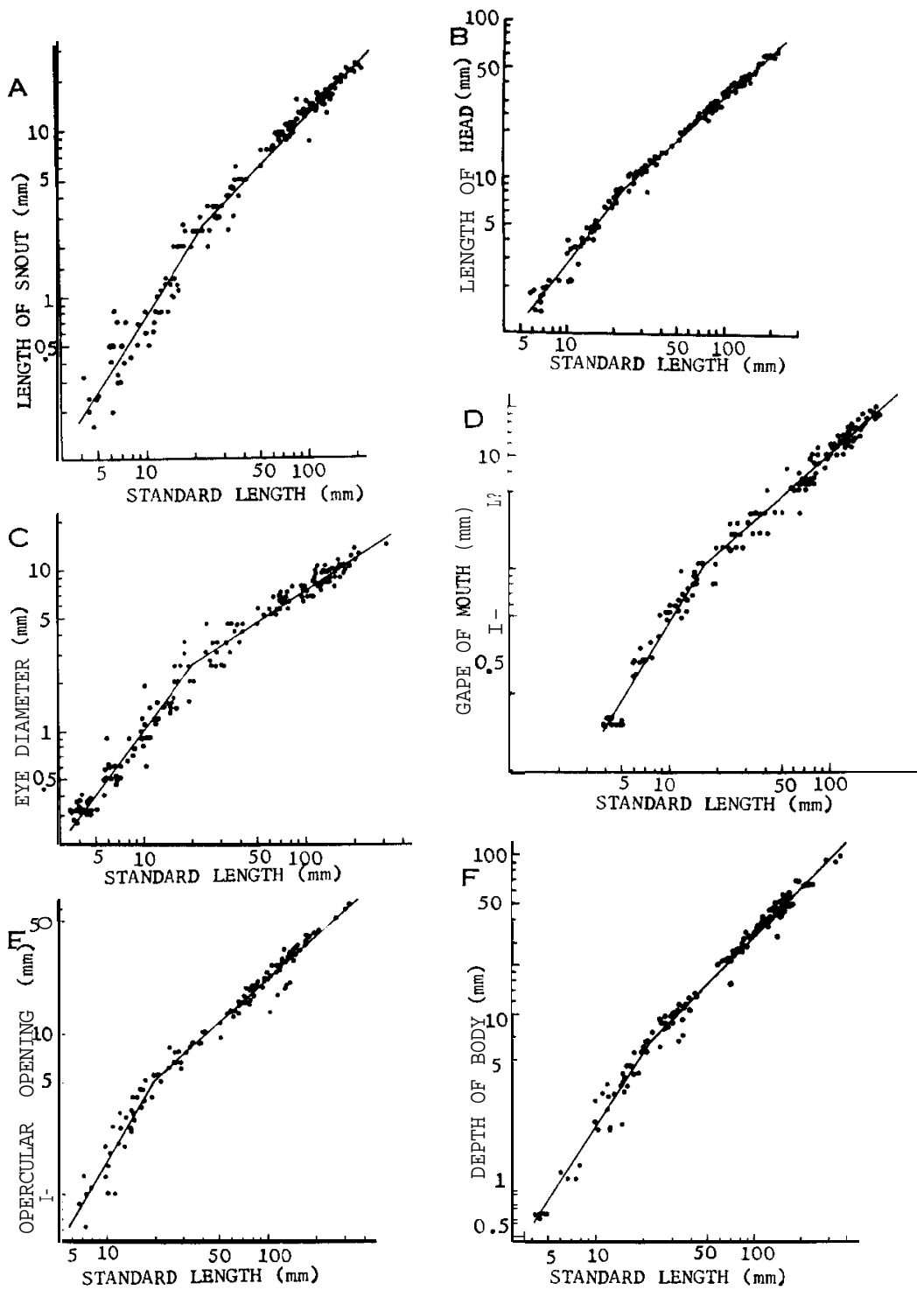

Fig. 39. Relation of organs to standard length.

A. snout length ; B. head length ; C. eye diameter ; D. mouth gape E. opercular opening; F. body depth. 

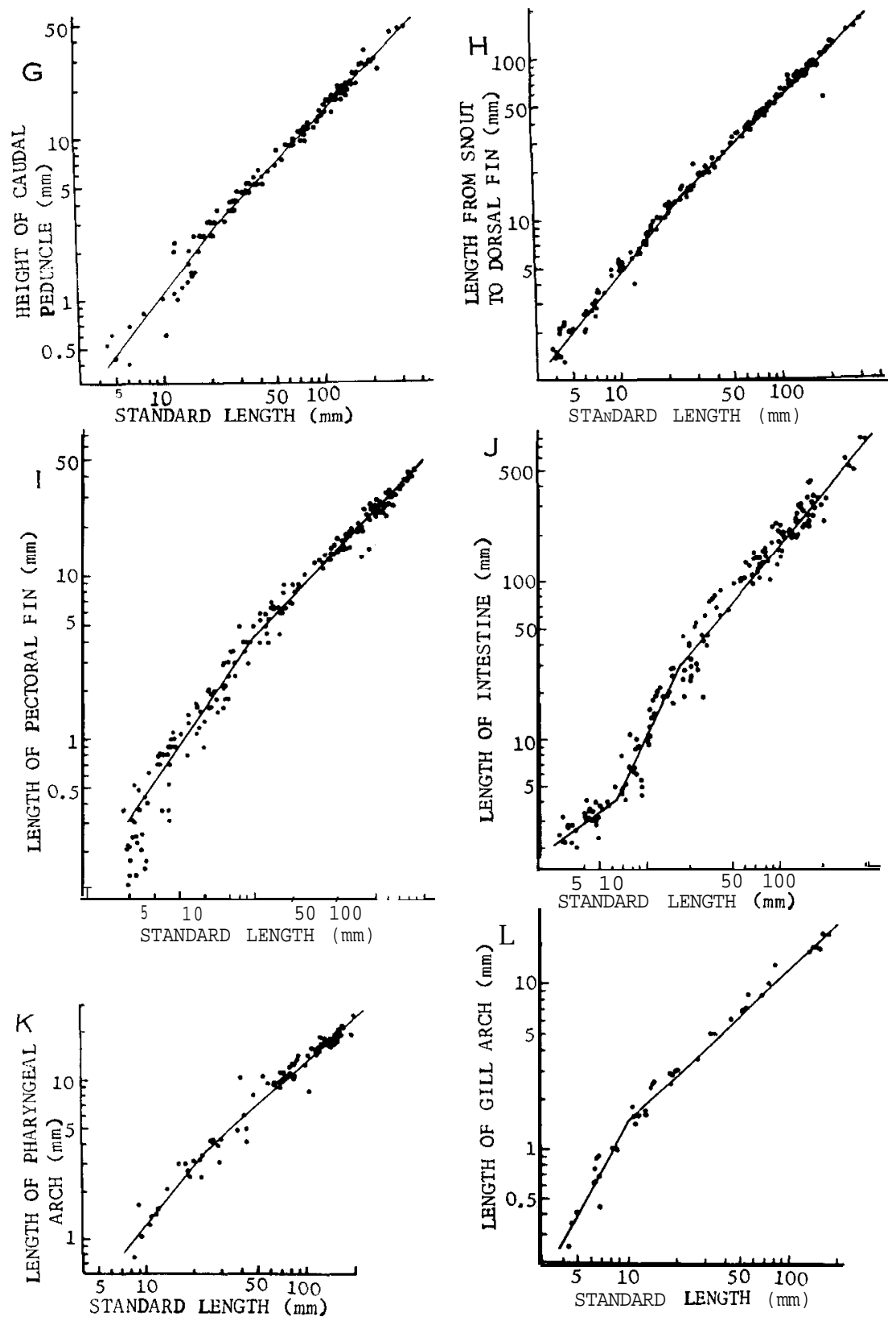

(Fig. 39, continued)

G. caudal peduncle height ; $\mathrm{H}$. snout-insertion of dorsal fin ; I. pectoral fin length; J. intestinal length $; \mathrm{K}$. pharyngeal arch length; L. gill arch length. 

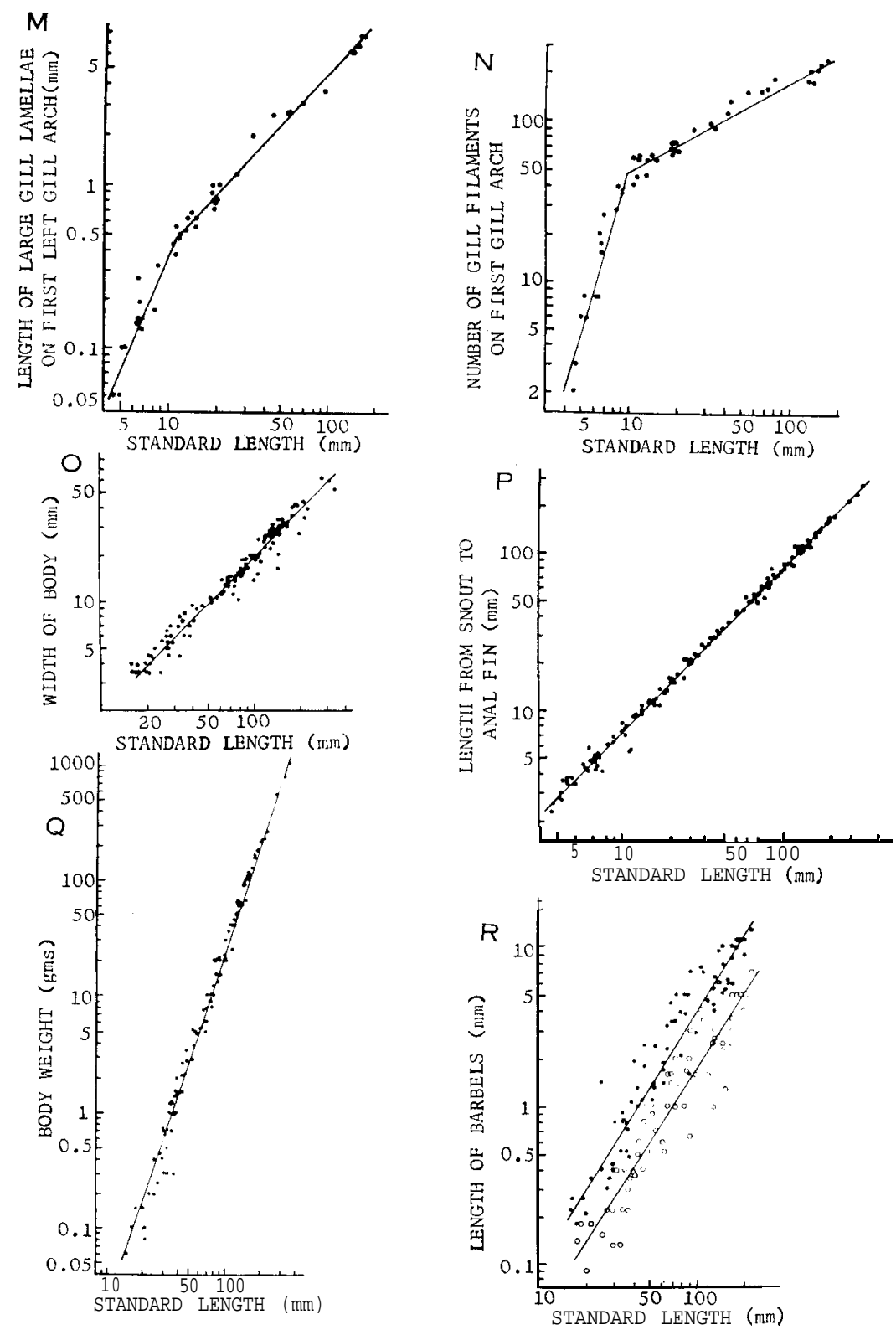

(Fig. 39, continued)

M. gill lamellae length; N. gill filament number ; 0 . body width; P. snout - insertion of anal fin length; Q. body weight ; R. barbel length (solid cirle, mandibular barbel ; open circle, maxillary barbel). 
(1.671) while the second one following this exhibits negative allometry (0.843).

Depth of body (Figs. 38, $39 \mathrm{~F}$ ). The depth of body gets the growth ratio 'changed at $22 \mathrm{~mm}$ before which length a positive allometry (1.514), and after which a definite isometry (0.945) is evident.

Height of caudal peduncle (Figs. 38, $39 \mathrm{G}$ ). One inflection point is observed on the growth curve marking the value of 1.229 in the first period before $20.5 \mathrm{~mm}$, and the same of 0.984 in the second period after this length. A shift from positive allometry to isometry indicates that its growth rate is constant after $20.5 \mathrm{~mm}$.

Length from snout to insertion of dorsal jin (Figs. 38, $39 \mathrm{H}$ ). Here 'again an inflection point is observed at $24 \mathrm{~mm}$ and the regression. coefficient reads as 1.777 showing an apparent positive allometry from the time of hatching to $24 \mathrm{~mm}$ after which it decreases to 0.944 showing isometry.

Length of pectoral fin (Figs. 38, 39 I). The pectoral fins are developed in the embryonic stage as stated before. In the early post-embryonic stage the growth rate of the pectoral fin does not seem to be regular, but soon it shows a regular growth marking a positive allometry (1.698) till $21 \mathrm{~mm}$ and after this length assuming nearly isometry (1.021).

Length of intestine (Figs. 38, $39 \mathrm{~J})$. Two inflection points are prominent on the growth curve of the intestinal length against the standard length of carp when they reach $9.5 \mathrm{~mm}$ and $22.5 \mathrm{~mm}$, respectively. Until the fish is $9.5 \mathrm{~mm}$ the growth coefficient is 0.642 showing negative allometry, but when they get longer than this the same is increased to 2.220 showing definite positive allometry three times greater than the former till $22.5 \mathrm{~mm}$; after this length the growth coefficient falls down but remains within the range of positive allometry (1.167). The tendency of positive allometry in the young-adult stage indicates the increasing length of intestine throughout the life of the carp.

Length of pharyngeal arch (Figs. 38, $39 \mathrm{~K}$ ). The measurements include the fish after the satisfactory penetration by Alizarine Red of an approximate $8.5 \mathrm{~mm}$ larva. Two different phases of growth are separated at an inflection point of $24 \mathrm{~mm}$. Till this stage the coefficient of relative growth is 1.195 , a case of positive allometry; which afterwards nears isometry (0.886) until $190 \mathrm{~mm}$ in standard length is reached.

Length of first gill arch (Figs. 38, 39 L). An inflection point is apparent when the fish reach $10 \mathrm{~mm}$ in total length. The growth coefficient is 1.791 , a positive allometry but the same is changed after this length to 0.933 , which is nearly an isometry. 
Length of gill lamellae (Figs. 38, $39 \mathrm{M}$ ). Two phases of growth rate are marked in the length of large gill lamellae on the first gill arch, one from the stage of formation of gill lamellae to $10.6 \mathrm{~mm}$, where positive allometry is observed (2.437), and the second stage following this in which the value decreases but still remains within the limit of positive allometry (1.077).

Number of gill flaments (Figs. 38, $39 \mathrm{~N}$ ). The growth rate of the number of gill filaments on the first gill arch also indicates an inflection point at $9.5 \mathrm{~mm}$. Before the attainment of this length it shows a high coefficient value of 3.550 , a positive allometry, which suddenly falls to 0.543 , an apparent negative allometry, marking no remarkable increase in the filament number of the adult condition.

Width of body, length from snout to insertion of anal fin, and length of barbels (Figs. 38, 39 0, P, Q). Width of body appears to increase with fish length showing an apparent isometry (1.035); the same condition is also noticed in the growth rate of length from snout to insertion of anal fin showing isometry (0.999) and no inflection point is observed on the growth curve (Fig. $39 \mathrm{P}$ ). The maxillary and mandible barbels increase with almost same rate showing positive allometry, the values of relative growth coefficients being 1.612 and 1.581, respectively. The regression lines appear running almost parallel to one another (Fig. 39 Q).

Body weight (Figs. 38, 39 R). Body weight against standard length

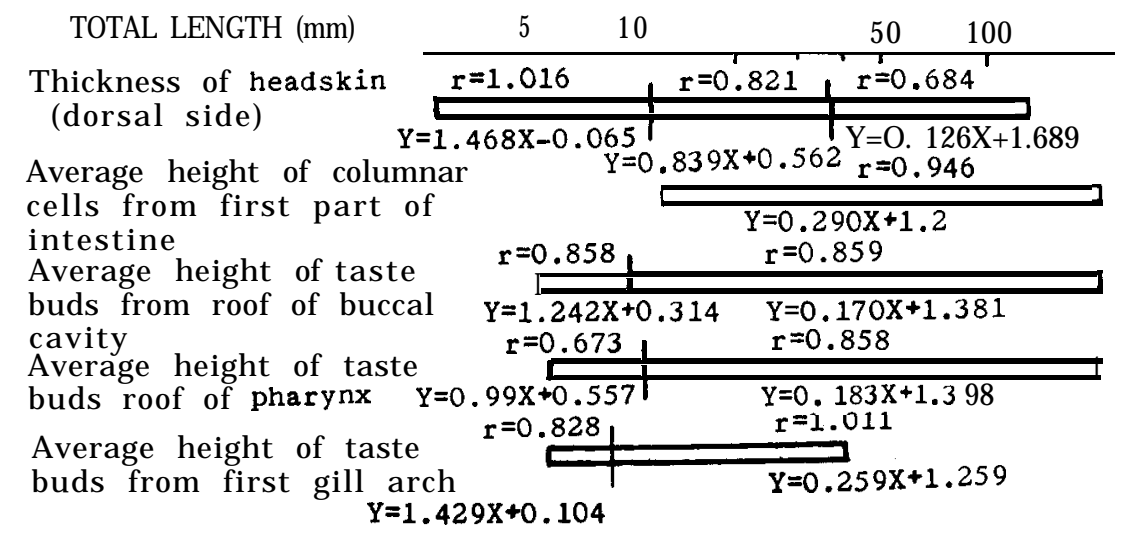

Fig. 40. Relative growth equations, coefficient of correlations (r), and inflection points of the relative growth of head skin thickness, intestinal columnar cells, and taste buds of carp. Vertical lines indicate the inflection points. Measurements were made from sections. 

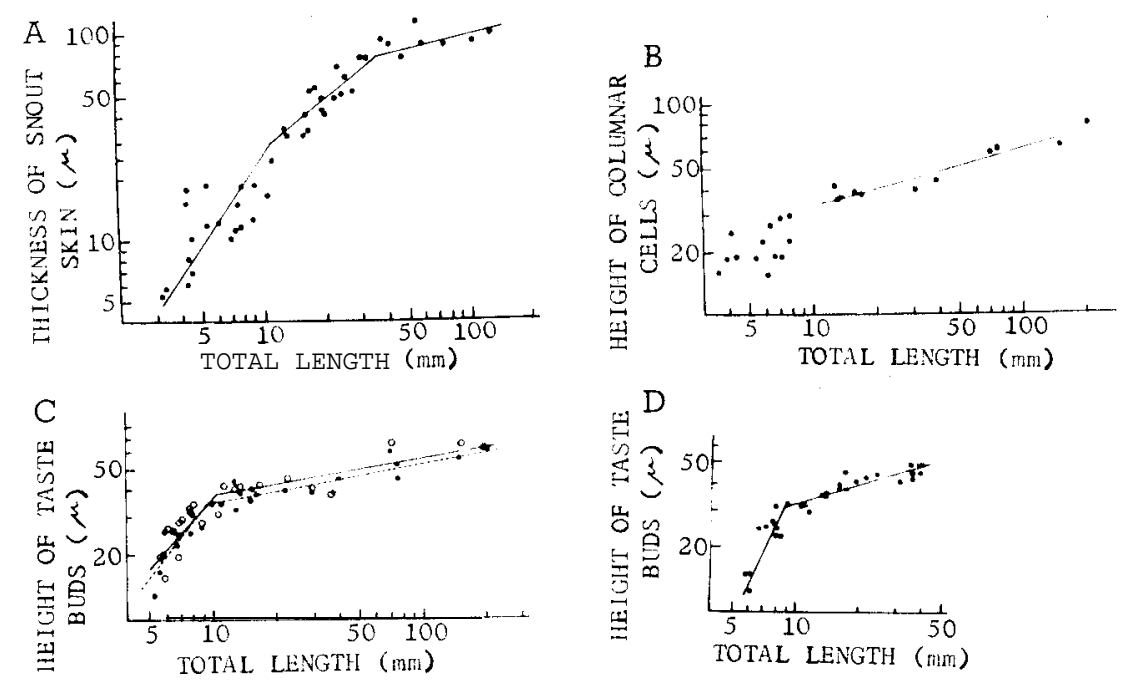

Fig. 41. Relation of tissues to total length of carp.

A. Epidermal thickness of snout skin ; B. Height of intestinal columnar cells; C. Height of taste buds (doted line, from buccal cavity; solid line, from pharyngeal cavity) ; D. Height of taste buds from gill arch.

is shown by a single growth line, the value being 3.046.

Epidermal thickness of head skin (Figs. 40, 41 A). Two inflection points are noticed at larvae 12 and $36 \mathrm{~mm}$ in total length, respectively. The regression coefficient till $12 \mathrm{~mm}$ is 1.468 (positive allometry) and after this length the value is reduced to 0.839 (negative allometry). A further reduction becomes apparent in the relative growth coefficient after $36 \mathrm{~mm}$ in total length showing strong negative allometry (0.126). The epidermal thickness of the snout skin between the upper lip and the nasal flap does not seem to increase considerably.

Height of columnar cells of intestine (Figs. 40, $41 \mathrm{~B}$ ). The height of the columnar cells from the first part of intestine appears to be irregularly increasing in the early stages but becomes constant only after $12 \mathrm{~mm}$ in total length showing negative allometry (0.290).

Height of taste buds from buccal cavity, pharyngeal cavity, and first gill arch (Figs. $40 ; 41 \mathrm{C}, \mathrm{D}$ ). An inflection point is marked in the growth of the height of taste buds either from the roof of the buccal cavity or the pharyngeal cavity showing relative growth coefficients of 1.242 and 0.99 in $9.8 \mathrm{~mm}$ and $10.6 \mathrm{~mm}$ larvae, respectively, and after these lengths they become constant showing negative allometry $(0.170$ and 0.183$)$. However, the height of the buds of pharynx remains slightly greater than that of those of the buccal cavity (Fig. 
$41 \mathrm{C}$ ), but in the first phase of growth they appear to be almost similar. On the other hand the height of buds from the gill arches changes at $8.6 \mathrm{~mm}$ with a value of 1.429 (positive allometry) and after this length it becomes constant showing a value of 0.259 (negative allometry).

From the study of the growth of organs and tissues related to length, it has been found that they usually show different growth coefficient values during the growth of carp. An inflection point is marked at an average standard length of $21.4 \mathrm{~mm}(17-24 \mathrm{~mm})$ in the case of snout, head, eye, mouth, opercular opening, body depth, caudal peduncle, snout-insertion of dorsal fin, and pharyngeal arch. Another inflection point is noted at an average standard length of $10.3 \mathrm{~mm}$ (9.5-10.6 $\mathrm{mm})$ in the case of gill arch, length and a number of lamellae. The height of the taste buds of the buccal cavity, phayngeal cavity, and gill arch show similar inflection points at an average total length of $9.8 \mathrm{~mm}(8.5-10.6 \mathrm{~mm})$. The length of the intestine and the thickness of the head skin show two inflection points, the former one at $9.5 \mathrm{~mm}$ and $22.5 \mathrm{~mm}$ in standard length, and the latter one at $11 \mathrm{~mm}$ and $36 \mathrm{~mm}$ in total length, respectively._ All the organs and tissues except the intestine in their first phase of growth show positive allometry and in the second phase isometry or negative allometry (Figs. 38,40 ). By $20-25 \mathrm{~mm}$ the protrusibility of the mouth is quite prominent (Fig. $21 \mathrm{E}$ ), which might affect the growth of the snout and hence, an, inflection point is marked at $24 \mathrm{~mm}$ with isometry. The mouth, opercular opening, and head length show a fall in the growth rate at $17-21 \mathrm{~mm}$ in standard length. Slow rate in the eye diameter is marked at $20 \mathrm{~mm}$ in standard length ; mandibular and maxillary barbels are visible at 18.5 and $22 \mathrm{~mm}$ in total length, respectively, with their taste buds being first observed at $22 \mathrm{~mm}$ in total length. These may be related to the change of feeding habits of the carp at this stage.

\section{Discussions and conclusions}

A characteristic feature of the spawning ground for carp is the presence of bushes or vegetations, and the same in the spawning pond was successfully simulated by long hyzex ribbons. The shallowness was maintained by keeping the water level at nearly $65 \mathrm{~cm}$. This suggests that anything like grasses or weeds, dense or scattered is essential for stimulating the spawning activities and attachment of spawned eggs. Different investigators have marked different optimal temperatures (i. e., $18-26^{\circ} \mathrm{C}$ ) for spawning of the carp and as per our observation of the same in confined water the optimal temperature is 
noticed to be $22-24^{\circ} \mathrm{C}$. Swee and McCrimmon (1966) stated that the spawning of the carp ceased at $28^{\circ} \mathrm{C}$, whereas we found that the spawning started at $28^{\circ} \mathrm{C}$ (Table 1 ).

The first sign of the formation of epidermal stratum (i. e., the fore runner of the ectoderm) in the carp is marked before morula stage when the blastodisc is 3-4 cells deep through the centre (Fig. 5 E) but Edward (1929) did not mark it before the blastula. The appearance of the oral valve or maxillary valve in the embryonic stage of the carp is interesting (Fig. $5 \mathrm{U}$ ). This structure, from the bottom-feeding fishes, has been described by many researchers, but its stage of development has not been pointed out before.

In a hatching embryo we see that all the necessary structures are developed to such an extent as to produce a self-supporting, highly organized and well-coordinated individual organism ; and major changes which occur after hatching involve further differentiation of tissues, growth of organs and change of proportion of parts, etc.

Certain differences in the stages of appearances or formations and differentiations of tissues and organs, i. e., pancreatic tissues, gall bladder, spleen, etc., have been marked from the previous workers which may safely be correlated with environmental factors and races of carp in different locations.

Alikunhi (1953) found that the Indian carp fry fed avidly on zooplankton one hour after hatching ; Klust (1939) and Swee and McCrimmon (1966) stated that the carp sac-fry had ingested both zoo- and phytoplankton. The present evidences on the nature and time of food taking are consonant with the latter ones but differ from the former one, as the sac-fry were found to take algae in our experimental ponds 24-32 hours after hatching and not one hour after hatching.

In the study of relative growth it has been found that gill arch length and number of gill lamellae appear to be related to each other as inflection points on the growth curve are indicated (Figs. 38, 39 L-N) and seem to be affected by the developmental stages of the carp. By 9.5-10.6 $\mathrm{mm}$ in total length the larvae pass into the post-larval stage. It is interesting to note that the inflection point of the height of taste buds on the gill arches at nearly the same stage (Figs. 40, $41 \mathrm{D}$ ). Though the number of the lamellae at first show apparent positive allometry, it suddenly sinks to negative allometry after $9.5 \mathrm{~mm}$ (Figs. $38,39 \mathrm{~N})$.

Two inflection points at 9.5 and $22.5 \mathrm{~mm}$ on the intestinal growth curve (Figs. 38, $39 \mathrm{~J}$ ) mark the stages when the right arm of the intestine rises above as a beginning for loop formation and the establishment of the three double loops, respectively (Table 13). By 9-10 $\mathrm{mm}$ in standard length all the fins have been evidenced. Bifurcation 
of the caudal fin is also marked. The three phases of the intestinal growth correspond with the larval, post-larval (juvenile), and youngadult stages, respectively. Further, the first inflection point marks the time when the carp is strongly carnivorous and the second one indicates tho omnivorous one. The thickness of the head skin showing inflection $\mathrm{po}_{\perp_{-}}$ts at $11 \mathrm{~mm}$ and $36 \mathrm{~mm}$ in total length (Figs. 40, $41 \mathrm{~A}$ ) appears to be affected by the integumental changes. Club cells were first marked at 11-12 $\mathrm{mm}$ in total length between the upper lip and the nasal cavity and the cytoplasmic extensions on the head skin disappear by this time. The scaling which began at $17-18 \mathrm{~mm}$ becomes completed by $24-30 \mathrm{~mm}$, which nearly coincides with the second inflection point. The height of taste buds as mentioned before show inflection points at $8.6-10.6 \mathrm{~mm}$ (Figs. $40,41 \mathrm{C}, \mathrm{D}$ ), which roughly agree with the period of rapid growth and differentiation of tissues and organs. The hepato-pancreas takes the young form by $10.6 \mathrm{~mm}$ (Fig. $13 \mathrm{~N}, \mathrm{P})$. The spleen becomes to be surrounded by the hepato-pancreatic mass by $11-12 \mathrm{~mm}$.

The taste buds appear first on the head skin at about $18 \mathrm{~mm}$ in total length and this is the stage when microscopic buds of the mandibular barbels are noticed; other parts were not investigated. There are large or giant cells with 3-16 nuclei distributed among the ordinary club cells (Fig. $16 \mathrm{E}$ ) and their function is unknown. No report is available on such giant cells from the head skin. A row of elongated cells below the basement membrane separated by collagenous fibres is marked and such arrangement of cells was not reported before from the sikn of the teleost (Fig. 16 F. G). Large secretory cells distributed along the ventral and ventro-lateral sides of the head are significant as they seem to help in fixation to the substratum (Figs. 5X, 16 A, B). Such cells have not been recorded before so far as our knowledge is concerned. They may be correlated with the cement gland (Nikolsky, 1962).

Miyadi et al (1963) marked the maxillary and mandibular barbels at 22 and $25 \mathrm{~mm}$ in total length but did not mention the time of occurrence of gustatory organs on them. In the present investigation the mandibular barbels first appeared as microscopic bud-like protuberances at $18.5 \mathrm{~mm}$ (Fig. $18 \mathrm{~A}$ ) and the maxillary ones at $22 \mathrm{~mm}$ in total length, and the taste buds were first marked on the mandibular barbels at this time. Three types of apices of taste buds from the barbels of the carp, i. e., protruded, truncated, and depressed ones, have been observed, the former two agree with the findings of Hirata (1966). It is interesting to point out that the same three types of apices of the taste buds are also recorded from the nasal flaps. Thus the nasal flaps may be called distant receptors and they appear 
to play at least a small part in search of food even though it may not be the reaction of seizing them. Further, this fish carries taste organs on the caudal fins, opercle and even the conjunctiva of the eye (Fig. 20 C) which may he attributed to its wide adaptability to various environment.

The changes in the mouth aperture have been marked from the developmental stand point (Fig. 21) and may be accounted for depending upon their change of food habits; thus it becomes necessary to take special care in supplying the rearing pond with necessary food at different stages. The manner of arrangement of the folds or ridges with papillae, the concavity of the roof, and elevation or convexity of the floor of the buccal cavity give a clear idea of there fitting into one another during the feeding process. It may be mentioned that the epithelia of the lips are studded with dense taste organs (Table 6), which aim at searching and selecting the food materials, but there are no mucous cells, whose function is lubrication which is only required after the food is in the mouth and swallowing has commenced. Further, it will not be out of place to point out that the presence of well developed papillae on the bucco-pharyngeal linings (Fig. 23) and the low ridges on the lips (Fig. 22) appear to be an adaptation to the bottom feeding habits.

It has been recognized that pointed and recurved teeth are the characteristics of the carnivores and flattened crowns with grooves are the adaptations for the herbivores. The appearance of the first flattening of the crown is slightly marked at about $17.3 \mathrm{~mm}$ (Fig. 24E) and with its gradual increase, the formation of grooves or furrows is evidently seen in about $28 \mathrm{~mm}$ carp (Fig. $24 \mathrm{~F}$ ). Thus a gradual adaptation of teeth from the carnivorous to the omnivorous (or rather herbivorous) type of feeding is seen. In the graph (Figs. 38, 39K) the change of the growth rate in the length of the pharyngeal arch occurs at $24 \mathrm{~mm}$ in standard length, and this is more or less the stage at which (i.e., $28 \mathrm{~mm}$ in total length), according to the present observation, $A$, or the last tooth of the first row becomes degenerate and small grooves are formed apparently on $A_{3}, A$, and $B$ (second row). In the larval and early young stages the number of teeth on either arch is not the same ; it varies between $7-8$, thereby indicating a bilateral asymmetry. The number of teeth in the advanced stage is always fixed to be $3: 1: 1$ or occasionally $3: 2: 1$. However, Al-Hussaini (1949) stated that ths teeth in the mirror carp are $2: 1: 1$ and their rows are not sharply defined as in the common carp $(3: 1: 1)$.

The horny pad is palpated as a soft structure by $13.1 \mathrm{~mm}$ in total length and as apparent hardness by $27-30 \mathrm{~mm}$ indicating its thickness, which may be correlated with its herbivorous nature. An interesting 
fact revealed in this study is the finding of taste buds in the horny pad which hitherto have not been reported from the teleosts. Thus the pad may be considered not only masticatory but to a certain extent gustatory, too.

In ascertaining the concluding remarks obtained on the various aspects of life history, it can be safely stated that the carp is highly prolific and it can be induced to spawn naturally in a rearing pond. Rate of fertility is fairly high. Gill slits, liver, anlage of the air bladder and pectoral fins are formed in the embryonic stage. The gut is functional, the blood vessels are well spread as a device in a less favourable condition and the large secretory cells are formed for attachment to an object in a newly hatched larva. The yolk is absorbed by $8 \mathrm{~mm}$ and the larva pass es a free life. In the larval stage all the fins are formed, which is needed for active swimming habit. The hepato-pancreas, spleen end gall bladder are formed. The ventral mouth is shifted to the anterior end. Intestinal loop begins. The larva becomes prominently carnivorous. Scales cover the whole body at 24$30 \mathrm{~mm}$ and by this time the adult type of intestinal looping is designed. Barbels are completely formed. The intesine increases and becomes complicatedly coiling. Food habit changes to an omnivorous one showing a close relation between this adaptive habit and the extensively developed intestine when compared with the carnivorous feeding larva. Stomach is absent but the anterior swollen part functions as a storage of food and consists of higher network folds and columnar cells than the posterior one. The pharyngeal teeth change from the larval curved and serrated type suited for carnivores to the crushing and molar type suited for herbivores. They act against the hard horny pad innervated by taste buds. In absence of buccal teeth, horny denticles born on the epithelium add efficiency for holding the food substances. The lips are thickened and slightly ridged containing dense taste organs which extend till the oesophagus. Mucous cells are abundant in the buccopharyngeal cavity and in the rectal region, the presence of which help in facile passing of bolus and faecal matter and is also suited for voracious eater like the carp. The taste buds spread until the gill lamellae, the barbels, skin, fins, and even the conjunctiva of the eye which mark its wide adaptibility. The mortality is considerably low and the carp is strong enough to cope with wide range of temperature variation from $4^{\circ} \mathrm{C}$ to $30^{\circ} \mathrm{C}$. The study of relative growth reveals that all the organs studied (Figs. 38, 39) in their first phase of growth by $9.5-10.6 \mathrm{~mm}$ show positive allometry and in the second phase by 17 $24 \mathrm{~mm}$ isometry or negative allometry, which correlate the changes of structure growth and feeding habit from larva to young The weight by $300-330 \mathrm{~mm}$ carp of two and a half years is increased to the marketable value of about $1 \mathrm{~kg}$. These appear to be the inferred bio- 
logical properties which enable the carp to be adaptationally well balanced at each stage of growth, possessing the innate potentialities to meet an environment ; such properties are much desired for the culture and propagation methods of a fish,

\section{Summary}

The main object of the present investigations was to work out on the problems in relation to the culture and the propagation of the carp. From this point of view a detailed study of the spawning behaviour, embryology, larval growth, digestive system, and other organs of the carp reared in the experimental pond of Fisheries Laboratory, Kyushu University, was made on the basis of microscopic preparations. The following distinctive remarks would be noteworthy.

1. The carp spawns on vegetations or like substances at an optimum water temperature of $22-24^{\circ} \mathrm{C}$ for nearly 6 hours at any time of the day, but usually at dawn from April to July at short and irregular intervals. During the spawning act the male nudges the female from behind and approximates the genital part, lying almost parallel to her side. Both lash the caudal region forcibly, discharging simultaneously the ova and milt, and then separate after swimming together for about $30-50 \mathrm{~cm}$. The total number of eggs in a spawning female, $590 \mathrm{~mm}$ in total length and $4.9 \mathrm{~kg}$ in weight, is nearly 765,000 , which is a considerably a high number for the production of fry.

2. In the embryonic and the larval stages, the blood vessels form a network on the yolk sac and fin folds, and are representations of well developed respiratory devices as an adaptation to less favourable conditions.

Large secretory cells are marked around the head and the yolk sac of the embryo and the larvae, and last till the yolk absorption. These seem to aid the larvae in sticking to the substratum, which is a natural device of safety against driftng by the current of stagnant water.

The first sign of the rudiment of the gut is marked as an endodermal thickening by about 40 hours after fertlization, which assumes a cylindrical form of double layered cells by 70 hours (18 hours before hatching). By 78 hours after hatching a lumen is formed by the retreat of cells rather than the evagination as in other vertebrates (Fig. $5 \mathrm{P}, \mathrm{R}, \mathrm{S}, \mathrm{T}$ ). The mouth is formed at about $8-10$ hours before hatching (Fig. $5 \mathrm{U}, \mathrm{V}$ ). The liver is formed on the latero-ventral sides of the gut (Fig. 5 T). Pharyngeal folds are marked at 41-45 hours after fertilization as two dorso-lateral endodermal outgrowths which 
proceed to meet an inwardly pushed layer of ectoderm to form gill slits by 56-57 hours after fertilzation (Fig. 5 Q).

Pectoral fins begin their formation at about 55 hours after fertilization and the median fin fold is prominently visible by 70 hours.

3. The period of incubation varies with the temperature (Table 2) and at $13-17^{\circ} \mathrm{C}$ the larvae hatch in 90 hours after incubation and measure 3.9-5.6 mm. Hatching is completed wthin 2.5-3.5 days. The yolk sac is completely absorbed in $8 \mathrm{~mm}$. All the fins are marked in 10 $\mathrm{mm}$. The posterior end of the notochord is begining to turn upward in 7.5-7.7 $\mathrm{mm}$ larvae. The heterocercal caudal fin starts its formation at 7.5-7.7 mm. Hypurals number 7 (Fig. 10). Scales first appear behind the opercle at 17-18 $\mathrm{mm}$, and cover the entire body surface of the carp by 24-30 $\mathrm{mm}$. Young carp of this length resembles the adult in appearance (Figs. 6, 13).

Liver cells start arranging themselves into lobular forms in $4.2 \mathrm{~mm}$ larva within 10 hours after hatching. The pancreas is differentiated along the left dorsal side of the intestine as a deeply stained mass of cells among the liver cells by $5.3 \mathrm{~mm}$ larva. The gall bladder is marked at this stage (Fig. $7 \mathrm{~F}, \mathrm{H}$ ). The hepato-pancreas assumes the young form by $9.6-10.5 \mathrm{~mm}$.

The anlage of the air bladder is marked a few hours before hatching (Fig. $5 \mathrm{~W}$ ) and becomes to be filled with air by $6 \mathrm{~mm}$ (Fig. $7 \mathrm{G}$ ) and pushes the first part of intestine. The anterior one is formed in about $10 \mathrm{~mm}$ larva. The newly hatched larva begins its active life after the absorption of yolk (i. e., 7-8 mm larva). Active preying habit on the zooplankton is quite prominent by this stage. Schooling behaviour, though, beginning at $9.5 \mathrm{~mm}$, at this stage or even after is not so significant. They start feeding $24-36$ hours after hatching. The juvenile and the young prefer to eat at short intervals, which seems to be advantageous for the absence of stomach. The power of discriminating eatable substances appears to be intense. Weberian ossicles are marked by $10.6 \mathrm{~mm}$ joining the ear bones anteriorly and the air bladder posteriorly. The longitudinal grooves and fenestrations are formed by 17-18 mm (Fig. 11).

4. The club cells appear at about $12 \mathrm{~mm}$ larva on the head skin between the upper lip and the nasal cavity and occasionally multinucleate giant cells are marked more along the dorsal side of the head than the ventral one (Fig. $16 \mathrm{E}$ ). By $6 \mathrm{~mm}$ the dorsal skin of the head shows wrinkles which are the cytoplasmic extensions of the cells. They seem to disappear at $12-13 \mathrm{~mm}$, which is the time of the appearance of club cells at that position. Taste buds first appear on the head skin (between the upper lip and the nasal cavity) at $18 \mathrm{~mm}$. Occasionally, promucous cells like those of the buccal epithelium are observed 
from the head skin epithelium. A girdle of elongated cells intercepted by collagenous fibres hanging down into the dermis from the basement membrane is observed : this has not been reportd before (Fig. $16 \mathrm{~F}$, G).

Mandibular barbels first appear at $18.5 \mathrm{~mm}$ in total length and measure about $217 \mu$, while the maxlilary ones are noticed at $22 \mathrm{~mm}$ which is the stage of the appearance of the taste buds on the barbels. Mucous cells and club cells are evidenced abundantly in the proximal or post-proximal regions of the barbels.

The epidermis enveloping the anterior side of the nasal flaps is thicker than that of the posterior one. Taste buds are marked from the distal anterior end. Club cells are absent from the middle and the distal region of the flaps (Fig. 19 A-D). The outer epidermis of the operculum appears to be thicker than the inner one and a few taste buds are noted from the outer side only. Conjunctiva of the eye and the caudal fin also possess taste organs in their epidermis (Fig. 20 AF). Their presence on all these organs are suggestive of their wide adaptability to environments.

5. Lips of the young and the adult are provided with low ridges and shallow furrows (Fig. 22) which appear to be helpful during the feeding activity from the bottom. Horny type of dentitions resting upon the membranous structure are marked on the inner posterior side of the lips of the larvae, juveniles and the young ones; these may help in holding the food materials (Fig. $27 \mathrm{C}, \mathrm{D}$ ).

The maxillary valve is marked with the opening of the mouth in the embryonic stage. It is a small, almost cresentic membranous structure hanging freely into the buccal cavity behind the upper lip. In 6.0-6.8 $\mathrm{mm}$ larvae the mucosa of the buccal cavity (roof) is marked to enter as a thin Iayer into the proximal of the maxillary valve. Mucous cells are greater and larger on the ventral sides of the valve than the dorsal one. One to 3 typical taste buds born on papillae are recorded only from the ventral surface of the valve, which come in direct touch with food substances (Fig. 27 C, E-G).

A few prominent papillary folds marked in the mouth cavity as early as $9-10 \mathrm{~mm}$ become regularly to be arranged by $15 \mathrm{~mm}$ in total length and 3-4 longitudinal folds are marked from the centre of the buccal cavity (roof). The roof is concave and the floor is slightly convex so as to fit nicely during the food taking. Papillae on the pharyngeal roof are more abundant than those of the buccal one and they decrease posteriorly; on the Aoor, they reach till the fourth gill arch (Fig. 23 A-F). Mucous cells are almost uniformly distributed in the buccal cavity. Promucous cells and club cells are occasionally marked (Fig. $27 \mathrm{M}$ ). Three types of taste buds are recognized from the epithelium 
of the cavity: buds with truncated, protruding, and depressed apices. Besides lymphocytes, vacuoles or oval cells are occasionally found towards the middle or distal ends of the buds (Fig. 29 E-J).

Five developmental stages of the mouth are marked (Fig. 21) in this study which are related to the change of feeding habits. Pharyngeal teeth are apparent in $6.8 \mathrm{~mm}$ in total length. In the larvae and the juveniles they are arranged asymmetrically in 3-4 rows totalling 7-8 on each arch. They are curved, serrated, and backwardly directed, which befits the carnivorous feeding habits. They hold the prey tightly and transfer them to the oesophageal cavity. The flatness on the crowns of teeth on the first and second row become apparent by 28 $\mathrm{mm}$ (Fig. $24 \mathrm{~F}$ ), and furrows are established by $45-50 \mathrm{~mm}$ in total length. This change of teeth formation is in correlation to the change of food habits from early carnivorous to the omnivorous one. The relative length and the width of the pharyngel arch appears to be greater (i.e., 3-4.26) till about $30 \mathrm{~mm}$ in total length after which it nearly becomes on an average of $2.87(2.2-3.46)$ by $45-50 \mathrm{~mm}$. The higher value is a characteristic of the carnivores and the lower one of the herbivores (Fig. 25).

The horny pad is biconvex and almost four cornered (Fig. $26 \mathrm{C}$ ). In the larval stage it is a soft structure but considerable hardness is felt by $28 \mathrm{~mm}$, this becoming quite apparent by $45-50 \mathrm{~mm}$ in total length. This appears to be in relation to the development of furrows or grooves on the crowns of the pharyngeal teeth. Hardness of the pad is correlated with more herbivorous habits than carnivorous ones. Well developed taste buds are recognized on the palatal organs and in the tissues of the pharyngeal teeth but the finding of the same in the middle layer of the horny pad seems to be of special significance in the gustatory sensitiveness during the act of feeding (Fig. 26 B, E).

Mucous cells are absent from the lips. These cells and the taste buds appear to be related to each other in their distribution in the pharyngeal and oesophageal cavities. The former increases posteriorly and the latter vice versa. The anterior part of the oesophagus is provided with more mucous cells and taste buds than the posterior one where mixed type of epithelium (oesophago-intestinal epithelium) is present. Taste buds in the oesophagus are marked in about $6.8 \mathrm{~mm}$ larva much later than the buccal cavity where immature buds are recognized at about 10-12 hours after hatching (Fig. 29 A). The function of the lip is essentially gustatory. hence, the taste organs. Once the food enters the buccal cavity its further passing posteriorly depends upon the slippery epithelium with simultanous food selection: hence both the mucous cells and taste buds. The same is true for pharynx and the oesophagus, too. The presence of gustatory organ in the 
oesophagus is an indication of the extreme delicacy of taste in accepting eatable substances by the carp.

The oesophageal mucosa are stratified like the pharynx and are thrown into longitudinal folds $6-8$ in number at $6.8 \mathrm{~mm}$ in total length In 200-300 $\mathrm{mm}$ carp about 24-27 folds are developed (Table 11). An oval thickening of unidentified character is marked at the oesophagointestinal junction but the exact function seems to be obscure.

6. Primary gill lamellae are observed as $2-3$ bud-like protuberances 15-16 hours after hatching on the first gill arch and the secondary gill lamellae are formed in 6.0-6.6 $\mathrm{mm}$ in total length (Fig. 30). The outer gill lamellae are larger in size than the inner ones which aid in covering the gill openings (Fig. $31 \mathrm{~L}$ ). The gill rakers are formed in $15-16 \mathrm{~mm}$ in total length (Figs. $30 \mathrm{H}, 31 \mathrm{E}$ ). The papillated gill rakers on the adjacent gill arches interdigitate with each other so closely over the narrow gill clefts as to form an accurate straining mechanism, which appears to be important for bottom feeding. The central cores of the joining ends of the epi- and cerato-branchials are cartilaginous, which help in the easy movement of the arches during respiration. Histologically, the arches, the rakers and the lamellae alike in their epithelial structures but differ in thickness. Typical taste buds like those of the arches and the rakers are noticed on the margins of the primary gill lamellae. A large number of rounded, oval, or elongated mucous cells are abundantly present on the gills, the secretion of which helps in entangling the food particles from surrounding water.

The intestinal folds are the continuations of the oesophageal ones ; they number about 8-13, and measure 25-42 $\mu$ in height in $6.8 \mathrm{~mm}$ larva. Network of the folds are formed in 20-24 $\mathrm{mm}$ larvae. Zigzag folds are also marked in 31-35 mm young carp. A double network of the folds are present in the large specimens and is higher and more complex in the first part of the intestine than the rest. Anal folds are always longitudinal like the oesophageal ones (Fig. 33).

7. The structure of the carp intestine is similar to that of other cyprinids. The development of the intestinal coiling is divided into seven stages in this study (Table 13). The initial step in the coiling is first marked at about $10-12 \mathrm{~mm}$ and is completed by $28-30 \mathrm{~mm}$. The complication of the coiling seems to depend upon the length of the intestine. Long intestine is a characteristic of the herbivores and is marked by $29 \mathrm{~mm}$ in total length in the carp. The intestine may be histologically divided into three regions. The anterior swollen part consists of a more complicated network of folds than the middle one which is almost uniform in diameter. The height of the columnar cells in the anterior part is greater than the middle one. The anal part consists of longitudinal folds covered by stratified epithe- 
lium containing mucous cells like those of the pharynx (Fig. $37 \mathrm{H}$, $\mathrm{I}<, \mathrm{L}$ ). True stomach is absent but the anterior swollen part may be regarded as a receptacle for storing the food. In the epithelium 4 or 5 types of cells are identified : mucous cells, wandering cells or lymphocytes, granular cells, pear-shaped cells, and certain unidentified large secretory cells. Mucous cells form stratification like those of the pharynx in the rectal region, while they are few in other parts of the intestine.

8. Inflection points of regression lines in the relative growth of snout length, head length, eye diameter, opercular opening, body depth, caudal peduncle height, snout-insertion of the dorsal fin length, pectoral fin length, intestine length, and pharyngeal arch length at 20-24 $\mathrm{mm}$ in standard length (Figs. 38, 39) are marked. The gill arch length, the large primary gill length, and the number or gill filaments on the first left gill arch show an inflection point on the growth curve at $9.5-10.5 \mathrm{~mm}$ which correlate with the differentiation and growth of tissues and organs i. e., hepato-pancreas, spleen, taste buds in the buc. cal cavity, pharynx, and the gill arch. The growth line of the intestine is represented by two inflection points which correspond with the coiling of the alimentary canal, the change of food habits and the developmental stages of the larva, post-larva and juvenile, young, and adult.

The epidermal thickness of the head skin (between the upper lip and the nasal cavity) shows two inflection points at 11 and $36 \mathrm{~mm}$ in total length, which appear to be related to the disappearance of the cytoplasmic extentions of the superficial cells and the appearance of the club cells in the epidermis in $12 \mathrm{~mm}$ in total length. The height of taste buds from the roof of the buccal cavity and pharynx to gill arch shows inflection ponits at $8.6-10.6 \mathrm{~mm}$ in total length and the same of the latter one is higher than the former ones. The coefficient of the weight-length is calculated to be 3.049 (Fig. 38). The growth of the organs or tissues may conclusively be represented by two inflection points (Figs. 38. 40) which are found to correlate with the transition period of food, developmental stages (larva, juvenile, young and adult) and other histological and morphological changes discussed.

\section{References}

Agassiz, A. and C. 0. Whiteman. 1881. On the development of some pelagic fish eggs. Proc. Amer. Acad. Art and Sci., 20.

Ahmed, N. 1944. The spawning habits and early stages in the development of the carp, Labeogonius (Ham.) with hints for distinguishing eggs, embryos and larvae of Labeo gonius, Cirrhina mrigala and Wallagonia attu. Proc. Nat. Inst. 
Sci. India, $10: 343-354$.

Al-Hussaini, A. H. 1946. The anatomy and histology of the alimentary canal of the bottom-feeder, Mulloides auriflamma (Forsk.). J. Morph., 78: 121-153.

- 1947. The anatomy and histology of the alimentary tract of the planktonfeeder, Atherina forskali (Rupp.). J. Morph., 80 : 251-286.

- 1947. The feeding habits and the morphology of the alimentary tract of some teleosts living in the neighbourhood of the Marine Biological Station, Ghardaqa (Red Sea). Pub. Mar. Biol. St., Ghardaqa, 5 : 1-61.

- 1949. On the functional morphology of the alimentary tract of some fish in relation to differences in their feeding habits : Cytology and Physiology. Quar. J. M. Sci., $90: 323-354$.

Alikunhi, K. F. 1958. Observations on feeding habits of young carp fry. Indian J. Fish., 5 : 65-106.

Amaoka, K. 1964. Development and growth of the sinistral flounder, Bothusmyriaster (T. \& S.) found in the Indian and Pacific Oceans. Bull. Misaki Marine Biol. Inst. Kyoto Univ., No. 5 : 11-19.

Andrew, W. 1959. Text book of comparative histology. Oxford Univ. Press, New York.

Atton, F. M. 1959. The invasion of Manitoba and Saskatchewan by carp. Trans. Amer. Fish. Soc., 88 : 203-205.

Babkin, B. P. and D. J. Bowie. 1928. The digestive system and its functions in Fundulus heteroclitus. Biol. Bull., 54 : 254-278.

Baecker, R. 1926. Beitrlge zur Histologie der Barteln der Fische.Zs. Micr.-anat. Forsch., 1: 489-507.

Baker, J. R. 1942. The free border of the intestinal epithelial cells of vertebrates. Quart. J. Micr. Sci., 84: 73.

Balfour, F. M. 1885. Comparative embryology. London.

Barrington, E. J. W. 1957. The alimentary canal and digestion. The physiology of fishes, vol.1 : 109-161, Acad. Inc. Pub., N. Y.

Bartlett, S. P. 1901. Discussion on carp. Trans. Amer. Fish. Soc. 30 : 114-132.

Bateson, W. 1890. The sense organs and perception of fishes with remarks on the supply of baits. J. Mar. Biol. Ass. London, 1 : 225-256.

Beamish, F. W. H. 1964. Respiration in fishes with special emphasis on standard oxygen consumption. Canad. J. Zool., 42 : 177-188.

Belogurov, A. 1940. Succession of pharyngeal teeth in the wild carp, Cyprinus carpio L. C. R. Acad. Sci. USSR, Moscow, 29 : 155-159.

Berg, L. S. 1964. Freshwater fishes of the USSR and adjacent countries. Vol. 2 Israel Program for Scientific Translation, Jerusalem.

Berner, L. M. 1948. The intestinal convolution. New generic characters for the separation of Carpiodes and Zctiobus. Copeia, No. 2 : 140.

Bevelander, G. 1935. A comparative study of the branchial epithelium in the fishes with special reference to extrarenal excretion. J. Morph., 57: 335-351.

—. 1946. Secretory cells in the branchial epithelium of fishes. Biol. Bull., 91 : 230-231.

Bhatti, I. H. 1930. The integument and dermal skeleton of Siiuroidea. Trans. Zool. Soc., 24.

Bijtel, J. H. 1947. The mechanism of movement of the gill filaments in Teleostei. Experimentia, $15: 158-160$. 
Bijtel, J. H.. 1949. The structure and mechanism of movements of the gill filaments in Teleostei. Arch. Neer. Zool., 8 : 267-288.

Bishop, C. and Ph. H. Odonese, 1966. Morphology of the digestive tract of the cod, Gadus morhua. J. Fish. Res. Bd. Can., 23 : 1607-1640.

Blake, I. H. 1930. Studies on the comparative histology of the digestive tube of certain teleost fishes-I. A predaceous fish, the sea bass (Centropristes striatus). J. Morph., 50: 39-70.

- 1936. Studies on the comparative histology of the digestive tube of certain teleost fishes-III. A bottom feeding fish, the robin (Prionotus carolinus). J. Morph., 60 : 77-107.

Bolton, L. L. 1940. Basophil (mast) cells in the alimentary canal of salmonoid fishes. J. Morph., 54: 549-582.

Breder, C. M. Jr. and D. E. Rosen. 1966. Modes of reproduction in fishes. American Museum of Natural History.

Byczkowska-smyk, W. 1961. Development of the respiratory surface in the gills of rainbow trout (Salmo irideus). Acta Biol. Cracov. Zool., 4 : 89-109.

Chaudhry, H. S. and 0. P. Khandewall. 1961. The anatomy and histology of the alimentary tract of $\mathbf{O}$ reinus plagiostomus (Haek). Annot. Zool. Jap., 34 : 139152.

Chitray, B. B. and D. B. Saxena. 1962. Functional anatomy of the digestive tube of freshwater fishes of India: Heteropneustes fossilis (Block) and Clarias batrachus (L.). Acta Soc. Zool. Bohm., 26 : 148159.

Chu, Y. T. 1935. Comparative stueies on the scales and on the pharyngeals and' their teeth in Chinese cyprinids with particular reference to taxonomy and evolution. Biol. Bull. St. Johns. Univ., 2: 1-225.

Clark, E. and J. M. Moulton. 1949. Emryological notes on Menidia. Copeia, No. $2: 153-154$.

Clark, F. M. 1934. Maturity of the California sardine (Sardinia caerulea) determined by ova diameter measurements. Calif. Fish and Game Comm., Fish Bull., $42: 48$.

Copeland, D. E. 1949. The cytological basis of chloride transfer in the gills of Fundulus heteroclitus. J. Morph., 82 : 201-227.

Crozier, W. J. and S. Hetcht. 1913. Correlations of weight, length and other body measurements in the Weak fish, Cynascion negalis. Bull. Bur. Fish., 33 : 141-147.

Cunningham, J. T. 1885. The significance of Kupffer's vesicle, with remarks on other questions of vertebrate morphology. Quart. J. Micr. Sci., 35.

Curry, E. 1935. The histology of the digestive tract of the carp (Cyprinus carpio communis). J. Morph., $65: 53-78$.

Dahlgren, U. 1898. The maxillary and mandibular breathing valves of teleost fishes. Zool. Bull., 2: 117-124.

Dawes, D. 1929. The histology of the alimentary tract of the plaice (Pleuronectes platessa). Quart. J. Micr. Sci., $73: 243-274$.

Doan, K. H. 1939. Growth of bass fry. Copeia, No. 2: 81-87.

Eber1-Rothe, G. 1952. Über die Entwicklung der Darmscheimhaut der Karpfens. Zs. Micr.-anat.Forsch., 59 : 364-384.

Edmund, A. G. 1960. Tooth replacement phenomenon in the lower vertebrates. Tronto Roy. Ontario Mus., Life Sci. Div. Contr., 52: 1-190. 
Edwards, L. F. 1926. The protractile apparatus of the mouth of the cntastomid fishes. Anat. Rec., 33 : 257-270.

Edwards, L. F. 1929. The origin of the pharyngeal teeth of the carp (Cyprinus carpio L.). Ohio J. Sci., 29 : 93-130.

English, T. S. 1952. Growth studies of the carp, Cyprinus carpio L. in Clear Lake, Iowa. Iowa St. Coll. J. Sci., 24: 527-540.

Еремеева, Е.Ф. 1957. Роговы зубы молоби карцовых рыб и их приспобитъдъное значение на разных 3таnax развития. тр. Кн-Та Морф. Жнвотных. 16: 299313.

Evans, I-I. E. 1965. External morphology of the brain and lips in catastomid fishes. Copeia, No. $4: 467-487$.

-. and E. E. Deubler, Jr. 1955. Pharyngeal teeth replacement in Semotilus atromaculatus and Clinostonus elongatus. Copeia, No. 1: 41-71.

Evans, H. M. 1924. A contribution to the anatomy and physiology of the air bladder and Weberian ossicles in Cyprinidae. Proc. Roy. Soc. Lond., 97: 545-576.

Frank, S. 1965. A contribution to the knowledge of the pharyngeal filter of some fishes of sub-order Characinoidei and Cyprinoidei. ActaSoc. 2001. Bohem, 29 : 146-155.

- 1966. On the morphology of the pharyngeal filter of some species of the genus Brachydanio. Ichthyologia, May, 1966.

Freeman, A. J. 1966. Goblet cell fine structure. Anat. Rec., 154 : 121-148.

Fukusho, K. 1969. Notes on the intestinal convolution of the fishes of the Pomacentridae (Perciformes). Jpn. J. Ichthyol., $16: 135-142$.

Girgis, S. 1952. The bucco-pharyngeal feeding mechanism in an herbivorous bottom-feeding cyprinoid fish, Labeo horie (Cuv.). J. Morph., 90: 281-315.

-, 1952. On the anatomy and the histology of the alimentary tract of an herbivorous bottom-feeding cyprinoid fish, Labeo horie (Cuv.). J. Morph., 90 : 317 362.

Goodrich, E. S. 1930. The structure and development of vertebrates. MacMillan and Co., London.

Gopinath, K. 1946. Preliminary observations on the food of post-larval fishes. Proc. 33rd. Ind. Sci. Cong. Part III : 130-131.

Gray, J. E. 1954. Comparative study of the gill area of marine fishes. Biol. Bull., $107: 219-225$.

Greene, C. W. 1912. Anatomy and histology of the alimentary tract of the king salmon. Bull. U.S. Fish., 32: 73-100.

Gudger, E. W. 1946. Oral breathing valves in fishes. J. Morph., 29 :263-285.

Gulland, G. L. 1898. Minute structure of the digestive tract of the salmon and the changes which occur in it in fresh water. Anat.Anz., $14: 441-455$.

Hamaguchi, A. 1961. Morphological investigations in the carp, the funa and their hybrids. Hyogo Suisan Jigyo Hokoku : 121-341.

Hamai, I. 1934. Relation between weight, volume and linear dimension in Meretrix meretrix (L.). Sci. Rep. Tohoku Imp. Univ. Biol., 9 : 39-42.

- 1941. A study of the growth of the Cyprinus carpio L. Ibid., 16: 17-90.

Hammett, F. S. and D. W. Hammett. 1939. Proportional length growth of gar (Lepidosteus platyrhynchus De Kay). Growth, 3 : 197-209.

Henrichson, C. R. and G. A. Matolsty. 1968. The line structure of teleost epidermis. J. Ultra Res., 21 : 194-232. 
Herrick, C. J. 1901. The cranial nerves and cutaneous sense organs of North American siluroid fishes. J. Comp. Neur., 11 : 177-249.

- 1903. On the phylogeny and morphological postion of the terminal buds of fishes. J. Com. Neur., 13: 121-138.

- 1904. The organ and sense of taste in fishes. Bull. U. S. Fish. Comm., 22: 237-272.

Hetcht, S. 1916. Form and growth in fishes. J. Morph., 27 : 379-400.

Higurashi, T. and N. Nakai. 1925. Optimum water temperature for hatching the eggs of carp. J. Imp. Fish. Inst. Tokyo, 21 : 12-16.

Hikita, T. 1956. On the anatomy and development of carp in Hokkaido. Sci. Kept. Hokkaido Fish Hatchery, 11 : 65-95.

Hirata, Y. 1966. Fine structure of the terminal buds on the barbels of some fishes. Arch. Hist. Jap., 26: 507-523.

Hoagland, H. 1933. Specific nerve impulses from gustatory and tactile receptors in catfish. J. Gen. Physiol., 16 : 685-693.

Hoar, W. S. 1937. Development of the swim bladder in the Atlantic salmon. J. Morph., 61 : 309-319.

Hora, S. L. 1945. Symposium on the factors influencing the spawning of Indian carps. $11: 303-330$.

Hubbs, C. L. and L. C. Hubbs. 1945. Bilateral asymmetry and bilateral variation in fiishes. Pap. Mich.Acad. Sci., $30: 229-310$.

Hubbs, C. L. and S. C. Whitelock, 1929. Diverse types of young in a single species of fish, the gizzard shad. Pap. Mich.Acad. Sci., 10 : 461-482.

Humason, G. L. and C. C. Lusbaugh. 1960. Selective demonstration of elastin reticulum and collagen by silver, orcein and aniline blue. Stain. Tech., 35 : 209214.

Huxley, J. S. 1932. Problems of relative growth. Methuen, London.

- and G. Teissier, 1936. Terminology of relative growth. Nature, $137: 780$.

Inaba, D. 1965. Procedure of adhesivity removal in carp egg membrane. In Pisciculture: $548-549$.

- - and M. Nomura. 1956. On the digestive system and feeding habits of young Chinese carps in the River Tone. J. Tokyo Univ. Fish., $42: 17-25$.

Innes, W. T. 1936. The propagation of gold fish. The Aquarium, Philadelphia, 4 : 265-266.

Ishida, J. 1935. The stomach of Mugilcephalus and its digestive enzymes. Annot. 2001. Jap., 15 : 182-189.

Ishida, M. and M. Sato. 1960. The anatomical and histological observations of alimentary tract of a cat fish, Parasilurusasotus (L.). Sci. Rept. Hirosaki Univ., 7 : 57-63.

Itazawa, Y. 1963. The ossification sequences of the vertebral column in the carp and the snake-head fish. Bull. Jap. Soc. Sci. Fish., 29 : 667-674.

Iwai, T. 1962. Studie on the Plecoglossus altivelis problems : Embryology and histophysiology of digestive and osmoregulatory organs. Bull. Misaki Mar. Biol. Inst. Kyoto Univ., No. 2 : 1-101.

- 1963. Development of lateral line copulae in the gobioid fish, Tridentiger trigonocephalus (Gill). Ibid., No. 4 : I-20.

- 1964. A comparative study of the taste buds in gill rakers and gill arches of teleostean fishes. Ibid., No. 7: 19-34. 
Iwai, T. 1963. Notes on the pear-shaped cell (Rodlet cell) in the epithelium of the digestive tract of fishes. Ibid., No. $34: 133-337$.

- 1969. Fine structure of gut epithelial cells larval and juvenile carp during absorption of fat and protein. Arch. Hist. Jap., 30 : 183-199.

Jncobshagen, E. 1911. Untersuchungen über das Darmystem der Fische und Dipnoier. Jena Zeitschr., Naturw., 47 : 529-568.

Jakubowski, M. 1960. The structure and vascularization of the skin of the leather carp (Cyprinus carpio L. var. nuda) and flounder (Pleuronectes flesus Pall). Acta. Biol. Cracov., Zool., 3 : 112-139.

- 1963. The structure and vascularization of the skin of the river bullhead (Cottus gobio L.) and black sea turbot (Rhombus maeoticus). Ibid., 6 : 159-175.

Johnston, P. M. 1953. The embryonic development of the swim bladder of the large-mouth black bass, Micropterus salmoides salmoides (Lac.). J. Morph., 93 : 45-68.

Jurine, L. 1821. Note sur les dents la mastication des poissons applele Cyprinus. Mem. Soc. Phys. et D'hist. Nat. Geneve, $1: 19-24$.

Kaczmarski, F. 1966. Structure and vascularization of the skin of the ruff (Acerina cernua L.). Acta Biol. Cracov. Zool., $9: 165-175$.

Kafuku, T. 1958. Speciation in cyprinid fishes on the basis of intestinal differentiation with some references to that among catastomids. Bull. Freshwater Fish. Res. Lab., $8: 45-78$.

-. 1966. Morphological differences on the process of differentiaton of the two carp races. Ibid., $16: 71-82$.

Kann, S. 1926. Die Histologie der Fische von Biologischen gesichtspunkten Bentrachtel. 2001. Zellfors. Micro. Anat., 4 :482-500.

Kano, Y. 1949. On the periblast of Tribolodon hakunensis hakunensis (Gunther). 2001. Mag. Jap., 58 : 91.

Kapoor, B. G. 1953. The anatomy and the histology of the alimentary canal in relation to its feeding habits of a siluroid fish, Wallagoattu. J. Zool. Soc. India, $5: 191-210$.

—. 1956. Oral valves of teleosts. Jpn. J. Ichthyol., 5 : 127-131.

- - 1957. The callous pad of the pharyngeal masticatory apparatus in Indian carps. Ibid., $6: 26-30$.

- 1966. Histological observations on the skin of the head of a clupeoid fish, Gadusia chapra (Ham.). Ibid., 15 : 107-109.

Kato, G. 1932. On the sex ratio and growth of body in Carassius auratus and its variety, "Iron-fish". Sci. Kept. Tohoku Imp. Univ. Biol., 7 :365-381.

Kato, K. 1935. On the intestinal epithelium of Nomeus gronovii. Annot.Zool.Jap., $15: 190-193$.

Kearney, H. L. 1914. On the relative growth of the organs and parts of the embryonic and young dogfish (Mustelus canis). Anat. Rec., 8 : Y-297.

Keys, A. and E. N. Wilmer. 1932. Chloride secreting cells in the gill of fishes with special references to the common eel. J. Physiol., $76: 368-378$.

Khan, H. 1924. Observations on the breeding habits of some freshwater fishes in the Punjab. J. Bombay Nat. Hist. Soc., 29 : 958-962.

Kilraski, W. 1960. Fat in some teleost fishes. Acta Biol. Cracov., Zool., $3: 23-57$. Klust, G. 1934. Der Dam Karpfen. Fisch. Zeit. Neudamm. 37.

- 1940. Über Entwichlung Bau und Funktion des Darmis beim Karpfen (Cyp- 
rinus carpio L.). Internat. Rev. Gest. Hydrobiol. Hydrogra., 39 : 498-536, 40 : 88-173.

Konishi, J. 1961. Taste function in the carp. An electrophysiological study on gustatory fiberes. Acta Physiol Scand., 52 : 150-161.

Konishi, J., M. Uchida and Y. Mori. 1966. Gustatory fibres in the sea cat. Jap. J. Physiol., 16 : 194-204.

- and Y. Zotterman. 1961. Function of the taste fibres in the carp. Nature, $191: 286-287$.

Kraats, W. C. 1924. The intestine of the minnow Campostomn anomalum (Rafi) with special reference to the development of its coiling. Ohio J. Sci., 24: 265298.

Krumholz, L. A. 1943. A comparative study of the Weberian ossicles in North American ostariophysine fishes. Copeia, No. $1: 33-40$.

Kubota, S. 1961. Studies on the ecology, growth and meta-morphosis in conger eel, Conger myriaster (Brev.). J. Fac. Fish. Pref. Univ. Mie, 5 : 190-370.

Kubota, S. and T. Iwai. 1954. Taste buds found in the gills of some fishes. Zool. Mag., $63: 125$.

Kuntz, A. and Radcliffe. 1917. Notes on the embryology and larval development of twelve teleostean fishes. Bull. Bur. Fish., 35 : 89-134.

Kuroki, E. 1939. Carps (Cyprinus carpio L.) and crucians (Carassius auratus L.) from the lakes of Aoki, Nakatuna and Kizaki, Nagano Prefecture, Bull. Jap. Soc. Sci., 8 : 69-77.

Lagler, K. F., J. E. Bardach and R. R. Miller. 1962. Ichthyology. John Willey and Sons, Inc., New York.

Lahiri, S. B. 1968. Histological re-examination of the barbels of a cat fish, Wallago attu. Copeia, No. 1 : 185-187.

Landacre, F. L. 1907. On the place of origin and method of distribution of taste buds in Ameiurus melas. J. Comp. Neur. Psychol., 17 : 1-66.

Laventer, H. and Z. Perah. 1966. Preliminary observations on late spawning of carp. Bamideg, 18: 31-36.

Leydig, F. 1851. U̇ber die Haut einiger Süsswasserfisch. Z. Wiss. Zool., 3 : 1-12.

Liem, F. K. 1967. Functional morphology of the integumentary, respiratory and digestive system of the synbranchoid fish, M onopterus albus. Copeia, No. 2 : 375-388.

Mahen, E. F. and W. S. Hoar. 1956. The early development of chum salmon, Oncorhynchus keta (Walbaum). J. Morph., 98: 1-24.

Makino, S. 1939. The chromosomes of the carp, Cyprinus carpio L. including those of some related species of Cyprinidae for comparison. Cytologia, 9 : 430-440.

- 1940. A karyological study of gold fish of Japan. Cytologia, 12.

--, Y. Ozima and Y. Matsui. 1955. Some cytological features of sterility in the carp funa hybrids. Annot. Zool. Jap., 28.

Martin, N. V. and F. K. Sandercock, 1967. Pyloric caeca and gill raker development in lake trout, Salvelinusnamaycush in Algonquin Park, Ontario. J. Fish. Res. Bd. Canada, 24 : 965-974.

Matsubara, K. 1935. Studies on the scorpionoid fishes of Japan, II. Statistical observation on Sebastodes inermes (C. \& V.). Bull. Jap.Soc. Sci. Fish., 4 : 217 223. 
Matui, I. 1938. The relation between the length, weight and age in Cyprinidae. 2001. Mag, $50: 184-185$.

Matui, Y. and M. Yamaguchi. 1955. On the relation growth of the unsegmental characters in three varieties of Carassius carassius (L.). Med. Biol., 36 : 169173.

May, R. M. 1925. The relation of the nerves to degenerating and regenerating taste buds. J. Exp. Zool., 42 : 371-410.

MacVay, J. A. and H. W. Kaan. 1940. The digestive tract of Carassius auratus. Biol. Bull., $78: 53-67$.

McCrimmon, H. R. 1968. Carp in Canada. Bull. Fish. Res. Bd. Canada, 165.

MacEwen, R. S. 1940. The early development of the swim bladder and certain adjacent parts in Hemichromis bimaculatus. J. Morph., $67: 1-57$.

Meng, F. 1924. Beiträge zur Kenntnis der Morphologie des Barten einiger Fische. 2001. Zahr., $14: 149-159$.

Mitchel, E. G. 1904. Oral breathing of teleosts, their modifications and relation to the shape of the mouth. Amer. Nat., 38: 153-164.

Miyadi, D. 1929. Notes on the skin and cutaneous sense organs of some cobitoid and gasterosteid fishes with special reference to the rudimentary nature of the lateral canal. Mem. Coll. Sci. Kyoto Univ., 4 : 81-96.

Miyadi, D., et al. 1963. Coloured illustrations of the freshwater fishes of Japan. Hoikusha, Osaka, Japan.

Mookerjee, H. K. 1951. Modification of the facial structures in the major carps of India in relation to their feeding habits. Anz. $98: 6-9$.

Mookerjee, H. K. and Ganguly. 1954. Pharyngeal teeth in relation to the food habits of freshwater fishes. Proc.32nd, Ind. Sci. Cong. Part III. Abstract, 17.

Moore, G. A. 1950. The cutaneous sense organs of barbelled minnows adapted to life in the muddy waters of the Great Plains regions. Trans. Am. Micros. Soc., 69 : 69-95.

Munschi, J. S. D. 1960. Studies on the structure of the gills of certain freshwater teleosts. Ind. Jour. Zool., 1 : 135-174.

—. 1964. Chloride cells in the gills of freshwater teleosts. Quart. J. Mic. Sci., $105: 79-89$.

Murray, R. and A. Murray. 1960. The fine structure of taste buds of R hesus and Cynomalgus monkeys. Anat. Rec., 138 : 211-233.

Nakamura, M. 1949. The life history of a cyprinid fish G nathopogon elongatus caerulescens (Sauvage) in Lake Biwa. Bull. Jap. Soc. Fish., 15. 88-96.

—. 1949. The life history of a cyprinid fish, Zshikauia steenackeri (Sauvage) in Lake Biwa. Ibid., $15: 833-840$.

Nakamura, N. 1948. On the relation between salinity contents of the water and living conditions and productivity of carps in pond near the sea. Tokyo Univ. Physiol. Soc. Res. Bull., 1 : (Abstract 27).

Needham, A. E. 1935. On the jaws of certain fishes. Proc. 2001. Soc. Lond., 773784.

Nelson, E. M. 1959. The embryology of the swim bladder in the common sucker, Catostomus commersoni (Lacépède). Amer. Mid. Nat., 61 : 245-252.

Nelson, E. 0. 1953. Comparative embryology of the vertebrates. Blakiston Company, Toronto.

Nelson, J. G. 1967. Gill arches of teleostean fishes of the family Clupeidae. Copeia, 
No. 2 : 389-399.

Nikolsky, G. V. 1962. The ecology of fishes. Acad. Press, Lond.

Odense, P. H. and C. Bishop. 1966. The ultrastructure of the epithelial border of the ileum, pyloric caeca and rectum of the cod, Gadus morhua. J. Fish. Res. Bd. Canada, 23 : 1841-1843.

Okada, Y. 1960. Studies on the freshwater fishes of Japan. Rep. Fac, Fish. Pref. Univ. Mie, $4: 1-860$.

- - and K. Suzuki. 1956. Ecological studies of the Ma-Anago, Astroconger myriaster (Brevoort). Notes on the composition of the total length, the relationship between total length-body weight and condition factor on the Ise Bay. Ibid., 2: 217-226.

- - and R. Seishi. 1938. Studies on the early life history of 9 species of fresh water fishes of Japan. Bull. Biogeogr. Soc. Jap., 8: 223-253.

-. and S. Kubota. 1956. Studies on the taste buds in oral cavity of Carassius auratus L. Zool. Mag., 65 : 347-351.

Olmsted, J. M. D. 1920. The results of cutting the cranial nerves in A meiurus nebulosus. J. Exp. Zool., 31 : 369-402.

Ozima, Y. 1943. Cytological observation on fertilization in the carp, Cyprinus carpio L. Jap. J. Genet., 19.

Parker, G. H. 1910. Olfactory reactions in fishes. J. Exp. Zool., 8: 533-541.

- 1911. The olfactory organ of the common killifish, Fundulus heteroclitus. Ibid., $10: 1-5$.

Pearse, A. G. E. 1960. Histochemistry. J. and A. Churchill Ltd., London.

Pfeiffer, W. 1962. The fright reaction in North American fish. Canad. J. Zool., $41: 69-77$.

—. 1963. Alarm substances. Experimentia, $19: 113-168$.

Pictet, A. 1909. Histologie de la muqpeuse buccala et intestinale des poissons cyprinoides (Leuciscus rutilus, Barbus fuviatilis, Cyprinus carpio, Carassius auratus et Tinca vulgaris). C. R. Soc. Phys. Hist. Nat. Geneva, $26: 35-38$.

Pillay, T. T. R. 1953. Studies on the food, feeding habits and alimentary canal of the gray mullet, Mugil tode (Forsk). Proc. Nat. Inst. Sci. India, 19 : 377 827.

Pitt, T. K., E. T. Garside and R. L. Hepburn. 1956. Temperature selection of the carp (Cyprinus carpio L.). Canada J. Zool, 34 : 554-557.

Purser, G. L. 1928. Calamoichthys calabaricus J. A. Smith. Part I. The alimentary canal and respiratory system. Trans. Roy. Soc.Edin,, 56 : 89-101.

Qasim, S. Z. 1956. The spawning habits and embryonic development of the shanny (Blennius pholis L.). Proc. Zool. Soc. London, 127 : 79-93.

Raffin-Peyloz, R. 1955. Etude histologique des barbillonsde quelques poissons d'eau douce. Trav. Lab. Hydro. Pisc. Univ. Grenoble, 42 : 73-97.

Rajbanshi, V. K. 1966. A note on the study of gustatory senses of the barbels of freshwater teleosts. Naturwiss., $8: 208-209$.

Rennie, J. 1903. Studies on the comparative histology of the digestive tube of certain teleost fishes, II. A minnow (Campostoma anomalus). J. Morph., 52 : $1-25$.

Rheder, D. D. 1959. Some aspects of the life history of the carp, Cyprinus carpio L. in the Des Moines River, Boone County, Iowa. Iowa St. J. Sci., 34 : 11-24.

Riddle, C. R. 1917. Early development of the chinook salmon. Puget Sound Marine 
St., 1: 319-339.

Rogick, M. D. 1931. Studies on the comparative histology of the digestive tube of certain teleost fishes. J. Morph., $52: 1-25$.

Ryder, J. A. 1882. Embryology of osseous fishes. Kep. Comm. Fish and Fisheries, 1882 .

- 1885. On the formation of the embryonic axis of the teleostean embryo by the concrescence of the rim of blastoderm. Amer. Natur., 19.

Saito, S. 1950. The embryological studies of fishes. I. General observations on the early development of the dog-salmon, O ncorhynchus keta (Walbaum). J. Fac. Agr. Hokkaido Univ., 48: 267-289.

Sarbahi, D. S. 1951. Studies of the digestive enzymes of the gold fish Carassius auratus (L.) and the largemouth black bass, Micropterus salmoides (Lac.). Biol. Bull., 100 : 244-257.

Sato, M. 1937. Histological observations on the barbels of fishes. Sci. Rept. Tohoku Imp. Univ., Ser. 4, Biol., 12 : 265-276.

- 1938. The sensibility of the barbel of Upeneus spilurus Bleeker with some notes on the schooling. Ibid., 12: 489-500.

- 1911. A comparative observation of the hind brain of fish possessing barbels, with special reference to their feeding habits. Ibid., $16: 157-164$.

- 1955. On the development of the neuromasts of the carp, Cyprinus carpio L. Jpn. J. Ichthyol., $4:$ 105-112.

- - and B. G. Kapoor. 1957. Histological observations on the barbels of Indian freshwater fishes, Alaska cod fish and Podothecus acipenserinus. Annot. 2001. Jap., 30 : 156-161.

Schreiber, B. and S. Angeletti. 1940. Rhythmic increase and decrease of nuclear volume of the hepatic cells of the carp, Cyprinus carpio var. specularis. Anat. Rec., 76 : 339-431.

Sehgel, P. 1960. The anatomy and histology of the alimentary canal of Mystus seengala (Syk.). Pun. Univ. Bull., 2 : 77-86.

Sigov, V. A. 1947. Biometrical criteria for the life adaptation of first-time wintering carp. Trud. Inst. Prud. Rub. Khoz., 4, Voromezh.

Singh, B. R. 1966. On the gill structure of cobitid fish, Lepidocephalichthys guntea (Ham.). Jpn. J. Ichthyol., $16: 103-106$.

Siraishi, Y and I. Uchida. 1957. On the morphological changes of the salmon fry with the absorption of yolk. Jpn. J. Ichthyol., 5: 89-92.

Smallwood, W. M.. 1931. The development of carp, Cyprinus carpio. I. The larval life of the carp with special reference to the development of the intestinal canal. J. Morph., 52: 217-231.

- - and M. B. Derrickson. 1933. The development of the carp, Cyprinus carpio. II. Development of the liverpancreas, islets of Langerhans and the spleen. J. Morph., 42 : 147-184.

- - and M. L. Smallwood. 1929. The German carp, an invited immigrant. Sci. Month, $29: 394-401$.

Soller, M., Y. Schchori, R. Moar, G. Wohlfarth and M. Lehman. 1965. Carp growth in brackish water. Bamidg, $17: 16-23$.

Srivastava, C. M. and A. N. Sinha, 1961. Contribution to the study of barvels of fishes. Acta Soc. 2001. Bohem., $25: 12-15$. 
Stewart, N. H. 1926. Development, growth and food habits of the white sucker, Catostomus commersonii Le Suer. Bull.U. S. Fish., 42 : 147-184.

Suyehiro, Y. 1942. A study of the digestive system and feeding habits of fishes. Jap. J. Zool., $1:$ 1-303

Swee, U. B. and H. R. McCrimmon. 1966. Reproductive biology of the carp, Cyprinus carpio L. in Lake St. Lawrence, Ontario. Trans. Amer. Fish. Soc., 95 : 372-380.

Szubinska, B. 1961. Further observation on the morphology of the yolk in Teleostei. Acta. Biol. Cracov., Zool., 4 : 1-21.

Takahashi, N. 1957. On the so-called accessory respiratory organ 'Gill-Helix' found in some clupeiform fishes with special reference to its function and its genealogy. Jpn. J. Ichthyol., 5 : 70-77.

Tanaka, M. 1969. Studies on the structure and function of the digestive system during prelarval stage. Jpn. J. Ichthyol., 16 : 1-9.

Tomoda, Y. 1962. Morphological studies on the development of the crucian carp in Lake Biwa. Bull. Osaka Mus. Nat, Hist., 18 : 3-30.

Trautman, M. N. and C. L. Hubbs. 1948. When do pikes shed their teeth ? Mic. Cons., $17: 4-10$.

Trujillo-Cenoz, 0. 1961. Electron microscopic observations on the chemo- and mechanico-receptor cells of fishes. Z. Zellf., 54 : 654-676.

Tsukahara, H. and S. M. S. Hoda. 1968. Histological observations on the barbels and the inner layer of mouth cavity of the carp, Cyprinus carpio L. (Preliminary report). 43rd Meeting of Japanese Scientific Fisheries Society. Abstract of reading paper : 24 .

Uchida, K. 1927. On the formation and fate of Kupffer's vesicle. J. Coll. Agr. Imp. Univ. Tokyo, $9:$ 159-169.

- - 1939. The fishes of Tyosen (Korea). Part 1. Bull. Fish. Exper. Stat. Gov. Tyosen, $6: 1-458$.

Vaas, K. F. 1957. Studies on the food and feeding habits of the common carp in Indonesian ponds (1). Changes in the diet during growth. I. P. F. C. 7th. Session, Bangkok.

- and M. Sachlan, 1956. Cultivation of common carp in running water in West Java. Proc. Gth. Session I. P. F. C. Tokyo, 1955, FAO, Bangkok.

Vasnetsov, V. V. 1948. Morphological characters which determine the feeding of the bream, roach and carp in all stages of development. U. S. S. R. Academy of Sciences Press.

Vladykov, V. D. 1934. Geographical variation in the number of rows of pharyngeal teeth in cyprinid genera. Copeia, No. 3: 134-136.

Weber, E. H. 1820. De aure et auditu hominis et animalum. Lepsiae.

Weinreb, E. L. and N. M. Bilstad. 1955. Histology of the digestive tract and adjacent structures of the rainbow trout, Salmo gairdneri irideus. Copeia, No. 3 : 194-204.

Weisel, G. F. 1962. Comparative study of the digestive tract of a sucker, Catostomus catostomus, and a predaceous minnow, Ptychocheilus oregonense. Am. Mid. Nat., 68 : 334-346.

-. 1967. The pharyngeal teeth of larval and juvenile suckers (Catostomus). Copeia, No. 1: 50-54. 
Wilson, H. F. 1889. Embryology of the sea bass (Serranus atrarius). Bull. U. S. Fish. Comm., 9 : 207-277.

Wright, R. R. 1884. On the nervous system and sense organs of Ameiurus. Proc. Canad. Inst. Toronto, $2: 251-269$.

Yamada, J. 1968. A study on the structure of the surface cell layers in the epidermis of some teleosts. Annot.Zool. Jap., $41: 1-8$.

Yamamoto, T. 1933. Studies on the rhythmical movements of early embryo of Oryziaslatipes. III. Temperature and the amplitude of the contraction waves. J. Fac. Sci. Imp. Univ. Tokyo, 3 : 105-110.

- 1966. An electron microscope study of the columnar epithelial cell in the intestine of freshwater teleost: Gold fish (Carassius auratus) and rainbow trout (Salmo irideus). Z. Zellf., 72: 66-87.

Yoshizaki, M. 1957. Morphological change of intestine in the larval stage of wild gold-fish (Carassius uurutus). I. Observation on variety 'Gengoro-buna'. Jpn. J. Ichthyol., $5: 78-82$.

- 1958. Morphological change of intestine in the larval stage of wild goldfish (Carassius carassius). II. Observation on variety 'Kin-buna'. Ibid., 7: 104-107. 